2012

\title{
A privacy framework for secondary use of medical data
}

Jennifer A. Heath

University of Wollongong, jheath@uow.edu.au

\section{Recommended Citation}

Heath, Jennifer A., A privacy framework for secondary use of medical data, Doctor of Philosophy thesis, School of Information Systems and Technology, University of Wollongong, 2012. http://ro.uow.edu.au/theses/3667 


\section{UNIVERSITY OF WOLLONGONG COPYRIGHT WARNING}

You may print or download ONE copy of this document for the purpose of your own research or study. The University does not authorise you to copy, communicate or otherwise make available electronically to any other person any copyright material contained on this site. You are reminded of the following:

Copyright owners are entitled to take legal action against persons who infringe their copyright. A reproduction of material that is protected by copyright may be a copyright infringement. A court may impose penalties and award damages in relation to offences and infringements relating to copyright material. Higher penalties may apply, and higher damages may be awarded, for offences and infringements involving the conversion of material into digital or electronic form. 
Faculty of Informatics

School of Information Systems and Technology

\section{A Privacy Framework for Secondary Use of Medical Data}

This thesis is presented as part of the requirements for the award of the Degree of

\section{Doctor of Philosophy}

from the

\section{University of Wollongong}

By

Jennifer Ann Heath

MSc(Hons), BA (Computer Studies), GradDipEd

February 2012 


\section{Thesis Certification}

\section{CERTIFICATION}

I, Jennifer Ann Heath, declare that this thesis, submitted in partial fulfilment of the requirements for the award of Doctor of Philosophy, in the School of Information Systems and Technology, University of Wollongong, is wholly my own work unless otherwise referenced or acknowledged. The document has not been submitted for qualifications at any other academic institution.

Jennifer A. Heath 


\begin{abstract}
Traditionally the privacy of medical patients personal information is protected through interpretations of the 'limited access' theory of privacy which in many cases was instantiated through to secure storage of physical paper charts and records. With the change of medium for capture and storage of personal medical information from paper based to electronic medium, the 'limited access' approach to privacy is under pressure due to the ease with which electronic information can be exchanged. The medical doctor's traditional 'gatekeeper' role to oversee patients' personal information is becoming harder to maintain with electronic health records. This is particularly the case in the context of the secondary use of medical data. Secondary uses of medical data are those uses not directly related to the delivery of healthcare to an individual. These secondary uses are diverse and include those aimed at improving societal knowledge of healthcare and medicine and far more commercial orientated activities, such as optimising insurance premiums or financial accounting associated with charges for medical services. Contemporary privacy theories move beyond the 'limited access' privacy theory and are well suited to application within the secondary use of medical data context. Meaningful engagement with patients/consumers is of growing importance in this context and consumer surveys attracting 1,573 responses from citizens in Australia and Canada investigated public opinion regarding the application of contemporary privacy theory in the secondary use of medical data. Survey results indicated that contemporary privacy theories can be applied to the secondary use of medical data. Survey respondents indicated diverse concerns and expectations regarding privacy with statistically significant results across gender, education level, age and healthcare workers. A Privacy Framework for secondary use of medical data is proposed. The framework is founded on contemporary privacy theories and includes a multi-level consumer engagement model informed by Australian and Canadian survey outcomes. This study was undertaken within the post-positivist and interpretive paradigms and utilized mixed methods with a concurrent triangulation design.
\end{abstract}




\section{ACKNOWLEDGEMENTS}

The guidance provided by my Research Supervisors has been invaluable from the early, formative stages of the research journey through to the completion and thesis submission. My sincere gratitude and thanks go to Associate Professor Katina Michael, Associate Professor Linda Dawson and Dr Russell Pearson at the University of Wollongong (UOW) and Professor Carolyn McGregor at the University of Ontario Institute of Technology (UOIT).

As the primary supervisor Katina has led the way with calm encouragement and guidance throughout the entire journey; particularly by providing insight on privacy matters. Linda provided supervision while Katina was on maternity leave and in the following years and I am very grateful for her enthusiastic guidance. Russell generously shared his thirty years of medical experience as a General Practitioner to guide and inform the secondary use of data issues from a clinicians' viewpoint. Carolyn shared health informatics knowledge and broader research experience and it has been wonderful to have her continued interest in my research.

I acknowledge the in-kind and/or financial support provided by the Centre for Canadian-Australian Studies (CCAS), the Institute for Innovation in Business and Social Research (IIBSoR), the University of Ontario Institute of Technology (UOIT) and the University of Wollongong (UOW). The UOW Statistical Consulting Service provided advice and guidance on the quantitative aspects of this study and I thank them for the valuable contribution.

Finally I must acknowledge the support and patience of my family Brad, Megan and Zoe. Living with a $\mathrm{PhD}$ candidate is not easy as the research tends to 'take over your life' and I am very grateful for the special consideration and care that my family have shown to me - especially over the last few months. 


\section{PUBLICATIONS, SUBMISSIONS, GRANTS \& SCHOLARSHIPS}

\section{Publications during PhD candidature}

Heath, J \& McGregor, C 2010, 'CRISP-DM ${ }_{0}$ : A method to extend CRISP-DM to support null hypothesis driven confirmatory data mining', paper presented to the 2010 Advances in Health Informatics Conference, Kitchener, Ontario, Canada, 28-30 April 2010.

Heath, J 2010, 'Emerging Consumers View of Secondary Uses of Medical Data', paper presented to the 2010 IEEE International Symposium on Technology and Society (ISTAS'10), Wollongong, Australia, 7-9 June 2010.

Heath, J 2011, 'Where did the consumer go?', paper presented to the Inaugural Health Informatics Society of Australia (HISA) Data Governance Conference, Melbourne, Australia, 19-20 May 2011.

Heath, J 2011, 'Consumers, ALRC Privacy Principles and the 2010 Healthcare Identifiers Act', Telecommunications Journal of Australia, vol.61, no.3, pp.46.1-46.8.

\section{Submissions during PhD candidature}

Heath, J, 2010, Parliamentary submission to Department of Health and Ageing regarding exposure draft 'Healthcare Identifier Bill 2010', accessed 29 Jan 2012 from http://www.health.gov.au/internet/main/publishing.nsf/Content/eHealth2-032.

\section{Grants \& Scholarships}

$2009 \mathrm{PhD}$ Travelling Scholarship, \$3,500 awarded by the Centre for Canadian-Australian Studies. 2009 Research grant, \$500 awarded by the Institute for Innovation in Business and Social Research. 2010 University Postgraduate Award, approx. \$45,000 awarded by the University of Wollongong. 2010 Research grant, $\$ 1,000$ awarded by the Centre for Canadian-Australian Studies. 


\section{TABLE OF CONTENTS}

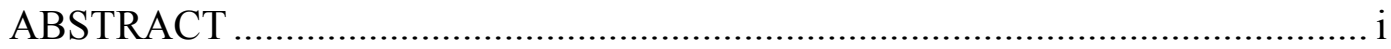

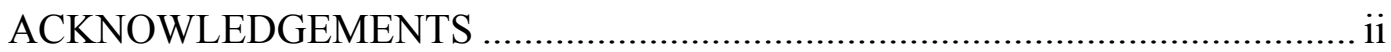

PUBLICATIONS, SUBMISSIONS, GRANTS \& SCHOLARSHIPS ................. iii

TABLE OF CONTENTS ...................................................................... iv

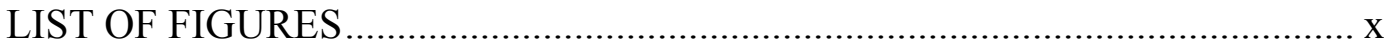

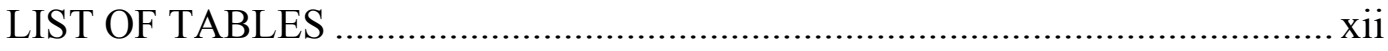

ACRONYMS AND ABBREVIATIONS …..................................................

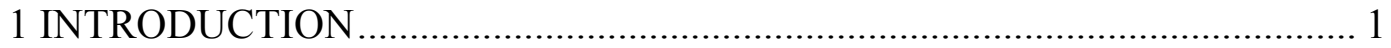

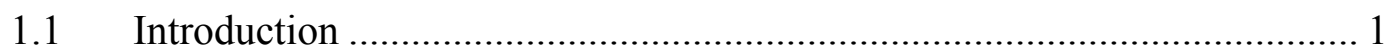

1.2 Background and Motivation for Research.............................................. 2

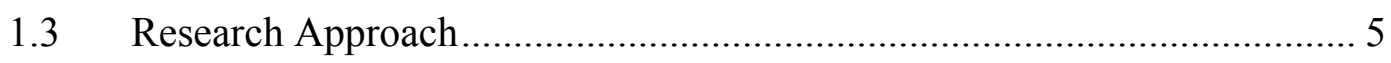

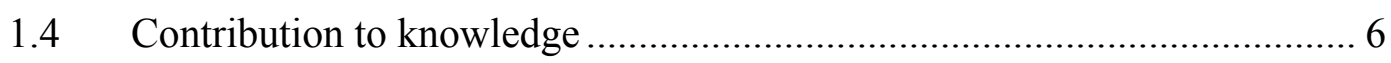

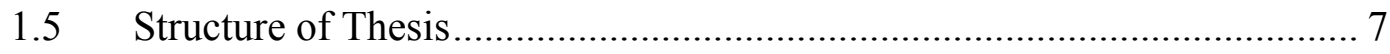

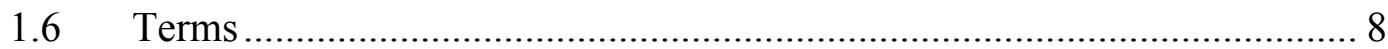

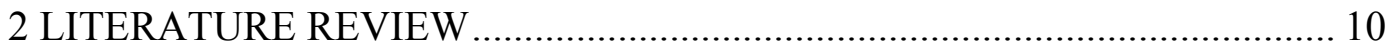

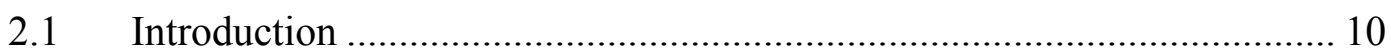

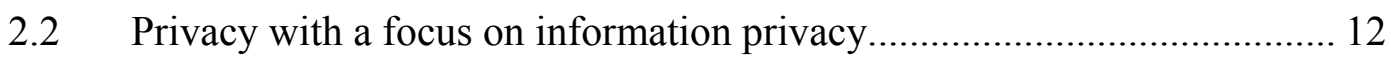

2.3 Privacy in the secondary use of medical data context ............................ 21

2.3.1 Partnering with consumers for research ............................................. 23

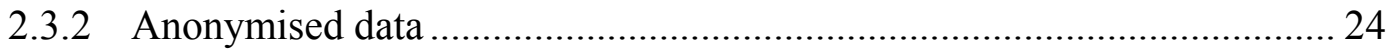

2.4 Stakeholder perspectives on privacy in the secondary use of

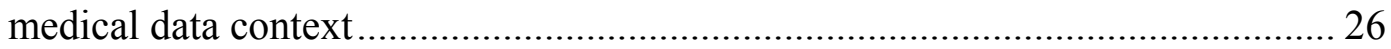

2.4.1 The medical researcher lens: research at risk ........................................ 28

2.4.1.1 Getting the balance right and challenges to research .............................. 29

2.4.1.2 Human Research Ethics Committees (HREC) ....................................... 36

2.4.2 The privacy advocate lens: an Orwellian future ….................................. 40

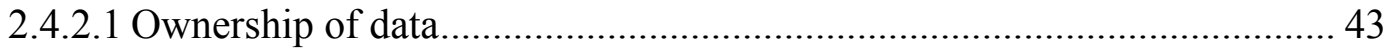

2.4.3 The government lens: big brother or privacy protector? ......................... 46

2.4.4 The commercial lens: profit through secondary use of medical data........ 51

2.4.5 The consumer lens: hearing the 'voice' of consumers ........................... 57

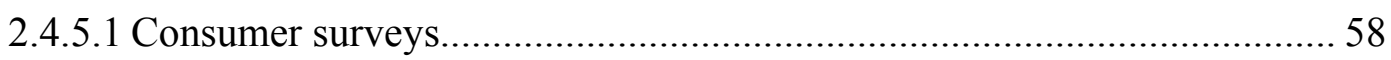

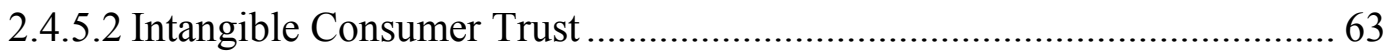




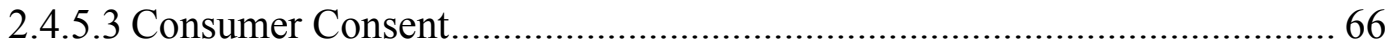

2.5 Summary of Open Research Questions .................................................. 69

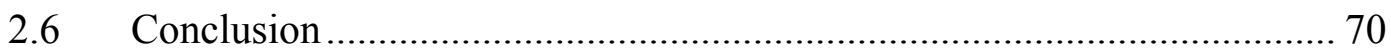

3 RESEARCH METHODOLOGY …............................................................... 72

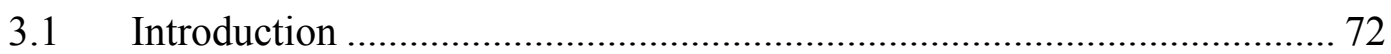

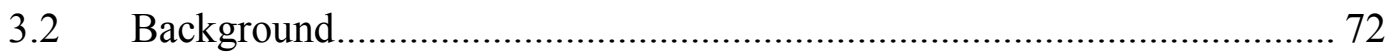

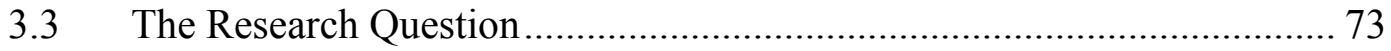

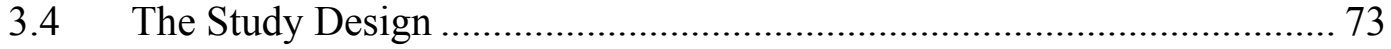

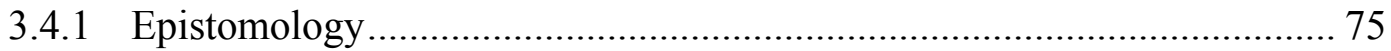

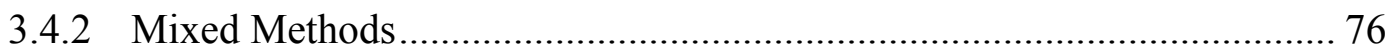

3.4.3 Why include a comparative study with Canada?.................................... 79

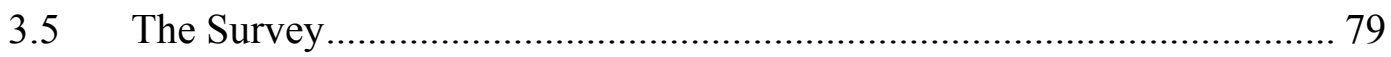

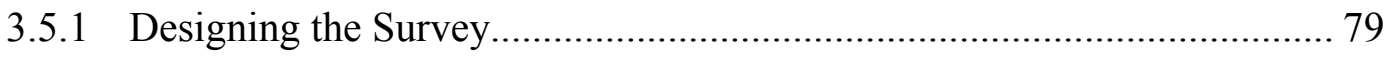

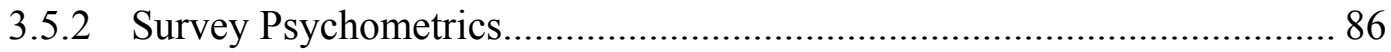

3.5.3 Focus Groups and Pilot Testing the Survey .......................................... 89

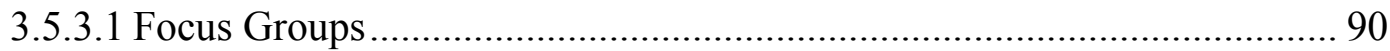

3.5.3.2 Australian and Canadian Pilot Survey ..................................................... 91

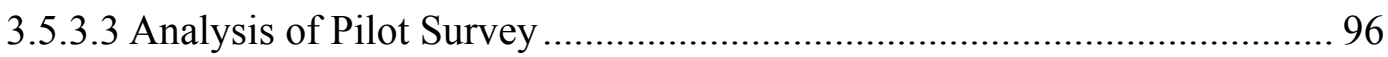

3.5.4 Improvements to Survey Design Resulting from the Pilot Survey ......... 100

3.5.5 Revised Survey Constructs............................................................ 102

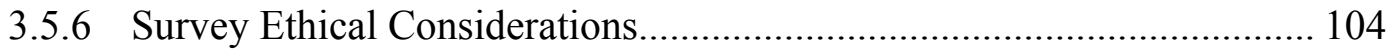

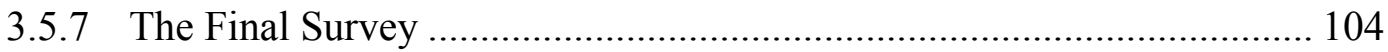

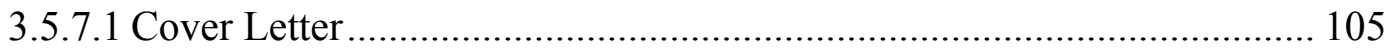

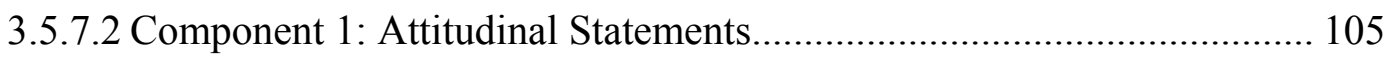

3.5.7.3 Component 2: Open ended questions ................................................ 109

3.5.7.4 The Final Survey Procedure …........................................................ 110

3.6 Managing and Analysing the Survey Data ........................................... 115

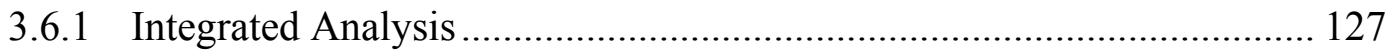

3.7 Australian and Canadian Consumer Survey Comparison ....................... 128

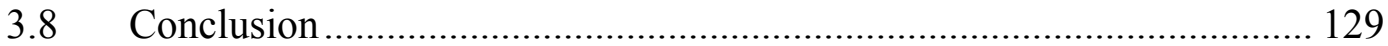

4 AUSTRALIAN CONSUMER PUBLIC OPINION SURVEY

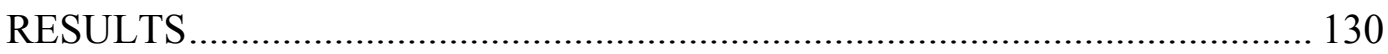

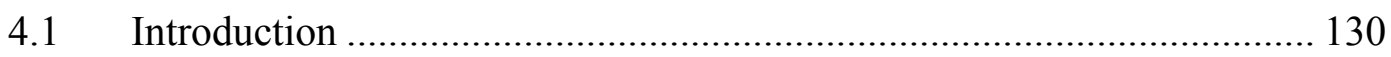




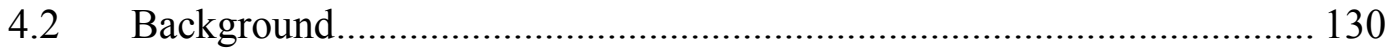

4.2.1 Descriptive Statistics .................................................................... 130

4.2.1.1 Response Frequency ........................................................................... 134

4.2.2 Mixed Method Analysis ........................................................................ 151

4.2.3 Tripartite Component: Privacy Concept - Quantitative Analysis ........... 152

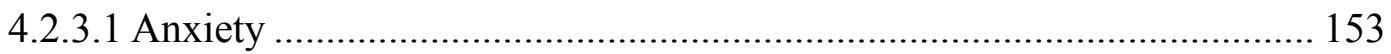

4.2.3.2 Restricted Access............................................................................... 157

4.2.4 Tripartite Component: Privacy Concept - Qualitative Analysis ............. 158

4.2.5 Tripartite Component: Privacy Justification - Quantitative Analysis..... 159

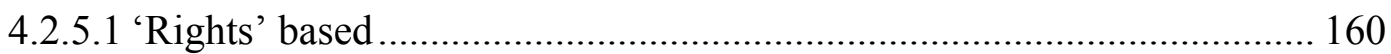

4.2.6 Tripartite Component: Privacy Justification - Qualitative Analysis....... 162

4.2.7 Tripartite Component: Privacy Management - Quantitative Analysis ... 164

4.2.7.1 Data Stewardship ................................................................................. 165

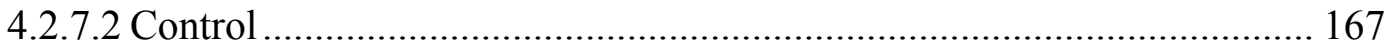

4.2.8 Tripartite Component: Privacy Management - Qualitative Analysis ..... 170

4.3 Emergent Qualitative Themes ................................................................ 173

4.4 Further Consideration of Results ......................................................... 174

4.5 Chapter Summary .............................................................................. 179

5 AUSTRALIAN CONSUMER PUBLIC OPINION SURVEY

ANALYSIS AND INTERPRETATION OF RESULTS ……………………...... 181

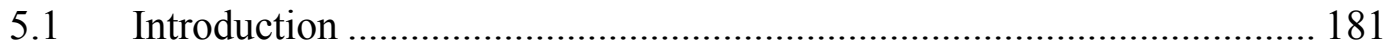

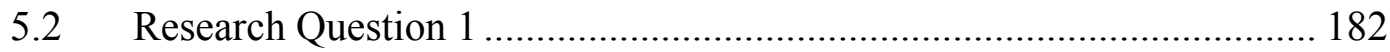

5.2.1 Tripartite Privacy Concept and Justification of Privacy........................... 183

5.2.1.1 Consumer Concerns and Expectations ..................................................... 183

5.2.1.2 Consumer Concern and Expectations Part 1 .......................................... 185

5.2.1.3 Influence of Highest Level of Education on Concern for Privacy .......... 186

5.2.1.4 Consumer Concern Regarding Insurance Sector Secondary Use............ 189

5.2.1.5 Consumer Concerns and Expectations Part 2......................................... 193

5.3 Summary of Research Question 1 Findings ............................................. 199

$5.4 \quad$ Research Question 2 ................................................................... 200

5.5 Summary of Research Question 2 Findings .......................................... 214

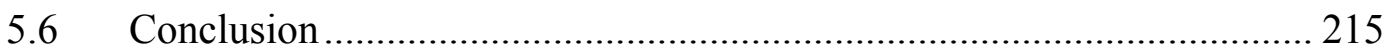


6 CANADIAN CONSUMER PUBLIC OPINION SURVEY

RESULTS AND COMPARISON TO AUSTRALIAN RESULTS

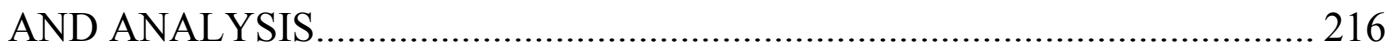

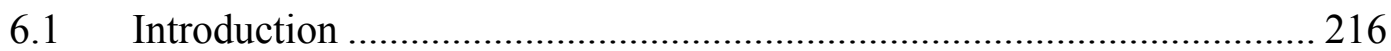

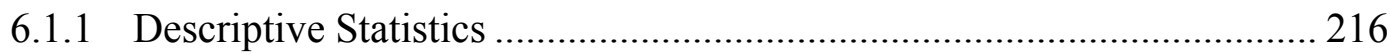

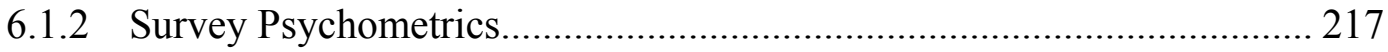

6.1.3 Response Frequency and Comparison.................................................. 218

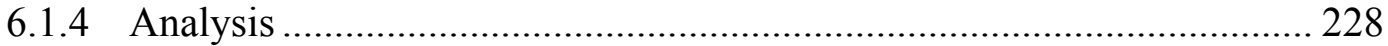

6.1.5 Tripartite Component - Privacy Concept............................................... 228

6.1.6 Tripartite Component - Privacy Justification......................................... 234

6.1.7 Tripartite Component - Privacy Management ...................................... 237

6.2 Emergent Qualitative Themes ............................................................ 240

6.3 Summary of Comparative Findings ..................................................... 241

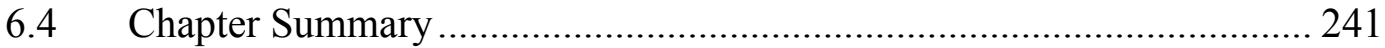

7 A PRIVACY FRAMEWORK FOR SECONDARY USE OF

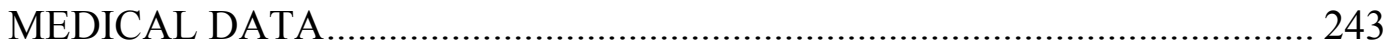

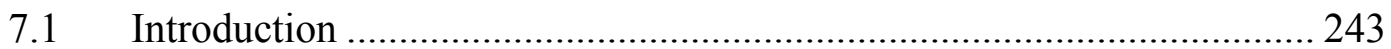

7.2 The Initial 'Skeleton' of the Framework ................................................ 244

7.3 Incorporating Consumers Expectations into the Framework ................. 249

7.3.1 Conceptualising Levels of Consumer Engagement............................... 249

7.3.2 Consumer data attributes and default sensitivity settings...................... 259

7.3.3 Combining the Skeleton of the Privacy Framework and the Levels of

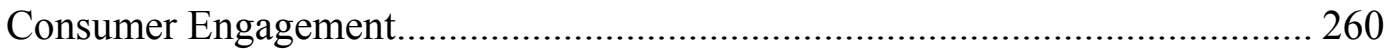

7.3.4 The matrix for terms and conditions of data flows................................ 263

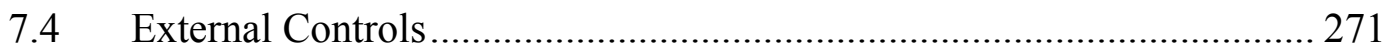

7.5 Limitations of the proposed Privacy Framework .................................. 272

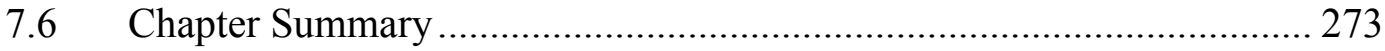

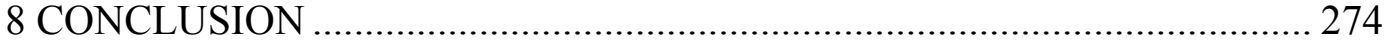

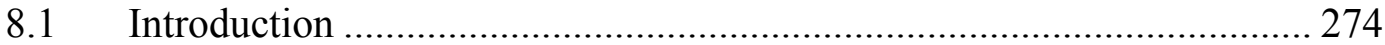

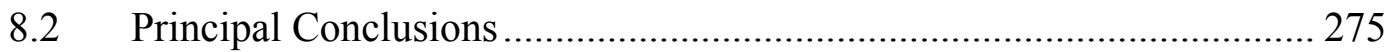

8.3 Links to Earlier Research .................................................................... 278

8.4 Major Implications ......................................................................... 280

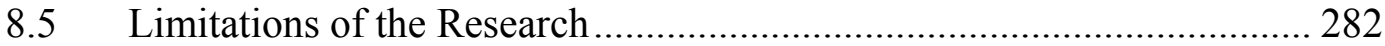




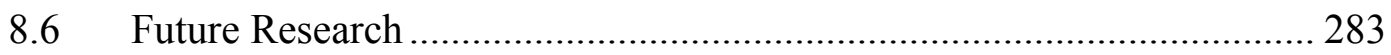

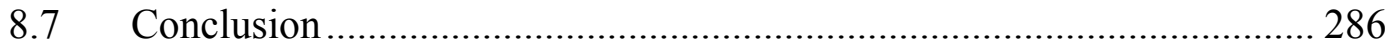

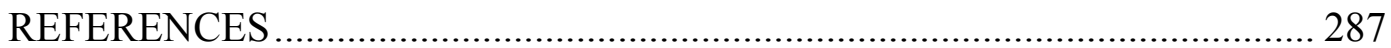

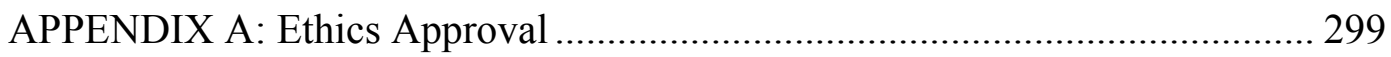

APPENDIX B: Final Survey Instrument................................................... 300

APPENDIX C: Australian and Canadian Survey Covering Letter ..................... 304

APPENDIX D: Final Survey Qualitative Data Encoding Sheet ......................... 306 
In a computerized world we leave electronic footprints everywhere and data collected for one purpose can be resurrected and used elsewhere. The problem of computer privacy is to keep proper vigilance on where such information can and should go.

James Moor, 1997 


\section{LIST OF FIGURES}

Figure 1: SDLC phases (adapted from Satzinger, Jackson et al. 2009, p. 40) ............ 4

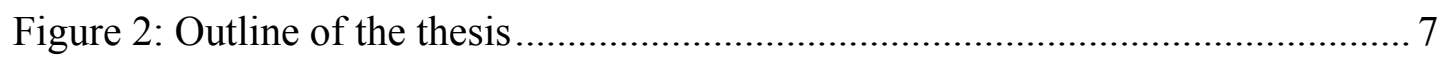

Figure 3: Structure of Literature Review with research assumptions and open research areas as outcomes. 11

Figure 4: Graphical representation of select privacy concepts ............................... 14

Figure 5: Visual representation of the tripartite privacy model ............................... 16

Figure 6: Balance between privacy and research (reproduced from Campbell

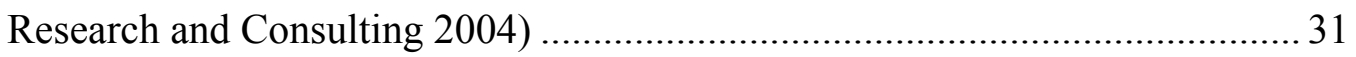

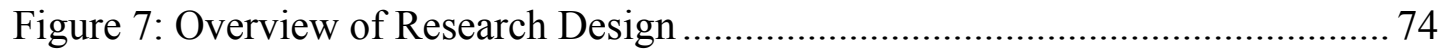

Figure 8: Creswell's Concurrent Triangulation Design ......................................... 77

Figure 9: Research Design, including concurrent triangulation............................... 78

Figure 10: Pilot survey response to Statement 1 .................................................. 97

Figure 11: Pilot survey Canadian response to Statements 8 and 9 .......................... 98

Figure 12: Pilot survey Australian response to Statement 8 and 9 .......................... 98

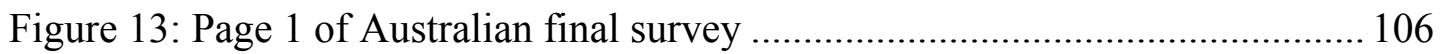

Figure 14: Page 2 of the Australian final survey................................................... 107

Figure 15: Page 3 of the Australian final survey................................................... 108

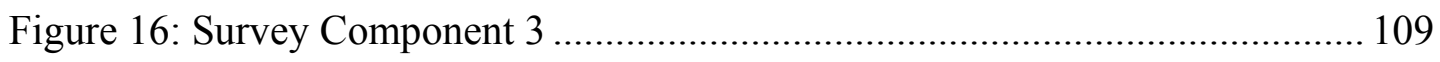

Figure 17: Canada Whitepages address \& neighbours ........................................ 112

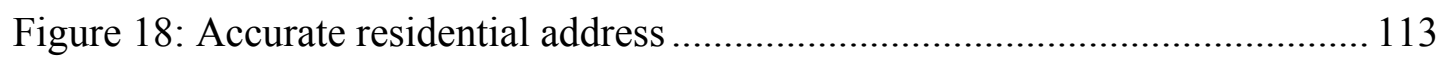

Figure 19: Sample populations in Australia......................................................... 114

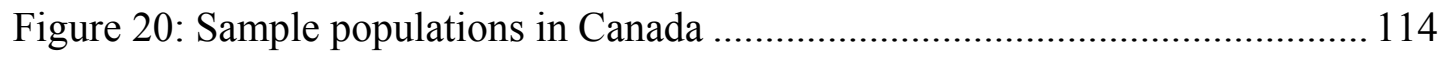

Figure 21: Structure of Survey table in custom database....................................... 116

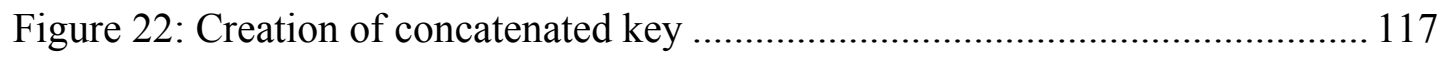

Figure 23: MSAccess database supporting qualitative analysis ........................... 118

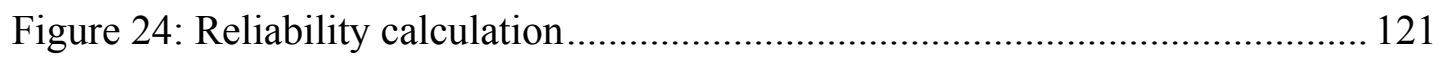

Figure 25: Survey 889, Component 2 open ended questions................................. 124

Figure 26: Survey 423, Component 2 open ended questions.................................. 125

Figure 27: Survey 602, Component 2 open ended questions.................................. 126

Figure 28: Mann-Whitney U test SPSS 17.0 dialogue box..................................... 128

Figure 29: Australian respondent demographics, gender..................................... 131

Figure 30: Australian respondent demographics, age ............................................ 131 
Figure 31: Australian respondent demographics, highest level of education 132

Figure 32: Australian respondent demographics, health sector worker 133

Figure 33: Respondents age group by Education Level 162

Figure 34: Consumer Concern and Expectations Part 1 184

Figure 35: Statement 6 - I am concerned that my medical information may be stolen, selected education level responses.

Figure 36: Statement 8 - I worry about medical receptionists reading my medical information, selected education level responses. 187

Figure 37: Frequency of responses for statements regarding concern over medical receptionist $(n=1,147)$ and IT professional $(n=1,148)$ access to consumer medical information. 188

Figure 38: Consumer Concerns and Expectations Part 2 ….................................. 194

Figure 39: Constructing the Privacy Framework Stage 1 ...................................... 247

Figure 40: Constructing the Privacy Framework Stage 2 ….................................. 248

Figure 41: Consumer engagement scenario 1 ................................................... 251

Figure 42: Consumer engagement scenario 2 ................................................... 252

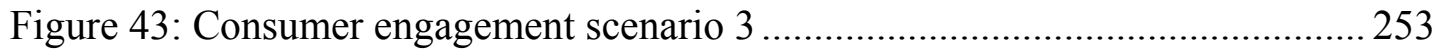

Figure 44: Privacy Framework combined with the Consumer Engagement Concept 260

Figure 45: Addition of the context to the Privacy Framework .............................. 261 


\section{LIST OF TABLES}

Table 1: Influential documents in two parallel activities of national importance: ALRC Privacy Principles and 2010 Healthcare Identifiers Bill ...................... 51

Table 2: Australian Schizophrenia Research Bank data release schedule ................. 54

Table 3: Summary of Research Questions Arising from the Literature Review ....... 69

Table 4: Mapping to broader study Research Questions 1 and 2........................... 70

Table 5: Bourque and Fielder (2003) self administered survey matters and comments on application in the pilot and final surveys ............................................... 81

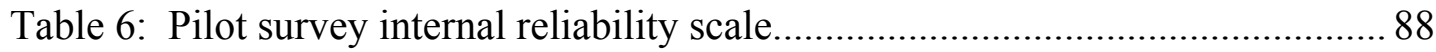

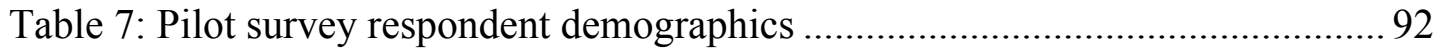

Table 8: Survey statements related to the tripartite 'Concept of Privacy' and 'Justification of Privacy'

Table 9: Survey Statements related 'Privacy Management'- control and commercial data use constructs.

Table 10: Survey statements related to 'Privacy Management'- data stewardship and altruism constructs 96

Table 11: Australian Cross tabulation of Highest Education Level and Statement 6 response. 99

Table 12: Final survey constructs 102

Table 13: Pilot and final survey summary 115

Table 14: Deductive themes used for qualitative analysis 119

Table 15: Frequency of open-ended comments by highest level of education

Table 16: Reliability of scales

Table 17: Privacy tripartite component - concept of privacy, survey response frequency

Table 18: Privacy tripartite component - justification of privacy, survey response frequency

Table 19: Privacy tripartite component - privacy management, survey response frequency

Table 20: Australian State and Territory Codes..... 152

Table 21: Privacy Concept Chi-Square statistically significant results. 152

Table 22: Statement 6 Pearsons Chi-Square statistically significant - Age 153 
Table 23: Statement 6 Pearsons Chi-Square statistically significant - Highest Level of Education

Table 24: Statement 8 Pearsons Chi-Square statistically significant - Age..... 154

Table 25: Statement 8 Pearsons Chi-Square statistically significant - Highest Level of Education

Table 26: Statement 25 Pearsons Chi-Square statistically significant - Highest Level of Education 156

Table 27: Statement 27 Pearson's Chi-Square - Statistically Significant - healthcare worker.

Table 28: Statement 11 Pearsons Chi-Square statistically significant - Healthcare Worker 157

Table 29: Privacy Concept Deductive Encoding Summary..................................... 158

Table 30: Tripartite - Privacy Concept deductive themes ........................................ 158

Table 31: Tripartite Privacy Justification Statistically Significant Results ............. 160

Table 32: Statement 12 Pearsons Chi-Square Statistically Significant - Age.......... 161

Table 33: Statement 12 Pearson Chi-Square Statistically Significant - Education Level 161

Table 34:Statement 28 Pearsons Chi-Square Statistically Significant - Gender...... 162

Table 35: Justification Qualitative Summary........................................................ 163

Table 36: Tripartite model - Justification of Privacy - Deductive themes .............. 163

Table 37: Privacy Management statistically significant results.............................. 164

Table 38: Statement 2 statistically significant - Healthcare worker......................... 165

Table 39: Statement 7 statistically significant - Healthcare Worker........................ 166

Table 40: Statement 30 Pearson Chi-Square statistically significant - Age.............. 166

Table 41: Statement 16 Pearson Chi-Square statistically significant - Age............. 167

Table 42: Statement 17 Pearsons Chi-Square statistically significant - Healthcare

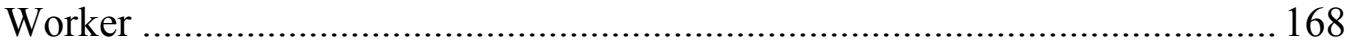

Table 43: Statement 22 Pearsons Chi-Square statistically significant - Age ........... 169

Table 44: Management Qualitative Summary ..................................................... 170

Table 45: Tripartite - Management of Privacy - deductive themes ....................... 171

Table 46: Further consideration of quantitative results.......................................... 175

Table 47:Statement 30 Chi-Square test results by highest education level ............ 178

Table 48:Statement 18 Chi-Square test results by healthcare worker..................... 179 
Table 49: Consumer Data Stewardship 201

Table 50: Consumer Privacy Management Part 1.................................................. 205

Table 51: Gender Differences Regarding Management of Privacy - Control......... 206

Table 52: Consumer Privacy Management Part 2.................................................... 211

Table 53: Canadian Survey Respondents Demographics ..................................... 216

Table 54: Canadian Survey Internal Reliability ................................................... 217

Table 55: Canadian and Australian Survey Response Frequency and Statistically Significant Mann-Whitney U test results..................................................... 220

Table 56: Canadian Province Codes ...................................................................... 230

Table 57: Tripartite Component - Privacy Concept, Canada- Qualitative Comment Count.

Table 58: Tripartite Component - Justification of Privacy, Canada - Qualitative Comment Count 235

Table 59: Statement 20 Pearsons Chi-Square statistically significant - Gender...... 237 Table 60: Tripartite Component - Management of Privacy- Qualitative Comment Count 238

Table 61: Elaboration of Consumer Engagement Level 0 and Level 1 ................... 254

Table 62: Elaboration of consumer engagement at Level 2 and Level 3................ 255

Table 63: Privacy Framework Transmission Principles Engagement Level 0 ........ 266

Table 64: Privacy Framework Transmission Principles Engagement Level 1 ........ 267

Table 65: Privacy Framework Transmission Principles Engagement Level 2 ........ 268

Table 66: Privacy Framework Transmission Principles Engagement Level 3 ........ 270 


\section{ACRONYMS AND ABBREVIATIONS}

AIHW

ALRC

APF

APP

ASRBCI

ASRI

CATI

DNA

EDPD

EHR

EPIC

GP

HIA

HIPAA

HISA

HREC

IPP

IHI

IT

NHMRC

NHS

NPP

OHIP

PCEHR

PIA

PIAG

RALC

REB

SDLC

UOIT

UOW

UPP
Australian Institute of Health and Welfare

Australian Law Reform Commission

Australian Privacy Foundation

Australian Privacy Principles

Australian Schizophrenia Research Bank Chief Investigator

Australian Schizophrenia Research Institute

Computer Assisted Telephone Interview

Deoxyribonucleic acid

European Data Protection Directive

Electronic Health Record

Electronic Privacy Information Centre

General Practitioner

Healthcare Identifiers Act (Australia)

Health Insurance Portability and Accountability Act (USA)

Health Informatics Society of Australia

Human Research Ethics Committee

Information Privacy Principles (Australia)

Individual Healthcare Identifier (Australia)

Information Technology

National Health and Medical Research Council (Australia)

National Health Service (United Kingdom)

National Privacy Principles (Australia)

Ontario Health Insurance Plan (Canada)

Personally Controlled Electronic Health Record

Privacy Impact Assessment

Patient Information Advisory Group (United Kingdom)

Restricted Access Limited Control

Research Ethics Board

System Development Life Cycle

University of Ontario Institute of Technology

University of Wollongong

Unified Privacy Principles (Australia) 


\section{INTRODUCTION}

\subsection{Introduction}

Traditionally the privacy of medical patients' personal information has been protected through application of the 'limited access' theory of privacy. With the change of medium used for capture and storage of personal medical information from paper to electronic the 'limited access' approach to privacy is under pressure due to the ease with which electronic information can be exchanged.

The medical doctors' traditional 'gatekeeper' role to oversee their patients' personal information is becoming harder to maintain with electronic health records. This is particularly the case in the secondary use of medical data context. Secondary uses of medical data are those uses not directly related to the delivery of healthcare to an individual (Safran, Bloomrosen et al. 2006). These secondary uses are diverse and include those associated with medical and health service research, more commercial, profit-driven activities, and increasingly government societal surveillance.

Two contemporary privacy theories proposed by Tavani and Moor (2001) and Nissenbaum (2010) move beyond the 'limited access' privacy theory and are well suited to application within the secondary use of medical data context. There is little published literature regarding the application of these theories to the 'real-world' and this study makes a contribution by combining these two theories and applying them to the secondary use of medical data.

Meaningful engagement with patients/consumers is of growing importance in the secondary use of medical data as the secondary use stakeholders vie to have their data use needs addressed. There is little published literature surrounding consumers concerns and expectations regarding secondary use of their personal medical data.

The aim of this research is to investigate privacy matters in the secondary use of medical data context with particular focus on the views of consumers. The study design includes the use of mixed methods employing a self administered, hardcopy consumer survey instrument to capture public opinion in Australia and Canada. 
Statistically significant findings emerged across demographics including age, gender and education level. Outputs from the research include a proposed privacy framework for secondary use of medical data.

Future research opportunities, starting in 2012, include the application of the Privacy Framework to two scenarios, the first in Australia and the second in Canada. The first opportunity builds on the results of the consumer survey indicating that women are more interested in engaging in secondary use matters and involves a General Practice based trial of the privacy framework with female consumers. The second opportunity relates specifically to the secondary use of physiological readings captured by life support devices. This trial involves the application of the Privacy Framework proposed in this thesis to support the capture, storage, transmission and analysis of this data within the secondary use context for population based retrospective analysis.

This chapter presents introductory material including the background and motivation for research, an overview of the research approach, and comments on the contribution to knowledge and structure of the thesis.

\subsection{Background and Motivation for Research}

The patient confidentiality aspect of the Hippocratic Oath, based on the premise of limiting access to sensitive information, is under pressure in the emerging electronic health records (EHR) environment. In the delivery of healthcare, facilitated by EHRs, the privacy approach continues to be one of 'limited access' thus reflecting the original interpretation of privacy offered by the Hippocratic Oath.

A paradigm shift away from 'limited access' privacy theory to a more contemporary approach involving deeper consumer engagement may better serve the secondary use of medical data objectives. Extending the 'limited access' approach to privacy in the secondary use context may not be the most forward thinking option despite claims from the healthcare and associated research sectors that 'privacy is well understood' as claimed by Lowerance (2003). Privacy researchers come from a broad range of professions and many state that privacy is a slippery concept that is not well understood and does not share a common definition (Warren and Brandeis 1890; 
Westin 1967; Moor 1997; Willison 2003; Floridi 2006; Tavani 2007b; Willison, Emerson et al. 2008; Shoemaker 2009; Nissenbaum 2010). This thesis explores more contemporary, approaches to privacy that may better meet the conflicting secondary use stakeholder expectations.

The movement away from paper based health records to electronic health records has the effect of 'greasing' the data (Moor 1997) which facilitates the ready transfer of sensitive, personal data from primary care contexts to secondary use contexts.

Examples of successful secondary use of medical data include discovery of links between antidepressant use and suicide (Jick, Dean et al. 1995) and between tranquilisers and road accidents (Barbone, McMahon et al. 1998) as reported by Singleton and Wadsworth (2006). There are many stakeholders in the secondary use context including, but not limited to: population health researchers, health service researchers and planners, data brokerage organisations, insurance and pharmaceutical sector stakeholders, multiple levels of Government, privacy advocates, and healthcare consumers. Privacy advocates argue strongly for consumer engagement concerning use of their medical data and issue warnings on the use of national de-facto identifiers fearing Orwellian type developments in dataveillance / surveillance / uberveillance (Magnusson 2004; Fernando 2009; Clarke 2010). Medical researchers argue strongly for secondary use of medical data to be an extension of healthcare delivery aimed at improving treatment for all members of society (Snider 1997; Al-Shahi and Warlow 2000; Doll and Peto 2001). Commercial entities seek access to the healthcare information of citizens' and present an array of justifications including profitability for their organisations (IMS-Health 2008; BroganInc 2010; BroganInc 2011). The literature review chapter of this thesis looks through various 'lenses' to provide insight into each competing stakeholder's perspective on the secondary use of medical data. Consumers have rarely been given an opportunity to have their voices heard in this secondary use debate (Ruyter, Louk et al. 2010).

It is widely acknowledged by the system analysis and design community that the early analysis stage of the system development life cycle (SDLC) involves clear problem definition leading to conceptual designs prior to physical implementation(s) 
and support (Satzinger, Jackson et al. 2009). The need for clear problem definition and conceptualisation is very important no matter which approach is taken to system analysis and design i.e. Waterfall, spiral, agile. Gathering stakeholders' system requirements is an important task in the early phases of the SDLC. Conceptual modelling precedes physical implementation. Jumping to the physical implementation stage of the SDLC without sufficient work in the early problem definition and conceptual modelling stage compromises the successful information system implementation.

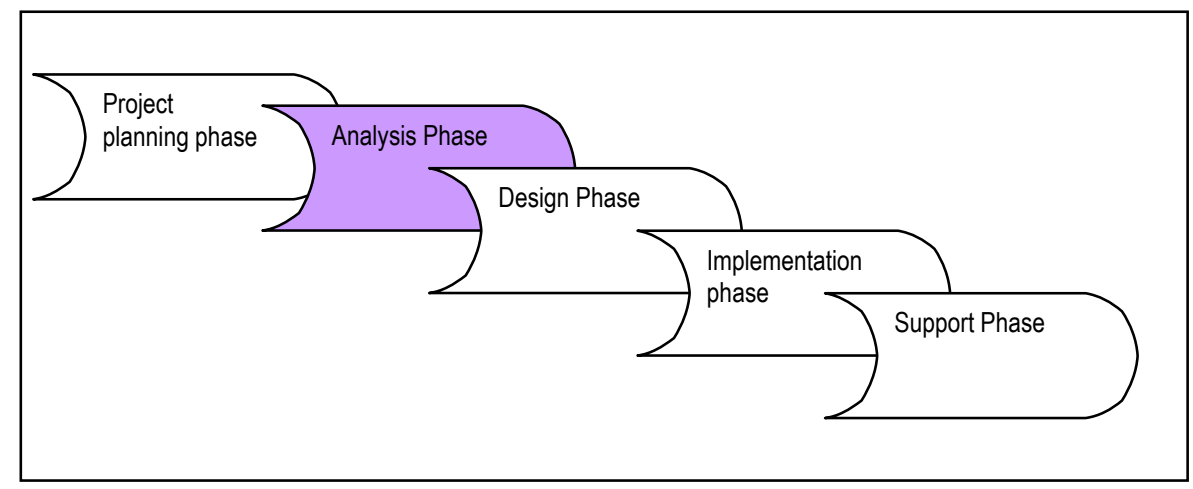

Figure 1: SDLC phases (adapted from Satzinger, Jackson et al. 2009, p. 40)

This study makes a contribution to the problem definition and conceptualisation of future health information systems by addressing foundation privacy issues. By separating the analysis phase problem definition from the traditional power brokers in health information systems (i.e. the healthcare providers or government) it is possible to have an independent consideration of secondary use privacy matters. The benefit of this $\mathrm{PhD}$ study is that there are no corporate sponsors or paying clients to influence the initial framing of the privacy challenge. For example, if a healthcare provider commissioned the SDLC analysis phase they would define the problem as one of needing to implement 'limitations on access to patient data to deliver privacy', thus continuing the 'limited access' privacy paradigm and bypassing the re-framing of privacy that is possible with contemporary privacy theories.

It is noted that the vast majority of stakeholders involved in the specification of the requirements of the Australian national ehealth records are medical professionals there has been little engagement with consumers. The research described in this thesis 
brings to the Australian context insight into the expectations of the overlooked stakeholder - the consumer.

The bulk of the research described in this dissertation is positioned within the Australian context. International experiences are considered in the literature review and part of the survey component includes comparison between Australian and Canadian consumer views.

\subsection{Research Approach}

The overall aim of this research study is to investigate privacy matters in the secondary use of medical data context with particular focus on the views of consumers which have previously been marginalised. Two overarching questions drive this investigation:

\section{Research Question 1}

What are consumer's expectations and concerns regarding secondary uses of their medical data, particularly pertaining to privacy matters?

\section{Research Question 2}

Does the RALC privacy theory (Tavani and Moor 2001) and the Framework for contextual integrity (Nissenbaum 2010) offer privacy concepts that can: (1) be applied in the secondary use of medical data context; and (2) gain support from interested consumers?

The overall exploratory nature of this study employed both post-positivist and interpretive paradigms, utilizing a mixed methods methodology with a concurrent triangulation design. The research undertaken in this study is exploratory rather than confirmatory

Canada was chosen for comparison as there is a history of cultural comparison studies between Australia and Canada including those with a focus on ethics and society (Kidd and Shannon 1996; Miller 1998; Wood 2000; Austin 2008), economics (Harchaoui, Jean et al. 2005), healthcare and training (Blendon, Schoen et al. 2002; Philippon and Braithwaite 2008; McCurdy, Duggan et al. 2009) and 
teaching (Mitchell, Clarke et al. 2007). Given the cultural similarities between Australia and Canada there is an opportunity to develop a shared privacy framework for secondary use of medical data.

\subsection{Contribution to knowledge}

This thesis describes the first substantial study of Australian and Canadian consumer views of secondary use of their medical data, particularly pertaining to privacy. The study explores the contemporary privacy theories proposed by Tavani, Moor and Nissenbaum (Moor 1997; Tavani 1999a; Tavani 1999b; Moor 2000; Tavani and Moor 2001; Tavani 2003; Moor 2005; Tavani 2007a; Tavani 2007b; Nissenbaum 2010) within the secondary use of medical data context. The specific research contributions of this study are:

- The combination and application of the Restricted Access Limited Control (RALC) (Tavani and Moor 2001) and contextual integrity (Nissenbaum 2010) privacy theory.

- An exploratory investigation into Australian and Canadian consumer views regarding secondary use of their medical data organised according to Tavani and Moor's tripartite model of privacy which includes the concept of privacy, justification of privacy, and management of privacy.

- A comparison between Australian and Canadian citizens views regarding the secondary use of their medical data within the tripartite model of privacy.

- A conceptual privacy framework for secondary use of medical data which describes and organises key privacy concepts, actors, attributes and information flows. This framework is grounded in the literature and is refined by consumer survey findings. The framework includes a new approach to engagement with consumers and demonstrates a shift away from relying on interpretations of the 'limited access' privacy theory.

The outcomes from this study have implications for medical research, government and policy makers, privacy advocates and privacy research, and information systems. 


\subsection{Structure of Thesis}

The remainder of this thesis includes seven additional Chapters moving from the conceptual study aspects to the consumer surveys and beyond to a proposed privacy framework and conclusions as illustrated in Figure 2.

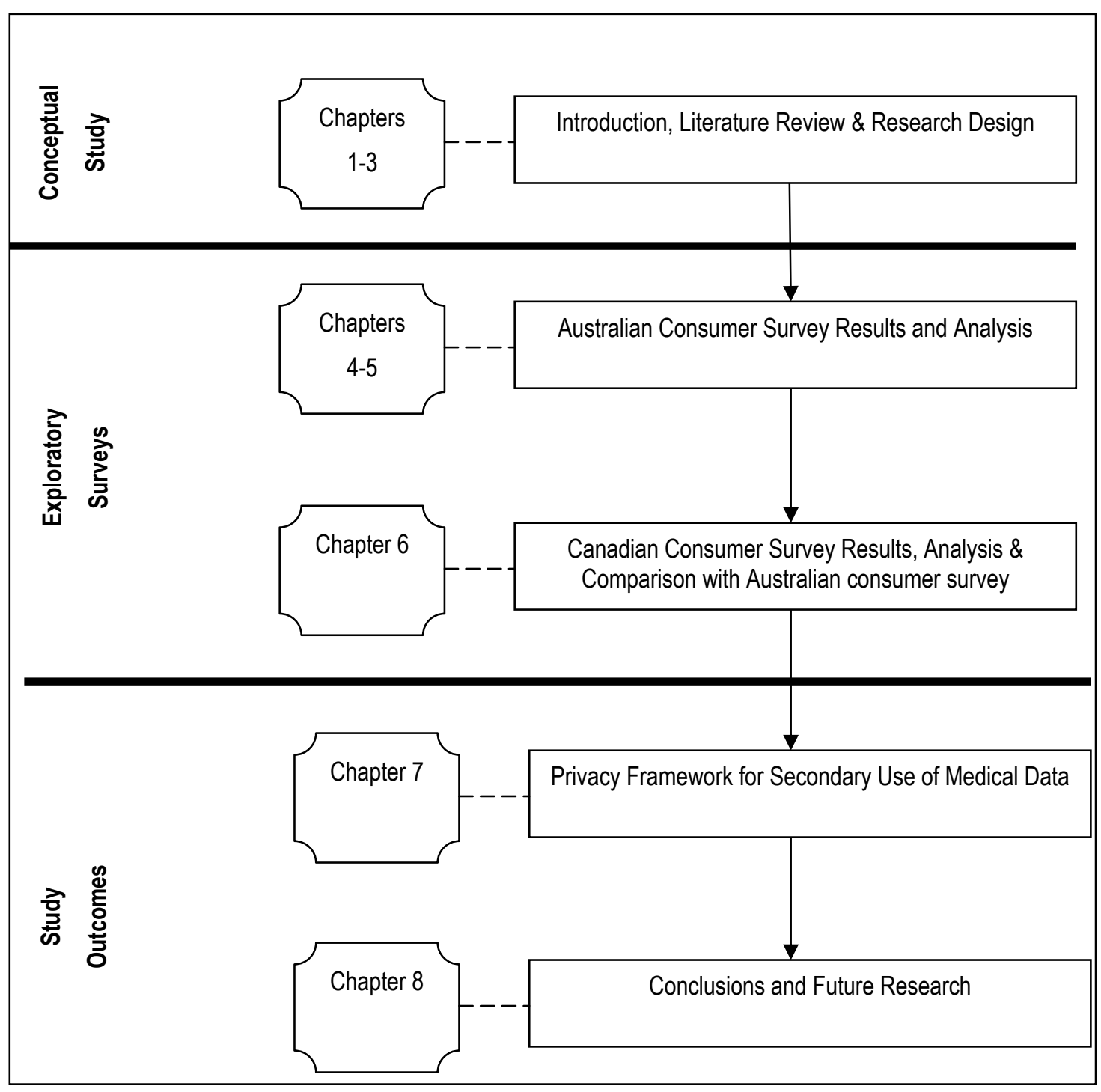

Figure 2: Outline of the thesis

Chapter 2 presents a literature review across the diverse domains that intersect when considering privacy and secondary uses of medical data. Chapter 3 elaborates on the chosen research methodology.

Chapter 4 presents the results of the Australian consumer survey with a joint presentation of quantitative and qualitative results. These results include raw data 
and outcomes from statistical testing with significant results and deductive themes found in consumers qualitative survey responses. The analysis of these Australian results is presented in Chapter 5 .

Chapter 6 presents the results and analysis of an identical Canadian consumer survey conducted as part of this study. This Chapter also includes a comparative analysis between the Australian and Canadian consumer opinions.

Chapter 7 proposes a privacy framework for secondary use of medical data using existing contemporary privacy theory and the results of consumer surveys to inform the framework. The final chapter, Chapter 8 considers study conclusions and areas of future research.

\subsection{Terms}

When an individual engages with the healthcare sector they are described as 'patients' and frequently report a perceived passive role with a lack of control as healthcare professionals go about the task of delivering healthcare services to the individual (Johnson 2001; Torrey 2011). Hence the sometimes disempowering term 'patient' is not the most ideal term and 'consumer' or 'citizen' have been adopted throughout this thesis. It is acknowledged that the term 'consumer' may cause discomfort amongst some providers in the healthcare sector who rail against the consumerism that is emerging in healthcare delivery and attribute special, responsible, caring meaning to the term 'patient' (Schattner 2011).

The terms 'consumer' and 'citizen' have been adopted in this thesis to re-enforce the notion that an individual should not necessarily be cast in a passive role when it comes to secondary use of their medical data.

The terms 'data' and 'information' are, as Turban and Aronson (2001) suggest, sometimes used interchangeably. Turban and Aronson provide a common definition for each: 
- Data. Data items about things, events, activities and transactions are recorded, classified and stored but are not organized to convey any specific meaning. Data items can be numeric, alphanumeric, figures, sounds or images.

- Information. Information is data that have been organized so that they have meaning for the recipient (Turban and Aronson 2001, p. 131).

These definitions of data and information are suitable for this study and given the non-technical, more conceptual nature of this dissertation the terms will be used interchangeably. 


\section{LITERATURE REVIEW}

\subsection{Introduction}

The intention of the literature review is to describe what is already known and what remains unaddressed regarding information privacy matters pertaining to the secondary use of medical data. This is a very broad and diverse area of research ranging from privacy theory to societal impacts and implications of secondary use of medical data. The purpose of the literature review is to arrive at specific research questions. To aid this journey the literature review chapter has been organised into four sections:

(1) A broad consideration of privacy theory with a focus on information privacy

(2) A review of information privacy in the secondary use of medical data context

(3) A review of multiple stakeholder points of view on information privacy matters related to secondary use of medical data

(4) A summary of open research questions and assumptions arising from sections 1-3.

At first these may appear to be an unusual collection of areas to consider together in one literature review. However emerging privacy theory from area (1) has the potential to inform how information privacy is addressed in (2). The stakeholder perspectives considered in (3) round out the literature review by providing diverse perspectives on information privacy matters related to the secondary use of medical data. Areas for further research are captured through sections (1) - (3) as open research questions. The chapter concludes with a concise summary of open research questions arising from the literature review. Each of these questions is mapped to over arching research questions.

The scope of this literature review is limited to secondary use of medical data matters rather than to the manner in which confidentiality is provided to patients during the delivery of healthcare services. Healthcare delivery issues are best considered by the members of the medical community responsible for the delivery of the services. The importance of clinicians having access to all available information when treating patients and delivering healthcare services is acknowledged. 
Figure 3 illustrates the structure of the literature review with the outcome of the literature review being research assumptions and identified open research areas informed by the reviewed sources.

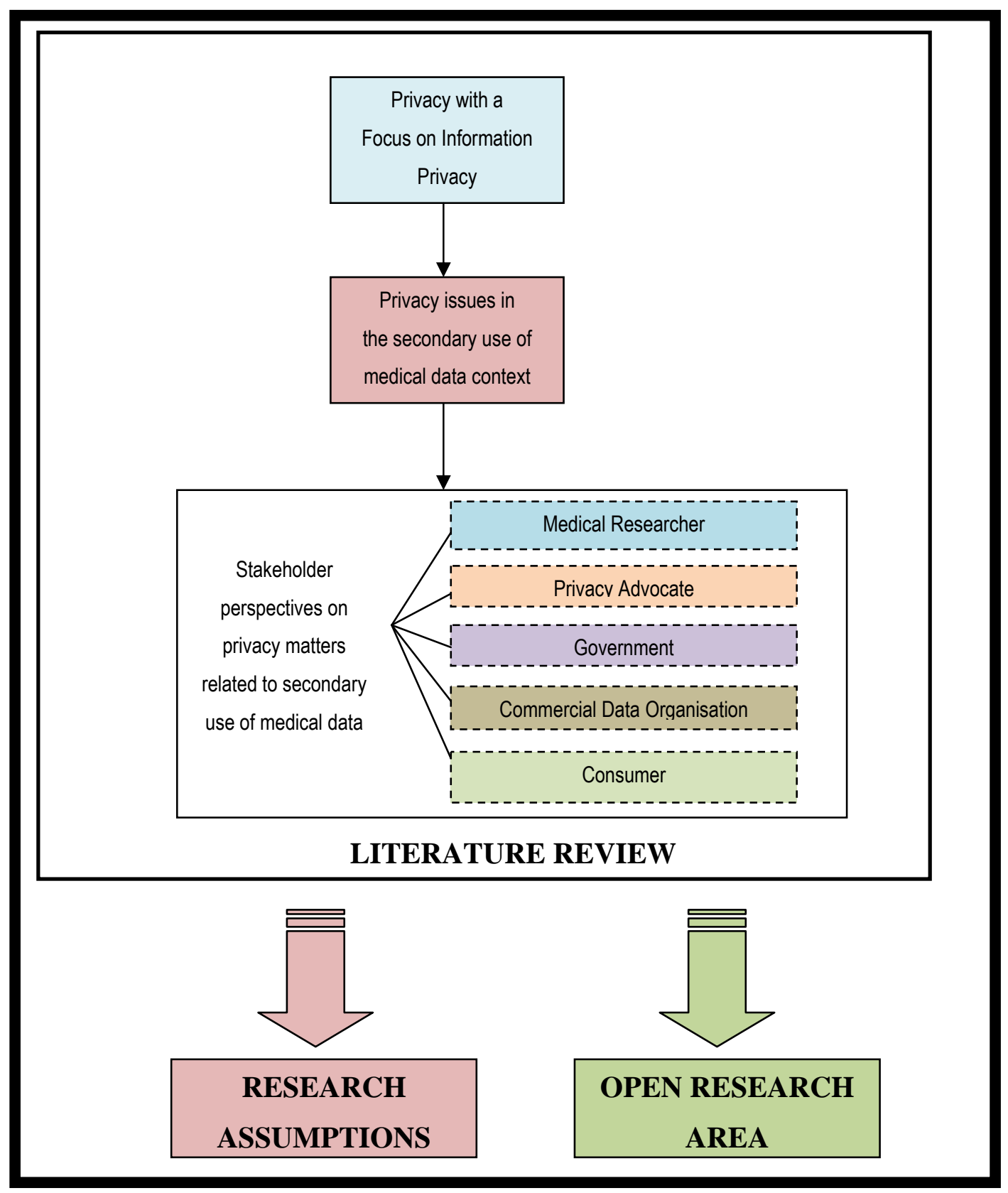

Figure 3: Structure of Literature Review with research assumptions and open research areas as outcomes. 


\subsection{Privacy with a focus on information privacy}

Philosopher Herman Tavani provides an insightful phrase which is a useful starting point for considering privacy matters: "Privacy is a concept that is neither clearly understood nor easily defined" (Tavani 1999a, p. 11). Moor (2000) suggests that the concept of privacy is culturally dependent and some cultures may value privacy and other cultures may not. The research documented here is based upon accepting privacy concepts as an important underlying moral philosophy associated with human-rights based ethics which contribute a valuable dimension to Western culture (Regan 1995; Cullen 2008; Maurushat 2008).

Publications concerning privacy matters in Western culture have been provided by researchers across multiple disciplines including: law (Warren and Brandeis 1890; Fried 1968; Rachels 1975; Gavison 1980; Kang 1998; Cohen 2000; Froomkin 2000) political science (Regan 1995), philosophy (Westin 1967; Rachels 1975; Moor 2000; Van den Hoven 2003; Floridi 2005; Floridi 2006), and socio-technical systems (Tavani 1996b; Tavani 1999a; Tavani 1999b; Tavani and Moor 2001; Tavani 2003; Moor 2005; Tavani 2007a; Tavani 2007b; Clarke 2010; Nissenbaum 2010; Clarke 2011a).

Figure 4 is a very simplified view of privacy to provide, at a glance, some insight into the very complex domain of privacy.

The first, blue zone, uses Culver et al. (Culver, Moor et al. 1994) concise conceptualisation of privacy where they argue that a person can be said to have privacy if in a given situation or context they are offered protection from intrusion and interference and information access by others.

The second, purple zone, describes two broad classifications that also assist in the conceptualisation of privacy; being normative and descriptive privacy. In a normatively private situation, individuals are protected by cultural norms such as formal laws or informal policies. Normatively private situations often include zones or contexts where normative protection is needed e.g. a patient in consultation with a clinician or client in discussions with his/her lawyer. Descriptive privacy results in 
situations where individuals can expect privacy by natural means such as physical barriers. Tavani and Moor suggest descriptive privacy is "privacy that exists as a matter of fact" (Tavani and Moor 2001, p. 7).

The third, green zone, presents early theories of privacy that focussed on allowing an individual complete control over all personal information, or limitations on the persons who could gain access to personal information. Debate regarding privacy has swung between argument for and against a particular approach to privacy with the limitation theory (Gavison 1980; Allen 1988) and control theory (Westin 1967; Rachels 1975) dominating.

The final (pink) zone includes three contemporary theories of informational privacy that move beyond the control theory versus limitation theory debate and offer a more holistic approach to privacy where the context (or infosphere in Floridi's work) emerges as a very important component of the privacy theory.

Nissenbaum moves the privacy debate beyond 'control' or 'limitation/constraint' by noting the value of both and encouraging a move beyond this debate:

Common usage suggests that intuitions behind both the constraint and control conceptions are sound: namely, that control over information about oneself is an important dimension of privacy, but so is the degree of access that others have to this information, irrespective of who is in control...In my view, the effect of these challenges, coupled with persuasive arguments, is not to prove that one or the other of these approaches is correct, but that both capture essential aspects of privacy that we seem to care about. A non-arbitrary resolution of this disagreement is not possible (Nissenbaum 2010, p. 71). 

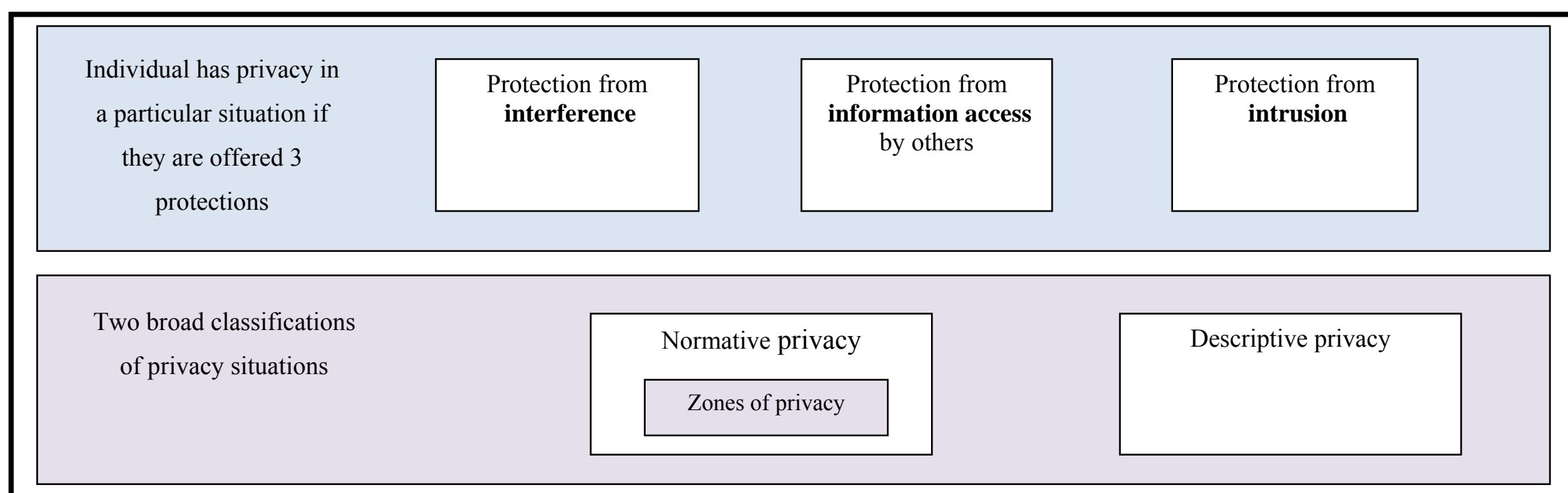

Early theories of privacy

Control theory

Limitation theory

More recently proposed information privacy theory aimed at achieving necessary protections by building on earlier theories and normative and descriptive privacy

Floridi ontological
theory of information
privacy

Nissenbaum contextual
integrity theory of
informational privacy

Moor \& Tavani hybrid RALC theory of privacy

Figure 4: Graphical representation of select privacy concepts 
The blue zone in Figure 4 refers to Culver et al. (Culver, Moor et al. 1994) conceptualisation of privacy that draws attention to the issue of informational privacy:

An individual or group has normative privacy in a situation with regard to others if and only if in that situation the individual or group is normatively protected from intrusion, interference, and information access by others (Culver, Moor et al. 1994, p. 6).

That quote acknowledges the aspect of privacy that was raised by Warren and Brandeis (1890) in their seminal paper on the rights of an individual to be left alone and free from intrusion and interference. In addition, this quote raises the notion of information privacy. Charles Fried (1968) suggested that personal information can be conceptualised on a continuum from more to less intimate and more to less sensitive. In contrast others have split information into dichotomies of 'personal' versus 'public' and zones of privacy (Gerstein 1984) with privacy expectations varying according to the classification of the information type.

This thesis relates to informational privacy; specifically electronic medical information privacy. Tavani has particular interest in cyber technologies and privacy and in 2007 he highlighted the impact that information technology has had on information privacy with respect to:

- The amount of personal information that can be gathered

- The speed at which personal information can be transmitted

- The duration of time that information can be retained

- The kind of information that can be transferred (Tavani 2007a)

All of these issues raised by Tanavi have relevance to the specific context under consideration for this study i.e. secondary use of medical data. Prior to Tavani's 2007 publication Moor provided a useful description of the challenge posed to informational privacy when he described the way that information is greased when it is computerised. 
When information is computerised, it is greased to slide easily and quickly to many ports of call. This makes information retrieval quick and convenient. But legitimate concerns about privacy arise when this speed and convenience lead to the improper exposure of information. Greased information is information that moves like lightning and is hard to hold onto (Moor 1997, p. 27).

Tavani and Moor have proposed a hybrid privacy theory in a series of individual and jointly authored publications (Moor 1997; Tavani 1999b; Moor 2000; Tavani and Moor 2001). These researchers sought to identify the fundamental, essential components necessary in a privacy theory. One outcome of their research is a tripartite model to describe a sufficient theory of privacy which they suggest must include three core aspects:

A good theory of privacy has at least three components: an account of the concept of privacy, an account of the justification for privacy, and an account of the management of privacy. This tripartite structure of the theory of privacy is important to keep in mind because each part of the theory performs a different function. To give an account of one of the parts is not to give an account of the others (Tavani and Moor 2001, p. 6).

Figure 5 is a visual representation of the tripartite privacy model proposed by Tavani and Moor, illustrating that the concept, justification, and management of privacy are complimentary and essential components of a privacy theory.

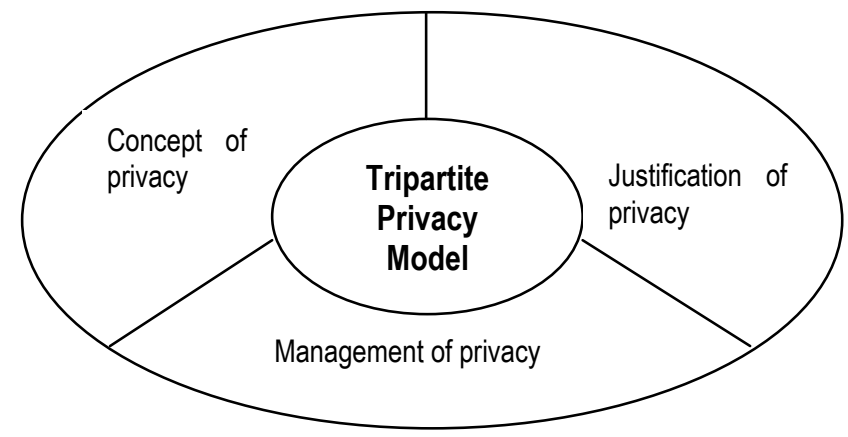

Figure 5: Visual representation of the tripartite privacy model 
Much of the literature regarding privacy considers one aspect of the tripartite model, for example the justification for privacy, rather than recognising the importance of the simultaneous existence of all three elements of concept, management and justification. For example, Kang (1998, p.1203) considered the extent to which an individual has control over the processing (acquisition, disclosure and use) of personal information. That could be considered 'management' of privacy. Reinman (1976) considered privacy to be the condition under which other people are deprived of access to either some information about individuals or some experience of the individual. That aspect could be considered important to the 'concept' of privacy. A further example is the work of Van de Hoven (2003) who suggested moral reasons why privacy deserves protection, which would be considered 'justification' of privacy.

Tavani and Moor (2001) consider individual control is important in both the justification and the management of privacy and they also defend the importance of restricted access in terms of the concept of privacy.

The privacy theory building research undertaken by Tavani and Moor has resulted in a context sensitive, hybrid Restricted Access/Limited Control (RALC) privacy theory (Tavani and Moor 2001). These philosophers go on to emphasise the importance of separating privacy from control with control having three possible means of expression; through choice, consent and correction. They go on to suggest that simply identifying the concept of control with privacy is misleading as it is not possible for an individual to exert control over the rapidly growing volumes of personal electronic data resident on information systems worldwide. Normative privacy concepts combine with the nuanced interpretation of control resulting in Tavani and Moor's hybrid Restricted Access/Limited Control (RALC) privacy theory.

A strength of Moor and Tavani's work is that they tackled the fundamental, important matter of developing a privacy theory rather than devising particular justifications or recommendations for the management of privacy that are suitable for 
particular contexts. Tavani was particularly determined to take a holistic view with the aim of providing a theory that can be effective in a wide range of contexts with adequate provision to respond to constantly developing cyber technologies that can bring insufficient conceptualisations of privacy undone (Tavani 1999a; Tavani 1999b; Tavani 2000; Tavani 2003; Tavani 2007a).

Similar to Tavani and Moor's privacy theory, Nissenbaum $(2004 ; 2010)$ also takes an holistic view of information privacy theory with an emphasis on the importance of the privacy context. Nissenbaum proposes 'contextual integrity' as an alternative conception of information privacy. Her approach is comprehensive with a goal of providing a decision heuristic to guide evaluation of information privacy.

Nissenbaum proposes informational norms which govern activities in contexts which she refers to as 'context-relative informational norms'. Context-relative informational norms are characterized by four key parameters:

(1) Contexts, (2) Actors, (3) Attributes and (4) Transmission principles.

Actors: There are three types of actors: (1) senders of information (2) recipients of information and (3) information subjects.

Attributes (Information types): Analysis of attributes in contextual integrity is more nuanced than the private or public dichotomy of information. Informational norms render certain attributes appropriate or inappropriate under certain conditions. Nissenbaum suggests that attributes co-evolve with contexts.

Transmission Principles: a constraint on the flow of information from party to party in a context. This parameter expresses terms and conditions under which such transfers should occur.

The idea that privacy implies a limitation of access by others is similar to Nissenbaums concept of an informational norm. In Nissenbaums theory, diminishment of access is just one way that information flow may be governed. 
Informational norms are far more comprehensive as they describe not only when access is reduced but it also enables specification of (1) what (2) about whom and (3) against whom.

Nissenbaum sets her privacy theory apart from others as she has "...not fully adopted any one of the standard theories as a framework for the intuitive notion of a context..."(Nissenbaum 2010, p. 132). The definition provided for contexts is comprehensive:

Contexts are structured social settings characterized by canonical activities, roles, relationships, power structures, norms (or rules), and internal values (goals, ends, purposes) (Nissenbaum 2010, p. 132).

Shoemaker (2009) critiqued the RALC proposal from Tavani and Moor, and Nissenbaum's contextual integrity saying the proposals were too vague in relying on shared understandings of normatively private zones and contexts. The secondary use of medical data provides an interesting opportunity to further consider this particular criticism made by Shoemaker. The internal values (goals, ends, purposes) of the many stakeholders with an interest in secondary use of consumers' medical data are quite different. For example the goals, ends and purposes of medical researchers are generally oriented around societal benefit through increased knowledge of disease and treatments. The goals, ends and purposes of the insurance industry use of medical data are more oriented towards profitability and minimisation of future liability. These stakeholders are operating in the shared context of secondary use of medical data but with very different internal values.

The application of the privacy theories of Moor, Tavani and Nissenbaum in the secondary use of medical data context is an open research area. The application of these contemporary theories to the secondary use of medical data provide an opportunity to see how stakeholders with different internal values can operate within a shared context. 
Shoemaker (2009) also argued that the control theory of privacy was less problematic than the limitation and hybrid RALC theory of privacy. Shoemaker introduces the concept of 'unauthorised exposure of one's identity' as a more useful approach than that in RALC and contextual integrity approaches to information privacy.

Luciano Floridi (2005) proposed an ontological theory of informational privacy based on information ethics. In a follow-up publication Floridi (2006) provides a concise summary of his theory including the concept of ontological friction:

To summarise: given a certain amount of personal information available in (a region of) the infosphere $I$, the lower the ontological friction in $I$, the higher the accessibility of personal information about the agents embedded in I, the smaller the informational gap among them, and the lower the level of informational privacy implementable about each of them. Put simply, informational privacy is a function of the ontological friction in the infosphere (Floridi 2006, p. 110).

Despite the use of illustrative examples in Floridi, Shoemaker, Moor, Nissenbaum and Tavani's publications there is little in the way of further publications that have explored the real world application of the proposed informational privacy theories (Grodzinsky and Tavani 2010a; Grodzinsky and Tavani 2010b). Taking the abstract informational privacy theories and applying them in the real world would add value to the body of knowledge surrounding informational privacy and this remains an open research area.

Applying Shoemaker and Floridi's privacy theories to the real world would be possible, however, the more tangible, less esoteric nature of Nissenbaum, Tavani and Moor's theories provide a useful bridge to the 'real world'.

As a result of considering the potential for application of contemporary privacy theory to the secondary use of medical data, this research proposes that the following research question exists: 


\section{Open Research Question}

1. Can Moor and Tavani's Restricted Access/Limited Control (RALC) and Nissenbaum's contextual integrity privacy theories be applied to the secondary use of medical data?

\subsection{Privacy in the secondary use of medical data context}

This section of the literature review transitions from broader privacy concepts to specific consideration in healthcare and specifically the privacy of medical data. The consideration of privacy presented in the previous section makes it clear that there is far more to privacy than simply the 'limitation theory'. The Hippocratic Oath has long guided medical doctors in the delivery of care to patients and the oath includes a specific reference to the provision of confidentiality:

Whatever I see or hear in the lives of my patients, whether in connection with my professional practice or not, which ought not to be spoken of outside, I will keep secret, as considering all such things to be private (as translated by North (2002)).

While not all medical schools include the recitation of the Hippocratic Oath at graduation, the matter of patient privacy does continue to have importance. For example, Cornell University continues the tradition with an updated version of the oath that continues to include reference to patient confidentiality:

That whatsoever I shall see or hear of the lives of my patients that is not fitting to be spoken, I will keep in confidence; (Weill Cornell Medical College 2005).

In support of the confidentiality aspect of the Hippocratic Oath, medical practitioners have kept their patients personal information private by restricting access to the information recorded on paper based health records. That approach applies the 'limitation theory' of privacy as depicted in the green zone of Figure 4. That paradigm of restricted or limited access to patient information and the expectation 
that it provides necessary patient privacy is inadequate with the move to an electronic medium for holding medical records, as discussed by Marwick (1996).

Lowrance (1997), echoing the concerns described by Marwick, provides a useful overview of the flow of consumer data through a data journey:

\begin{abstract}
Although physicians, and staff nominally under their supervision, still collect much of the most intimate data, they are not necessarily any longer in position to control the movements, uses or fate of the data. Data from a routine patient encounter with the healthcare system quickly are transmitted among care-providers and their local institutions, various technical support services, the paying institutions, and a variety of supervisors, inspectors, and researchers many far removed from the data subject, many not medically certified, and possibly many not sworn to confidentiality
\end{abstract} (Lowrance 1997, p. 19).

Croll (2011) agrees that the limited access approach was relatively easy to implement when health records were stored on hardcopy documents and stored in physicians or hospital data repositories. A shift in the established school of thought adopted by the medical profession requires a move away from the limitation theory of privacy towards a more comprehensive information privacy theory. This could aid in adequately support the adoption of electronic health records where the information is available in multiple contexts without the medical practitioner acting as 'gate keeper' in the manner described by Magnusson (2004).

Clinicians and researchers around the world are wrestling with the collision of health privacy and the emerging information and communication technologies. These researchers include those in Ireland (Buckley, Murphy et al. 2011), the United States of America (Appelbaum 2000; Bansal, Zahedi et al. 2008b), Australia (Hansen, Gurney et al. 2011; Showell 2011), Germany (Iacono 2007), The Netherlands 
(Townend 2010), Portugal (Falcao-Reis, Cost-Pereira et al. 2008), Scotland (Fraser 2003), Greece and Denmark (Orphanoudaki, Voss et al. 2007).

\subsubsection{Partnering with consumers for research}

Emerging research suggests the way forward regarding secondary uses of medical data would best be served by ensuring consumers are better informed about secondary uses of their data and, perhaps, by viewing consumers as partners in the research process (Whiddett, Hunter et al. 2007; Buckley 2008; Ruyter, Louk et al. 2010; Townend 2010; Shelton 2011). That involvement may include acknowledging the value of consumers' data; whether it is possible to identify the individual or whether the data forms a small component of a vast array of suitable anonymised data. The work of Ruyter, Louk et al. (2010) calls for the European Data Protection Directive (EDPD) (95/96/EC) to reconceptualise the secondary use of medical data as an everyday type activity rather than one requiring an 'exemption'. This would draw on consumers as partners who could view medical data storage in large biobanks as the default choice to support a 'research track'. Trinidad, Fullerton et al. (2011) published a view where citizens could be regarded as 'research participants' rather than 'research subjects'.

We propose a shift from paternalistic protections to respectful engagement with individuals and groups whose conceptions of risk, benefit, and harm deserve consideration. Such an approach would treat participants as true stakeholders in research, who willingly take on risk because they see potential benefits to society outweighing potential harms (Trinidad, Fullerton et al. 2011, p. 288).

That is an empowering attitude shift for consumers in terms of secondary use of their medical data. Buckley (2008) also makes a persuasive argument for greater understanding of medical research amongst the general public to aid engagement.

Robert H. Shelton gives a commentary, in a non-peer reviewed publication, that urges medical researchers to confront this issue 'head-on': 
Rather than viewing privacy concerns as an impediment, policy-makers, scientists, and HIT specialists should embrace privacy as an opportunity that, if addressed, can enhance the flow of information. Confronting this issue head-on by establishing an effective electronic process for consent - one that honours each patient's specific privacy needs and desires - can enhance patient participation in research, expand access to data and biological samples, reduce the costs and time associated with the recruitment of patients for clinical trials and accelerate the discovery of new treatments (Shelton 2011, p. 1).

Shelton goes on to describe a pilot study where patients were given an opportunity to register their detailed privacy preferences concerning access to their medical information using electronic platforms that provide a digital consent process. No details of the small pilot study were published. However similar initiatives are likely to become a broadening research area and this thesis investigates a similarly motivated consumer empowered approach.

\subsubsection{Anonymised data}

The use of anonymised data for secondary use is widespread amongst many stakeholders including health researchers, health economists, insurance and pharmaceutical organisations and healthcare providers. Often consumer consent is not sought if the data to be used for a secondary purpose is to be anonymised. An alternative is to use identifiable data where it is possible to recognise the individuals concerned. The medical research community operate within an ethical framework that would generally seek a consumers consent prior to using identifiable data. Other secondary use stakeholders may not operate within such containing ethical frameworks.

Several of the contemporary privacy theories previously presented have direct impact for this research when considering the appropriate use of anonymised data. In 
particular Nissenbaum's contextual integrity assists in unpacking the anonymisation of data as a means of delivering privacy to a consumer. The actors involved in the process of medical data anonymisation are: healthcare provider (sender), the secondary user (recipient) and the consumer (information subject). The contexts vary from commercial oriented eg. insurance organisations who often aggregate data to detect trends to aid in optimising premiums to health researchers working towards more utilitarian goals. Using Nissenbaums 'contextual integrity' approach to privacy, an information subject would be able to influence the attributes and transmission principles according to context to establish suitable privacy. The use of anonymised data may be consistent with the context, actors, attributes and transmission principles required to provide privacy to the information subject. Alternatively the context, actors, attributes and transmission principles may indicate that the use of anonymised data is not suitable to provide privacy to the information subject. The widespread use of anonymised data certainly rests comfortably with the 'restricted access' approach to privacy which is based on the early concept of privacy whereby if you can't identify an individual there is no problem. Contemporary theories of privacy are more nuanced.

A simple scenario using anonymised data illustrates - if a consumers medical data is anonymised and then aggregated with similar consumer data, over a period of time patterns can emerge across the attributes that comprise the aggregated, anonymised datasets. That would result in the emergence of intelligence that was unrecognised when dealing with one single consumer health record. If the operating context was health research that would likely be viewed positively. In contrast, if the context was commercial, say a personal insurance context, the use of seemingly innocuous anonymised data takes on a whole new dimension. Business intelligence models developed using aggregated, anonymised data can deliver far more power than may have been imagined with the single anonymous health record. Anonymised data is not as safe as many citizens believe. This thesis acknowledges the suitability of anonymised data in some secondary use context - but not all.

Returning to the contemporary privacy research of Moor and Tavani, they suggest that "Privacy is fundamentally about protection from intrusion and information 
gathering by others." (Tavani and Moor 2001, p. 6). These researchers do not propose that "Privacy is fundamentally about protection from intrusion and identifiable information gathering by others". Anonymised information gathering by secondary use stakeholders may have a negative impact on information subjects when considering the power of aggregated data. These issues move well beyond the simplistic concept that as long as an individual is not personally identified there can be no problem using their data.

This thesis seeks to explore the application of contemporary privacy theories to the secondary use of medical data to inform the debate regarding future use of both anonymised and identifiable consumer health information. The next section of the literature review presents multiple perspectives on the secondary use of medical data. To be able to progress this challenging field of research it is necessary to engage in the debate from multiple points of view.

\subsection{Stakeholder perspectives on privacy in the secondary use of medical data context}

This section contains five sub-sections where stakeholder points of view regarding privacy and the secondary use of medical data are considered. The stakeholders considered are:

1. medical researchers

2. privacy advocates

3. commercial organisations

4. the Australian government and

5. consumers

The recent European based research of Townend (2010) is initially presented as his work includes multiple stakeholder perspectives through conceptual vectors, with the consumer vector the most under represented.

Townend (2010) explores three competing vectors in the health privacy domain.

1. The healthcare vector (e.g. medical research)

2. The commercial use vector (e.g. insurance industry)

3. The public opinion vector 
Townend's focus was particularly on genetic data, however his insights are also very applicable to broader healthcare data. Townend used the privacy concepts introduced in the first part of this literature review to explore the tensions between these three vectors. A three-fold analysis of the traditional elements of privacy are considered; including privacy as a normative engine in society, and privacy as a relationally flexible boundary keeper between individuals in society and these are expressed through transactional areas including 'physical' privacy, 'informational' privacy, 'decisional' privacy and 'proprietary' privacy (Townend 2010).

The healthcare vector (medical research)

Townend posits that the history of the development of the healthcare vector started with protecting the physical integrity of research participants and then progressed to add informational and decisional privacy. That vector is configured around laws and regulations that relate to data protection, informed consent, and good practice. The medical research vector also adopts norms about the responsibility of citizens to participate in the health enterprise. The notion of balancing individual rights to privacy against common good dominates here.

The commercial use vector

Townend (2010) suggested that the commercial vector starts with property and proprietary privacy. "Data are given a commodity value through the addition of labor", such as analysis and synthesis of data. The consumer and the healthcare provider are accommodated on Townend's commercial use vector with the capacity to shift backwards and forwards to indicate which party has the greater proprietary privacy claim. That vector is configured around laws relating to health law or intellectual property law. Decisional and informational privacy are important on this vector. Data protection law is employed within this vector and supports the flow of personal data as a commodity and enabler of commercial 'activity'. Normative privacy is important here with individual autonomy for consumers as embedded in the European socio-legal arrangements. 
The public opinion vector

As Townend (2010) suggested, the public opinion vector is the most under developed and hence is clearly an area for further research. The diverse range of opinions expressed by citizens about secondary uses of their data is accommodated within that vector. Townend noted there are few surveys identifying respondents' opinions about this subject in Europe. That vector is stronger on normative privacy than the other two vectors. Townend considers public trust and finds confidence underpin information based medical research and hence regulations must support the broadest possible spectrum of opinions held and not just the majorities. That contrasts with the medical research approach to privacy that tend to adopt binary approaches such as consent, offering little accommodation for diverse consumer opinion.

As a result of the recognition of the under developed public opinion vector this research proposes that the following research question exists:

Open Research Questions

2. How diverse are consumer views regarding privacy and the use of their personal medical data for secondary purposes?

\subsubsection{The medical researcher lens: research at risk}

The knowledge of medical researchers and associates, supported by the use of sophisticated information technologies, has without doubt brought great benefit to human society through retrospective, observational studies. With the rapid growth in capture and storage of electronic medical data and ongoing developments in medical research there is enormous potential for future enhancement of our understanding of human health. This thesis seeks to support this work through developing an understanding of the possibilities for engagement between consumers, researchers, technologies and contemporary privacy theories.

The application of sophisticated information technology tools and software to capture, store and analyse large datasets, including medical datasets, has prompted 
the creation of privacy protecting legislation. With the advent of legislative requirements in many nations concerning the use of personal medical records for secondary purposes, healthcare providers and medical researchers have published numerous concerns about limitations arising from the legislation (Melton 1997; Dyer 2009; Buckley, Murphy et al. 2011). Following legislative amendments, medical researchers have reported difficulties in gaining access to consumers' medical data for secondary purposes and highlight the constraint this applies to retrospective, observational research (McCarthy, Shatin et al. 1999; Al-Shahi and Warlow 2000; Helliwell 2001; Croll 2007; Dyer 2009; Buckley, Murphy et al. 2011)

\subsubsection{Getting the balance right and challenges to research}

Medical researchers engage in debate about how to 'get-the-balance-right' between the privacy needs of an individual and the broader societal benefit that can arise from using medical data to advance understanding of human health to achieve better health outcomes for all (Melton 1997; Walton, Doll et al. 1999; Lowrance 2003; Whiddett, Hunter et al. 2007; Zeps, Iacopetta et al. 2007; Dyer 2009; Buckley, Murphy et al. 2011).

The 2004 the Australian National Health and Medical Research Council (NHMRC) privacy consultation with stakeholders involved a survey that was administered to 188 medical and health service researchers; 112 individuals responded to the survey (60\% response rate). Most respondents had been conducting research for an average of 13 years. No claims were made about this being a representative sample. This research found common issues related to data access, consent and scientific rigour:

The most common issues raised related to restricted access to registries or databases hindering research by affecting scientific rigor. Access to registries was commonly linked to recruitment and consent. Where consent was not possible, or was difficult or problematic, privacy legislation was considered to impede recruitment. Sampling was identified as a major factor affecting scientific rigor. Sample bias undermines confidence in the generalisability of results to the 
study population (Campbell Research And Consulting 2004, p. 12).

In addition, apart from hindering the scientific rigour, a recurring theme in the medical researcher's responses to the NHMRC survey is the matter of the administrative burden created by privacy legislation. Of the research respondents, $73 \%$ identified an increased administrative burden arising from Commonwealth privacy legislation (Campbell Research And Consulting 2004, p. 15).

The administrative burden was reflected in additional cost in terms of staff time, overall time taken for approval and start up of research and the associated cost of changed research practices to accommodate privacy requirement (Campbell Research And Consulting 2004, p. 13).

These Australian researchers suggested improvements to legislation and guidelines to reduce the tensions between privacy and medical research. There was no reported consideration of viewing consumers as research partners and there was no consideration of the broader societal notions of increased surveillance through linked databases coming from the medical and health service researchers surveyed.

One survey question specifically explored the 'getting-the-balance-right' debate. The medical research community expressed stronger feelings about the disadvantage of privacy legislation than did other groups such as allied health professionals and peak bodies. This is graphically illustrated in one of the charts from the NHMRC 2005 report, refer to Figure 6 which reproduces Figure 10 from the NHMRC report (Campbell Research And Consulting 2004, p.42).

The study groups in that figure are:

ST3 - medical \& allied health professionals;

ST4 - medical and health service researchers;

ST5 - data custodians;

ST6 - ethics committee members and 
ST7 - peak bodies.

The ST4 group of medical and health service researchers clearly provided the strongest disagreement with the NHMRC survey statement "The current privacy framework strikes the right balance between protecting the rights of individuals and enabling effective health research".

Figure 10: Attitudes about privacy framework and the balance between privacy and research

Q. The current privacy framework strikes the right balance between protecting the rights of individuals and enabling effective bealth research
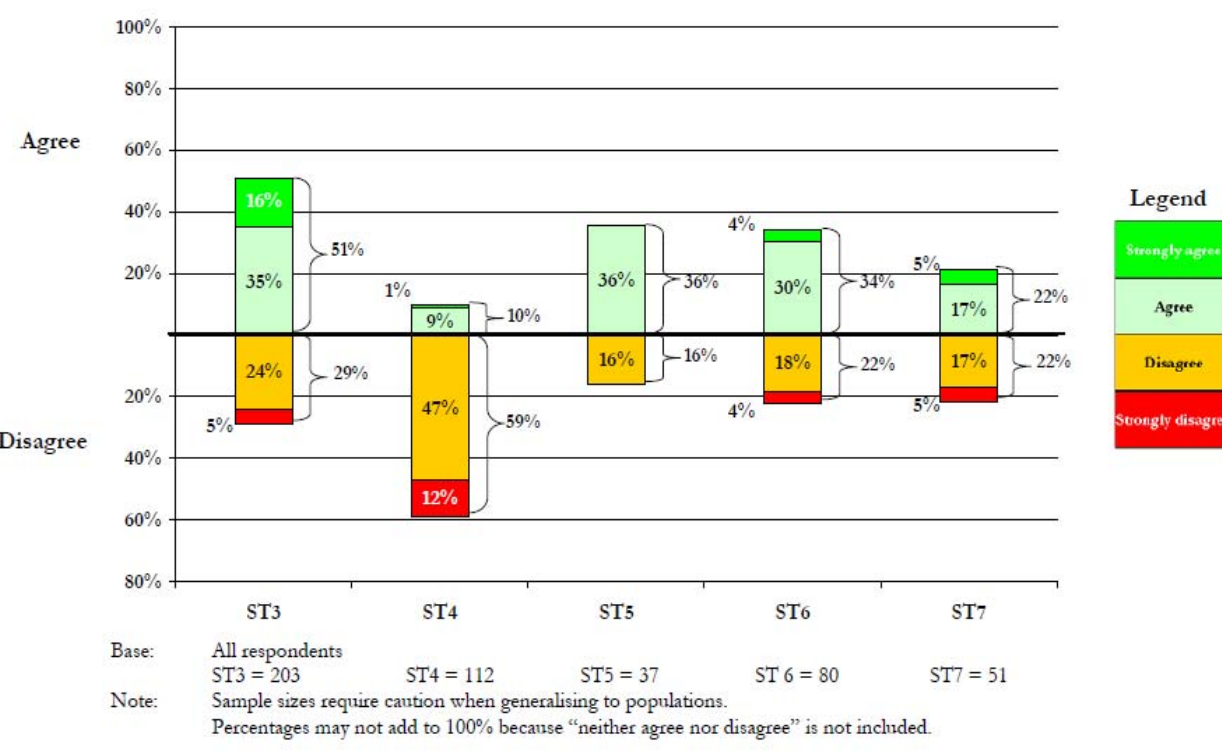

Percentages may not add to $100 \%$ because "neither agree nor disagree" is not included.

Figure 6: Balance between privacy and research (reproduced from Campbell Research and Consulting 2004)

"In general, research respondents favoured automatic access to individual information without obtaining specific consent" (Campbell Research And Consulting 2004, p. 13). That contrasts sharply with the consumer stakeholder study outcomes reported in earlier sections of the NHMRC report.

Rodwin (2009) argues the case for public ownership of patient data, similar to the medical and health service researchers above, with secondary use of medical data seen as a public good. 
There are a large number of publications available considering the 'getting-thebalance-right' debate. The health research community are very influential in setting the direction and nature of secondary use of consumers medical data.

Gordis, Gold and Seltser (1977) argued that retrospective observational type studies were hindered due to the growing impact of privacy concerns as reported in the American Journal of Epidemiology:

In recent years, however, widespread societal concern for privacy and confidentiality, often manifest in confusing or ambiguous regulations, has made many types of epidemiologic and other medical investigations increasingly difficult to conduct and, in fact, now threatens to make such studies virtually impossible (Gordis, Gold et al. 1977, p. 163).

The Gordis paper continues with a list of significant epidemiological studies facilitated by secondary use of medical information, often with individually identifiable data. Those researchers use a single lens to view the matters discussed; that of an epidemiologist, with no regard for other points-of-view. These epidemiologist argue for access to medical information that includes individually identifiable information "because access to these records is only a first step in ascertaining and identifying these patients so that they can be subsequently contacted and, with their informed consent, interviewed and studied" (Gordis, Gold et al. 1977, p. 166). The British General Medical Council moved towards sharing of patient information with expressed permission which prompted Doll and Peto (2001) to write to the editor of the British Medical Journal stating:

The right to medical care should, we suggest, generally continue to include the responsibility to allow the information gained in its course to be used for the benefit of others who develop a similar disease, or are at risk of developing it. Confidential sharing of information about patients between doctors and bona fide medical research workers (with 
exceptions only in particular cases) has done no harm and has achieved much good. Why destroy it? (Doll and Peto 2001, p. 730).

That note is again written through a single lens without acknowledging the broader stakeholders who also lay claims (of varying veracity) to the need to access consumers' medical records. The tone of that article is best captured through the header 'Rights involve responsibilities for patients'. Consumers are being told that they have both a right to healthcare and a responsibility to others and should thus allow their personal medical information to be available for research. It is clear that the clinicians have utilitarian motivations. That is similar to the view taken by Lowrance in the Nuffield Trust report (Lowrance 2002). Earlier Al-Shahi and Warlow (2000) expressed a view that called for public consultation to investigate the ideal balance between individual confidentiality and data protection, and the legitimate use of patient-identifiable data without consent.

Researchers' concerns regarding access to data can be broadly categorised into those pertaining to compromised research design, consent bias, small data volumes, delays in implementing studies, and associated costs and audit versus research issues. AlShahi and Warlow raised these issues in the British Medical Journal:

A blanket requirement for anonymisation of data, as well as informed consent from all individuals to use identifiable data about them would jeopardise the methodological integrity of research and audit (Al-Shahi and Warlow 2000, p. 1031).

The undesired introduction of 'consent bias' and effects on validity of research design are also often reported (Buckley, Murphy et al. 2011). That issue arises when researchers can only gain access to consumers who have consented to having their data used in studies. It is possible that bias may be introduced into study designs as there may be a group of individuals with common characteristics who refuse to participate. Any evidence generated by such a study would perhaps not be generalisable due to the swaying of results by the missing cohort. 
Other concerns relate to the smaller volumes of data available for research when consumer consent is required - such as the publications of McCarthy et al. who state:

Efforts to protect patient privacy may come into conflict with the ability to produce timely and valid research to safeguard and improve public health (McCarthy, Shatin et al. 1999, p. 417).

Medical researchers report on the impact of the delays to undertaking research studies and increased costs when consumer privacy matters, including implementation of consent mechanisms, impede research (Melton 1997; McCarthy, Shatin et al. 1999; Croll 2007; Metcalfe, Martin et al. 2008; Morton, Smith et al. 2009).

The fine line between what is considered research rather than a quality audit is also commented upon. For example, Morton et al. (2009) comments about broad Australian Law Reform Commission proposals to limit all research where research is broadly considered to be the compilation of statistics. That definition could potentially compromise practice audits and quality reviews which form an essential part of healthcare delivery contexts.

The Nuffield Trust report paragraph labelled Privacy, confidentiality, and related notions does not acknowledge possible existence of privacy theory beyond 'limited access'. Lowrance opens with the statement "Privacy is a widely understood and deeply felt, but elusive, concept" (Lowrance 2002, p. 7). Many privacy researchers would disagree that privacy is a well understood concept (Tavani 1999a) as described at the start of this literature review.

Lowrance summarises a number of foundation assumptions related to privacy: 
Privacy is a relative status, and claims to it must be negotiated against countering claims such as rights of others or collective societal goods (Lowrance 2002, p. 8).

Data may be about a patient, for instance, but that person does not "own" the data in the sense that they are his in some exclusive proprietary way to take away, sell or destroy (Lowrance 2002, p. 3).

If data are not identifiable the data are not 'personal', and unless safeguards are compromised the data-subjects stand only a very low risk of being harmed (Lowrance 2002, p. 24).

If data aren't identifiable they aren't 'personal', and a variety of rights, obligations and sanctions that apply to personal data are not relevant. Research on anonymised data is just research on cases, not persons (Lowrance 2002, p. 27).

Investigation of consumers response to the above set of assumptions and statements is an open research area as little evidence is available to present consumers views on these matters.

The Nuffield Trust report (Lowrance 2002) attracted some negative feedback from medical researchers concerned with privacy in healthcare. Following the publication of Lowrance's Nuffield Trust report, Willison (2003) criticized an implicit assumption underlying the report - that researchers' interests are aligned with those of the public. Willison argues that "researchers interests cannot be equated with those of the public" (Willison 2003, S1:20) particularly when they are increasingly engaged in commercial research. In addition Willison does not agree with Lowrance's depiction of privacy as an individual rather than societal concern: 
The report pits this societal interest against the privacy interests of a minority of individuals who choose to withhold their own data from analysis while benefitting from the largesse of others who have contributed their data. These individuals are then exhorted to be more civic-minded (Willison 2003,S1:19).

Willison continues by disagreeing with the manner in which Lowrance has framed privacy as an interest of selfish individuals when so much research exists to depict privacy as a broad societal interest. Willison states: "A high regard for privacy has been associated with ancient Greece, English Protestantism and common law traditions and with American constitutionalism" (Willison 2003, S1:20).

As a result of recognising the imperatives behind medical research and the frequent use of anonymised data this research proposes that the following research question exists:

\section{Open Research Question}

3. What are consumer views regarding a sense of altruism towards the use of medical data 'for the common good', consumer ownership of medical data, and the use of anonymised data?

\subsubsection{Human Research Ethics Committees (HREC)}

HREC are expected to advise researchers on any research studies that involve people and personal data concerning individuals. That places HREC in the front line of secondary uses of medical data. The exponential growth of medical data and subsequent booming interest in using data for secondary purposes may have outstripped the HREC ability to keep pace with the number of such request.

The role of Human Research and Ethics Committees (HREC) have been criticized by some as being over-protective and hindering beneficial research (Campbell Research And Consulting 2004; Croll 2007). The role of the HREC is to protect the rights of 
consumers whose very personal, sensitive medical information is sought for a wide range of secondary uses. There is some variation in the way that HREC apply ethics guidelines which adds weight to the criticisms (Zeps, Iacopetta et al. 2007; Willison, Emerson et al. 2008).

Prior research publications, largely coming from the medical research community, question if HREC include members with suitable skills to make the necessary decisions (Zeps, Iacopetta et al. 2007; Cullen 2008). For example, Metcalfe et al. (2008) report that the particular UK Patient Information Advisory Group (PIAG), deciding if permission should be granted to access patient records without consent, did not include a legal experts. Metcalfe et al. (2008) highlight that this committee changed its interpretation of the law over time.

Research by Willison et al. (2008) involved face-to-face interviews with Canadian research ethics boards (REBs) and administrators affiliated with medicine faculties at Canadian Universities. During these interviews, structured questions regarding a case study explored participants' expectations regarding consent and associated matters. The results of that study also indicate a large variation across REBs regarding requirements for consumer consent. To illustrate; fourteen sites (47\%) required individual patient consent and eleven sites (38\%) did not require consent for secondary data use. Willison et al. suggest that training and collaboration across REBs would be beneficial:

\begin{abstract}
REBs need training in best practices for protecting privacy and confidentiality in health research. A forum for REB chairs to confidentially share concerns and decisions about specific studies could also reduce variation in decisions (Willison, Emerson et al. 2008, p. 308).
\end{abstract}

A more recent publication sharing experiences from a secondary data use project across seven clinical centres in five countries provides a concise reflection on HREC operation: 
To a certain extent, the ethical requirements placed on a research project are prone to the subjective interpretations by local ethics committees of the general principles encapsulated in the guidelines to which they work (Elger, Lavindrasana et al. 2010, p. 236).

In the Australian context, researchers suggested "Ethics committees do not fully understand privacy legislation and generally oppose access to health information without consent" (Croll and Croll 2006, p. 2). The 2007 submission from the Health Informatics Society of Australia (HISA) to the Australian Law Reform Commission (ALRC) regarding the review of Australian Privacy Law considers the capabilities of HREC. That report notes the important role played by HREC but also notes the inconsistency and delays associated with these committees:

Concern has been raised that currently there is not sufficient consistency across the various HRECs and many do not have the necessary skills and resources to carry out the proposed functions as proposed by the ALRC discussion paper. In particular, concern has been raised about how to avoid the inevitable bureaucratic backlog associated with HRECs unless these issues are adequately addressed (Croll 2007, p. $5)$.

The HISA submission also reports on an earlier submission by the National Health and Medical Research Council (NHMRC) urging a rethink on HREC operation:

ALRC reconsider the role of HRECs in decisions about the privacy implications of the collection, use or disclosure of health information in research. The NHMRC is of the view that these considerations could be managed without intervention by an HREC although we have not yet identified a replacement mechanism at the stage.(58.120) as reported in (Croll 2007, p. 12). 
The HISA report flags an opportunity to develop an innovative mechanism to replace HREC intervention when considering privacy matters and this remains an open research area. That mechanism will be further investigated via this $\mathrm{PhD}$ research with particular emphasis placed on consumer engagement in the development and operation of such a mechanism. The potential domains for use of such an alternative mechanism is wide, as indicated by the numerous national contexts where HREC issues have been raised. Any alternate mechanism to HREC, as suggested by Croll, would aid in overcoming the documented inconsistencies between the operation of HRECs as raised by Elger et al. (2010) and Willison et al. (2008). Development of a mechanism to support consumers stating their preferences for secondary use would offer some relief to the volume of data access requests HREC process and aid in overcoming delays in gaining approvals, as described in Section 2.4.1.

As a result of the issues regarding operation of HREC this research proposes that the following research question exists:

\section{Open Research Question}

4. Are consumers interested in a mechanism that would offer an opportunity for them to provide some direction regarding use of their medical data, rather than relying on HREC operation?

Each of the stakeholder groups brings a different set of 'values' to the secondary use of medical data context. Nissenbaum's privacy research, as previously discussed, includes values as an important aspect of any context with the values including the goals, ends and purposes. Nisenbaum's work implies that each context has a single set of values and an open research area surrounds the understanding of a context where various stakeholders operate within one context but operate with very different 'values'. Much of the tension in the secondary use of medical data relates to the conflicting 'values' each stakeholder brings to the shared context.

The values, using Nissenbaums (2010) interpretation, driving medical researchers involvement within the secondary use of medical data context are generally about advancing the body of knowledge related to human health. When medical 
researchers engage with consumers, seeking their support of research activities, this is the type of purpose or goal usually presented. There are published accounts of consumers accepting these values from medical researchers resulting in consumers consenting to have their personal data included in secondary use activities (Robling, Hood et al. 2004; Barrett, Cassell et al. 2006; Baird, Jackson et al. 2009).

That presentation of the values of medical researchers is somewhat oversimplified with the importance of collaborations between medical researchers and organisations that have a commercial interest in exploitation of research outcomes not emphasised. Medical research can journey from values of an altruistic nature at the outset to morphing (perhaps necessarily) into more commercial values at a later date. The values of the stakeholder have thus shifted from initially altruistic (as marketed to consumers) to far more commercial in nature.

The impact of stakeholder values on possible engagement with consumers in the secondary use of medical data context is an open research area further pursued through this thesis.

As a result of the consideration of stakeholder values and consumer acceptance of these values, this research proposes that the following research questions exist:

\section{Open Research Questions}

5a. Can consumers discern the 'values' that different stakeholders bring to the secondary use of medical data?

$5 b$. Does this impact on their willingness to contribute personal data for secondary use?

\subsubsection{The privacy advocate lens: an Orwellian future}

Privacy advocates can be found across a range of professions (including medical research) and there are few individuals who state 'privacy advocate' as their profession. This has a negative impact on the advocacy or championing of privacy issues. Privacy advocates have formed organisations to aid their shared objectives 
regarding privacy. Such organisations include the Australian Privacy Foundation (APF), Privacy International (Privacy International), the Privacy Rights Clearing House (Privacy Rights Clearing House) and Electronic Privacy Information Centre (EPIC). These groups look beyond the present to future implications of the adoption of technology and provide comprehensive portals to a vast array of policy documents, privacy related legal proceedings, and media reports regarding privacy matters. Privacy advocates contribute material to newspapers (Stout and Zeller 2006; Dash 2007; Staff-Reporter 2008; Dearne 2010; Staff-Reporter 2011), on-line publications (Electronic Privacy Information Centre ; Australian Privacy Foundation 1998) and calls for government submissions on privacy matters (Fernando 2011a; Clarke 2011c). Frequently privacy advocacy groups respond to Government initiatives that are inadequate in terms of consumer health privacy with representations made to government hearings such as that made by Clarke and Fernando to the Australian Senate Community Affairs Legislation Committee concerning the Healthcare Identifiers Bill 2010 and, most recently, Personally Controlled Health Records (Parliament of Australia 2012). Privacy advocacy groups call for patient autonomy and strongly disagree with the notion that individual rights must be lessened to receive healthcare (Fernando 2009; Fernando 2011b).

Issues raised by privacy advocates include, but are not limited to, issues regarding: lack of transparency; inconsistency with democratic society; harms to dignity; rapid advances of technology outpacing privacy legislation and data ownership. Research publications have reported that when an individual does not know 'who' has access to their medical data or 'how' their data may be used for secondary purposes, they are less willing to share (Schneider, Kerwin et al. 2009; Tarini, Goldenberg et al. 2010). It has also been suggested that this lack of transparency may lead to patients not disclosing essential information required for their healthcare with possible adverse effects (Woodward 1995; Steeves 2004; Sutcliffe 2006). Nehf (2003) describes a web of anxieties people face as a result of diminishing privacy, and lack of transparency and control: 
The more cognizable and immediate problem with a loss of information privacy, and the problem that is most likely to produce a political resolution, is our inability to avoid circumstances in which others control information that can affect us in material ways - whether we get a job, become licensed to practise a profession, obtain a critical loan or fall victim to identity theft. We cannot avoid the collection and circulation of information that can profoundly affect our lives. We feel that we have little or no voice or choice in the data collection and sharing process. We do not know who has what information, how they got it, what purposes or motives those entities have, or what will be done with the information in the future. Even if the information in databases is accurate and complete in all relevant aspects, it can still harm us if it falls into the wrong hands or if it is used for a purpose we did not envision when we disclosed it (Nehf 2003, p. 26).

The anxieties described by Nehf are particularly apparent when considering the secondary use of medical data. Patients provide very sensitive, confidential, personal information to their medical doctors in the traditional patient-doctor relationship. This information moves from this initial protective context into the secondary use context without the privacy protection afforded in the initial context, with such moves often not transparent to consumers. Privacy advocates seek to minimise the situations in which consumers are exposed to the anxieties described by Nehf.

As a result of the anxieties described by Nehf and of concerns raised by privacy advocates this research proposes that the following research question exists:

\section{Open Research Question}

6. Are consumers feeling the anxieties described by Nehf due to loss of privacy? 
Harms to dignity resulting from inappropriate use of personal information have been raised by a range of privacy advocates. For example, Trinidad, Fullerton et al. (2011) draw attention to claims of harm including "breaches of autonomy and privacy, stigmatization or other negative social consequences and uninvited challenges against deeply held beliefs". Consumers perceived harms to dignity have not been widely canvassed and as Croll and Morarji (2006) advises, consumer's perceptions - even if ill informed - are possible barriers to secondary use of medical data.

Rapid advances in information technology often outpace slow moving legislation and challenge organisations information privacy and data governance mechanisms (Fernando 2004; Trope, Power et al. 2007). That rapid advance has frequently left privacy concerns unaddressed (Clarke 2011a; Clarke 2011b). Members of the legal profession are often called upon to assist in legislating on privacy issues. That profession looks through a broad societal lens and provide a valuable contribution to the protection of the Western cultural notion of privacy as a right for all citizens, as noted in the opening literature review section addressing privacy in general. The research of Magnusson is informative in illustrating how legislation can be inadequate. Magnusson describes challenges to health information privacy shifting through three broad conceptual shifts from (1) patient-centred health records to (2) multi-function health data holdings and finally (3) trans-organisational data flows to facilitate national linkage and surveillance (Magnusson 2004). Magnusson notes the inadequacy of legislation in dealing with the accompanying shift in secondary use of an individual's medical data from extraordinary in (1) to routine in (3).

\subsubsection{Ownership of data}

Rodwin (2009) presents the advantages of public ownership of medical data and dismisses patients from having exclusive property rights to their medical data due to the prohibitive cost of navigating such ownership in the collection of data. Section 1.3.1 of this Literature Review Chapter considered viewing consumers as partners rather than research subjects and that concept is relevant to ownership of data matters. In contrast to Rodwins public ownership approach to data, Ruyter et al. (2010) encourage meaningful engagement with consumers as stakeholders in the 
data. Ruyter et al. (2010) discussions surround the notion that in a liberal society citizens need an organisation to distrust itself. From that foundation of distrust the organisation would establish mechanisms to ensure that the organisation is worthy of the trust of the public. Ruyter et al. (2010) go on to suggest that a secondary use 'interactive opt-out' register would enable citizens to express their distrust in an organisation and empower them to remove themselves from secondary use of their medical data. That 'opt-out' register is a mechanism that allows individuals to exercise a freedom of choice and some sense of ownership over their medical data. Metcalfe et al. (2008) calls for a similar opt-out mechanism for the UK. The opt-out paradigm would challenge the current European regulatory framework paradigm which relies on patient consent mechanisms. Discussion considers a 'register of sensitivities' where consumers can respond to questions to indicate their particular sensitivities to secondary data use. The example given is consumers responding to the question "I would like my data to be used for the following types of research:" and then a series of areas of medical research are offered with corresponding tick boxes (Ruyter, Louk et al. 2010, p. 307).

Trinidad et al. (2011) make a number of recommendations that provide consumers with some sense of ownership over their medical data, including:

1. Methods to ensure that participants are informed about the use of their data in research, including potential inclusion in data repositories, and to grant the opportunity to decline participation in wide sharing;

2. Mechanisms to provide access to current information about how samples are being used on either an individual or study-wide basis;

3. Transparent, accountable oversight processes that include community representation; and

4. Opportunities for participants to provide input concerning stewardship of their data e.g. dialogue between researchers and participants, ongoing community consultation, or deliberative processes. 
As a result of the suggestions put forward by Trinidad et al. (2011) and Ruyter et al. (2010) emphasis on consumer engagement, this research proposes that the following research question exists:

\section{Open Research Question}

7. Are consumers willing to engage regarding secondary use of their medical data?

A landmark legal case in Australia poses a challenge to the concept of consumers having ownership over their medical information. The Case of Breen vs Williams was litigated as a test on behalf of thousands of Australia consumers who suffered problems following the use of breast implants supplied by the Dow Corning Corporation. The consumers suffered as a result of silicon leakage and other problems associated with the implants. An Australian woman, Ms Breen, sought to be involved in compensation via a US court-approved agreement distributing $\$ 4.2$ billion United States Dollar (USD) settlement worldwide. Ms Breen did not allege any breach of duty on the part of the defendant - her cosmetic surgeon in Australia, Dr Williams. Her claim was against the US manufacturer of the breast implants. Dr Williams refused to allow Ms Breen to copy her medical records. The case came to an end when

The High Court held unanimously that a patient has no general right to inspect or copy medical records documenting the patients medical history and relevant relationship with a healthcare provider (Magnusson and Opie 1998, p. 99).

Opie and Magnusson quote the joint judgements from Judges Gaudron and McHugh JJ:

Many [people], Ms Breen among them, no doubt think that a patient should have access to [the medical records that concern them], subject to limited exceptions. (Magnusson and Opie 1998, p. 100). 
It is not clear what the Australian public opinion is about the Breen V's Williams case and this research seeks to gather feedback on this matter from the general public to add to knowledge in this complex data ownership related matter.

The perceived ownership of medical records is a vexing issue. Rosenbaum (2010) describes a study of more than 500 United States of America Health Insurance Portability and Accountability Act (HIPAA) Privacy Rule cases and finds that one of the most common cases involves healthcare providers resisting the release of data to patients. This is largely due to liability concerns. The publications of Beckerman et al. (Beckerman, Potts et al. 2008) and Terry (2009) report that US healthcare providers and health plans tend to resist broad health information transparency as reported by Rosenbaum (2010). Rodwin emphasises the commercial importance of medical data (Rodwin 2009). Hall (Hall 2009) also wrestles with the US legal uncertainties of medical data ownership reflecting on the transition from paper based to electronic medical record keeping and resultant uncertainty of ownership.

As a result of consideration of the data ownership and associated decision making this research proposes that the following research questions exist:

\section{Open Research Question}

8. Do consumers agree that medical records belong to their doctors?

9. Do consumers seek more empowerment as suggested by privacy advocates?

The next section of the literature review considers the role that government plays in the privacy of citizen health information and the use of personal medical data beyond delivering healthcare to the individual.

\subsubsection{The government lens: big brother or privacy protector?}

The bulk of the research positioning associated with this thesis is in Australia and this section of the literature review focuses on the Australian context and the manner in which the Australian Government is positioned between privacy advocates; largely the Australian Law Reform Commission, (ALRC) and the healthcare 
community. Tension exists between the ALRC goal of protecting citizens' privacy and personal identification requirements for developing effective information systems to support the delivery of healthcare to citizens. Societal surveillance is facilitated by the development of national identifiers, such as those frequently used for healthcare systems. The primary purpose of the identifiers is the accurate identification of consumers as they interact with the health system. However, given the key role of government entities such as Medicare in processing health related transactions for the bulk of Australian citizens, the development of vast databases of identifiable medical data result. Section 1.4.2.1 of this thesis considered data ownership issues and as the custodian of vast volumes of healthcare data generated by the Australian healthcare system the Government has become an important data custodian. The Government has a challenge in simultaneously governing and legislating across: citizen privacy, digital surveillance, healthcare and secondary use of medical data requirements. The notion of monitoring Australian health system performance is currently under debate in the Medical Journal of Australia (Braithwaite and Mannion 2011; Jorm and Frommer 2011).

Similar tensions have arisen in the United States of America (USA). The Clinton administration supported the creation of unique national healthcare identifiers but in the summer of 1998 this support was reserved until Congress established comprehensive legislation to protect patient privacy ( $\mathrm{Ng} 2000)$.

The Australian Government has not taken a similar approach to the USA, rather the legislation authorising the creation of national healthcare identifiers was completed prior to the completion of legislation concerning privacy.

A patchwork of Commonwealth and State legislation operates in the scope of secondary uses of medical data. For example, National Privacy Principles appear in Schedule 3 of the Australian Privacy Act 1988 (Cth) (Australian Government 1988). These privacy principles apply to private sector handling of data; collection, use and disclosure; data quality; data security; openness; access and correction; identifiers; anonymity; transborder data flows and sensitive information. The Information 
Privacy Principles (IPP) are documented in Section 14 of the Privacy Act 1988 (Cth). These principles apply to Australian and ACT government agencies:

Principle 1- Manner and purpose of collection of personal information

Principle 2- Solicitation of personal information from individual concerned

Principle 3- Solicitation of personal information generally

Principle 4 - Storage and security of personal information

Principle 5 - Information relating to records kept by record-keeper

Principle 6 - Access to records containing personal information

Principle 7 - Alteration of records containing personal information

Principle 8 - Record-keeper to check accuracy etc of personal information before use

Principle 9 - Personal information to be used only for relevant purposes

Principle 10 - Limits on use of personal information

Principle 11 - Limits on disclosure of personal information

Aspects of the IPP and Privacy Act have been 'worked around' to enable healthcare identifier creation. The introduction of electronic health records (EHR) has proven to be a challenge in Australia, as it has been elsewhere in the world (Gunter and Terry 2005; Kalra 2006; Hayrinen, Saranto et al. 2008; Ludwick, Manca et al. 2010; Baird, North et al. 2011). The benefits of such information systems are strongly argued as providing a benefit to both individual healthcare consumers and society as a whole. An important step towards the introduction of the Australian EHR was undertaken in 2010 with the passing of the Healthcare Identifiers Act (HIA) through the Australian Parliament. Individual and Provider Identifiers are fundamental building blocks of the information systems, including EHR, that provide the vast volumes of data needed for corporate and trans-organisational and national performance monitoring. These identifiers also enable levels of surveillance that are uncomfortable to many citizens with an interest in privacy.

In parallel to the above developments in the healthcare sector, the Australian Law Reform Commission (ALRC) has wrestled with the concept of privacy in the $21^{\text {st }}$ century. In particular the ALRC considered the challenges associated with 
maintaining two separate sets of privacy principles where both do not always take a consistent approach to privacy matters. Following extensive consultation with community members and policy and law makers, the ALRC proposed a set of eleven Unified Privacy Principles (UPP) for Australia (Australian Law Reform Commission 2008). The objective was to unify and enhance the provision of the Commonwealth sector Information Privacy Principles (IPP) and the private sector National Privacy Principles (NPP).

The Healthcare identifiers and privacy: Discussion paper on proposals for legislative support was issued by the Australian Health Ministers' Advisory Council in July 2009. This paper described legislative proposals to support the creation and implementation of Australian national healthcare identifiers and associated arrangements for privacy of health information. Included in this proposal is the creation of an Individual Healthcare Identifier (IHI) for every Australian.

The discussion paper puts forward the case for establishment of the national healthcare identifiers with the associated Health Identifier Service expected to be operational by mid 2010. It was noted in the Executive Summary of the Healthcare identifiers and privacy: Discussion paper on proposals for legislative support that "Discussions between governments about a national privacy framework across all jurisdictions and its implementation may not be completed by that time" (Australian Health Ministers Advisory Council 2009, p. 3). A well established national privacy framework would have been advantageous for consumers both now and in the future as the identifiers are more widely adopted.

The Discussion paper states that "assignment of IHIs will be authorised by legislation and individual consent will not be sought" (Australian Health Ministers Advisory Council 2009, p. 25). The arguments for this are sound from an information systems point of view; that is, from the outset the health data management goals would be best served by a complete, valid and comprehensive set of individual identifiers. That approach can also be seen as very 'heavy-handed' and somewhat paternalistic and an 'opt-out' option for Australian consumers who did not wish to participate in the de facto national identifiers could also have been argued 
strongly. Arguments against the failed Australia Card (Clarke 1988) are pertinent here but will not be revisited.

The discussion paper also describes how healthcare providers will be given approval to adopt the new Individual Healthcare Identifiers in their health information systems. That suggestion is in direct conflict with the Australian Law Reform Commission (ALRC) policy objective that prevents the adoption of such identifiers due to concern regarding data linkage and the future potential for surveillance. That is also in direct conflict with the risks raised by the Australian Privacy Commissioner where the issues with shared identifier use are not initially obvious but become more apparent over time with broader adoption by a growing number of organisations. That has direct implications for secondary use of medical data as linkage across IHI's is much easier when multiple information systems adopt the same unique identifier for individuals. The Discussion paper also acknowledges that this aspect of the Healthcare Identifier proposal is at odds with the Commonwealth Privacy Act 1988:

\begin{abstract}
Specific authority will be given to private sector healthcare provider organisations to adopt, use or disclose and IHI or HPI-I for health information management and communication purposes. This is to overcome a restriction in the present Commonwealth Privacy Act 1988 (3).
\end{abstract}

The draft Exposure Healthcare Identifiers Bill was available for scrutiny and comment across the Christmas-New Year period from mid December 2009 to 7 Jan 2010. The brief consultation across the traditional holiday period was not ideal for consumer engagement. The 2010 Healthcare Identifiers Act was enacted in July 2010 with all Australians allocated a sixteen digit unique identifier. The impact of this on future Australian society is alarming yet this legislation has passed fairly quietly through Australian Federal Parliament.

Table 1 provides a timeline to illustrate the parallel journey these two important national endeavours have taken over the last few years. 
Table 1: Influential documents in two parallel activities of national importance: ALRC Privacy Principles and 2010 Healthcare Identifiers Bill

\begin{tabular}{|l|l|}
\hline Published & Document \\
\hline May 2008 & Australian Law Reform Commission Model Unified Privacy Principles. \\
\hline July 2009 & Healthcare identifiers and privacy: Discussion paper on proposals for legislative support. \\
\hline June 2010 & Exposure Australian Privacy Principles. \\
\hline July 2010 & $\begin{array}{l}\text { Healthcare Identifiers Act 2010. } \\
\text { Draft released for comment: in mid Dec 2009, Submissions closed: } 7 \text { Jan } 2010 .\end{array}$ \\
\hline $\begin{array}{l}\text { Due July } \\
2011\end{array}$ & Senate Committee report on Exposure Australian Privacy Principles. \\
\hline
\end{tabular}

Given that the citizens were not given an option to opt-out of the national identifiers and that organisations are authorised to adopt the national identifier within their information systems a privacy framework for secondary use becomes increasingly important.

Richard Sobel, writing The Demeaning of Identity and Personhood in National Identification Systems in the Harvard Journal of Law and Technology (Sobel 2002), states that the development of national identification systems "contradict the constitutional and philosophical bases of democratic government and undermine the fundamental foundations of political and personal identity" (Sobel 2002, p. 320).

As a result of the Government's approach to medical information privacy management this research proposes that the following research question exists:

Open Research Question

10. What are the consumer views on the Government taking on the data stewardship role, overseeing secondary use of medical data?

\subsubsection{The commercial lens: profit through secondary use of medical data}

Commercial uses of medical data include health service product development, pharmaceutical development, insurance industry purposes, direct marketing and market surveillance. In Australia there are specific legislative provisions (Privacy Act 1988 and Schedule 3 National Privacy Principles and Section 14 National Privacy Principles) to prevent the disclosure or use of individual's medical information for direct marketing without consumers consent. 
Commercial health sector organisations consolidate an individual patient's data for secondary uses and then use the data as a revenue source by selling the results of data analyses and reports to interested parties in industries in the pharmaceutical and healthcare sectors. The particular details of commercial arrangements between hospitals supplying data and the commercial data brokers are not readily available for scrutiny. These commercial agreements would also cover the matter of on-selling patient data to 'fourth' parties - these are referred to as 'fourth' parties rather than 'third' parties because the consumer is party 1 , the healthcare provider is party 2 and the commercial data broker is party 3 .

An example of a commercial organisation that broker/trade in consumer's health data is IMS Brogan Ottawa, Canada (BroganInc 2010). Brogan Inc was acquired by IMS Health in 2010 and Rodwin (2009) reported that IMS Health operates in more than 100 countries and earned more than $\$ 2$ billion United States Dollars (USD) selling medical data in 2006. The 2008 Annual Report for IMS Health reported revenue of \$2.3 billion USD (IMS-Health 2008).

IMS Brogan is a "leading provider of market intelligence to the pharmaceutical and healthcare industries" (BroganInc 2010). In mid 2008 this organisation requested information from the Children's Hospital of Eastern Ontario (CHEO) in Ottawa, Canada. Similar datasets had already been acquired from 100 other hospitals across Canada as reported by Dr Khaled El Emam (Silversides 2009). This appears to be largely a self regulating industry with each organisation making statements similar to that expressed in Silversides' (2009) Canadian journal article:

The firm also brokers' prescription drug information obtained from public drug plans, insurance companies and pharmacies... the company (Brogan Inc) began collecting hospital data five years ago and has taken "extraordinary measures" to clean up and standardize information (Silversides 2009, E287). 
Research into consumer's reaction to the operation of data brokerage organisations, such as IMS Health and the commercial data supply department in Medicare Australia, is not widely available. There are examples where consumers have become aware of secondary use of their medical information and they have strongly objected. For example, Sadan reported an example of two Washington D.C pharmacy chains, CVS and Giant Foods, sending consumers' prescription records to Elensy which is a marketing organisation. Elensy mailed reminders to patients to refill their prescriptions and provided unsolicited information about new drugs (Sadan 2000). The consumers were unaware that their personal prescription information was being used for such commercial secondary uses. The pharmacy chains cancelled this commercial secondary use following adverse publicity (Lo and Alpers 2000).

As early as 1997 Rhindfleish (1997) raised the matter of commercial use of medical data:

It may be argued there is nothing wrong with using healthcare information to make prudent and profitable business decisions. It's merely capitalism at work. But these uses conflict deeply with the confidential understandings most patients have when they sign consent forms... We should at the very least openly discuss and decide these policy issues at a national level (Rindfleish 1997, p. 87).

The emergence of data brokerage organisations such as IMS Health, appears to have 'flown under the radar' and there is little evidence of national debate in the US and Canada over the operation of such organisations. Elger et al. (2010) acknowledged the journey that personal medical data often takes from clinical care through to commercial dealings. Those researchers suggest that it is important to inform consumers of the potential commercial use of their data at the time consumers provide informed consent. Elger et al. claim "such information at the outset incorporated in the consent is protective of the interests of downstream business entities" (Elger, Lavindrasana et al. 2010, p. 234). 
If data moves from a non-commercial context to a commercial context consumers should be informed of relevant actors and activities - as described by Nissenbaum (2010) - to aid in gauging levels of privacy concern. An organisation that has adopted this approach to clarifying context and actors and roles and activities is the Australian Schizophrenia Research Institute (ASRI). The ASRI has initiated the Australian Schizophrenia Research Bank, which "aims to collect and link genetic, neuroanatomical, cognitive and clinical information from people with schizophrenia and healthy, non-psychiatric control volunteers to support research into the genetics of schizophrenia" (Australian Schizophrenia Research Institute). The Australian Schizophrenia Research Institute called for donations to a Research Bank and a timetable was described that showed a widening use of the collected data as adapted and summarised in below:

Table 2: Australian Schizophrenia Research Bank data release schedule

\begin{tabular}{|l|l|}
\hline Date & Data Users \\
\hline April 2008 & $\begin{array}{l}\text { Australian Schizophrenia Research Bank Chief Investigators (ASRBCI) are able to access their } \\
\text { locally collected samples/data }\end{array}$ \\
\hline June 2009 & $\begin{array}{l}\text { (ASRBCI) are able to access the entire sample/data collection. (ASRBCI) and non-commercial } \\
\text { NSW based investigators only are able to recruit volunteers from the Bank. }\end{array}$ \\
\hline July 2010 & $\begin{array}{l}\text { All non-commercial Australian researchers are able to access the entire sample/data collection. } \\
\text { Studies may involve collaboration with researchers from overseas; however the actual analysis of } \\
\text { data and/or samples must be carried out in an Australian institution, with the first Chief } \\
\text { Investigator on the application residing in Australia. All non-commercial Australian researchers are } \\
\text { able to recruit volunteers from the Bank in QLD, WA, VIC and ACT }\end{array}$ \\
\hline July 2011 & $\begin{array}{l}\text { Projected opening date for access to the entire sample/data collection to international researchers } \\
\text { and commercial entities. After access is extended to all researchers, priority may still be given to } \\
\text { local Australian and/or non-commercial researchers. Projected opening date for access to } \\
\text { recruiting volunteers by Australian commercial entities. After access is extended to all } \\
\text { researchers, priority may still be given to non-commercial researchers }\end{array}$ \\
\hline Adapted from \\
http://www.schizophreniaresearch.org.au/bank/index.php?r=5\&menu=Access+Process\&p=4
\end{tabular}

The Australian Schizophrenia Research Bank Guidelines for researchers clarifies that the access to data is covered by a cost recovery mechanism with a tiered system of costs.

That provides further insight into the values journey; away from altruistic motivations towards commercial motivations as first described in the medical researcher stakeholder section. It is possible that similar future commercial use of consumers' data may influence the willingness of consumers to participate in 
research. This is an unaddressed, open research area that will be further pursued via the research presented in this thesis.

The commercial matters intersects with the data ownership matters previously raised in this literature review. In an attempt to clarify commercial stakeholders access to data for secondary purposes, Rosenbaum (2010) offers a number of ways forward to resolve what she sees as a 'data ownership' versus 'data access' debate in the US:

Option 1: provide incentives for data access through payment for the information. That involves suitable data stewards purchasing health information that researchers expect to be useful in assisting with patient safety, population health and analysis of comparative effectiveness of treatment. In this approach the information that is output/created during the delivery of healthcare is commodified and the government could negotiate with interested 'buyers' over the scope, terms of access and secondary uses. Rosenbaum claims that the strength of this approach is the recognition of data ownership rights regarding the healthcare data.

As Rosenbaum notes, taxpayers may not be enamoured with this option as they would effectively pay twice; the first time when supporting federal health programs, and the second to access the healthcare data that their expenditure created.

Option 2: treat the information output from healthcare delivery "as a public good, available for use by entities structured and operated in accordance with principles of data stewardship" (Rosenbaum 2010, p. 1452).

That option would likely assist the altruistic values of medical researchers but does not meet the needs of commercial organisations.

Health data governed by submission requirements could be aggregated, managed and prepared for use by data stewardship entities which in turn could freely licence the data for use by researchers who are able to demonstrate compliance with data stewardship responsibilities (Rosenbaum 2010, p. 1452). 
This second option does not endorse the notion that healthcare providers can on sell the data gathered during the provision of healthcare and there is likely to be a rift in this area between government funded healthcare providers and private healthcare providers.

A report from Pricewaterhouse Coopers (PwC) (2009) focussed on secondary use of medical data, the opening statement gives a broad insight into commercial possibilities with health data fuelling new business opportunities:

A handful of forward-thinking healthcare organizations have understood that the data they have been amassing in their various IT systems holds enormous potential outside of their enterprises. They have launched into uncharted territory by using their data for secondary purposes such as clinical-studies validation and post-market surveillance of drugs. Absent any model to follow, they developed their own guidelines and infrastructure. As more organizations implement health IT, more data will be produced and the potential for secondary use of that data will grow, as well. In the near future, organizations may be asked to submit data to participate in initiatives or collaborations, or use their data to create business opportunities (PricewaterhouseCoopers 2009, p. 3).

The PwC report continues with statements reflecting on the commercial value of the healthcare data held by health sector organisations in terms of business opportunities, "Secondary data use offers business and collaboration opportunities, potential benefits to all stakeholders" (PricewaterhouseCoopers 2009, p. 3). The report addressed incentive payments to physicians to ensure consumer medical data is recorded, "Alignment of incentives for the clinical community and payment reform to collect, share and use data are paramount to expanding secondary use of data" (PricewaterhouseCoopers 2009, p. 20). That report provides a very commercial lens on the secondary use of medical data, and calls for frameworks to be established by 
private organisations to ensure maximum return on investment on IT systems and effective secondary data use.

The commercial reuse of data (including anonymised data) gathered in confidential doctor-patient scenarios requires further research and consumers views on this matter will be pursued through this research.

As a result of the emergence of commercially driven secondary uses of medical data this research proposes that the following research question exists:

\section{Open Research Question}

11. What are the consumer views regarding commercial, profit driven, secondary use of data gathered through healthcare delivery?

\subsubsection{The consumer lens: hearing the 'voice' of consumers}

As reported by Buckley (2008) there is a trend towards personal choice for consumers in areas such as housing, schooling and healthcare. These personal choices are empowering. Over recent decades, attempts have been made to reduce medical paternalism and thus empower consumers when they engage with healthcare professionals. That notion of partnership needs to be carried forward into the secondary use arena. Treating consumers as partners in the secondary use of medical data and engaging them in the decision making, as suggested by Mechanic (1998), should facilitate the development of trust that will lubricate the information flows necessary to support large scale secondary use. As described in Section 2.3.1, very recently there have been calls to re-conceptualise consumers as partners in research rather than as research subjects. Some of these calls have come from within the medical community.

As Townend (2010) and Buckley et al. (2011) recently observed, there has been little research into consumer opinion regarding issues surrounding secondary use of their medical information. 
Yet few large studies among representative samples of national populations have been conducted, so it is difficult to draw robust conclusions about approaches to confidentiality and consent that may be generally acceptable (Buckley, Murphy et al. 2011, p. 50).

The next section of this thesis provides a sample of the research that has been undertaken by various stakeholders into consumer's opinions regarding secondary use of medical data and privacy matters.

\subsubsection{Consumer surveys}

The surveys included here are not specifically about secondary uses of medical data; however, a small number have included a couple of questions regarding secondary use and related privacy matters. The term 'secondary use' has not necessarily been used in the surveys; however, upon examining the questions and results we do see outcomes that inform the gathering of information about secondary uses.

Mulligan (2001) reported on a 1999 cross-sectional descriptive, household survey conducted in South Australia to investigate consumers attitudes towards doctors and hospitals acting as data custodians, and unauthorised release of information from health services. Participants were 3013 randomly selected residents aged over 15 years. With regard to doctors and hospitals as data custodians, Mulligan reports:

While most participants expressed confidence in doctors or hospitals to keep and use information responsibly, nearly one in 10 participants did not share this confidence. There was no significant difference between men and women in level of confidence, but there were significant differences in confidence with age: participants aged 25-34 years were significantly less confident about doctors and hospitals as data custodians than those in other age groups $(P<0.001)$ (Mulligan 2001, p. 638). 
During 2002 and 2003, a Canadian study (Perera, Holbrook et al. 2011) investigated patients' and physicians' attitudes towards sharing electronic patient data for healthcare delivery and secondary uses. Reasons for the gap between conduct of the study and publishing outcomes is not known. The study design included a beforeafter survey of patients and providers in practices using electronic health records enrolled in a clinical trial in Ontario, Canada. Participants included 511 patients and 46 physicians. Thirteen questions in four general domains investigated attitudes towards:

- the privacy of electronic health records,

- outsider's use of patient's health information,

- the sharing of patient's information within the health care system,

- and the overall perception of benefits versus harms of computerization in health care.

Very broadly, the outcome of that study was that the majority of physicians and patients valued the use of electronic health records in the delivery of care. A large minority had concerns about the secondary use of de-identified information. As Perera et al. report:

Both patients and physicians were more cautious about the use of the patient's health information by outsiders for research purposes - even with personal identifiers removed. Sixty-seven percent of patients and $79 \%$ of physicians did not want private insurance companies to have access to the patient's information, $45 \%$ of patients and $70 \%$ of physicians did not want the pharmaceutical industry to have access to the information, and $40 \%$ of patients and $23 \%$ of physicians did not want the government (source of public insurance) to have access to the patient's information (Perera, Holbrook et al. 2011, p. 96).

The Australian National Health and Medical Research Council (NHMRC) conducted consultation with stakeholders in February and March 2004 with the objective of providing a comprehensive assessment of the key privacy regulation issues for consumers, researchers, and other stakeholders ready for use in a submission to an 
upcoming privacy review. The focus of the study was on attitudes toward privacy in healthcare and medical research. Qualitative aspects of this study included nine focus groups with consumers classified into two broad groups; health consumers and the general public. All health consumer groups included participants with current or previous involvement in medical research. Qualitative findings included low awarenss of privacy legislation, confusing privacy and confidentiality, and lack of trust of medical research use of personal data. Quantitative aspects included computer assisted telephone interviews (CATI) with 301 members of the general public and 60 health consumers. The quantitative results confirmed the qualitative study. There was a substantial minority of consumers who were concerned about the potential misuse of their health information.

There was general acceptance of approved researchers access and data matching medical information from disparate databases. There remained a substantial minority who considered such access to be unacceptable. There was generally an attitude of support for research but a substantial minority of consumers did not want automatic access to data.

Results were presented in a comparative analysis stakeholder report (Campbell Research And Consulting 2004). In the domain of secondary uses of medical data the NHMRC consultation found:

Consumer attitudes toward linked databases were, in general, cautious. Considering the potential risk of misuses of linked databases and the possible problems arising from database linkage, the overall view was that linking databases should be avoided. Consumers did not think that technical solutions to preserve individual privacy (they could only think of deidentification and allocation of a number) would be sufficient to prevent abuses if unethical research was to be undertaken (Campbell Research And Consulting 2004, p. 4). 
That comparative study also found that persons who are high users of the health system, including persons with life threatening, serious or communicable diseases, were looking for greater involvement in decision making regarding use of their data for research.

In 2004, Canadian researchers conducted a series of four focus groups to evaluate a patient decision aid designed to capture information regarding the health information a consumer is willing to share (Tracy, Dantas et al. 2004). The focus groups attracted 28 participants and data was analysed using qualitative methods. The outcomes included mistrust expressed by participants regarding how their information would be used and protected, suggestions to allow customisation of the use of data for specific needs rather than allowing complete access, and optimism of the tool to aid regulation of health information.

The California Healthcare Foundation 2005 National Consumer Health Privacy Survey (Bishop, Holmes et al. 2005) does not specifically focus on secondary use of medical data. However, the results of this survey do inform our understanding of the broader health privacy context in the United States. In summary:

- Consumers remain concerned about the privacy of their health information

- Recent privacy breaches have raised the level of concern

- Employee concern about misuse of medical claim information rose dramatically

- Consumers are unfamiliar with HIPAA protections

- Privacy-protective behaviours persist

- Consumers will share their personal medical information.

A 2007 study undertaken in Canada, commissioned by the Office of the Privacy Commissioner and Canada Health Infoway, included broad objectives:

- perceptions of personal privacy and privacy of personal health information;

- awareness of laws / oversight bodies in relation to personal health information;

- $\quad$ perceptions and experiences related to electronic health information; 
- secondary use of electronic health information; and

- the public's level of trust, comfort and tolerance for the electronic health record

(EKOS Research Associates 2007, p. 1).

The fourth objective focussed on secondary use of electronic health information for health research. The Canadian research involved 20 minute telephone surveys with 2,469 Canadians in June-July 2007. Regarding secondary use of electronic medical information for health research, $84 \%$ of respondents supported this use if names and addresses are removed. The support rate drops to $50 \%$ if personal details are not removed. The linking of health information with broader personal information, such as education level and income, was not widely supported by respondents.

In 2010, New Zealand based researchers, Parkin and Paul (2011), convened a group of nine members of the general public into a citizens jury to consider secondary use of identifiable data without consumer consent. The research sessions ran across three days and the outcome was a unanimous decision of the jury to support identifiable consumer data use without consent. Parkin and Paul came to the conclusion that contextualising data use influenced participants:

$$
\begin{aligned}
& \ldots \text { the framing of the public interest and privacy } \\
& \text { considerations - in the context of scientific, legal, ethical, } \\
& \text { clinical and consumer input - and the opportunity to } \\
& \text { deliberate, may explain why the conclusions of the jury differ } \\
& \text { from public opinion surveys about secondary uses of medical } \\
& \text { information (Parkin and Paul 2011, p. 150). }
\end{aligned}
$$

In late 2011, Buckley et al. (2011) reported on a mixed methods study, conducted in Ireland, which investigated general public attitudes towards research using General Practitioners (GP) records. Focus groups were used to determine major themes and then a postal survey was despatched. The hardcopy questionnaire that had been distributed to residences was completed by 1,575 respondents. A $40 \%$ response rate was achieved and attitudes were diverse, with a large majority indicating: 
- $68 \%$ were unwilling to allow GPs to decide which researchers could access patient identifiable medical data

- $89.5 \%$ agreed to ongoing consent arrangements for use of anonymous data by researchers without a study-by-study consent

The conclusion from that study is that sufficient consumers are likely to opt in to a prior consent arrangement with GPs to enable the use of consumer data for valid, consent-dependent observational studies.

Those consumer surveys do not provide a comprehensive understanding of citizens' views on secondary use of their electronic medical data. Little attempt has been made to determine consumers' expectations or concerns for privacy and none of these surveys has moved beyond the limited access privacy theory. Clearly this is an open research area.

The next sections of the consumer lens will consider trust and consent as these are integral to appreciating the consumer perspective.

\subsubsection{Intangible Consumer Trust}

Trust is an intangible concept that is very important in secondary use of medical data research. Lack of trust in a secondary use could prevent a consumer from agreeing to use of their personal data. This section considers the literature regarding trust as applicable to consumers and re-use of their medical data. In the secondary use of medical data context consumers trust is a lubricant that enhances the flow of information for secondary purposes. When approached to contribute personal medical data for secondary purposes, a consumer is more likely to agree if they have trust in the party requesting information; hence more readily allowing the release of requested data and lubricating the secondary use processes.

The work of Bansal, Zahedi and Gefen (2008a; 2008b) considers the impact of privacy policy statements and privacy assurance cues on increasing trust and 
individual decisions to disclose information online. The consumers' initial level of privacy concern is found to influence the readiness to accept privacy assurances. This research specifically considers the importance of context:

While understandability of privacy-policy statement has no effect on trust in e-commerce and finance contexts, it plays a significant role in the health context (Bansal, Zahedi et al. 2008a, p. 15).

An important conclusion from this work has implications for the establishment of consumers trust in secondary uses of their medical data, particularly to privacypolicy statements: "The statement should address issues related to the way private data is collected, the way errors are handled, and assurances about secondary use, unauthorized access, and use of private data" (Bansal, Zahedi et al. 2008a, p. 16).

The authors warn that the underlying study has limited generalisability because the study sample is based on college students in the Midwest USA. The researchers highlight the importance of a holistic strategy in dealing with consumers' privacy concerns.

Damschroder et al. (2007) also found that the level of trust that a patient has in healthcare providers influences decisions regarding secondary use. That research focussed on a survey of members of the military who are cared for by US Veterans Affairs (VA) healthcare providers. Mechanic (1998) also suggests that consumers level of trust in an organisation relates to how well consumers privacy is protected. Buckley et al. (2011) contribute by reporting that "University researchers are reportedly regarded more positively than pharmaceutical industry researchers. Concerns exist about employers, schools or insurance companies seeking access to personal health information".

Croll has also published regarding fragile nature of consumer trust in eHealth (Croll and Morarji 2006; Croll and Croll 2007; Croll 2008). In a more recent publication, Croll illustrates the relationship between trust, confidentiality, privacy and security in 
healthcare (Croll 2011). In the 2011 publication Privacy Impact Assessments - the Organisational versus the Individual's viewpoints, Croll includes trust in a formal approach to privacy analysis which aids the development of Privacy Impact Assessments (PIA). Croll encourages a focus on individuals to obtain the full benefit of a Privacy Impact Assessment and he warns "The risk of ignoring people's concerns can be a real show stopper for emerging projects, especially in health" (Croll 2008, p. 5).

William Lowrance has provided a clear statement regarding the broad importance of trust and consent particularly to secondary use of data for research:

As consent of any form implies confidence, and confidence implies trust, the ramifications of confidentiality and trust must be considered along with consent. These fundamentals apply to far more than secondary use of data in research, but they are crucial to it (Lowrance 2003, p. S1:6).

The qualitative study conducted by the Australian NHMRC (Campbell Research And Consulting 2004) with consumer focus groups found that when it came to trust in medical research, consumers had low levels of trust which the report writer attributed to a lack of knowledge of medical research:

Most consumers were unsure about what medical research encompasses ... the lack of familiarity with medical research tended to generate a degree of mistrust among consumers, and contributed to their conservative approach to the application of privacy principles (Campbell Research And Consulting 2004, p. $5)$.

Given that many of the consumer cohort had previously participated in medical research, (Campbell Research And Consulting 2004, p. 3), that conclusion regarding trust may not be entirely appropriate. Camp, Nissenbaum and McGrath (2002) posit that the secondary use of medical data context calls upon the consumer to trust their 
physician, organisations collecting, storing and using their medical data, and ubiquitous computer technology.

As a result of the recognition of the importance of consumer trust in health information management and medical research this research proposes that the following research questions exist:

\section{Open Research Question}

12a. Do consumers trust healthcare and related workers in the handling of their health information?

12b. How does trust impact on willingness to engage in secondary use?

The next section of this literature review considers consent because, as Lowrance (2003) states, trust and consent are closely coupled and are needed to lubricate the flow of medical data for secondary purposes as described by Dinev et al. (2006).

\subsubsection{Consumer Consent}

While trust is intangible, consent mechanisms are tangible and convey a sense of trust. The connection between the importance of trust and patient consent for secondary use was emphasised by the American Medical Association in 1998 when they argued that "Trust is essential to the patient-physician relationship, and confidentiality of communications is a cornerstone of that trust" and "consents should specify the information to be shared, with whom, and for what purpose" (Mitka 1998, p. 1897). There are nuanced notions of consent including express consent versus implied consent and detailed consent versus broad consent.

Doll (Doll and Peto 2001) suggests that by accepting the provision of healthcare consumers are giving implied consent to the use of their data for the advancement of medical knowledge to benefit society. The Icelandic Healthcare Database was constructed based on a similar assumption with a presumed consent model (Gulcher and Stefansson 2000). Gulcher et al. note "Some argue that presumed consent is inconsistent with the right of individuals to decide for themselves and actually amounts to no consent at all" (p. 1827). 
The NHMRC investigation into the impact of privacy regulation on NHMRC stakeholders included a qualitative study of consumers' opinions. The outcomes of the study include:

- Participants reported that the act of requesting consent represented a demonstration of respect by medical practitioners. Health professionals should request consent as a matter of "courtesy" (assuming consumers are medically able to give their consent). However consumers (especially consumers from the General Public) did not see themselves as having the expertise to give consent on any other basis.

- When written consent is requested, consumers understood this procedure to be mostly a form of protection for the medical professionals against future litigation risks (Campbell Research And Consulting 2004, p. 3).

- Consumers did not want to be contacted directly by researchers. They were also quite concerned about how their medical information may be used, and wished to be asked for consent via their treating practitioner prior to their medical information being used by researchers (Campbell Research And Consulting 2004, p. 4).

Beskow and Dean (2008) researched the opinions of 40 consumers on key issues of consent related to a consumer donating medical information and bio-samples to a registry. The issues included the frequency of update of donor contact information, types of medical information consumers would consent to donate, issues that would lead to donors withdrawing from studies, types of research that the donors would support, contact about additional research, perceived risks with being involved, commercialisation, and consumer access to research results. 
Despite the small number of participants this research is informative and draws attention to the complexity of consumer consent and provides an open research area for further investigation. The outcomes of a recent Australian survey into personally controlled health records also identifies patient, informed consent as an open issue (Pettigrew, Roman et al. 2010).

As a result of the consumer survey results and researcher publications regarding consent this research proposes that the following research question exists:

\section{Open Research Question}

13. What are consumers' views regarding consent for secondary use of their medical data, in particular how engaged do the consumers want to be in providing consent instructions/directions?

Consumers were the final group of stakeholders to be considered in this literature review and the next thesis section presents a summary of the open research questions highlighted throughout the literature review. 


\subsection{Summary of Open Research Questions}

The open research questions identified through the literature review are summarised in Table 3.

Table 3: Summary of Research Questions Arising from the Literature Review

\begin{tabular}{|c|c|c|}
\hline $\begin{array}{l}\text { Literature } \\
\text { Review section }\end{array}$ & Rese & Q Question arising from Literature Review \\
\hline 2.2 & 1 & $\begin{array}{l}\text { Can Tavani's and Moor's Restricted Access/Limited Control (RALC) } \\
\text { and Nissenbaum's contextual integrity privacy theories be applied to } \\
\text { the secondary use of medical data context? }\end{array}$ \\
\hline 2.4 & 2 & $\begin{array}{l}\text { How diverse are consumer views regarding privacy and the } \\
\text { use of their personal medical data for secondary purposes? }\end{array}$ \\
\hline 2.4 .1 .3 & 3 & $\begin{array}{l}\text { What are consumer views regarding a sense of altruism } \\
\text { towards the use of medical data 'for the common good' } \\
\text { consumer ownership of medical data and the use of } \\
\text { anonymised data? }\end{array}$ \\
\hline 2.4.1.4 & 4 & $\begin{array}{l}\text { Are consumers interested in a mechanism that would offer an } \\
\text { opportunity for them to provide some direction regarding use of their } \\
\text { medical data, rather than relying on HREC operation? }\end{array}$ \\
\hline 2.4 .1 .5 & $5 \mathrm{a}$ & $\begin{array}{l}\text { Can consumers discern the 'values' that different stakeholders } \\
\text { bring to the secondary use of medical data? }\end{array}$ \\
\hline 2.4 .1 .5 & $5 b$ & $\begin{array}{l}\text { Does this impact on their willingness to contribute personal data for } \\
\text { secondary use? }\end{array}$ \\
\hline 2.4.2.1 & 6 & $\begin{array}{l}\text { Are consumers feeling the anxieties described by Nehf due to loss of } \\
\text { privacy? }\end{array}$ \\
\hline 2.4 .2 .3 & 7 & $\begin{array}{l}\text { Are consumers willing to engage regarding secondary use of their } \\
\text { medical data? }\end{array}$ \\
\hline 2.4 .2 .4 & 8 & Do consumers agree that medical records belong to their doctors? \\
\hline 2.4 .2 .4 & 9 & $\begin{array}{l}\text { Do consumers seek more empowerment as suggested by privacy } \\
\text { advocates? }\end{array}$ \\
\hline 2.4 .3 .3 & 10 & $\begin{array}{l}\text { What are the consumer views on the Government taking on the data } \\
\text { stewardship role; overseeing secondary use of medical data? }\end{array}$ \\
\hline 2.4 .4 & 11 & $\begin{array}{l}\text { What are the consumer views regarding commercial, profit driven, } \\
\text { secondary use of data gathered through healthcare delivery? }\end{array}$ \\
\hline 2.4 .5 .2 & $12 \mathrm{a}$ & $\begin{array}{l}\text { Do consumers trust healthcare and related workers in the handling of } \\
\text { their health information? }\end{array}$ \\
\hline 2.4 .5 .2 & $12 b$ & How does trust impact on willingness to engage in secondary use? \\
\hline 2.4 .5 .3 & 13 & $\begin{array}{l}\text { What are consumers' views regarding consent for secondary use of their } \\
\text { medical data; in particular how engaged do the consumers want to be in } \\
\text { providing consent instructions/directions? }\end{array}$ \\
\hline
\end{tabular}

The open research questions arising from the literature review provide an overall research objective:

To better understand consumers' views of secondary uses of medical data with a particular focus on privacy matters. 
Two specific research questions were articulated to offer an opportunity to investigate the literature review open research questions. Table 4: Mapping to broader study Research Questions 1 and 2, summarises the mapping of the thirteen open research questions to the research questions used for this study.

Table 4: Mapping to broader study Research Questions 1 and 2

\begin{tabular}{|c|c|}
\hline & $\begin{array}{l}\text { Mapping of Research Questions } \\
\text { Arising from the Literature Review }\end{array}$ \\
\hline $\begin{array}{l}\text { Study Research Question } 1 \\
\text { What are consumers' expectations and concerns regarding } \\
\text { secondary uses of their medical data; particularly with } \\
\text { respect to privacy matters? }\end{array}$ & $\begin{array}{l}2,3,4,5 a, 5 b, 6,7,8,9,10,11,12 a, \\
12 b, 13\end{array}$ \\
\hline $\begin{array}{l}\text { Study Research Question } 2 \\
\text { Does the RALC theory (Tavani and Moor 2001) and the } \\
\text { framework for contextual integrity (Nissenbaum 2010) offer } \\
\text { privacy concepts that can: (1) be applied in the secondary } \\
\text { use of medical data context and (2) gain support from } \\
\text { interested consumers? }\end{array}$ & $1,2,4,7,9,12 a, 12 b, 13$ \\
\hline
\end{tabular}

Some of the open research questions, such as question 2: How diverse are consumer views regarding privacy and the use of their personal medical data for secondary purposes? contribute to both of the study research questions. This open research question contributes to both Study Research Question 1 and 2 as further research will help describe both the expectations and concerns of consumers and also investigate the suitability of the privacy theories in supporting possibly diverse consumer views regarding privacy and secondary data use.

\subsection{Conclusion}

In conclusion, there are very diverse views amongst stakeholders with an interest in the secondary use of medical data. Changes in legislation regarding consumer privacy have impacted on the secondary use of data and the medical research community lament lost and hindered opportunities for advancing healthcare knowledge. Privacy advocates, including lawyers responsible for leading legislative changes, continue to express frustration regarding the level of dis-empowerment experienced by consumers in this context. Few studies have attempted to consider 
consumers' opinions regarding the secondary use of their medical data by stakeholders including commercially oriented and government surveillance type activities.

The 'limited access' privacy theory has served the medical profession well for centuries however the shift to electronic medium for data storage has challenged the adequacy of this privacy theory. Contemporary privacy theories offer opportunities for fresh interpretations of privacy and these theories have emerged at a time when there are simultaneous calls for greater engagement with consumers regarding secondary use of medical data, especially for altruistic research purposes. The contemporary privacy theories may aid deeper, more meaningful engagement with consumers and allow society to move to a more sophisticated understanding of privacy.

The remainder of this thesis explores these complex, inter-related issues, beginning with the next chapter that elaborates on the research methodology adopted for this study. 


\section{RESEARCH METHODOLOGY}

\subsection{Introduction}

This chapter begins with consideration of the major research questions then moves to consideration of the broad research epistemology, chosen methodology, and specific study design including data collection and analysis. Alternate research design choices are considered throughout and justifications for the chosen approach are provided.

This thesis describes the exploratory research conducted within a post-positivist and interpretive espistomology using mixed methods. A hardcopy, self administered survey investigating public opinion regarding secondary use of medical data was distributed to citizens in Australia and Canada. Use of quantitative and qualitative survey data, gathered concurrently, facilitated triangulation. A Likert scale was used to capture public opinion expressed in response to thirty attitudinal statements. Survey psychometrics investigated internal reliability and validity of the survey. Focus groups and pilots studies were conducted in Australia and Canada. Null hypothesis driven analyses were conducted across respondent demographics and between the two Nations surveys.

\subsection{Background}

This chapter describes the important aspects of the research design that guided the conduct of this study. The research described here makes two basic assumptions that arise from the literature:

Assumption 1: with increased use of health information systems, consumer medical data will be increasingly used for secondary purposes; and

Assumption 2: a shift from regarding consumers as research subjects to research partners will benefit society in the longer term.

Assumption 1 is supported by Magnusson (2004), Lowerance (Lowrance 1997; Lowrance 2002; Lowrance 2003) and O'Keefe and Connolly (O'Keefe 2008; O'Keefe and Connolly 2010), and Assumption 2 is supported by Townend (2010) and Ruyter (Ruyter, Louk et al. 2010). 


\subsection{The Research Question}

The overall research objective is to better understand consumer's views of secondary uses of medical data with a particular focus on privacy matters. The research questions were posed to provide the consumer perspective on information systems, legal and health professionals responsible for designing electronic health records, and on supporting data governance frameworks and enabling legislation.

Tavani and Moor's (2001) Restricted Access/Limited Control (RALC) privacy theory has philosophical foundations that enable support of Assumption 2 above, hence RALC will be further explored through the consumer survey.

\section{Research Question 1}

What are consumer's expectations and concerns regarding secondary uses of their medical data, particularly with respect to privacy matters?

\section{Research Question 2}

Does the RALC theory (Tavani and Moor 2001) and the framework for contextual integrity (Nissenbaum 2010) offer privacy concepts that can: (1) be applied in the secondary use of medical data context and (2) gain support from interested consumers?

\subsection{The Study Design}

The next section describes the overall exploratory nature of this study which employs both post-positivist and interpretive paradigms and utilizes a mixed methods methodology with a concurrent triangulation design. 


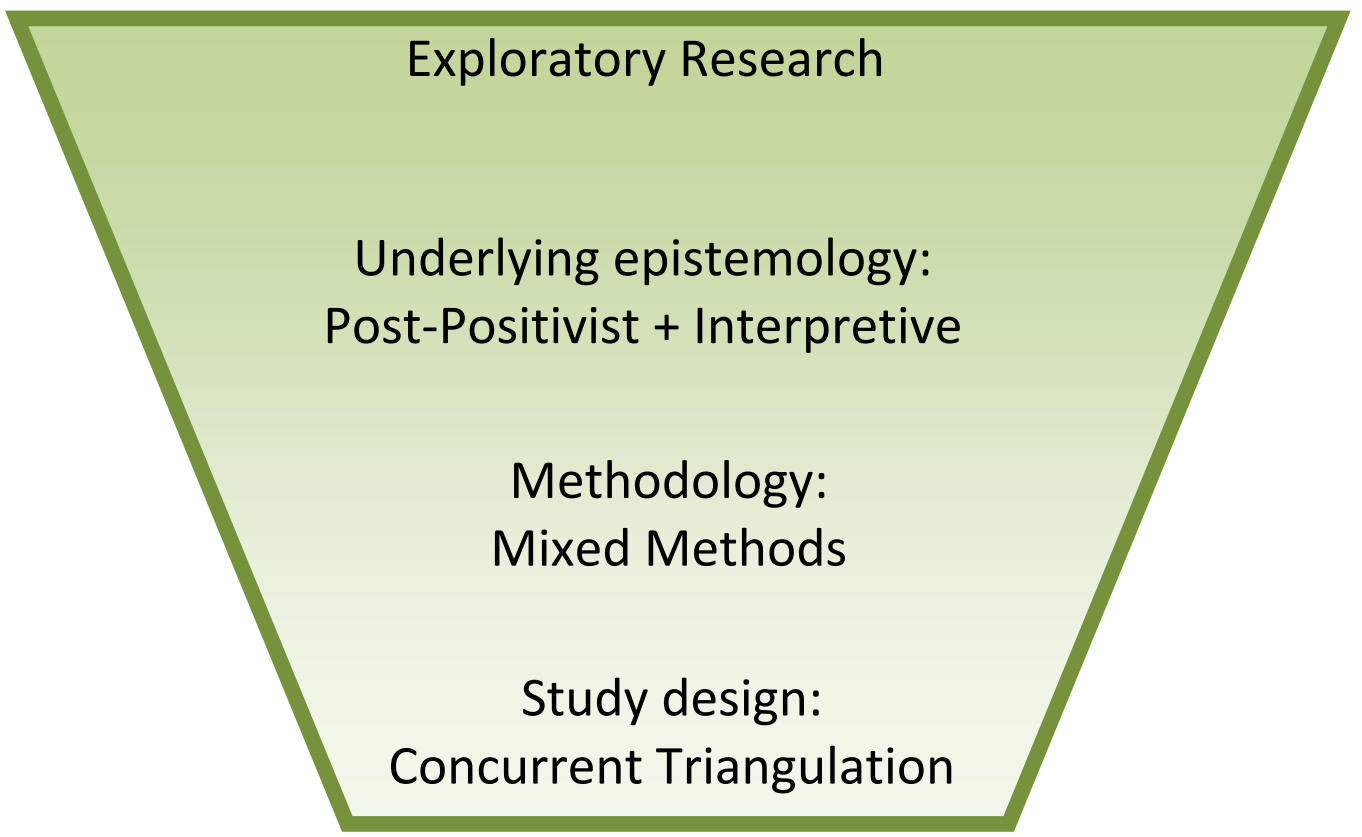

Figure 7: Overview of Research Design

The investigation of consumers' views regarding secondary use of their medical data is an exploratory study. As Myers (2011) reports, Hair et al. (1995) describe exploratory studies as those which define possible relationships in a general form. In contrast Hair et el (1995) describe confirmatory studies as those with a goal of testing or confirming an a priori relationship. The aspects of the study that relate to the RALC privacy theory do not seek to confirm the validity of the theory - that would be confirmatory research. Rather the RALC privacy theory is used in an exploratory manner with broad notions from the theory informing the construct of 'real-life' secondary data use scenarios which consumers are asked to consider. Tavani and Moor (2001) offer the tripartite approach to considering privacy matters which considers Privacy Concepts, Privacy Justification and Privacy Management. This tripartite approach guides the exploration of consumers view on secondary use of medical data and provides a useful framework for the consumer survey described in Chapters 4, 5 and 6. 


\subsubsection{Epistomology}

The underlying epistemology draws from post-positivist and interpretive approaches. The combination of these paradigms is not unusual within information systems research (Straub ; Straub, Gefen et al. 2004; Myers 2011; Myers and Klein 2011). The post-positivist epistemology is suitable for this study as the positivist approach where knowledge is only derived through observation and measurement - is inadequate because consumer opinion and perceptions can only be approximated. Post-positivist approaches acknowledge that observations and measurements are imperfect and employ triangulation to measure phenomena in multiple ways (Straub ; Straub, Gefen et al. 2004). The qualitative and quantitative mixed methods used in this study aim to address the issue of 'data triangulation'.

Interpretive aspects of this study acknowledge that attempts are made here to understand phenomena through the meanings that people assign to them - shared meanings that are in fact social constructs (Orlikowski and Baroudi 1991; Myers 2011). The material included in the literature review chapter has been organised to present the multiple, disparate points of view regarding secondary use of medical data thus re-enforcing the value placed on interpretive approaches. The inclusion of open comments sections in the consumer surveys also provides opportunities for consumers to elaborate on their interpretations. The present study aims to lead to an understanding of the secondary data-use context and specifically from a consumer perspective using their existing shared meanings. This interpretive approach is consistent with Deem (2002) as reported by Creswell:

Interpretive research involves using issues, language, and approaches to research that empower the participants, recognize their silenced voices, honor their individual differences, and position both the researcher's and the participant's views in a historical/personal/political context (Creswell et al. 2006, p. 5).

This study gives consumers an opportunity to have their diverse opinions heard and, thus, attempts to empower the study participants. 


\subsubsection{Mixed Methods}

This study used a mixed method design with both qualitative and quantitative methods employed. As observed by Creswell mixed methods research has gained popularity because " ... more insight can be gained from the combination of qualitative and quantitative research than either form by itself. Their combination provides an expanded understanding of research problems" (Creswell 2009, p. 203).

Creswell (2009) draws our attention to the evolution of the mixed method by reflecting on earlier research. In the late 1950s, Campbell and Fiske (1959) employed a multi-trait-multimethod matrix in their research. In the late 1970's Jick (1979) described the converging, or triangulating, of different quantitative and qualitative data sources.

More recently Tashakkorri, Teddlie, Creswell and Plano Clark have contributed to the development of mixed methods as a distinct methodology of inquiry in single author publications (Creswell 2008; Creswell 2009; Plano Clark 2010) and collaborative publications (Tashakkori and Teddlie 1998; Creswell, Plano Clark et al. 2003; Creswell, Fetters et al. 2004; Creswell, Shope et al. 2006; Creswell and Tashakkori 2007; Plano Clark and Creswell 2008; Plano Clark, Garrett et al. 2010).

The mixed method approach has gained acceptance within the health research community (Creswell, Fetters et al. 2004; Creswell 2009) and, given that health is the context for this study, it is reasonable to use this method.

As Creswell notes in numerous publications there are challenges posed by the mixed methods methodology including: extensive data collection, time intensive nature of both text and numeric data, and requirement for the researcher to be familiar with both quantitative and qualitative methods.

Each of these challenges is apparent in this study; questionnaires were despatched across Australia and Canada for the pilot and final surveys and capturing and analysing the ordinal and text data in returned surveys was time consuming with 
additional human resources used for the qualitative analysis. A solid understanding of quantitative and qualitative design, capture and analysis skills was required.

Creswell calls for consideration of the issue of timing, weighting and mixing when designing a mixed methods study. A concurrent triangulation design was used for this study with quantitative and qualitative data collected and analysed at the same time; as described by Creswell (2008; 2009).

The quantitative and qualitative aspects were given equal priority and both addressed the same research questions. Data analysis was conducted separately and integration took place at the data interpretation stage. Creswell's concurrent triangulation design, using the standard mixed method notation, is reproduced in Figure 8.

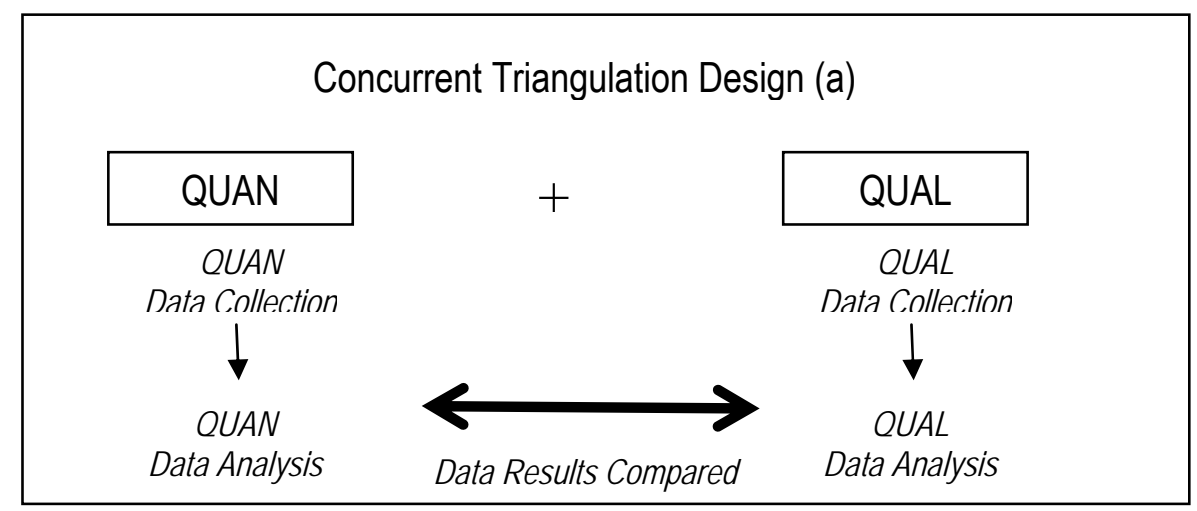

Figure 8: Creswell's Concurrent Triangulation Design

The overall research design used for this study is illustrated in Figure 9. It includes the important integrated analysis of both qualitative and quantitative results for each nation prior to the comparative analysis. 


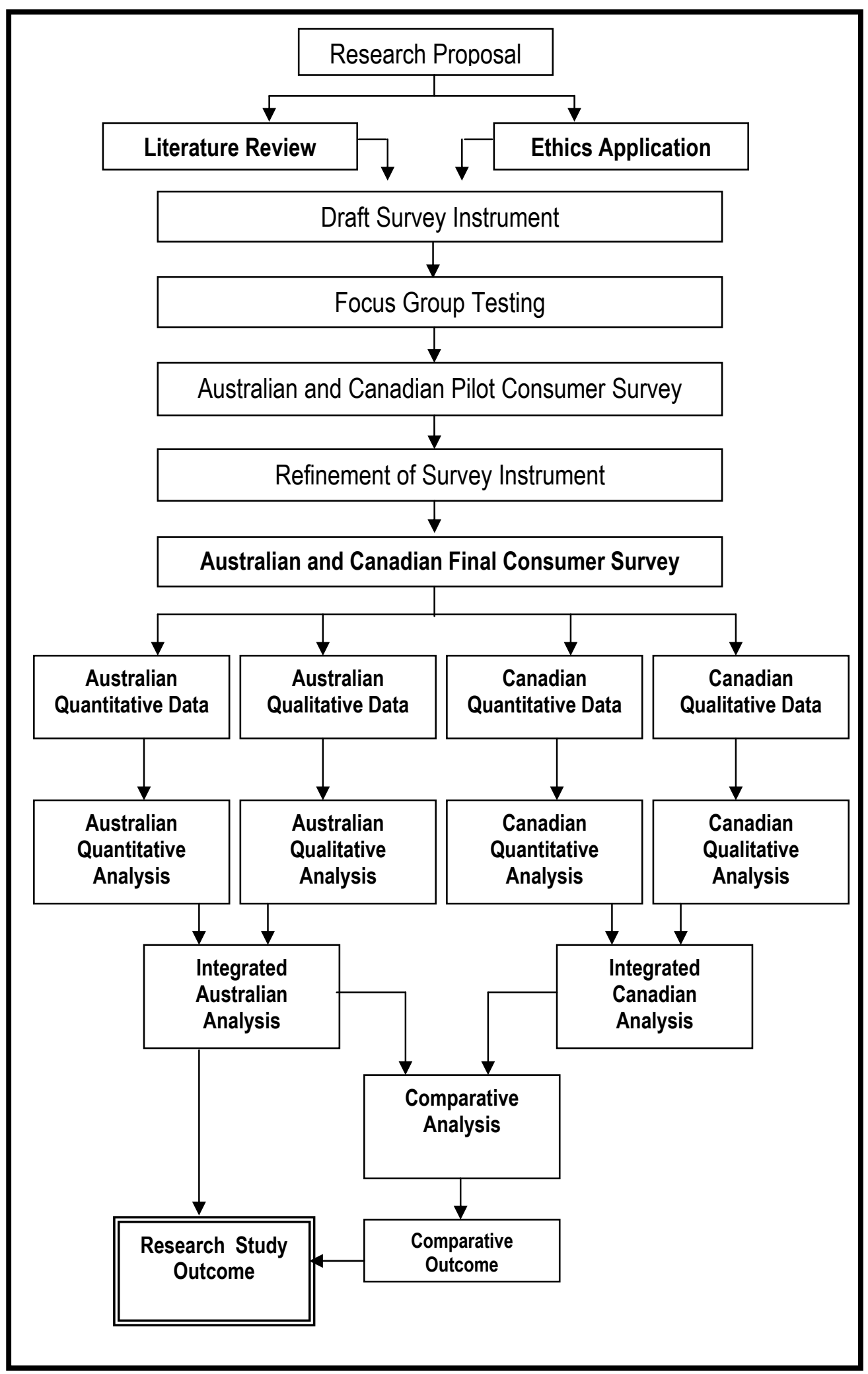

Figure 9: Research Design, including concurrent triangulation. 


\subsubsection{Why include a comparative study with Canada?}

There is a history of cultural comparison studies between Australia and Canada including those with a focus on ethics and society (Kidd and Shannon 1996; Miller 1998; Wood 2000; Austin 2008), economics (Harchaoui, Jean et al. 2005), healthcare and training (Blendon, Schoen et al. 2002; Philippon and Braithwaite 2008; McCurdy, Duggan et al. 2009) and teaching (Mitchell, Clarke et al. 2007). The comparative study continues the exploratory approach underpinning this research study. The exploration continues by comparing Australian and Canadian consumer views on secondary use of their medical data.

The earlier Canadian consumer health related research conducted by Willison (2003), Willison, Keshavjee et al. (2003), Willison, Schwartz et al. (2007) and Willison, Emerson et al. (2009) provided useful background information which informed the design of the consumer survey used in this study. The results of the earlier Canadian work also provided opportunities for comparison of Australian consumer views with those of Canadians.

The cultural similarities may also provide an opportunity to develop shared, national privacy and secondary use of medical data frameworks and guidelines. The consumer focussed research questions driving this study are suitable for exploration in both Canada and Australia and results will provide more insight into consumers views in both Nations.

\subsection{The Survey}

This section introduces the survey used in this study and describes the design decisions, validity and reliability issues and data analysis methods used with the survey.

\subsubsection{Designing the Survey}

The approach taken to the design and deployment of the public opinion survey is informed by the work of researchers such as Fink (2005), Bourque and Fielder (2003) and Svensson (2001). Online surveys, telephone surveys, and face-to-face interviews were all possible methods that could have been used to capture public 
opinion. Bourque and Fielder (2003) suggest the advantages and disadvantages of self-administered surveys mailed to residential addresses.

To provide an ordered approach to presenting many of the design decisions related to the pilot and final surveys used in this study Table 5 has been compiled. The first and second columns of the table presents the issues pertaining to self administered mail surveys as suggested by Boureque and Fielder (2003). The third column considers how these issues were dealt with for the pilot and final surveys used in this study. This table is intended to provide an overview of the survey activity and further details of some aspects are elaborated upon in later sections. 
Table 5: Bourque and Fielder (2003) self administered survey matters and comments on application in the pilot and final surveys

\begin{tabular}{|c|c|c|}
\hline \multicolumn{2}{|c|}{ Bourque and Fielder comments on mail surveys } & Comments for the consumer public opinion survey deployed in this study \\
\hline \multicolumn{3}{|c|}{ Advantages } \\
\hline Cost & $\begin{array}{l}\text { Lower cost than in-person and telephone } \\
\text { interview; costs are } 75 \% \text { and } 50 \% \text { lower } \\
\text { respectively. }\end{array}$ & $\begin{array}{l}\text { Online survey would be less costly but some citizens such as those who are aged or poor may } \\
\text { be overlooked due to unavailability of internet access. Also need valid emailing lists for } \\
\text { invitations to participate in the survey and these were not available for this study. }\end{array}$ \\
\hline \multicolumn{3}{|l|}{ Sampling } \\
\hline $\begin{array}{l}\text { Geographic } \\
\text { coverage }\end{array}$ & $\begin{array}{l}\text { Wider geographic coverage as trained } \\
\text { interviewers not needed for in-person } \\
\text { interviews. }\end{array}$ & $\begin{array}{l}\text { The Australian and Canadian postal services were used to deliver surveys and hence enabled } \\
\text { wide geographic coverage from the centre of large cities such as Melbourne and Vancouver to } \\
\text { remote areas such as Whitehorse in the Yukon and Alice Springs in the Northern Territory of } \\
\text { Australia. }\end{array}$ \\
\hline Larger samples & $\begin{array}{l}\text { Lower unit cost of mail survey combined with } \\
\text { mail ability to cover wider geographic area } \\
\text { allows study of larger sample size. }\end{array}$ & $\begin{array}{l}\text { The cost of surveys in Australia was lower than Canada as the University of Wollongong had in } \\
\text { place a reply-paid mail contract. This enabled respondents to return the survey at no cost to the } \\
\text { respondent and the University was only charged for postage on the surveys that were returned. } \\
\text { In Canada the UOIT did not have a similar contract with Canada Post, therefore all return } \\
\text { addressed envelopes included in the survey packages had to have postage affixed prior to } \\
\text { despatch. } \\
\text { Sample size estimates for both Australia and Canada, using a confidence level of } 95 \% \text { and } \\
5.0 \% \text { margin of error, are } 384 \text {. The Australian final survey exceeded the sample size estimate } \\
\text { (1158) however the Canadian final survey did not reach sample size (203). }\end{array}$ \\
\hline $\begin{array}{l}\text { Wider coverage } \\
\text { within sample } \\
\text { population }\end{array}$ & $\begin{array}{l}\text { Increase in recent years in reluctance of } \\
\text { people to talk to strangers on the phone - } \\
\text { especially in urban areas. Also reluctance to } \\
\text { be available at a specific time is overcome with } \\
\text { mail survey as it can be completed at } \\
\text { respondent's convenience. }\end{array}$ & $\begin{array}{l}\text { Having the flexibility to complete the survey at a time of convenience to the respondent is a } \\
\text { great advantage over trying to book interview times. This is apparent as some of the returned } \\
\text { surveys included comments such as "Sorry for the delay in returning the survey - l've been } \\
\text { overseas, hope it is not too late to be included" }\end{array}$ \\
\hline
\end{tabular}




\begin{tabular}{|c|c|c|}
\hline \multicolumn{2}{|c|}{ Bourque and Fielder comments on mail surveys } & \multirow{2}{*}{$\begin{array}{l}\text { Comments for the consumer public opinion survey deployed in this study } \\
\text { In addition to the sampling advantages noted by Bourque and Fielder the opportunity to offer a } \\
\text { more personal connection was possible with the addressing of survey packages. The majority } \\
\text { of Australian pilot and final survey packages were despatched with hand-written addresses. } \\
\text { This was done in an attempt to engage with the householders in a less mechanistic manner. } \\
\text { The Canadian pilot surveys were also hand addressed. Computer generated print labels were } \\
\text { used for the Canadian final survey. Australian respondents noted the hand written addresses - } \\
\text { this is apparent through open ended comments complimenting the research team on such } \\
\text { dedication and commitment. }\end{array}$} \\
\hline & & \\
\hline Implementation & $\begin{array}{l}\text { Fewer personnel required. Minimal equipment } \\
\text { needed - compare with the Computer-assisted } \\
\text { telephone interviewing (CATI) needed for } \\
\text { phone interviews. Technical skills needed to } \\
\text { implement on-line survey. }\end{array}$ & $\begin{array}{l}\text { Data entry was a large task with the mail surveys. If an online survey had been used the data } \\
\text { captured would have generated a clean data set not requiring any additional resources for data } \\
\text { entry. }\end{array}$ \\
\hline Timing & $\begin{array}{l}\text { When members of the general public receive } \\
\text { surveys at the same time the potential } \\
\text { influence of events outside or unrelated to the } \\
\text { study is reduced and can be assumed to be } \\
\text { equal for all recipients. }\end{array}$ & $\begin{array}{l}\text { The Canadian surveys were despatched across a time frame of a couple of weeks. The } \\
\text { Australian surveys were despatched to different parts of Australia across a timeframe of a few } \\
\text { months. The open ended comments received on the Canadian pilot study indicate that } \\
\text { respondents were aware of a current issue in Ontario related to the cost over runs of the roll-out } \\
\text { of electronic health records (EHR) in Ontario. During the week of the pilot survey the Ontario } \\
\text { Minister responsible for EHR resigned. The pilot study was entirely conducted in Ontario hence } \\
\text { the sample population was exposed to the same event. During the timeframe of the longer } \\
\text { Australia wide roll out there were no similar influencing events. }\end{array}$ \\
\hline $\begin{array}{l}\text { Sensitive } \\
\text { topics }\end{array}$ & $\begin{array}{l}\text { Some studies have suggested that people are } \\
\text { more likely to give complete and truthful } \\
\text { information on sensitive topics in a self } \\
\text { administered questionnaire. In contrast, more } \\
\text { recent studies suggest that capable } \\
\text { interviewers and secure online methods are } \\
\text { also effective in collecting responses to } \\
\text { sensitive topics. }\end{array}$ & $\begin{array}{l}\text { Some of the open ended comments elicited via the public opinion survey offer very personal } \\
\text { experiences and reflections on close family members and the sensitive topic of medical } \\
\text { information. It is clear that at least some respondents have been very comfortable sharing such } \\
\text { sensitive information through the self administered survey. }\end{array}$ \\
\hline
\end{tabular}




\begin{tabular}{|c|c|c|}
\hline \multicolumn{2}{|c|}{ Bourque and Fielder comments on mail surveys } & Comments for the consumer public opinion survey deployed in this study \\
\hline \multicolumn{2}{|r|}{ Disadvantages } & \\
\hline \multicolumn{3}{|l|}{ Sampling } \\
\hline $\begin{array}{l}\text { Availability of } \\
\text { lists }\end{array}$ & $\begin{array}{l}\text { The importance of probability rather than } \\
\text { convenience samples is emphasised - } \\
\text { particularly when the aim is to generalise to a } \\
\text { particular population. }\end{array}$ & $\begin{array}{l}\text { Final surveys for both Australia and Canada attempted to engage with a diverse population and } \\
\text { the demographics captured helps to profile the responses. The survey packages were } \\
\text { despatched to urban, regional, rural and remote communities and to low medium and high socio } \\
\text { economic status communities in every state and territory of Australia and the English speaking } \\
\text { provinces of Canada. } \\
\text { Bourque and Fielder (2003) do not thoroughly consider the difficulties in accessing an available } \\
\text { list of accurate addresses. Generation of accurate residential address information was a } \\
\text { challenge for this study and this issue is documented thoroughly in Section 3.5.7.4 of the thesis. }\end{array}$ \\
\hline Response rates & $\begin{array}{l}\text { One of the greatest and most studied } \\
\text { disadvantages of mail questionnaires is low } \\
\text { response rates - no greater than } 20 \% \text { should } \\
\text { be expected when no incentives are included. } \\
\text { Even in the best case, response rates for mail } \\
\text { are lower than telephone or in-person } \\
\text { interviews. }\end{array}$ & $\begin{array}{l}\text { The Australian and Canadian pilot surveys in this study generated response rates of } 34.8 \% \text { and } \\
21.5 \% \text { respectively. This included the use of a small incentive, which was not included in the } \\
\text { final surveys, which resulted in a } 23.6 \% \text { response rate for Australia and a } 12.8 \% \text { response rate } \\
\text { for Canada. }\end{array}$ \\
\hline $\begin{array}{l}\text { Literacy and } \\
\text { language }\end{array}$ & $\begin{array}{l}\text { Response rates are particularly poor in studies } \\
\text { targeted at general community samples due to } \\
\text { poor literacy amongst population. Older } \\
\text { citizens may have visual acuity problems and } \\
\text { others may suffer from dyslexia and the effort } \\
\text { required to read and respond to the survey } \\
\text { may be too great. }\end{array}$ & $\begin{array}{l}\text { An objective of this study was to ensure that a diverse group of citizens were able to engage } \\
\text { with the survey - particular attention was paid to the literacy and language used in the survey. } \\
\text { Where ever possible simple language constructs and wording were used to provide maximum } \\
\text { opportunity for engagement with consumers. }\end{array}$ \\
\hline
\end{tabular}




\begin{tabular}{|c|c|c|}
\hline \multicolumn{2}{|c|}{ Bourque and Fielder comments on mail surveys } & Comments for the consumer public opinion survey deployed in this study \\
\hline $\begin{array}{r}\text { Questionnaire } \\
\text { construction }\end{array}$ & & \\
\hline Objective & $\begin{array}{l}\text { The objective of the study must be clear and } \\
\text { there should be a reasonable expectation that } \\
\text { respondents will have some interest in the } \\
\text { objective otherwise response rates will be } \\
\text { poor. }\end{array}$ & $\begin{array}{l}\text { The objective of this study was specified in the covering letter and the response rates tend to } \\
\text { suggest that there was interest in the secondary use of medical data. }\end{array}$ \\
\hline Format & $\begin{array}{l}\text { Self-administered questionnaires must be } \\
\text { shorter than questionnaires administered in } \\
\text { other ways. Most of the questions need to be } \\
\text { closed-ended as only highly motivated } \\
\text { respondents will be willing to answer open } \\
\text { ended questions. The self-administered } \\
\text { questionnaire must stand alone - all } \\
\text { information respondents may need must be } \\
\text { provided on the questionnaire itself as there is } \\
\text { no interviewer available to provide } \\
\text { clarification. The questionnaire should not } \\
\text { have branches or skips. }\end{array}$ & $\begin{array}{l}\text { One of the goals in creating the survey was too keep it to just a few pages in length. The } \\
\text { candidate survey questions were prioritised and the most influential questions were selected - } \\
\text { many were not included due to the importance of keeping the survey of a size that most citizens } \\
\text { would think was possible to complete within the estimated ten minutes. Thirty two questions } \\
\text { were included and only two were open ended. It was possible to complete the survey without } \\
\text { additional explanatory material. A design decision was made to not include a glossary of terms } \\
\text { and definitions as this would have started to shape the responses. No branches or skips were } \\
\text { included in the survey - citizens were asked to respond to every statement and the 'don't know' } \\
\text { option was included on the Likert scale. }\end{array}$ \\
\hline Order effects & $\begin{array}{l}\text { In self-administered survey everything is } \\
\text { simultaneously available to the respondent - } \\
\text { this contrasts with online and interviewer } \\
\text { controlled surveys. Using self-administered } \\
\text { surveys is difficult when order effect may be } \\
\text { an issue. This is when one set of questions is } \\
\text { likely to contaminate, bias, or influence } \\
\text { respondents' answers to another section of } \\
\text { the questionnaire. }\end{array}$ & $\begin{array}{l}\text { There is no hierarchy or order inherent is the survey questions. The survey started out with } \\
\text { some of the most simple syntax to give respondents some sense of being able to readily } \\
\text { understand and respond to the attitudinal statements. }\end{array}$ \\
\hline
\end{tabular}




\begin{tabular}{|c|c|c|}
\hline \multicolumn{2}{|c|}{ Bourque and Fielder comments on mail surveys } & Comments for the consumer public opinion survey deployed in this study \\
\hline Administration & & \\
\hline $\begin{array}{l}\text { Lack of control } \\
\text { over who } \\
\text { responds }\end{array}$ & $\begin{array}{l}\text { Single biggest disadvantage of self } \\
\text { administered questionnaires is that once the } \\
\text { survey is despatched the researcher has no } \\
\text { control over who completes the survey. } \\
\text { Researchers must accept completed } \\
\text { questionnaires 'on faith'. }\end{array}$ & $\begin{array}{l}\text { The surveys returned in this study were received and accepted 'on faith'. Inclusion of the } \\
\text { optional demographics capture for only one person is a gentle reminder that only one person } \\
\text { should complete the survey. Some citizens worked around this limitation of the study design by } \\
\text { photocopying the survey and returning two completed surveys in one envelope. Others } \\
\text { provided single responses to the attitudinal statements and went on to provide two selections in } \\
\text { the demographics and wrote open ended comments that "we worked together to complete the } \\
\text { survey" - thus illustrating the disadvantage raised by Bourque and Fielder. No respondent } \\
\text { demographics were recorded when it was clear that respondents had tried to record multiple } \\
\text { sets of demographics on one survey. }\end{array}$ \\
\hline $\begin{array}{l}\text { Quick } \\
\text { turnaround }\end{array}$ & $\begin{array}{l}\text { Generally it takes a minimum of two weeks } \\
\text { after each mail out for completed } \\
\text { questionnaires to be returned. If surveyor uses } \\
\text { follow up mailing to increase response rates } \\
\text { the survey period may extend out to two or } \\
\text { three months. In contrast telephone surveys } \\
\text { can be conducted relatively quickly. }\end{array}$ & $\begin{array}{l}\text { Follow up mailings were not used in this study. The delay in return of surveys did not have a } \\
\text { negative impact on the conduct of this study. As resources were limited to support the surveying } \\
\text { the researcher moved in a cyclical way between compiling valid address list, preparing surveys, } \\
\text { despatching and data entry of returned surveys. These tasks took place over many months for } \\
\text { the pilot and final surveys. }\end{array}$ \\
\hline
\end{tabular}


There are three components to the survey:

Component 1: thirty attitudinal statements utilizing a Likert scale

Component 2: two open ended questions

Component 3: an optional demographic component.

The open ended questions provided respondents an opportunity to explain, justify or add further information to the quantitative responses. A copy of the survey instrument used in the Australian final survey is presented later in this chapter. The focus here is on discussing the journey to the final survey instrument.

\subsubsection{Survey Psychometrics}

This section investigates the validity and reliability of the consumer public opinion survey instrument. This involves an empirical test regarding reliability to measure internal consistency and the second is consideration of the validity of scale. Guidance for the task of assessing and interpreting the consumer survey psychometrics has been drawn from work of Litwin (Litwin 2003). As described by Litwin "Psychometrics provides survey researchers with a way to quantify the precision of the measurement of qualitative concepts, such as consumer satisfaction, depression and marital interaction" (Litwin 2003, p. 1). This approach is ideally suited to the interpretive research undertaken in this study of public opinion regarding secondary use of medical data. As Litwin states "Strictly speaking, it is difficult to assess the quality of the data we collect. It is easier to assess the accuracy of the survey instrument that is used to collect the data. This assessment consists primarily of looking at the reliability and the validity of the survey instrument" (Litwin 2003, p. 3), hence the next sections consider the reliability and validity of the survey instrument.

There are a variety of approaches to evaluate the reliability characteristics of a survey instrument including test-retest, alternate form, and internal reliability. The test-retest approach is not feasible for this research given the anonymous nature of the diverse populations. The alternate form method, as described by Litwin, also relies on being 
able to administer the items or scales to the same population at a later time to enable calculation of correlation coefficients between the two alternate forms. Again this approach was not feasible for this study. The internal consistency reliability psychometric measure was used for this study as it was expected that only a single engagement with the population would be possible.

The reliability measure was applied to groups of items that measure different aspects of the same concept. For example there were multiple statements (items) related to consumer anxiety within the broader privacy concept in the survey instrument used for this study. Internal consistency metrics indicate how well the different statements measure the same issue - in this example consumer anxiety over privacy. Cronbach's coefficient alpha was used to measure internal consistency reliability among the privacy concept, justification and management tripartite components to form a single scale. Table 6 illustrates the association of multiple survey items to a related construct. For example, five statements explore consumers views on anxiety which contributes to the broader tripartite concept of privacy construct. More detail on the pilot survey statements that comprise each tripartite component are provided in thesis Section 3.5.3.2. The high level details are presented here to give insight into the efforts made to address survey validity and reliability.

The Cronbach alpha calculations were conducted using SPSS 17.0. Satisfactory levels of Cronbach Alpha metrics for exploratory research are acceptable at 0.6 (Nunnally 1978; Nunnally and Berstein 1994). The broad reconsideration of Cronbach alpha presented by Spiliotopoulou (2009) was also influential in the present study. Table 6 presents the survey constructs, organised within appropriate tripartite privacy components, for both the Australian and Canadian pilot survey scales. Chapter 4 includes the internal reliability scales for the Australian final survey and Chapter 6 includes the same for the Canadian final survey. 
Table 6: Pilot survey internal reliability scale

\begin{tabular}{|c|c|c|c|c|c|}
\hline $\begin{array}{l}\text { Tripartite } \\
\text { Component }\end{array}$ & Construct & Code & $\begin{array}{c}\text { Australian } \\
\text { Cronbach Alpha } \\
\text { (a) }\end{array}$ & $\begin{array}{c}\text { Canadian } \\
\text { Cronbach Alpha } \\
\text { (a) }\end{array}$ & $\begin{array}{c}\text { Number of } \\
\text { items }\end{array}$ \\
\hline \multirow[t]{2}{*}{ Concept } & Anxiety & C-A & 0.761 & 0.695 & 5 \\
\hline & Sensitivity & C-S & -0.022 & 0.265 & 2 \\
\hline \multirow[t]{3}{*}{ Justification } & Rights based & J-RB & 0.579 & 0.508 & 2 \\
\hline & Balance & $J-B$ & 0.454 & 0.603 & 2 \\
\hline & $\begin{array}{l}\text { Provide } \\
\text { feedback }\end{array}$ & J-PF & 0.431 & 0.702 & 2 \\
\hline \multirow[t]{4}{*}{ Management } & Control & $M-C$ & 0.668 & 0.712 & 7 \\
\hline & $\begin{array}{l}\text { Commercial } \\
\text { data use }\end{array}$ & $M-C D$ & 0.162 & 0.274 & 3 \\
\hline & $\begin{array}{l}\text { Data } \\
\text { Stewardship }\end{array}$ & M-DS & 0.002 & 0.581 & 4 \\
\hline & Altruism & $M-U$ & 0.297 & 0.459 & 3 \\
\hline
\end{tabular}

The Australian and Canadian pilot survey results indicated that adjustments would be necessary to the survey prior to national deployment to improve the internal reliability. The adjustments made are further discussed in Section 3.5.4 Improvements to Survey Design Resulting from the Pilot Survey.

There are several approaches to investigating survey validity including face, content, criterion and construct (Litwin 2003; Fink 2005). Criterion validity was not undertaken as there was no comparative instrument available. Construct validity involves a theoretical measure of how meaningful a survey instrument is and can generally be established after years of experience with numerous investigators (Litwin 2003, p. 43). As this is the inaugural consumer survey on secondary use of medical data this was not pursued at this time. Face validity, the most casual measure of a survey's accuracy (Litwin 2003), was considered by the focus groups. Face validity included consideration of the validity issues as summarised by Fink (2005); Does it seem to ask all the required questions? Does it use the appropriate language and language level to do so? The findings from the focus groups are discussed in Section 3.5.3.1 below. 
Content validity was addressed by two individuals - a General Practice medical practitioner and an information systems lecturer at an Australian University. Both individuals made recommendations regarding the subject matter of the survey which led to improvements prior to pilot study deployment.

The qualitative data contributing to this study has relied on process and triangulation for establishment of validity, as suggested by Byrne (2002). These issues are discussed fully later in this chapter.

\subsubsection{Focus Groups and Pilot Testing the Survey}

The survey used in this study is the instrument used to explore consumer attitudes towards secondary use of their medical data. There were few existing survey instruments exploring this domain to guide the development of the survey for this study. The survey aimed to engage with consumers of varying education level across diverse communities in Australia and Canada. Using complex academic level English language was to be avoided as many citizens would find such an approach disengaging. The input of many consumers was sought on the design, wording and length of the survey. This was achieved through multiple focus groups. Once the survey had been adjusted following focus group comments the instrument was then deployed in a pilot study to 'test-the-water' with the broader community. The sample populations chosen for the pilot survey were closely located to the host Universities as it was expected the local communities would likely engage with the survey when it arrived unsolicited in residential letterboxes. The response rate from citizens familiar with the Universities would likely be more positive than in geographic areas further afield. This assumption was explored through the deployment of the pilot survey to Darwin. The pilot survey results offered more opportunities for improvement and adjustments were made prior to deployment of the final surveys. Every effort, through focus groups and pilot studies, was made to offer consumers a survey instrument that they could readily understand and complete. As Litwin (2003) and Fink (2005) suggest, the use of focus groups and pilot testing improves the likelihood of success. This section describes the focus groups and pilot studies conducted in both Australia and Canada. 


\subsubsection{Focus Groups}

Australia

All three components of the survey were included in a draft that was prepared and administered to small focus groups in June-July 2009. The diverse focus group participants were purposefully selected, by the principal researcher, to capture "information rich" feedback. The Australian focus groups included a diverse population that included teenagers, octogenarians, non-English speaking backgrounds (Norwegian and Chinese), women, men, post graduate educated, less than 12 years of high school education, healthcare workers, non- healthcare workers, and residents of New South Wales and of Western Australia.

The focus groups provided valuable insight into the format and content of the survey. For example, the male octogenarian involved suggested that many of his elderly friends, particularly those suffering dementia, would struggle to concentrate through the entire survey. The wording of some statements was criticized for being too complex. In addition, the problem of common methods bias was raised by some in the focus groups as they found that the nature and ordering of the statements caused the respondents to try and respond in such a way that they would avoid cognitive dissonance. The statements were reworded and reordered for the pilot study to try and overcome this common methods bias.

The dot point instructions were well received and focus group members appreciated the clarification that there were no 'right' or 'wrong' answers and they felt comfortable expressing their opinion. Some focus group participants felt that the questions were repeated with slightly different phrasing. Time to complete the survey was on average 10 minutes. The New South Wales focus group participants had the researcher available in the room to provide any clarification if needed on the intent of the questions however no such clarification was sought. The West Australian focus group participants received the survey via Australia Post and commented that the entire package was 'neat and easily understood'. It was important to have remote members of the focus group to test the consumer response to the unexpected arrival of the survey package. 


\section{Canada}

The Canadian pilot survey was tested with a convenience sample of staff and students and family members associated with the Health Informatics Research Group at UOIT. The task for this focus group was to comment on how accessible the language would be to Canadians and to update the Canada specific aspects. Survey Component 1, 'attitudinal statements', was adjusted to reflect references to the appropriate level of the Canadian Government. Survey Component 3, 'optional demographics', required adjustment for use in Canada to better reflect education levels and to provide suitable anonymity with postal codes. The full Canadian Postal code narrows in to small residential areas, sometimes as few as a dozen homes, and this was not a suitable level of anonymity; hence only the first three alphanumerics of the postal code were requested. These three alphanumerics provided sufficient information to locate respondents to a broad geographic area similar to an Australian postcode.

As Straub , Litwin (2003) and Fink (2005) suggest, the use of focus groups and pilot testing improves the likelihood of success.

\subsubsection{Australian and Canadian Pilot Survey}

Australia

Between August and November 2009, 482 hardcopy self-administered surveys were distributed to sample populations in residential blocks in regional NSW and Darwin; the capital city of Australia's Northern Territory. High, medium and low socioeconomic areas were surveyed in urban and regional populations. A survey completion incentive was included in the survey packages despatched for the pilot survey. US research indicated that inclusion of a \$1USD note in hardcopy surveys improved response rates. As Australia no longer uses this currency an equivalent item was sought. Two Australian postage stamps were included in the pilot surveys as an incentive. The Australia Post reply paid service was used to ensure that respondents did not have to pay the postage on returned surveys. The number of surveys returned was 168 giving a response rate of $34.8 \%$.

Component 1 of the pilot survey included the thirty attitudinal statements used in the focus groups with re-wording for clarity on the unclear statements identified by focus group participants. A seven point Likert scale was used in the pilot survey instrument 
ranging through 'strongly disagree', 'disagree', 'tend to disagree', 'neutral', 'tend to agree', 'agree' and 'strongly agree'. An eighth option of 'Don't know' was also included.

\section{Canada}

During October and November 2009, 250 hardcopy self-administered surveys were distributed to sample populations in residential blocks in Ontario, Canada. The urban areas around the University of Ontario Institute of Technology were included in the pilot survey population. In an approach identical to that used in Australia, two Canada Post postage stamps were included in the pilot surveys as an incentive. All preaddressed return envelopes had Canada Post stamps attached to ensure that respondents did not have to pay the postage on returned surveys. A response rate of $21.5 \%$ was achieved. The structure of the Canadian Pilot Survey was identical to the Australian Pilot Survey with minor changes made for the Canadian context.

Table 7 summarises the demographics of both the Australian and Canadian pilot survey respondents. One of the aims of the survey design was to ensure that a diverse range of education levels could engage with the survey instrument and it was pleasing to note that $44 \%$ of the Australian respondents had high school or trade indicated as their highest level of education and $40.9 \%$ of the Canadian respondents had college or trade indicated as their highest level of education.

Table 7: Pilot survey respondent demographics

\begin{tabular}{|c|c|c|c|c|}
\hline \multirow[b]{2}{*}{ Respondent characteristics } & \multicolumn{2}{|c|}{ Australia } & \multicolumn{2}{|c|}{ Canada } \\
\hline & $\begin{array}{l}\text { Frequency } \\
\text { (n) }\end{array}$ & $\begin{array}{c}\text { Percentage of } \\
\text { total }\end{array}$ & $\begin{array}{l}\text { Frequency } \\
\text { (n) }\end{array}$ & $\begin{array}{c}\text { Percentage of } \\
\text { total }\end{array}$ \\
\hline Gender & & & & \\
\hline Female & 119 & $70.8 \%$ & 28 & $63.6 \%$ \\
\hline Male & 48 & $28.6 \%$ & 14 & $31.8 \%$ \\
\hline Not specified & 1 & $0.6 \%$ & 2 & $4.5 \%$ \\
\hline Age & & & & \\
\hline $18-25$ & 3 & $1.8 \%$ & 2 & $4.5 \%$ \\
\hline $26-39$ & 17 & $10.1 \%$ & 17 & $38.6 \%$ \\
\hline $40-50$ & 38 & $22.6 \%$ & 11 & $25.0 \%$ \\
\hline $51-65$ & 72 & $42.9 \%$ & 9 & $20.5 \%$ \\
\hline $66-80$ & 31 & $18.5 \%$ & 4 & $9.1 \%$ \\
\hline Over 80 & 4 & $2.4 \%$ & 0 & \\
\hline Unknown & 3 & $1.8 \%$ & 1 & $2.3 \%$ \\
\hline
\end{tabular}




\begin{tabular}{|r|r|r|r|r|}
\hline Highest Level of Education & & & & \\
\hline Left school before Year 10 & 10 & $6.0 \%$ & $\mathrm{n} / \mathrm{a}$ & $\mathrm{n} / \mathrm{a}$ \\
\hline Year 10 & 33 & $19.6 \%$ & 3 & $22.7 \%$ \\
\hline Year 12 & 19 & $11.3 \%$ & 10 & $11.4 \%$ \\
\hline Trade Qualification & 12 & $7.1 \%$ & 5 & $4.5 \%$ \\
\hline Professional Qualification & 35 & $20.8 \%$ & 2 & $31.8 \%$ \\
\hline Bachelor Degree & 41 & $24.4 \%$ & 14 & $20.5 \%$ \\
\hline Postgraduate & 14 & $8.3 \%$ & 9 & $2.3 \%$ \\
\hline Unknown & 4 & $2.4 \%$ & 1 & $13.6 \%$ \\
\hline Yes & 25 & $14.9 \%$ & 6 & $86.4 \%$ \\
\hline No & 143 & $85.1 \%$ & 38 & \\
\hline
\end{tabular}

This indicated that the survey instrument was gaining the interest of broad members of the community. The majority of respondents were female; $70.8 \%$ in Australia and $63.6 \%$ in Canada. This is not surprising as it is frequently women who engage with health related studies (Arora and McHorney 2000). Response rates from citizens aged 18-25 were disappointing and it may be that alternate survey methods, such as online or social networking tools, may provide more engagement with this age group. On the other end of the age scale it was heartening to see Australian citizens aged over 80 years were prepared to complete the survey. Given the warning provided by the octogenarian in the focus group is was pleasing to see these older consumers presenting their opinion. Unfortunately no octogenarian Canadians responded.

The pilot survey attracted similar percentage of respondents self-reporting as having worked in the healthcare sector in Australia (14.9\%) and Canada (13.6\%). This response level allows consumers to be identified as those who have worked in the healthcare sector and those who have not. This has implications for likely conceptualisation of privacy with healthcare workers very familiar with the 'limited access' approach to privacy management.

As previously described the tripartite approach to privacy issues has guided the development of the consumer survey used in the pilot study. The first tripartite component presented explores the concept of privacy held by consumers. The literature review indicates that consumers experience anxiety and are more sensitive 
about privacy matters regarding data that could be potentially stigmatising and these issues are explored through seven statements as summarised in Table 8.

Table 8: Survey statements related to the tripartite 'Concept of Privacy' and

'Justification of Privacy'

\begin{tabular}{|c|c|c|c|c|}
\hline $\begin{array}{l}\text { Privacy } \\
\text { Tripartite } \\
\text { Component }\end{array}$ & Construct & Code & $\begin{array}{l}\text { Survey } \\
\text { Statement } \\
\text { Number }\end{array}$ & Pilot Survey Statement \\
\hline \multirow[t]{7}{*}{ Concept } & Anxiety & C-A1 & 6 & $\begin{array}{l}\text { I am concerned that my medical information may be } \\
\text { stolen. }\end{array}$ \\
\hline & & C-A2 & 8 & $\begin{array}{l}\text { I worry about medical receptionists reading my } \\
\text { medical information. }\end{array}$ \\
\hline & & C-A3 & 9 & $\begin{array}{l}\text { I worry about computer staff being able to read my } \\
\text { medical information when they are looking after } \\
\text { medical systems. }\end{array}$ \\
\hline & & C-A4 & 25 & $\begin{array}{l}\text { I would never agree to donate my medical } \\
\text { information to anyone because I worry about } \\
\text { potential misuse of the information. }\end{array}$ \\
\hline & & C-A5 & 5 & $\begin{array}{l}\text { I am influenced by media reports about medical } \\
\text { information that is stolen or not kept private and } \\
\text { confidential. }\end{array}$ \\
\hline & Sensitivity & C-S1 & 27 & $\begin{array}{l}\text { The collection of genetic /DNA type medical } \\
\text { information is likely to be a higher risk to my personal } \\
\text { privacy than other types of medical information. }\end{array}$ \\
\hline & & C-S2 & 28 & $\begin{array}{l}\text { If members of my family were unwell I would agree } \\
\text { that my genetic/DNA medical information could be } \\
\text { used to assist the family member. }\end{array}$ \\
\hline \multirow[t]{6}{*}{ Justification } & $\begin{array}{l}\text { Rights } \\
\text { Based }\end{array}$ & J-RB1 & 1 & I believe that I have a 'right' to personal privacy. \\
\hline & & J-RB2 & 3 & $\begin{array}{l}\text { I have the 'right' to share my medical information with } \\
\text { others. }\end{array}$ \\
\hline & $\begin{array}{l}\text { Balance } \\
\text { "common } \\
\text { good" }\end{array}$ & J-B1 & 12 & $\begin{array}{l}\text { If information about my health can be used to help } \\
\text { others who are suffering ill-health then I believe my } \\
\text { information should be used to help those people. }\end{array}$ \\
\hline & & J-B2 & 20 & $\begin{array}{l}\text { I support the idea of medical information donation } \\
\text { when the information is used in a way that benefits } \\
\text { society. }\end{array}$ \\
\hline & $\begin{array}{l}\text { Provide } \\
\text { feedback }\end{array}$ & J-PF1 & 21 & $\begin{array}{l}\text { If I donated my medical information for medical } \\
\text { research I would expect the researchers to be able to } \\
\text { contact my Doctor if they found something potentially } \\
\text { poor about my health. }\end{array}$ \\
\hline & & J-PF2 & 22 & $\begin{array}{l}\text { If I donated my medical information for medical } \\
\text { research I would want this to always be totally } \\
\text { anonymous and would not expect any information to } \\
\text { come back to me from the medical researchers. }\end{array}$ \\
\hline
\end{tabular}

The survey statements related to the tripartite component of 'privacy justification' are also included in Table 8 . 
Table 9: Survey Statements related 'Privacy Management'- control and commercial data use constructs

\begin{tabular}{|c|c|c|c|c|}
\hline $\begin{array}{c}\text { Privacy } \\
\text { Tripartite } \\
\text { Component }\end{array}$ & Construct & Code & $\begin{array}{l}\text { Survey } \\
\text { Statement } \\
\text { Number }\end{array}$ & Pilot Survey Statement \\
\hline \multirow[t]{10}{*}{ Management } & Control & $\mathrm{M}-\mathrm{C} 1$ & 15 & $\begin{array}{l}\text { If I donated my medical information for research I } \\
\text { would want to choose the level of privacy I } \\
\text { required. For example I may choose (1) 'always } \\
\text { anonymous' or (2) 'name and OHIP number can } \\
\text { always be used'. }\end{array}$ \\
\hline & & M-C2 & 13 & $\begin{array}{l}\text { If my health information could be made anonymous } \\
\text { by removing things like my name, address, phone } \\
\text { number and OHIP number I would be more likely to } \\
\text { agree for the information to be used for medical } \\
\text { research. }\end{array}$ \\
\hline & & M-C3 & 17 & $\begin{array}{l}\text { If I give consent for my health information to be } \\
\text { used for research I want to be able to say who can } \\
\text { use my information like 'medical researchers', } \\
\text { 'drug companies', 'university researchers' or } \\
\text { 'insurance companies'. }\end{array}$ \\
\hline & & M-C4 & 23 & $\begin{array}{l}\text { If people agree to donate their data for medical } \\
\text { research there must be a way for them to stop the } \\
\text { donation agreement. }\end{array}$ \\
\hline & & M-C5 & 24 & $\begin{array}{l}\text { If people agree to donate their data for medical } \\
\text { research from time to time they must be asked if } \\
\text { they want to continue to donate. }\end{array}$ \\
\hline & & M-C6 & 14 & $\begin{array}{l}\text { I support the idea of people being given a personal } \\
\text { choice about 'donating' their medical information } \\
\text { for research. }\end{array}$ \\
\hline & & $\mathrm{M}-\mathrm{C} 7$ & 26 & $\begin{array}{l}\text { If I was in hospital and a medical device was used } \\
\text { to care for me - like a heart monitor or oxygen } \\
\text { saturation monitor - I would agree for the } \\
\text { information displayed on the screen to be saved in } \\
\text { an anonymous way and used for medical research } \\
\text { purposes. }\end{array}$ \\
\hline & $\begin{array}{l}\text { Commercial } \\
\text { data use }\end{array}$ & $\begin{array}{l}M- \\
\text { CD1 }\end{array}$ & 18 & $\begin{array}{l}\text { Using my donated medical information for profit } \\
\text { making purposes is not OK. }\end{array}$ \\
\hline & & $\begin{array}{l}\mathrm{M}- \\
\mathrm{CD} 2\end{array}$ & 19 & $\begin{array}{l}\text { I would expect to be paid if I provided my medical } \\
\text { information to someone who was using the } \\
\text { information for profit making purposes. In this case } \\
\text { my data should not be considered a donation. }\end{array}$ \\
\hline & & $\begin{array}{l}\mathrm{M}- \\
\mathrm{CD} 3\end{array}$ & 29 & $\begin{array}{l}\text { Insurance companies should be allowed to use } \\
\text { donated anonymous data to help them assess } \\
\text { insurance costs. }\end{array}$ \\
\hline
\end{tabular}

The 'Privacy Management' related statements appear in Table 9 and Table 10. Table 10 presents the statements pertaining to the data stewardship aspects of privacy management and the underlying sense of altruism amongst consumers. 
Table 10: Survey statements related to 'Privacy Management'- data stewardship and altruism constructs

\begin{tabular}{|l|c|c|c|l|}
\hline $\begin{array}{c}\text { Privacy } \\
\text { Tripartite } \\
\text { Component }\end{array}$ & Construct & Code & $\begin{array}{c}\text { Survey } \\
\text { Statement } \\
\text { Number }\end{array}$ & \multicolumn{1}{|c|}{ Pilot Survey Statement } \\
\hline stewardship & DS1 & 2 & $\begin{array}{l}\text { I think that my medical records belong to me - they } \\
\text { don't just belong to my Doctor(s). }\end{array}$ \\
\hline & M- & 16 & $\begin{array}{l}\text { If I trust my Doctor I would let him/her decide who } \\
\text { can use my anonymous medical information for } \\
\text { research. }\end{array}$ \\
\hline & DS2 & M- & 4 & $\begin{array}{l}\text { The only reason my health information should be } \\
\text { recorded is to help look after me. }\end{array}$ \\
\hline & DS3 & DS4 & 7 & $\begin{array}{l}\text { Storing my medical information on paper files in my } \\
\text { Doctor's office protects my privacy better than } \\
\text { when information is kept on computers. }\end{array}$ \\
\hline & M-U1 & 10 & $\begin{array}{l}\text { I support the idea of people making money } \\
\text { donations to support medical research. }\end{array}$ \\
\hline & M-U2 & 11 & $\begin{array}{l}\text { I support the idea of people making voluntary blood } \\
\text { donations. }\end{array}$ \\
\hline & M-U3 & 30 & $\begin{array}{l}\text { People who have some experience with serious } \\
\text { illness are more likely to support the donation of } \\
\text { medical information for research purposes. }\end{array}$ \\
\hline
\end{tabular}

The altruism statements have been included due to the reliance health researchers have on a citizen's sense of altruism to allow secondary data use to support research. Statements 10, 11 and 30 broadly explore public opinion regarding altruism concerning financial donations to support medical research, blood donation and medical information.

\subsubsection{Analysis of Pilot Survey}

The purpose of the pilot studies was to test the validity, and reliability of the survey statements and to gain some insight into citizen interest in responding to the unsolicited surveys. that the response rates were encouraging and would hopefully continue with the final surveys. It is not proposed to include comprehensive pilot survey results in this thesis; the following are a selection of examples to illustrate the type of research decisions made surrounding the pilot survey and progression to the final surveys.

\section{Quantitative}

A selection of descriptive statistics is reported here as these aided in the evaluation of the pilot survey and helped inform the choice of statements to be carried forward to 
the final surveys. Consumers responded positively to the Statement 1 - 'I believe that I have a 'right' to personal privacy', Figure 10 depicts summary response frequency as a percentage. This statement explores the consumers perceptions of privacy - do they perceive privacy in a manner similar to Warren and Brandeis (1890) with a basis in an individuals legal 'rights'? The result is that Australian and Canadian citizens are overwhelmingly in agreement with this justification of privacy.

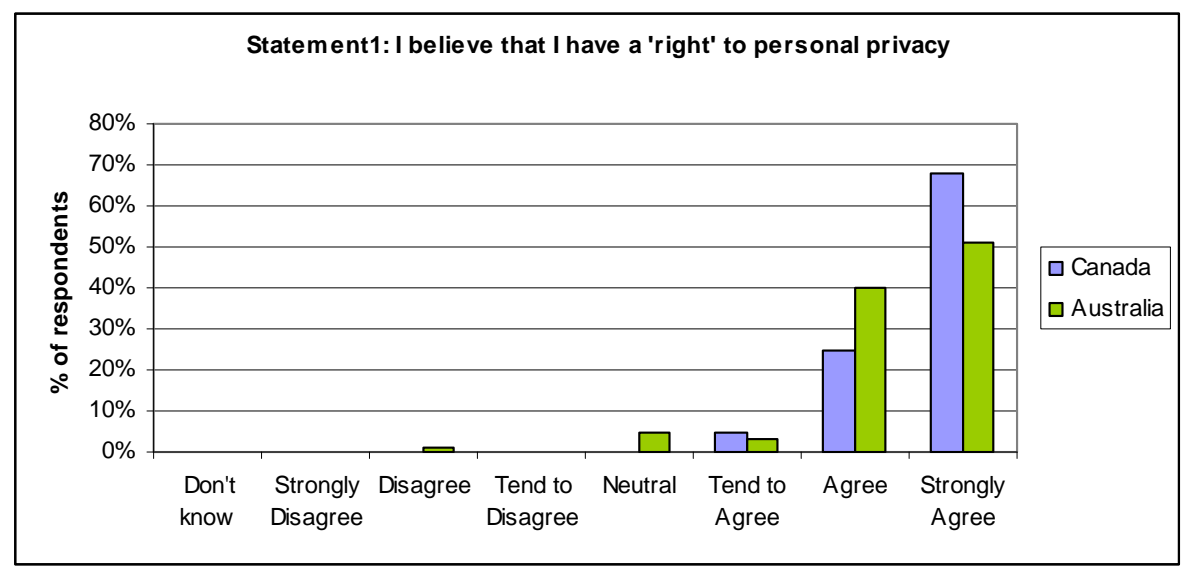

Figure 10: Pilot survey response to Statement 1

One of the few earlier surveys (EKOS Research Associates 2007) to consider the consumers' views on access to their medical information indicated more concern regarding IT staff access than concern about medical receptionist access to personal information. Statements 8 and 9 in the pilot survey sought similar attitudinal data to aid in understanding the tripartite concept of privacy, particularly anxiety aspects. The two statements are 'I worry about medical receptionists reading my medical information' and ' I worry about computer staff being able to read my medical information when they are looking after medical systems'. As Figure 11 illustrates, Canadian pilot survey respondents are expressing concern regarding IT staff accessing patients medical information. This result varies with earlier Canadian research (EKOS Research Associates 2007) where access by IT professionals caused more concern than access by medical receptionists. 


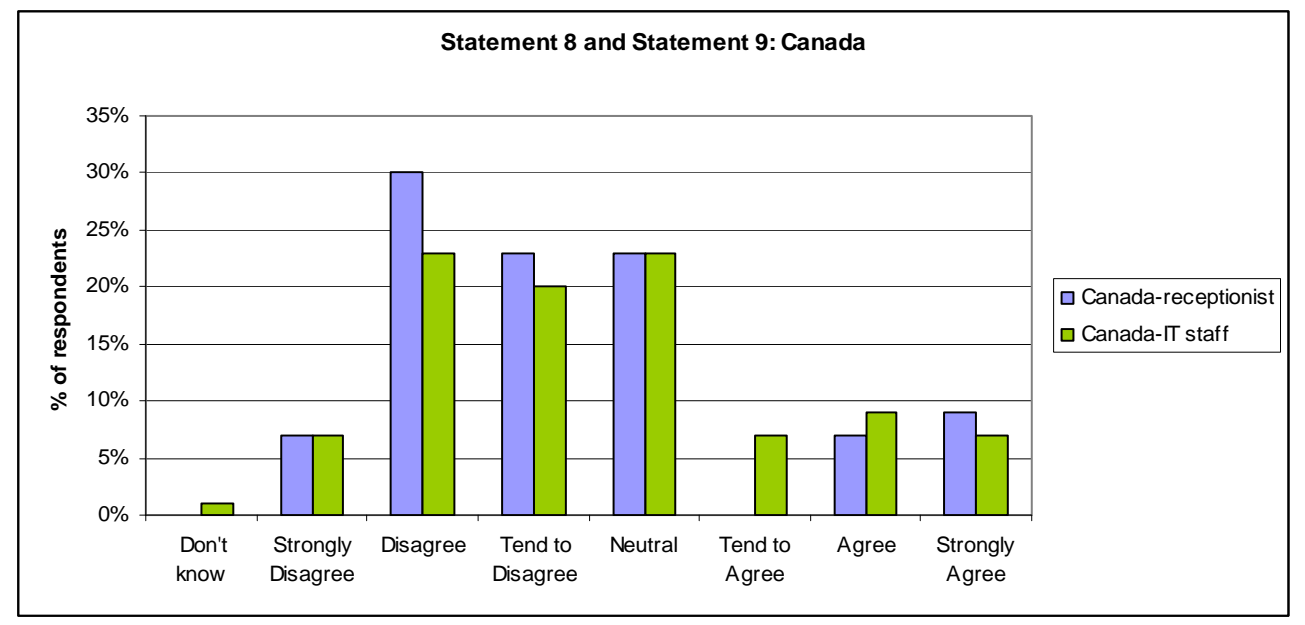

Figure 11: Pilot survey Canadian response to Statements 8 and 9

The Australian pilot study results indicate Australian respondents were more concerned regarding IT staff having access to their medical information.

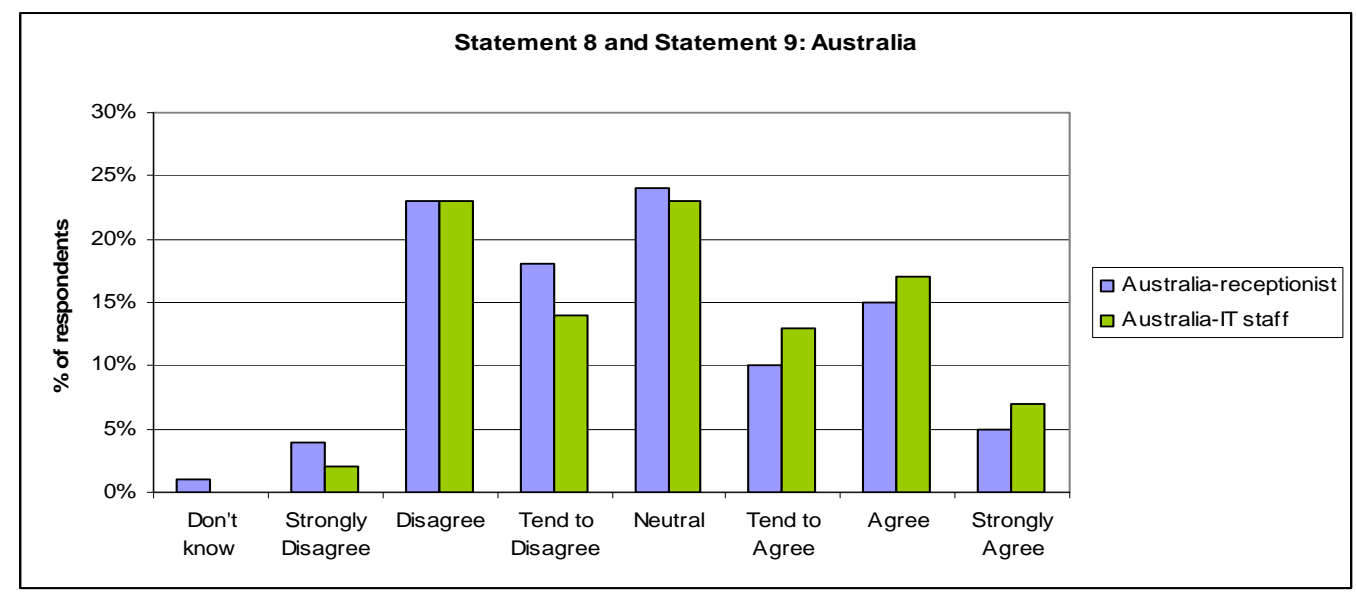

Figure 12: Pilot survey Australian response to Statement 8 and 9

An unanticipated outcome from the pilot survey was a clear difference of opinion across consumer education levels regarding anxiety over potential theft of medical information. Post graduate level educated respondents strongly disagree with the Statement 6 - 'I am concerned that my medical information may be stolen'. Twenty percent of respondents who left school prior to completing 10 years of schooling strongly agree with the statement. Table 11 presents a cross tabulation of Highest Level of Education and Australian consumer attitudinal response. 
Table 11: Australian Cross tabulation of Highest Education Level and Statement 6 response

\begin{tabular}{|c|c|c|c|c|c|c|c|c|}
\hline \multirow[b]{2}{*}{ Highest Education } & \multicolumn{8}{|c|}{ Q6. I am concerned that my medical information may be stolen. } \\
\hline & $\begin{array}{l}\text { Strongly } \\
\text { disagree }\end{array}$ & Disagree & $\begin{array}{c}\text { Tend } \\
\text { to } \\
\text { disagree }\end{array}$ & Neutral & $\begin{array}{l}\text { Tend to } \\
\text { agree }\end{array}$ & Agree & $\begin{array}{c}\text { Strongly } \\
\text { agree }\end{array}$ & $\begin{array}{l}\text { Don't } \\
\text { know }\end{array}$ \\
\hline & & $25.0 \%$ & & & $25.0 \%$ & $50.0 \%$ & & \\
\hline Left before Year10 & & $20.0 \%$ & $10.0 \%$ & $20.0 \%$ & $20.0 \%$ & $10.0 \%$ & $20.0 \%$ & \\
\hline Year 10/4thForm & $6.1 \%$ & $12.1 \%$ & $18.2 \%$ & $24.2 \%$ & $12.1 \%$ & $21.2 \%$ & $3.0 \%$ & $3.0 \%$ \\
\hline Year12/6thForm/Leaving & $5.3 \%$ & $5.3 \%$ & $5.3 \%$ & $21.1 \%$ & $31.6 \%$ & $21.1 \%$ & $10.5 \%$ & \\
\hline Trade Qualification & & $18.2 \%$ & $9.1 \%$ & $27.3 \%$ & $18.2 \%$ & $18.2 \%$ & $9.1 \%$ & \\
\hline Professional Qualification & & $22.9 \%$ & $20.0 \%$ & $20.0 \%$ & $14.3 \%$ & $17.1 \%$ & $2.9 \%$ & $2.9 \%$ \\
\hline Bachelor Degree & $2.5 \%$ & $27.5 \%$ & $15.0 \%$ & $35.0 \%$ & $7.5 \%$ & $12.5 \%$ & & \\
\hline Postgraduate & $15.4 \%$ & $15.4 \%$ & $23.1 \%$ & $38.5 \%$ & & $7.7 \%$ & & \\
\hline Total & $3.6 \%$ & $18.8 \%$ & $15.2 \%$ & $26.1 \%$ & $13.9 \%$ & $17.0 \%$ & $4.2 \%$ & $1.2 \%$ \\
\hline
\end{tabular}

Chapters 4, 5 and 6 further investigate this emergent outcome as highest level of education, as apparent in this early pilot study analysis, is an important factor in consumers' concepts of privacy and expectations regarding management of privacy.

Consumers' views regarding altruism and 'for the common good' utilitarian attitudes were displayed through the surveys as they voiced support for blood donations and financial donations to support medical research. Statements 10 and 11 'I support the idea of people making money donations to support medical research' and 'I support the idea of people making voluntary blood donations' were used to capture consumer views.

Given the poor internal reliability associated with the altruism construct these statements were removed from the final surveys. Consumer responses to the two open-ended survey questions provided an opportunity for the elaboration of their views and altruism is a deductive qualitative theme described in the next thesis section and Chapters 4,5 and 6. Hence, despite the poor quantitative results regarding altruism, this important issue has been better addressed with the qualitative methods. 


\section{Qualitative}

In the pilot Australian and Canadian studies three qualitative researchers were involved in analysing and classifying the qualitative data. Inclusion of multiple qualitative data evaluators contributes 'investigator triangulation' thus strengthening the overall validity. The themes used for encoding were generated in a deductive manner from the literature that informed the survey design. Any emergent themes were noted by the qualitative encoders. To enhance reliability the encoded qualitative themes found in each qualitative survey submission, as identified by each qualitative researcher, were compared and where discrepancies existed the researchers discussed the classifications until an agreed set of themes for each returned survey were agreed.

As a researcher read through the survey comments they annotated the survey number against the theme and once this was completed a tally was included. This approach was sufficient for the small number of surveys in the pilot study, however a more rigorous approach was adopted for the final surveys.

\subsubsection{Improvements to Survey Design Resulting from the Pilot Survey}

The reason for conducting the pilot studies was to improve the consumer public opinion survey instrument. This section discusses changes made to the survey prior to national deployment.

The seven point Likert scale was reduced to a five point scale for the final survey. There is debate surrounding the ideal scale for surveys (Rossiter 2002; Bergkvist and Rossiter 2007). Originally the seven point Likert response scale was included due to the expectation that it would be possible to record greater discrimination in categories of the statement responses. Pilot survey data analysis indicated little benefit in maintaining the seven point scale and hence the scale was reduced to five points for the final surveys. The reduction in number of Likert response categories also simplified the visual appearance of the survey instrument and it was hoped that this would lead to further engagement with consumers.

The poor internal reliability of some parts of the survey, as reported earlier led to removal of some statements and replacement with alternate statements. For example 
the construct exploring consumers opinion regarding altruism was removed. With Cronbach Alpha $(\alpha)=.297$ for Australia and .459 for Canada, these statements were not offering acceptable levels of internal reliability. Similarly the statements pertaining to data stewardship resulted in very low Cronbach Alpha $(a)=.002$ for Australia and .459 for Canada. In this case there was such a discrepancy between the two pilot survey results the Australian results took precedent due to the larger sample size in Australia (168) as compared to Canada (44). The larger sample size was likely more indicative of performance on the final survey. Similarly the commercial data use construct resulted in poor internal reliability with Cronbach Alpha (a) $=.162$ for Australia and .274 for Canada. The negative Cronbach Alpha on the Australian sensitivity construct indicates a negative covariance amongst the two items (statements), which violates the reliability model assumption. After checking the item coding and entered data no explanation could be found for this negative Australian value. This construct was removed from the final surveys. All of the constructs were analysed and their merit for inclusion in the final surveys considered, leading to changes to the statements prior to final survey deployment.

The construct relating to the provision of feedback from research studies to consumers was closer to the internal reliability threshold for an exploratory study however these statements were re-worked in an attempt to boost the performance of the overall survey. These statements were also reconsidered as they were perhaps more appropriately placed in the 'privacy management' rather than 'privacy justification' tripartite component.

The inclusion of an incentive was also dropped from the final survey. It is difficult to quantify the impact that the incentive had on the survey response rate. Some respondents wrote polite notes such as "Thanks for the stamps - I would have completed the survey even if you had not sent me the stamps". Given that such sentiment was expressed and there was no clear advantage the incentives were not used in the final surveys. 


\subsubsection{Revised Survey Constructs}

Following the survey focus group and pilot testing the final version of the survey was determined and Table 12 summarises the privacy tripartite components, associated constructs, codes and survey statements to be included in the final Australian and Canadian surveys.

Table 12: Final survey constructs

\begin{tabular}{|c|c|c|c|c|}
\hline $\begin{array}{c}\text { Privacy } \\
\text { Tripartite } \\
\text { Component }\end{array}$ & Construct & Code & $\begin{array}{l}\text { Survey } \\
\text { Statement } \\
\text { Number }\end{array}$ & Survey Statement \\
\hline \multirow[t]{8}{*}{ Concept } & Anxiety & C-A1 & 5 & $\begin{array}{l}\text { If an unauthorised person gained access to my } \\
\text { medical information then I would feel that my privacy } \\
\text { had been violated. }\end{array}$ \\
\hline & & C-A2 & 6 & $\begin{array}{l}\text { I am concerned that my medical information may be } \\
\text { stolen. }\end{array}$ \\
\hline & & C-A3 & 8 & $\begin{array}{l}\text { I worry about medical receptionists reading my } \\
\text { medical information. }\end{array}$ \\
\hline & & C-A4 & 9 & $\begin{array}{l}\text { I worry about computer staff being able to read my } \\
\text { medical information when they are looking after } \\
\text { medical systems. }\end{array}$ \\
\hline & & C-A5 & 25 & $\begin{array}{l}\text { I would never agree to donate my medical information } \\
\text { to anyone because I worry about potential misuse of } \\
\text { the information. }\end{array}$ \\
\hline & & C-A6 & 27 & $\begin{array}{l}\text { I worry about insurance companies getting access to } \\
\text { medical information because they may not use } \\
\text { information in a way that benefits society. }\end{array}$ \\
\hline & $\begin{array}{l}\text { Limited } \\
\text { Access }\end{array}$ & C-LA1 & 10 & $\begin{array}{l}\text { In Australia my healthcare providers try to protect my } \\
\text { privacy by restricting access to my medical } \\
\text { information. }\end{array}$ \\
\hline & & C-LA2 & 11 & $\begin{array}{l}\text { It seems that my healthcare providers feel that the } \\
\text { fewer people who see my medical information the } \\
\text { higher the level of privacy they have provided for me. }\end{array}$ \\
\hline \multirow[t]{6}{*}{ Justification } & $\begin{array}{l}\text { Rights } \\
\text { Based }\end{array}$ & J-RB1 & 1 & I believe that I have a 'right' to personal privacy. \\
\hline & & J-RB2 & 3 & $\begin{array}{l}\text { I have the 'right' to share my medical information with } \\
\text { others. }\end{array}$ \\
\hline & & J-RB3 & 4 & $\begin{array}{l}\text { I expect Australian laws and healthcare guidelines to } \\
\text { protect my personal privacy. }\end{array}$ \\
\hline & $\begin{array}{l}\text { Balance } \\
\text { 'common } \\
\text { good' and } \\
\text { individual }\end{array}$ & J-B1 & 12 & $\begin{array}{l}\text { If information about my health can be used to help } \\
\text { others who are suffering ill-health then I believe my } \\
\text { information should be used to help those people. }\end{array}$ \\
\hline & & J-B2 & 26 & $\begin{array}{l}\text { I support the idea of medical information donation } \\
\text { when the information is used in a way that benefits } \\
\text { society. }\end{array}$ \\
\hline & & J-B3 & 28 & $\begin{array}{l}\text { Using medical information for the 'common good' is } \\
\text { OK but I worry about the risk to a person's privacy. }\end{array}$ \\
\hline
\end{tabular}




\begin{tabular}{|c|c|c|c|c|}
\hline $\begin{array}{l}\text { Privacy } \\
\text { Tripartite } \\
\text { Component }\end{array}$ & Construct & Code & $\begin{array}{l}\text { Survey } \\
\text { Statement } \\
\text { Number }\end{array}$ & Survey Statement \\
\hline \multirow[t]{16}{*}{ Management } & Control & $\mathrm{M}-\mathrm{C} 1$ & 16 & $\begin{array}{l}\text { If I donated my medical information for research } \\
\text { would want to choose the level of privacy I required. } \\
\text { For example I may choose (1) 'always anonymous' or } \\
\text { (2) 'name and Medicare number can always be used'. }\end{array}$ \\
\hline & & $\mathrm{M}-\mathrm{C} 2$ & 13 & $\begin{array}{l}\text { If my health information could be made anonymous by } \\
\text { removing things like my name, address, phone } \\
\text { number and Medicare number I would be more likely } \\
\text { to agree for the information to be used for medical } \\
\text { research. }\end{array}$ \\
\hline & & $\mathrm{M}-\mathrm{C} 3$ & 14 & $\begin{array}{l}\text { I feel that I continue to have privacy even when other } \\
\text { people have access to my personal information if I am } \\
\text { the one who has granted the other people access. }\end{array}$ \\
\hline & & M-C4 & 17 & $\begin{array}{l}\text { If I give consent for my health information to be used } \\
\text { for research I want to be able to say who can use my } \\
\text { information like 'medical researchers', 'drug } \\
\text { companies', 'university researchers' or 'insurance } \\
\text { companies'. }\end{array}$ \\
\hline & & $\mathrm{M}-\mathrm{C5}$ & 19 & $\begin{array}{l}\text { A person must be able to choose to keep their medical } \\
\text { information private and never consent to release their } \\
\text { medical information for any purpose. }\end{array}$ \\
\hline & & $\mathrm{M}-\mathrm{C} 6$ & 20 & $\begin{array}{l}\text { If I donated my medical information for research } \\
\text { would like to give my consent once - at the time of } \\
\text { 'signing up' as a data donor. }\end{array}$ \\
\hline & & $\mathrm{M}-\mathrm{C} 7$ & 21 & $\begin{array}{l}\text { If people agree to donate their data for medical } \\
\text { research there must be a way for them to stop the } \\
\text { donation agreement at any time. }\end{array}$ \\
\hline & & $\mathrm{M}-\mathrm{C} 8$ & 22 & $\begin{array}{l}\text { If people agree to donate their data for medical } \\
\text { research from time to time they must be asked if they } \\
\text { want to continue to donate. }\end{array}$ \\
\hline & & M-C9 & 23 & $\begin{array}{l}\text { If I choose to donate my medical information then } \\
\text { healthcare providers should release the information } \\
\text { according to my instructions. }\end{array}$ \\
\hline & & $\mathrm{M}-\mathrm{C} 10$ & 29 & $\begin{array}{l}\text { I should be able to see my medical information and it } \\
\text { should be easy to correct any mistakes in the } \\
\text { information. }\end{array}$ \\
\hline & & M-C11 & 15 & $\begin{array}{l}\text { I support the idea of people being given a personal } \\
\text { choice about 'donating' their medical information for } \\
\text { research. }\end{array}$ \\
\hline & $\begin{array}{l}\text { Data } \\
\text { Stewardship }\end{array}$ & M-DS1 & 24 & $\begin{array}{l}\text { I would be happy to let the Australian Government } \\
\text { decide who can use my medical information. }\end{array}$ \\
\hline & & M-DS2 & 7 & $\begin{array}{l}\text { When my medical information is stored on a computer } \\
\text { owned by a healthcare provider they should not } \\
\text { assume that they 'own' the information. }\end{array}$ \\
\hline & & M-DS3 & 30 & $\begin{array}{l}\text { A legal judge in Australia decided that the notes } \\
\text { written about a patient, by a Doctor, are owned by the } \\
\text { Doctor not the patient. This decision seems } \\
\text { reasonable to me. }\end{array}$ \\
\hline & & M-DS4 & 2 & $\begin{array}{l}\text { I think that my medical records belong to me - they } \\
\text { don't just belong to my healthcare providers. }\end{array}$ \\
\hline & & M-DS5 & 18 & $\begin{array}{l}\text { Any medical research groups who want to use } \\
\text { 'donated' data must comply with the wishes of the } \\
\text { person who has 'donated' the data. }\end{array}$ \\
\hline
\end{tabular}




\subsubsection{Survey Ethical Considerations}

Ethics approval to conduct the survey was requested from the University of Wollongong Human Research Ethics Committee (HREC). This committee is accredited by the Australian National Health and Medical Research Council and operates according to the Australian National Statement on Ethical Conduct in Research Involving Humans (NHMRC 2007).

An initial research approval was provided by the University of Wollongong in mid 2009, a copy is included in Appendix A. An ethics renewal was required in 2010 and a final report on ethical aspects of research was completed and submitted to the HREC in August 2011. Ethics approval was also required to conduct the Canadian aspects of this study and the University of Ontario Institute of Technology (UOIT) Research Ethics Board (REB) provided approval. This REB ensures research in Canada is conducted in compliance with the Tri-Council Policy Statement: Integrity in Research and Scholarship. The UOIT REB provided initial approval for this study in 2009 and a renewal was applied for and granted in 2010.

The survey used in this study was anonymous with respondents asked to provide nonmandatory, non-identifying demographic characteristics via survey component 2 . Given the nature of this research, providing research participants with a mechanism to enable engagement in a non-identifying manner was very important. All of the returned surveys from Australia and Canada are held securely within the School of Information Systems and Technology at the University of Wollongong. These surveys are to be securely stored for the next five years and cannot be used as part of any other research study.

\subsubsection{The Final Survey}

The organisation of the survey questions broadly moves through concept, justification and management of privacy reflecting the RALC constructs. All of the gathered survey data contributes empirical knowledge to Townend's consumer vector (2010). The final Australian survey can be found in Appendix B. 


\subsubsection{Cover Letter}

A one page cover letter was included in the survey packages. The cover letter introduced the survey topic to residents, estimated the time it would take to complete the survey, and provided names, photographs, home Faculties, email addresses and telephone numbers for the researchers. Residents were also told that ethics approval had been granted and contact phone numbers were provided for the Institutional ethics officers. The cover letters for the Australian and Canadian surveys can be found in Appendix C.

\subsubsection{Component 1: Attitudinal Statements}

Component 1 investigated the respondents' opinions regarding abstract and tangible aspects of privacy within the secondary use of medical data context. No preliminary information was provided to respondents. The survey is a snapshot of citizen's current perceptions of privacy without any attempt to shape the notion of privacy or data ownership, legal rights or suitable secondary uses through background or preliminary discussion. The absence of early opinion forming materials, that are sometimes used by researchers to frame issues prior to asking respondents to complete the survey, have been purposefully avoided. Respondents used their 'common knowledge' interpretation of the attitudinal statements.

This is a valid approach as there is ongoing debate regarding the definition and evolving meaning of privacy in the Information Age as described in the Literature Review of this thesis. The capture of citizens' opinions as expressed via this survey instrument may provide a 'baseline' position that can be used in future research regarding public opinion as our understanding of privacy evolves. Figure 13, Figure 14 and Figure 15 present the first three pages of the Australian final survey instrument. 
Public Opinion Survey Regarding Secondary Use of Medical Data

- There are no 'right' or 'wrong' responses to the following statements.

- Please read the opinion statements and circle the number on the scale to indicate how you feel about the statement.

- The scale is from 1: Strongly disagree through to 5 : Strongly agree

- If you do not know how to respond to the statement please put an $\mathrm{X}$ in the 'Don't know' box.

Below is an example that shows a person agreeing with the statement ' 1 often wait more than two days to get an appointment with my local Doctor'

\begin{tabular}{|c|c|c|c|c|c|c|}
\hline Opinion statement & $\begin{array}{l}\text { Strongly } \\
\text { disagree }\end{array}$ & Disagree & Neutral & Agree & $\begin{array}{c}\text { Strongly } \\
\text { agree }\end{array}$ & $\begin{array}{l}\text { Don't } \\
\text { Know }\end{array}$ \\
\hline 1. I often wait more than two days to get an appointment with my local Doctor. & 1 & 2 & 3 & 4 & 5 & \\
\hline
\end{tabular}

Please circle only one number on the scale to show your opinion. After completing the survey please return the survey as soon as possible to Jennifer Heath using the pre-paid addressed envelope.

\begin{tabular}{|c|c|c|c|c|c|c|}
\hline Opinion statement & \begin{tabular}{|l|} 
Strongly \\
disagree
\end{tabular} & Disagree & Neutal & Agree & $\begin{array}{c}\text { Strongly } \\
\text { agree }\end{array}$ & $\begin{array}{l}\text { Don't } \\
\text { Knowi }\end{array}$ \\
\hline 1. I believe that I have a 'right' to personal privacy. & 1 & 2 & 3 & 4 & 5 & \\
\hline $\begin{array}{l}2 \text {. I think that my medical records belong to me- they don't just belong to my healthcare } \\
\text { providers. }\end{array}$ & 1 & 2 & 3 & 4 & 5 & \\
\hline 3. I have the 'right' to share my medical information with others. & 1 & 2 & 3 & 4 & 5 & \\
\hline 4. I expect Australian laws and healthcare guidelines to protect my personal privacy. & 1 & 2 & 3 & 4 & 5 & \\
\hline $\begin{array}{l}\text { 5. If an unauthorised person gained access to my medical information then I would feel that } \\
\text { my privacy had been violated. }\end{array}$ & 1 & 2 & 3 & 4 & 5 & \\
\hline 6. I am concerned that my medical information may be stolen. & 1 & 2 & 3 & 4 & 5 & \\
\hline $\begin{array}{l}\text { 7. When my medical information is stored on a computer owned by a healthcare provider they } \\
\text { should not assume that they 'own' the information. }\end{array}$ & 1 & 2 & 3 & 4 & 5 & \\
\hline 8. I worry about medical receptionists reading my medical information. & 1 & 2 & 3 & 4 & 5 & \\
\hline $\begin{array}{l}\text { 9. I worry about computer staff being able to read my medical information when they are } \\
\text { looking after medical systems. }\end{array}$ & 1 & 2 & 3 & 4 & 5 & \\
\hline $\begin{array}{l}\text { 10. In Australia my healthcare providers try to protect my privacy by restricting access to my } \\
\text { medical information. }\end{array}$ & 1 & 2 & 3 & 4 & 5 & \\
\hline
\end{tabular}

Figure 13: Page 1 of Australian final survey

The statements on the survey do not explore the tripartite privacy components and constructs in sequential order. For example Statement 6 explores consumer concepts of privacy, particularly their concern about theft of medical information. This statement is followed by Statement 7 which explores responses to data stewardship. This is followed by a return to the anxiety aspects of the concept of privacy with Statements 8 and 9. Page 1 finishes with a statement exploring consumers awareness of the 'limited access' approach to privacy that dominates the health sector. 


\begin{tabular}{|c|c|c|c|c|c|c|}
\hline Opinion statement & $\begin{array}{l}\text { Strongly } \\
\text { disagree }\end{array}$ & Disagree & Neutral & Agree & $\begin{array}{c}\text { Strongly } \\
\text { agree }\end{array}$ & $\begin{array}{l}\text { Don't } \\
\text { Know } \\
\end{array}$ \\
\hline $\begin{array}{l}\text { 11. It seems that my healthcare providers feel that the fewer people who see my medical } \\
\text { information the higher the level of privacy they have provided for me. }\end{array}$ & 1 & 2 & 3 & 4 & 5 & \\
\hline $\begin{array}{l}\text { 12. If information about my health can be used to help others who are suffering ill-health then } \\
\text { I believe my information should be used to help those people. }\end{array}$ & 1 & 2 & 3 & 4 & 5 & \\
\hline $\begin{array}{l}\text { 13. If my health information could be made anonymous by removing things like my name, } \\
\text { address, phone number and Medicare number I would be more likely to agree for the } \\
\text { information to be used for medical research. }\end{array}$ & 1 & 2 & 3 & 4 & 5 & \\
\hline $\begin{array}{l}\text { 14. I feel that I continue to have privacy even when other people have access to my personal } \\
\text { information if I am the one who has granted the other people access. }\end{array}$ & 1 & 2 & 3 & 4 & 5 & \\
\hline $\begin{array}{l}\text { 15. I support the idea of people being given a personal choice about 'donating' their medical } \\
\text { information for research. }\end{array}$ & 1 & 2 & 3 & 4 & 5 & \\
\hline $\begin{array}{l}\text { 16. If I donated my medical information for research I would want to choose the level of } \\
\text { privacy I required. For example I may choose (1) 'always anonymous' or (2) 'name and } \\
\text { Medicare number can always be used'. }\end{array}$ & 1 & 2 & 3 & 4 & 5 & \\
\hline $\begin{array}{l}\text { 17. If I give consent for my health information to be used for research I want to be able to say } \\
\text { who can use my information like 'medical researchers', 'drug companies', 'university } \\
\text { researchers' or 'insurance companies'. }\end{array}$ & 1 & 2 & 3 & 4 & 5 & \\
\hline $\begin{array}{l}\text { 18. Any medical research groups who want to use 'donated' data must comply with the } \\
\text { wishes of the person who has 'donated' the data. }\end{array}$ & 1 & 2 & 3 & 4 & 5 & \\
\hline $\begin{array}{l}\text { 19. A person must be able to choose to keep their medical information private and never } \\
\text { consent to release their medical information for any purpose. }\end{array}$ & 1 & 2 & 3 & 4 & 5 & \\
\hline $\begin{array}{l}\text { 20. If I donated my medical information for research I would like to give my consent once - at } \\
\text { the time of 'signing up' as a data donor. }\end{array}$ & 1 & 2 & 3 & 4 & 5 & \\
\hline $\begin{array}{l}\text { 21. If people agree to donate their data for medical research there must be a way for them to } \\
\text { stop the donation agreement at any time. }\end{array}$ & 1 & 2 & 3 & 4 & 5 & \\
\hline $\begin{array}{l}\text { 22. If people agree to donate their data for medical research from time to time they must be } \\
\text { asked if they want to continue to donate. }\end{array}$ & 1 & 2 & 3 & 4 & 5 & \\
\hline
\end{tabular}

Figure 14: Page 2 of the Australian final survey

Consistent with this approach, 'everyday language' has been used in the survey to assist in engagement with the general public. Expression in the first person was used to aid in respondents' personal engagement. This research did not use any of the specific questions found in the earlier surveys described in the Literature Review. However, this survey does explore the surveyed themes of data ownership, confidentiality and consent broadly explored in earlier surveys. 


\begin{tabular}{|c|c|c|c|c|c|c|}
\hline Opinion statement & $\begin{array}{l}\text { Strongly } \\
\text { disagree }\end{array}$ & Disagree & Neutral & Agree & $\begin{array}{c}\text { Strongly } \\
\text { agree }\end{array}$ & $\begin{array}{l}\text { Don't } \\
\text { Know }\end{array}$ \\
\hline $\begin{array}{l}\text { 23. If I choose to donate my medical information then healthcare providers should release the } \\
\text { information according to my instructions. }\end{array}$ & 1 & 2 & 3 & 4 & 5 & \\
\hline $\begin{array}{l}\text { 24. I would be happy to let the Australian Government decide who can use my medical } \\
\text { information. }\end{array}$ & 1 & 2 & 3 & 4 & 5 & \\
\hline $\begin{array}{l}\text { 25. I would never agree to donate my medical information to anyone because I worry about } \\
\text { potential misuse of the information. }\end{array}$ & 1 & 2 & 3 & 4 & 5 & \\
\hline $\begin{array}{l}\text { 26. I support the idea of medical information donation when the information is used in a way } \\
\text { that benefits society. }\end{array}$ & 1 & 2 & 3 & 4 & 5 & \\
\hline $\begin{array}{l}\text { 27. I worry about insurance companies getting access to medical information because they } \\
\text { may not use information in a way that benefits society. }\end{array}$ & 1 & 2 & 3 & 4 & 5 & \\
\hline $\begin{array}{l}\text { 28. Using medical information for the 'common good' is OK but I worry about the risk to a } \\
\text { person's privacy. }\end{array}$ & 1 & 2 & 3 & 4 & 5 & \\
\hline $\begin{array}{l}\text { 29. I should be able to see my medical information and it should be easy to correct any } \\
\text { mistakes in the information. }\end{array}$ & 1 & 2 & 3 & 4 & 5 & \\
\hline $\begin{array}{l}\text { 30. A legal judge in Australia decided that the notes written about a patient, by a Doctor, are } \\
\text { owned by the Doctor not the patient. This decision seems reasonable to me. }\end{array}$ & 1 & 2 & 3 & 4 & 5 & \\
\hline
\end{tabular}

Optional questions about you. Please turn over to write any additional comments you have regarding the use of your medical information.

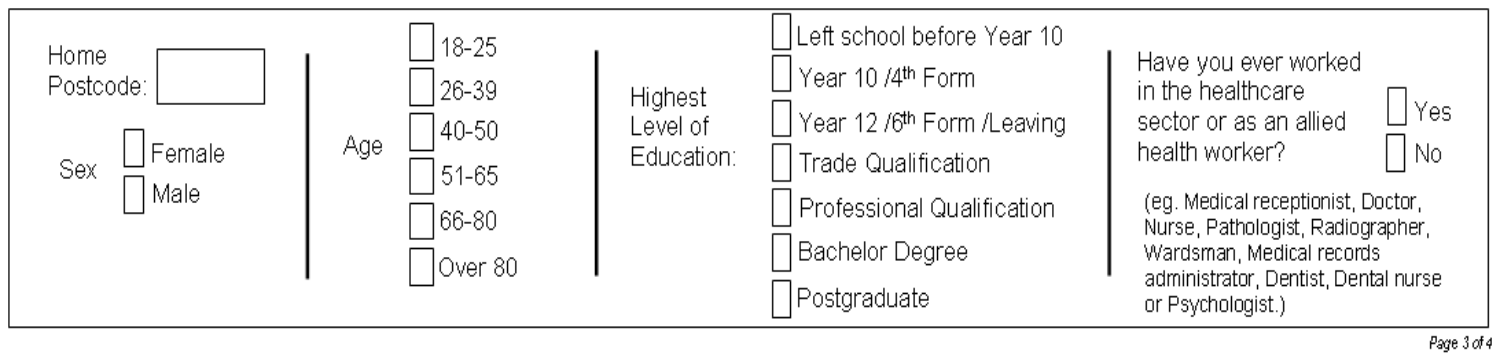

Figure 15: Page 3 of the Australian final survey

A potential issue regarding the choice of a five point Likert scale is that central tendency bias may lead to consumers avoiding the extreme response categories with a tendency to select the central 'neutral' response. A four point scale could have been used to force a choice upon the respondent. This was not adopted as a 'neutral' response is reasonable when the consumer does not have an opinion as positive or negative. This outcome is as informative as a positive or negative response, hence the five point scale. The 'Don't know' item is also informative as with no background explanatory information provided it is possible that respondents will be faced with statements where they 'Don't know' how to respond. A scale with both positively and negatively keyed comments helps to overcome acquiescence bias and, where possible, a variety of statements have been included in this survey.

Moor and Tavani's Restricted Access/Limited Control (RALC) theory informed the construct of many of the attitudinal questions. 'Concept' of privacy, 'justification' of privacy and 'management' of privacy are the broad RALC notions explored through 
survey component 1 . There are also statements exploring consumer response to the landmark Breen V Williams outcomes and to Magnusson's Trans-Organisational Concept (2002; 2004).

\subsubsection{Component 2: Open ended questions}

Open ended questions are used in Component 2. The first open ended prompt used was "Do you have any concerns regarding the collection and re-use of medical data?" and the second question was "Other Comments?" A full A4 page was allocated to capturing responses to these open ended questions. Some respondents filled the entire page with their hand written responses and others chose not to provide any comments.

The purpose of including Component 2 was to offer respondents an opportunity to enrich their quantitative responses to Component 1 with narrative descriptions and elucidation of their opinions.

Component 3: Optional demographics

Component 3 provided an opportunity for respondents to provide demographic characteristics. This component appeared in the survey at the end of Component 1 and prior to the start of Component 2, as illustrated in Figure 16. Capturing this data enabled stratified analysis of both the qualitative and quantitative survey data.

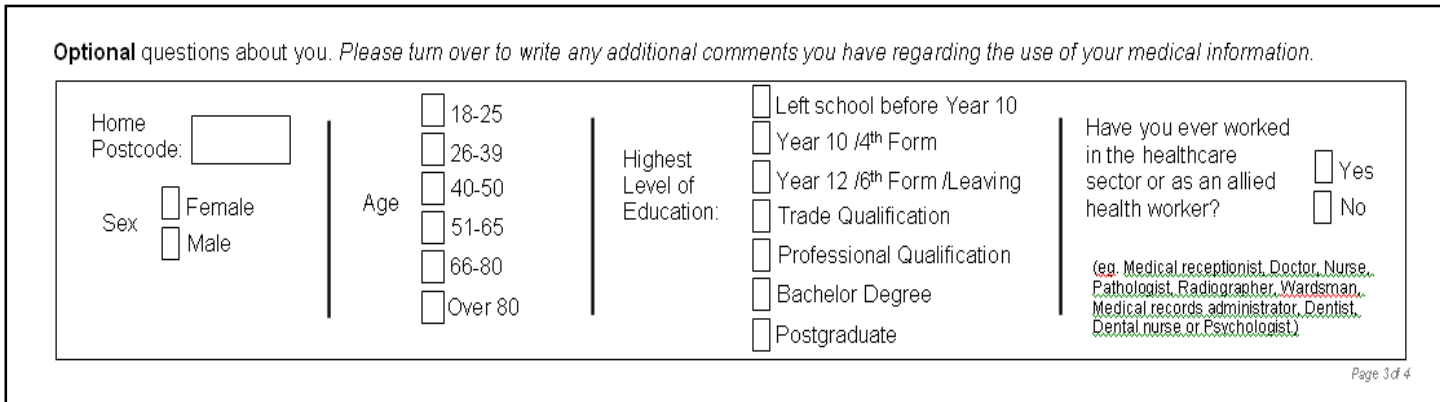

Figure 16: Survey Component 3

Respondents were asked to self identify if they had ever worked in the healthcare sector. This is a very broad classification and future research could benefit from a more rigorous approach to classifying employment categories of health workers. Healthcare workers are well educated in terms of traditional restricted access approaches to privacy and this training and experience is likely to bias their opinions 
as expressed in their responses to the survey. As described in the Literature Review, healthcare workers have a particular view of secondary use of medical data and the inclusion of this demographic should enable comparison of healthcare workers against general population.

\subsubsection{The Final Survey Procedure}

This section of the chapter describes the procedures followed in developing and deploying the surveys in Australia and Canada. The results of the surveys and analysis of results are presented in Chapters 4, 5 and 6. One of the biggest practical challenges of this research was establishing valid address lists. The same approach could not be used in both Australia and Canada due to different postal arrangements, and citizens' directory information from Australia Post and Canada Post also varied.

\section{Australia}

Three approaches were taken to create the list of valid residential addresses for the pilot and final surveys.

1. Residential blocks were selected and the survey package envelopes were preaddressed with all details except the property number. The research team walked down the selected streets and added the accurate property numbers, such as Unit 4A or 1/200 to the pre-addressed envelopes. Simultaneously the accurate property numbers were recorded on a running sheet to complete the details for each mapped residential block. These areas included some Melbourne suburbs, Sydney suburbs, areas within the Illawarra and Southern Highlands and Darwin. This approach was used for all Australian pilot surveys.

2. Google maps streetview tool was used to identify (where possible) the accurate street numbers for targeted survey streets. The survey packages were prepared - including the Google maps streetview house number - and delivered by Australia Post. This approach enabled the conduct of the survey in areas well beyond the research teams such as Perth, Hobart, Benalla, Adelaide and Alice Springs. 
3. If the research team could elicit help in gathering accurate street numbers in areas of interest for this survey then colleagues visiting the targeted areas would gather accurate address details - pass these on to the research team and survey packages would be despatched. These areas included parts of Darwin, Brisbane, Perth, Adelaide and Melbourne.

4. The Telstra White Pages telephone directory was also used to assist in finding accurate street addresses. This approach was used for geographic areas that were small and well defined by their suburb name to enable development of mailing lists that were restricted to a few residential blocks, for example Fern Tree Gully in Victoria and Stanwell Park in New South Wales.

The second approach was the most inaccurate and resulted in the highest rate of returned mail. Once the surveys had been distributed, the Australia Post prepaid envelopes, included in the survey packs, were used to return all mail to the researcher.

To ensure the broadest possible engagement with the community, the sample populations included low, medium and high socio-economic status areas in urban, regional and remote areas. There was diversity amongst the nature of the dwellings including: single residential dwellings, high rise blocks of units, rural properties, and duplex dwellings. Any property displaying a 'no junk mail' sign was omitted from the study.

\section{Canada}

In Canada most residential properties, particularly those in new areas, do not have post boxes out the front of houses. There are consolidated post boxes at the end of streets and the only entity authorised to put anything into the boxes is Canada Post. Junk mail is not a problem for Canadian households. This restriction caused some challenges for this study as the intention was to keep the cost of the pilot studies as low as possible by having the research team deliver the survey packages to letterboxes. 
Two approaches were taken to create the list of valid residential addresses for the pilot and final surveys.

1. A small number of residential areas near the University of Ontario Institute of Technology (UOIT) in Oshawa, Ontario, were selected for the Canadian pilot study. The research team walked the streets compiling a list of valid residential addresses. The research packages were prepared and despatched via Canada Post.

2. The internet based telephone directory used in Canada (whitepages 2011) offers functionality called 'address \& neighbours' and this tool was used to develop valid street addresses across Canada. By entering a street name and location the white pages directory retrieves and displays a large number of residential properties located on the selected street. Figure 17 illustrates the details returned by entering the name of the street that UOIT is located on Simcoe Street North, Oshawa, Ontario. Names have been obscured on this image.

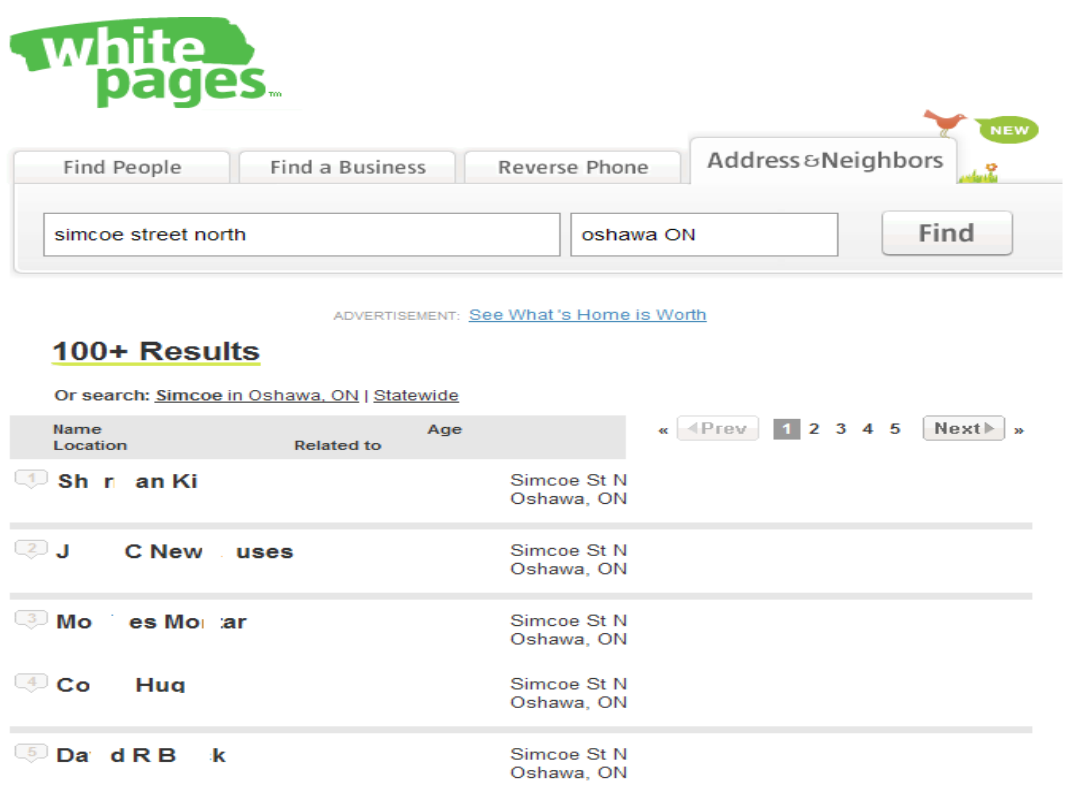

Figure 17: Canada Whitepages address \& neighbours 
By selecting a particular returned individual address the website displays the entire, accurate address for properties located on the chosen street; as illustrated in Figure 18. Part of the name and telephone number have been obscured in this image, however such privacy provisions do not normally apply when using this publically available tool. Survey packages were prepared and despatched 'To The Resident' at the addresses obtained from the white pages website.

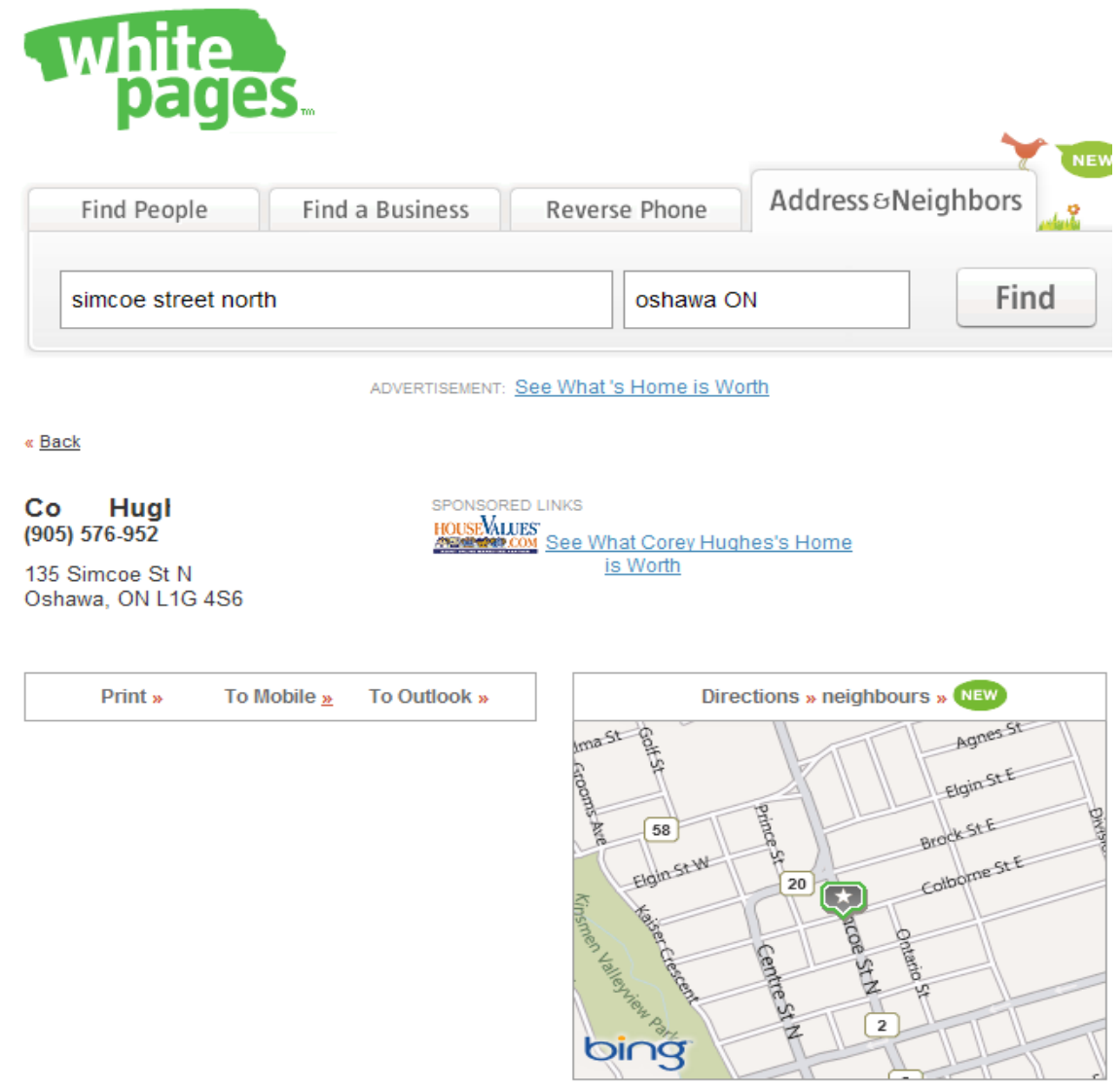

Figure 18: Accurate residential address

Thus it was possible for the researcher located in Wollongong, Australia to construct accurate mailing lists for use in this study. Every Province across Canada - except the French speaking Province of Quebec, had a sample population included in the final survey. 
Australia

Surveys were despatched to every State and Territory in Australia. The survey sampling strategy made use of the Australian Institute of Health and Welfare recommended Australian Standard Geographic Classification (ASGC) Remoteness Areas (RA) to target diverse populations (Australian Institute of Health and Welfare 2012). The ASGC RA uses five categories: major cities, inner regional, outer regional, remote and very remote. Figure 19 illustrates the locations included in the Australian survey.

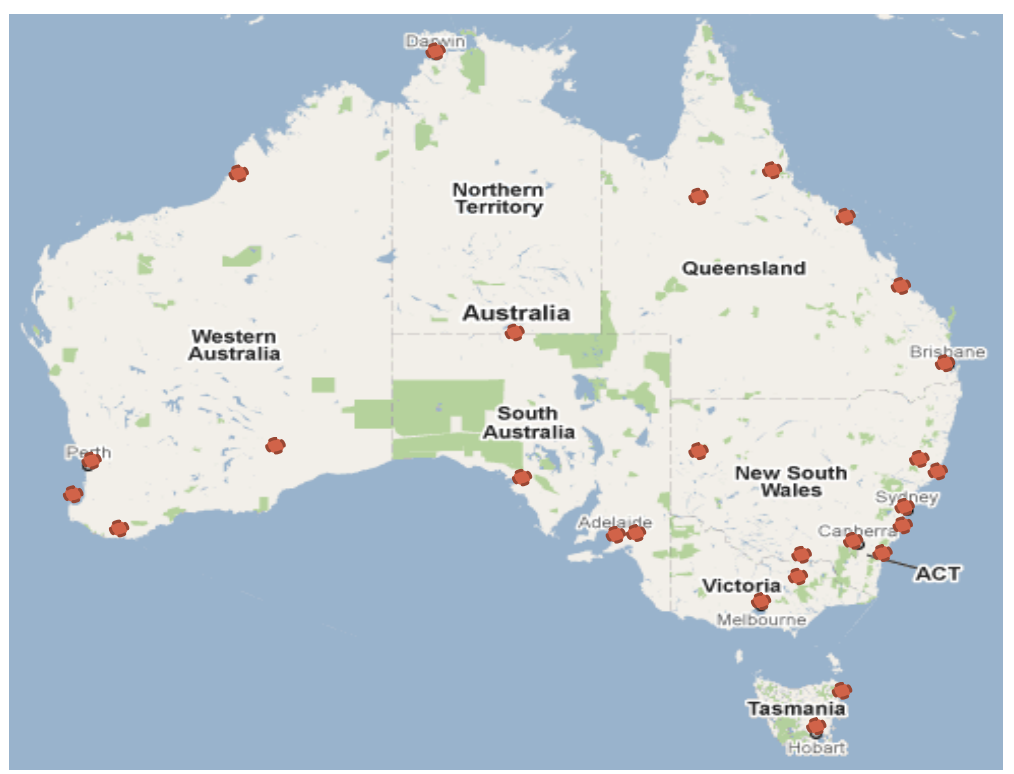

Figure 19: Sample populations in Australia

Canada

In Canada surveys were despatched to diverse populations in every English speaking Province, except Nunavut. Figure 20 illustrates the sample sites included in the Canadian survey.

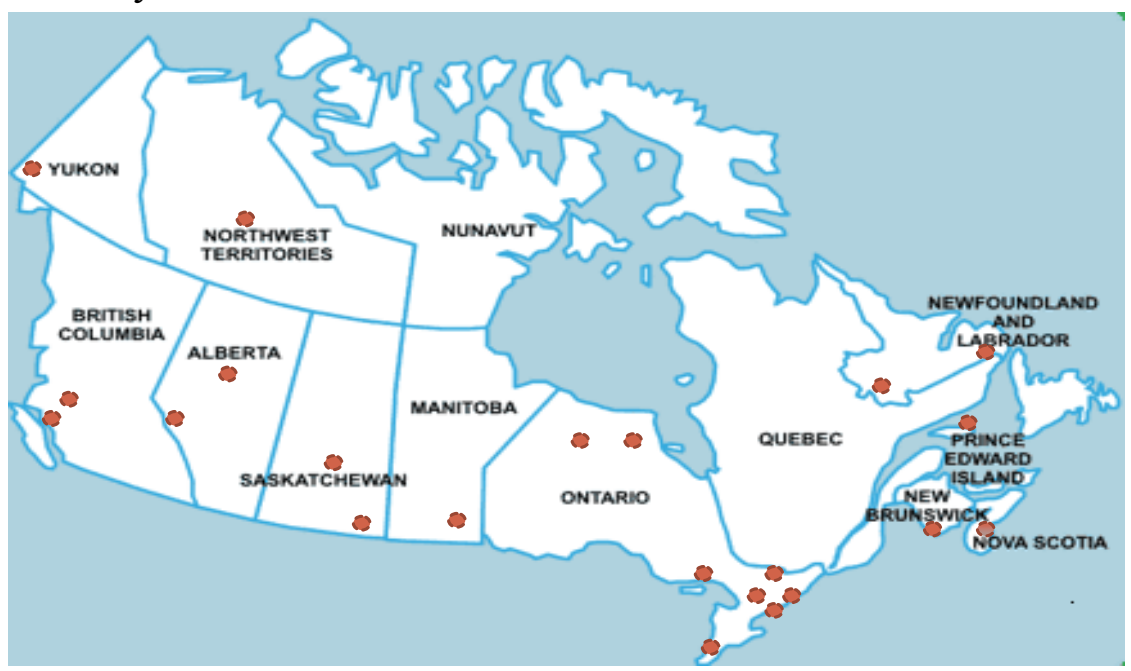

Figure 20: Sample populations in Canada 


\subsection{Managing and Analysing the Survey Data}

The ordinal data (quantitative) gathered via the public opinion survey was collected at the same time as the collection of the open ended (qualitative) question responses, thus being concurrent. The respondent responses to the statements were, as previously described, captured on a Likert scale. These ordinal measurements were represented using numerical values to denote the ordering information. These only reflect the ranking order and no inference is made regarding the distances between adjacent values as emphasised by Svensson (2001), Powers and Xie (2000). In total 1,573 pilot and final surveys were returned, Table 13 presents a summary of the surveys.

Table 13: Pilot and final survey summary

\begin{tabular}{|l|r|r|r|r|}
\hline \multicolumn{1}{|c|}{ Survey } & \multicolumn{1}{|c|}{$\begin{array}{c}\text { Number } \\
\text { returned } \\
\text { surveys }\end{array}$} & $\begin{array}{c}\text { Number of } \\
\text { surveys } \\
\text { despatched }\end{array}$ & $\begin{array}{c}\text { Number of } \\
\text { surveys that } \\
\text { could not be } \\
\text { delivered }\end{array}$ & $\begin{array}{c}\text { Response Rate } \\
\%\end{array}$ \\
\hline Pilot - Australia & 168 & 482 & 0 & 34.8 \\
\hline Pilot - Canada & 44 & 250 & 46 & 17.6 \\
\hline Final - Australia & 1158 & 5173 & 267 & 12.8 \\
\hline Final - Canada & 203 & 1640 & 376 & \\
\hline TOTAL & 1573 & 7545 & 63 & \\
\hline
\end{tabular}

The quantitative and qualitative pilot study survey data was captured using a custom-built MSAccess database with data entered manually. There were four datasets in total that were stored in four separate databases: (1) Australian pilot (2) Australian final (3) Canadian pilot (4) Canadian final. The structure of the databases was identical for each dataset. Validation at the point of data entry was applied to the fields in the tables to ensure only valid, clean data was captured. Figure 21 depicts the table structure for the table within the database that held the survey data. 


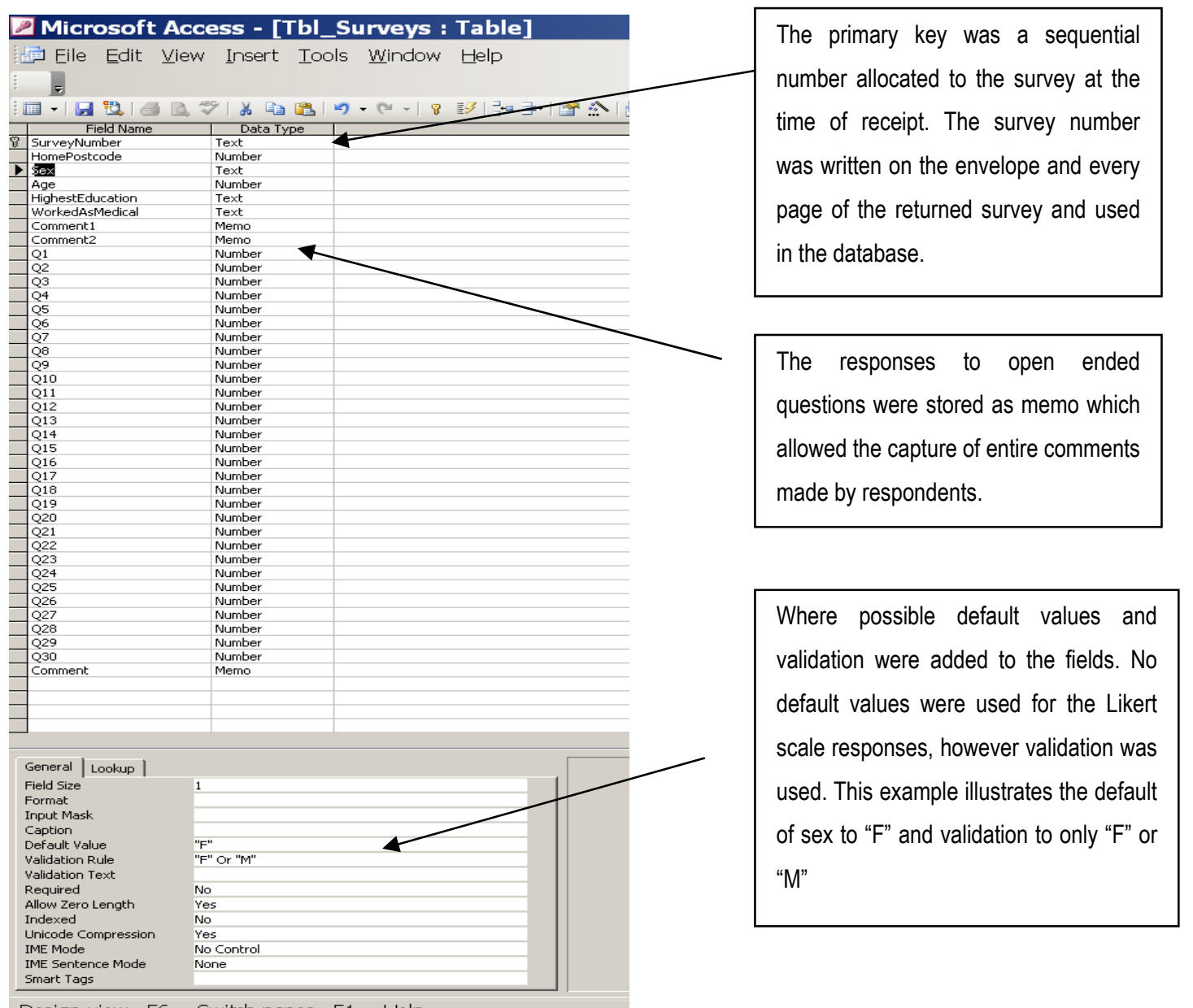

Figure 21: Structure of Survey table in custom database

Statistical analysis was undertaken using SPSS 17.0 and all the data, apart from qualitative comments, were exported from the MSAccess database to SPSS. The SPSS Package supported the analysis of the survey data as the demographics of respondents were available with the Likert scale responses to enable statistical evaluation. The non-parametric Chi-Square, Mann Whitney U-test and Cronbach Alpha tests were heavily relied upon for this study and Chapters 4, 5 and 6 present the results of these tests with many statistically significant results emerging.

The Pearson Chi-Square $\left(x^{2}\right)$ test was used to evaluate relationships between two categorical variables. The Pearson Chi-Square test is widely used when analysing non numeric variables such as the Likert scale attitudinal responses gathered through the consumer surveys used in this study. This non parametric test was used to 
investigate statistically significant relationships between two categorical variables to address the null hypothesis stated at the start of this chapter. The statistically significant results are included in the next section. The test results included in this section are those where results fall below the commonly used significance level of 0.05 . The larger the $\chi^{2}$ value the more likely the variables are related. There can be small or large differences between the number of times a Likert response is expected and the actual number of times the respondents chose the Likert response. The matrix type layout of test results in this chapter is intended to clearly show both the expected number of Likert responses and the actual number of responses in each category. The cells in the matrix that contribute the most to the Chi-Square result are those where the expected and actual counts are very different. The $d f$ parameter is the degrees-offreedom which is calculated for each matrix as:

$$
\mathrm{df}=(\text { number of rows }-1) \times \text { (number of columns }-1)
$$

The Chi-Square values and the df value are used together to determine the significance level of the test result. The observed versus expected counts have been included to provide insight into the nature of the relationship, however the Pearson Chi-Square test does not allow any conclusions beyond identifying where a relationship exists between the consumers' demographics and the response to survey statements.

The custom-built MSAccess database continued to provide support for the qualitative analysis. Hardcopy coding sheets were used by the qualitative researchers as described more fully below. Once the coding sheet sets had been completed the encoding data was added to the MSAccess database as a separate table for each qualitative researchers coding. The survey number and thematic code were recorded and a concatenated key created from the joining of these data items, as illustrated in Figure 22.

\begin{tabular}{l|l|l|l|}
\hline & SurveyNumber & QualCode & \multicolumn{1}{c|}{ concatkey } \\
\hline 1002 & $1 \mathrm{~B}$ & $10021 \mathrm{~B}$ \\
\hline 1002 & $2 \mathrm{~A}$ & $10022 \mathrm{~A}$ \\
\hline 1002 & $2 \mathrm{~B}$ & $10022 \mathrm{~B}$ \\
\hline 1002 & $3 \mathrm{E}$ & $10023 \mathrm{E}$ \\
\hline 1002 & $3 \mathrm{H}$ & $10023 \mathrm{H}$ \\
\hline
\end{tabular}

Figure 22: Creation of concatenated key 
Once all researchers coding had been identified by the concatenated key an SQL query was created to capture differences between the researcher's encoding, as illustrated in Figure 23.

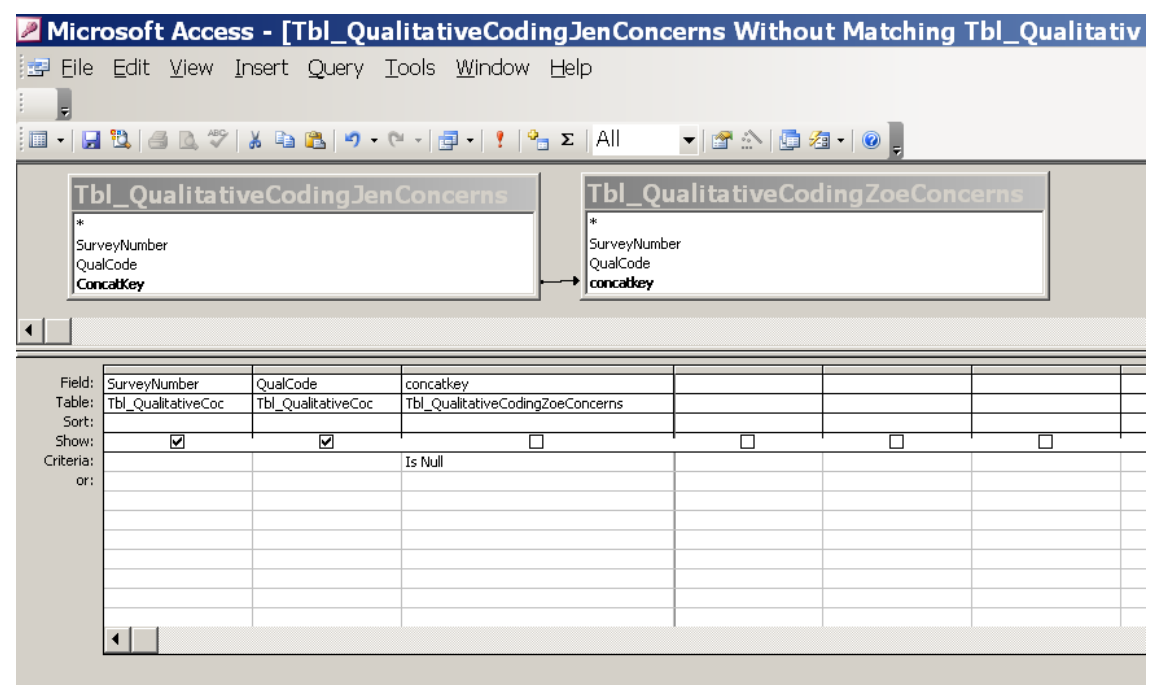

Figure 23: MSAccess database supporting qualitative analysis

The results of this query were combined with the full text of the consumer's response. This report formed the basis of discussions between the qualitative encoders regarding differences in encoding and assisted the process towards building consensus. This data management mechanism assisted in developing the systematic approach to qualitative analysis (Spencer, Ritchie et al. 2003) and reduced 'data overload' (Miles and Huberman 1994). The demographics of consumer respondents were withheld from qualitative researchers in an attempt to keep them from being influenced by factors beyond the consumer comments.

The design, capture and analysis of the qualitative aspects of this study were influenced by the earlier work of Miles and Huberman (1994). The qualitative data was stored in the same custom-built relational database that held the Likert scale data. Themes identified in the literature review, and relevant to the research questions driving this study, were organised into a hierarchical structure within the tripartite privacy model. Miles and Huberman's earlier work on deductive data analysis using a priori themes based on the literature review findings influenced this aspect of the research design. Table 14 presents the thematic classification scheme that was used in a deductive manner during the analysis of the qualitative data. 
Table 14: Deductive themes used for qualitative analysis

\begin{tabular}{|c|c|c|c|c|}
\hline Code & & $\begin{array}{l}\text { Sub } \\
\text { Code }\end{array}$ & Theme & Related Source \\
\hline \multirow[t]{5}{*}{1} & Concept & A & Expressing anxiety & (Nehf 2003), (Nissenbaum 2010) \\
\hline & & B & Not anxious about secondary use of data & (Barrett, Cassell et al. 2006) \\
\hline & & C & Consumer TRUST - Don't know who has information - Lack of transparency & $\begin{array}{l}\text { (Woodward 1995; Fraser 2003; Nehf 2003; Croll and Morarji 2006; } \\
\text { Sutcliffe 2006; Schneider, Kerwin et al. 2009; Tarini, Goldenberg } \\
\text { et al. 2010) }\end{array}$ \\
\hline & & $\mathrm{D}$ & Not everyone who has access has patients' best interests at heart & (Magnusson 2004; Fernando 2009; Clarke 2010) \\
\hline & & $\mathrm{E}$ & Surveillance & (Magnusson 2004; Clarke 2010) \\
\hline \multirow[t]{4}{*}{2} & Justification & A & 'Right' to privacy & (Warren and Brandeis 1890) \\
\hline & & B & $\begin{array}{l}\text { Responsibility of citizens to participate in secondary use. Individual rights } \\
\text { versus 'common good' }\end{array}$ & $\begin{array}{l}\text { (Melton 1997; Walton, Doll et al. 1999; Lowrance 2003; Whiddett, } \\
\text { Hunter et al. 2007; Zeps, lacopetta et al. 2007; Willison, Emerson } \\
\text { et al. 2008; Dyer 2009; Rodwin 2009; Townend 2010; Buckley, } \\
\text { Murphy et al. 2011) }\end{array}$ \\
\hline & & C & Personal data as a commercial commodity; Commercial aspects of data use & $\begin{array}{l}\text { (Rindfleish 1997; Rodwin 2009; Rosenbaum 2010; Townend } \\
\text { 2010) }\end{array}$ \\
\hline & & $\mathrm{D}$ & Ownership of data & (Magnusson and Opie 1998; Rodwin 2009) \\
\hline \multirow[t]{5}{*}{3} & Management & A & $\begin{array}{l}\text { Good data stewardship required and consumers need confidence in } \\
\text { arrangements underpinning secondary use }\end{array}$ & (Fraser 2003; Rosenbaum 2010) \\
\hline & & B & Consumers as research partners not research subjects & $\begin{array}{l}\text { (Whiddett, Hunter et al. 2007; Ruyter, Louk et al. 2010; Townend } \\
\text { 2010; Trinidad, Fullerton et al. 2011) }\end{array}$ \\
\hline & & C & Consumer control of data issues & (Tavani and Moor 2001) \\
\hline & & $\mathrm{D}$ & Restricted access to consumer data issues & (Tavani and Moor 2001) \\
\hline & & $\mathrm{E}$ & De-identification of data & $\begin{array}{l}\text { (Lowrance 1997; Lowrance 2002; Lowrance 2003; O'Keefe 2008; } \\
\text { Willison, Steeves et al. 2009; O'Keefe and Connolly 2010) }\end{array}$ \\
\hline
\end{tabular}




\begin{tabular}{|c|c|c|c|c|}
\hline & & $\mathrm{F}$ & Consent & $\begin{array}{l}\text { (Woolf, Rothemich et al. 2000; Willison, Keshavjee et al. 2003; } \\
\text { Singleton and Wadsworth 2006; Willison, Schwartz et al. 2007; } \\
\text { Beskow and Dean 2008; Willison, Steeves et al. 2009; Elger, } \\
\text { Lavindrasana et al. 2010) }\end{array}$ \\
\hline & & G & Payment for use of data & (PricewaterhouseCoopers 2009; Rosenbaum 2010) \\
\hline & & $\mathrm{H}$ & Legal system to protect consumers & $\begin{array}{l}\text { (Warren and Brandeis 1890; Magnusson 2002; Magnusson 2004; } \\
\text { Australian Law Reform Commission 2008) }\end{array}$ \\
\hline & & I & $\begin{array}{l}\text { Consumers to provide input on data stewardship - including being able to } \\
\text { decline to participate }\end{array}$ & (Sadan 2000; Trinidad, Fullerton et al. 2011) \\
\hline & & $\mathrm{J}$ & Role of Government & (Magnusson 2004) \\
\hline & & K & $\begin{array}{l}\text { Secondary use mechanisms: Human Research Ethics Committees; computer } \\
\text { technology }\end{array}$ & (Croll and Croll 2006) \\
\hline & & $\mathrm{L}$ & Comments in support of secondary use & \\
\hline & & M & $\begin{array}{l}\text { Comments about sensitivity of different types of information eg. Sexual health, } \\
\text { mental health }\end{array}$ & $\begin{array}{l}\text { (Tavani and Moor 2001; Willison, Steeves et al. 2009; } \\
\text { Nissenbaum 2010) }\end{array}$ \\
\hline & & $\mathrm{N}$ & $\begin{array}{l}\text { Comments about the purpose of data use e.g. OK for research but not OK for } \\
\text { commercial secondary use }\end{array}$ & (Nissenbaum 2010) \\
\hline \multirow[t]{2}{*}{4} & Survey design & A & Positive & \\
\hline & & B & Negative & \\
\hline \multirow[t]{2}{*}{5} & $\begin{array}{l}\text { Recounting } \\
\text { health industry } \\
\text { experiences }\end{array}$ & A & Positive & \\
\hline & & B & Negative & \\
\hline
\end{tabular}


Where appropriate, Table 14 also includes the literature sources informing the themes. Any emergent themes were noted and further discussed amongst the qualitative researchers. They are presented in Chapter 4 and in Chapter 6.

Analysis of the larger final surveys was undertaken by two Australian researchers. As outlined with the pilot study, this study has relied on process and triangulation for establishment of validity of the qualitative data as suggested by Byrne (2002, p. 152). Miles and Huberman's (1994) work on intercoder agreement in qualitative research informed the design of qualitative aspects of this study. The suggested measure is depicted in Figure 24.

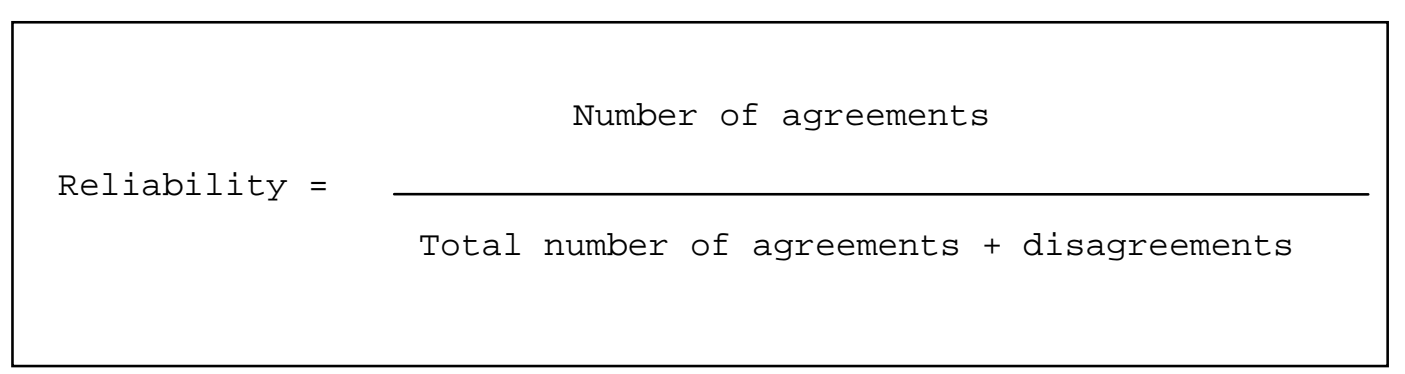

Figure 24: Reliability calculation

This reliability measure was used iteratively during the evaluation of each qualitative researchers coding of the consumers responses. Miles and Huberman's estimate of intercoder agreement in the $90 \%$ range was the target for reliability adopted in this study.

The interwoven processes of data reduction, data display and conclusion drawing/verification formed the basis of qualitative 'analysis' in this study (Miles and Huberman 1994). The main focus and aims of the qualitative data analysis revolved around content analysis of the two open ended questions included in the public opinion survey. Themes were identified with a focus on the way the theme was treated and the frequency of occurrence. The analysis was then linked to demographic variables such as gender, level of education and self reported experience working in healthcare sector. 
The focus of analysis here is not on the language itself. Narrative analysis was considered as a suitable approach for this research but was rejected as the majority of respondents did not write in a manner that developed narrative structures as described by Kohler Riessman (2002).

The focus of analysis is on content where attempts are made to capture and interpret the substantive meanings in the data as described by Spencer, Ritchie and O'Connor (2003). A common system of categories has been applied largely informed by existing knowledge. As Spencer, Ritchie et al. suggest:

This approach is felt to offer a systematic overview of the scope of the data; to aid finding themes or examples that do not appear in an orderly way in the data; to aid locating conceptual, analytical categories in the data; and to help getting a handle on the data for making comparisons or connections connections (Spencer, Ritchie et al. 2003).

As Miles and Huberman (1994) indicate 'naming and classifying' is insufficient and this study attempts to understand the patterns within the qualitative data within the tripartite privacy framework proposed by Moor and Tanavi (Tavani and Moor 2001). These results and further analysis are presented in Chapters 4,5 and 6 .

No in vivo coding was conducted - the coding template came from the informing theory and literature. Each of the qualitative researchers received two sets of hardcopy encoding sheets - one set including consumer responses to the question 'Do you have any concerns regarding data re-use' and the other encoding sheets for responses to the prompt 'Other Comments'. A sample encoding sheet is included in Appendix D. The layout of the encoding sheets was intended to support the qualitative researchers in the evaluation of consumer comments. The full text of the consumer response, preformatted boxes for recording thematic codes and space to allow further brief comments were combined on the form. The concise presentation of the qualitative codes on a single A4 page enabled quick look-up without the need to flick through multiple pages (Miles and Huberman 1994, p. 52). 
By presenting the entire text of the consumer comment it was possible to gain insight into the consumer's response without causing fragmentation of the text which can lead to poor analysis results. As Miles and Huberman caution "Words are fatter than numbers and usually have multiple meanings" (1994, p. 52), therefore the surrounding text is important in understanding consumers meaning. Multiple themes can be found in each consumer comment. The next three pages present the qualitative components provided by consumers on Australian surveys numbered 889,602 and 423 . These have been included to illustrate the effort that consumers directed towards their qualitative responses. The majority of consumers left survey Component 2 open ended questions blank. Some wrote brief comments, and as the examples here illustrate in Figure 25, Figure 26 and Figure 27, some respondents took full advantage of the opportunity to express their opinion. 
Do you have any concerns regarding the collection and re-use of medical data?

- lack of control over vito geins access.

- unetriod practies evolving by staff who have occers such as zitselliog" fine informotion, kickbacks from information seekers/dany componies

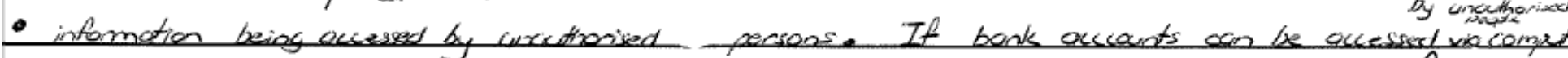

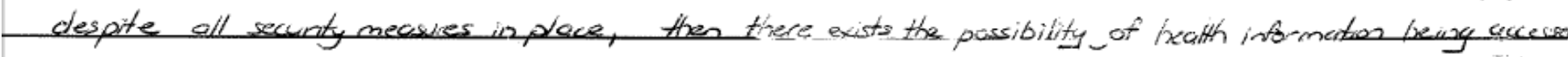
- a personi has a wight to totel poivacy of their weath information.

Other Comments?

My age, life experienes educction, t emplaument in the becuth walustry couse ine to be vary

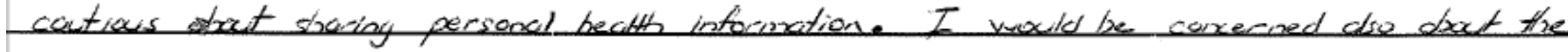
agendes of druy companier being wrovided with scets infornation.

I would not teust any Gevenument to wake decisions abot who con we my beath intormestion.

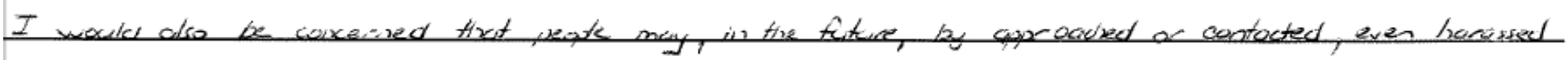

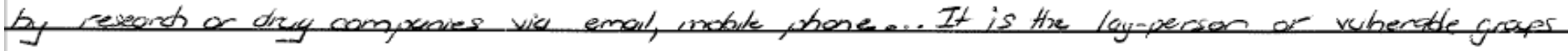

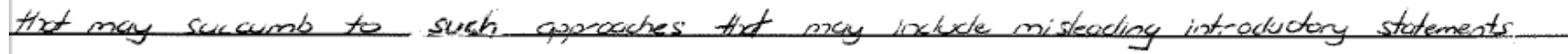
and 'boiting' consuners, - le pacties not calles Telemanting componies.

\section{Thank you for helping with this research.}

Figure 25: Survey 889, Component 2 open ended questions 
Do you have any concerns regarding the collection and re-use of medical data?

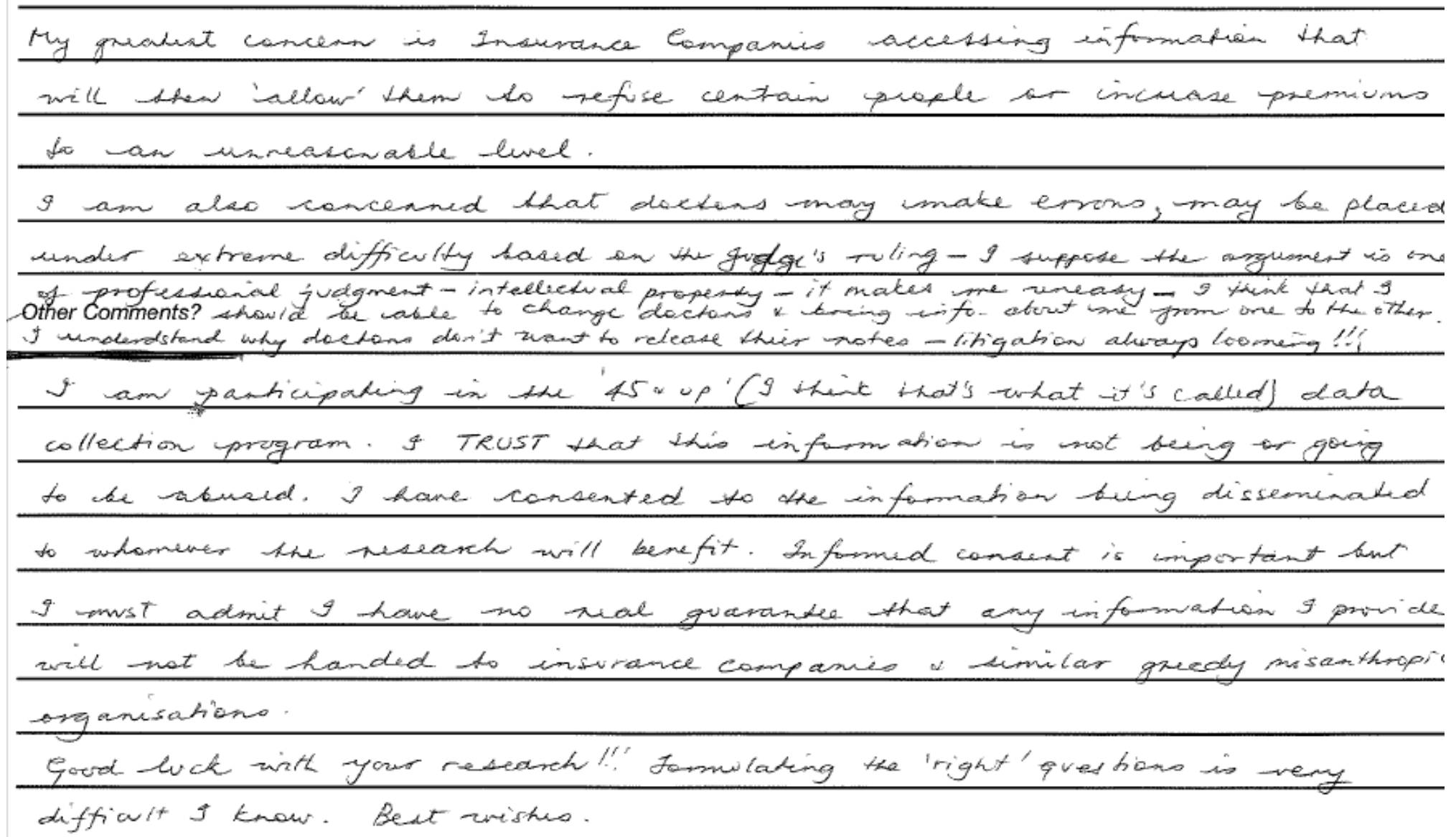

Thank you for helping with this research.

Figure 26: Survey 423, Component 2 open ended questions 
Do you have any concerns regarding the collection and re-use of medical data?

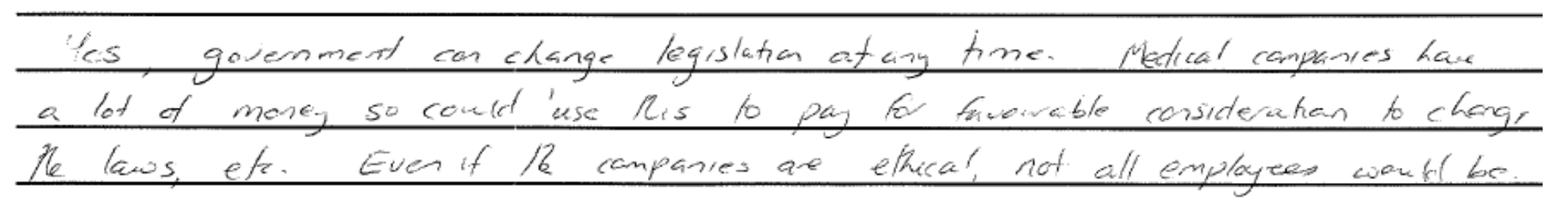

Other Comments?

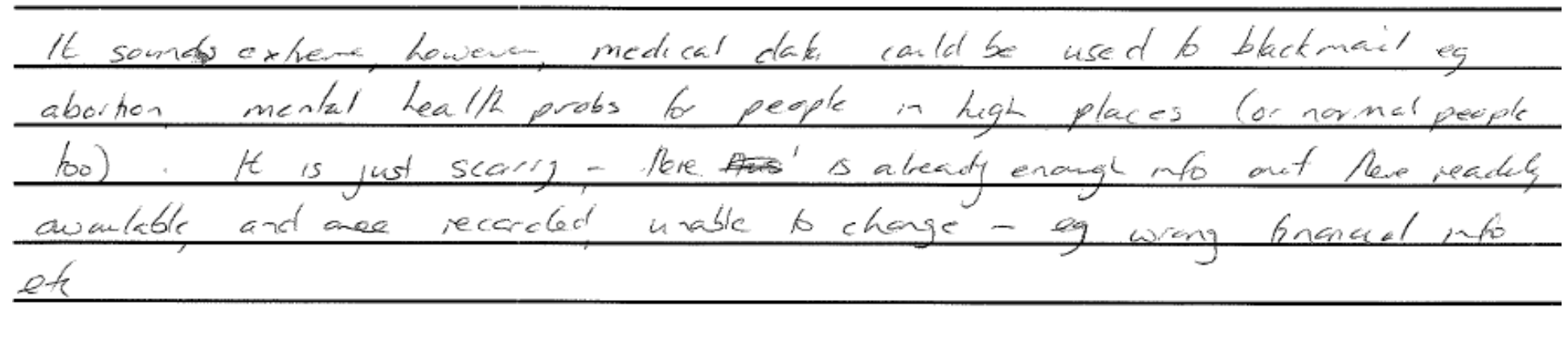

\section{Thank you for helping with this research.}

Figure 27: Survey 602, Component 2 open ended questions 


\title{
3.6.1 Integrated Analysis
}

Fusing Quantitative and Qualitative Data

The concerns raised by Bryman (2007) regarding the lack of genuine integration of qualitative and quantitative data in mixed methods studies is acknowledged. This study addresses these concerns by: (1) deliberately fusing the quantitative and qualitative data and (2) through the organisation and structure of thesis chapters.

The quantitative and qualitative data is presented in Chapters 4, 5 and 6 in an integrated manner similar to that proposed by Creswell (2009; Creswell and Plano Clark 2011). In keeping with the recommendations of Creswell:

\begin{abstract}
In a concurrent study, the quantitative and qualitative data collection may be presented in separate sections, but the analysis and interpretation combines the two forms of data to seek convergence or similarities amongst the results. (Creswell 2009, p. 220)
\end{abstract}

The fusing of quantitative and qualitative data in this study is assisted by the fact that the quantitative and qualitative aspects address the same research questions. This aspect of the research design goes someway to answering Bryman's (2006) concerns about many mixed methods studies having multiple sets of questions where some are addressed by quantitative and other questions are addressed by qualitative components. This thesis describes a genuinely fused mixed methods design. Interpretation of the qualitative and quantitative public opinion survey data considered the extent to which the datasets triangulate and converge. As Hanson et al. (2005) and Bryman (2006) suggest this mixed method design is useful in confirming, cross-validating and corroborating earlier public opinion survey findings. Inclusion of multiple data sources and methods contributes data triangulation and method triangulation. 


\subsection{Australian and Canadian Consumer Survey Comparison}

The same questions and formatting were used for the larger Australian and Canadian surveys that followed the pilot surveys. Validity of inter-survey comparisons was aided by keeping the questions and formatting the same for both countries.

A null hypothesis was formulated to guide the comparison between the two independent groups i.e. Canada and Australia:

$\mathrm{H}_{0}$ : There is no significant difference between Canadian and Australian consumer opinion as expressed through responses to the public opinion survey used in this study where $p<=0.05$.

The non parametric Mann-Whitney $U$ test was used to investigate the differences between the Canadian and Australian survey results. This test was chosen as it is suitable for the ordinal data gathered with the Likert scale where no assumptions are made about normal distribution. Canada was coded as country ' 1 ' and Australia country '2' within SPSS 17.0 as illustrated in Figure 28.

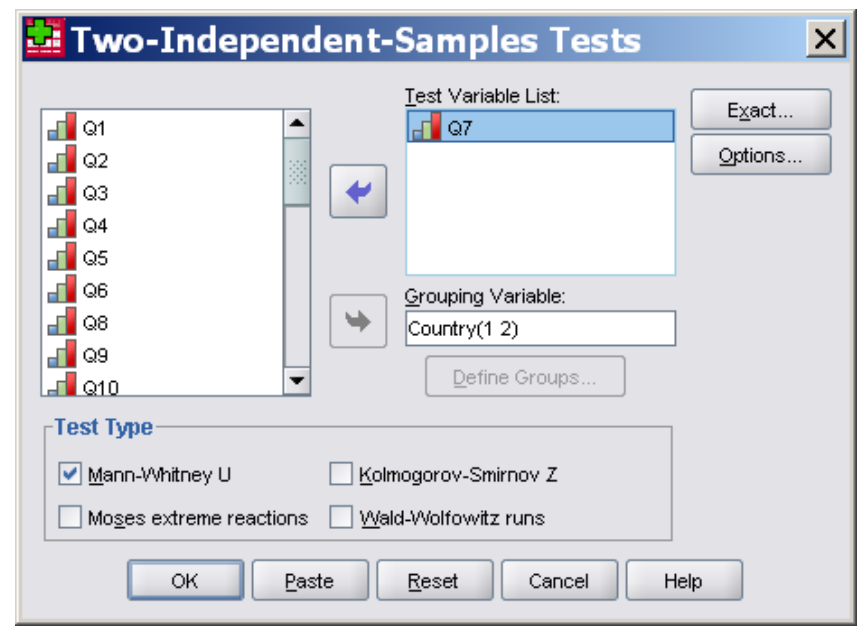

Figure 28: Mann-Whitney U test SPSS 17.0 dialogue box

This test is also suitable because it is not necessary to have the same number of samples in each independent group. The results of the comparison are presented in Chapter 6. 


\subsection{Conclusion}

This Chapter described the overall exploratory research design and articulated the research questions and assumptions from the literature. Epistemology and methodology were considered with justification for the approaches used in this study. The influence of Bryman (2006; 2007), Creswell (2009) and Plano Clark (Plano Clark and Creswell 2008; Creswell and Plano Clark 2011) in choice of mixed methods and Miles and Huberman (1994) on qualitative methods is apparent in the research design. The public opinion survey instrument was introduced and the design decisions taken regarding the instrument were considered against the framework provided by Bourque and Fielder (2003).

The pilot and final surveys were described. In total, 1,573 consumers contributed their opinion regarding secondary use of medical data, particularly pertaining to privacy matters, through the surveys. These survey responses were organised around 'concept', 'justification' and 'management' of privacy (Tavani and Moor 2001). The understanding of consumer views is an integral part of the early stages of the system development life cycle where the problem definition and requirements are specified. Usually it is the proponents of information systems who dictate the problem to be solved and system requirements. The use of the consumer surveys has enabled this study to capture public opinion for use in developing a conceptual model, including consumer expectations of privacy, which may inform future physical implementations of information systems in the healthcare sector and beyond.

As foreshadowed, the results of deployment and fusing of mixed method findings and conclusions are presented in following Chapters. 


\section{AUSTRALIAN CONSUMER PUBLIC OPINION SURVEY RESULTS}

\subsection{Introduction}

The Research Methodology Chapter described the journey from literature review to pilot survey development, focus group testing, deployment, analysis of results and improvement of the instrument, leading to the final survey instrument which was also described.

A null hypothesis was formulated to investigate the diversity of opinion expressed by different groups of consumers:

$\mathrm{H}_{0}$ : There is no significant difference between groups of consumers as expressed through responses to the public opinion survey used in this study where $p<=0.05$.

This chapter presents the survey respondent demographics and descriptive statistics, consideration of instrument internal reliability, frequency response statistics for every opinion statement and non-parametric quantitative test results, and qualitative results.

The next chapter includes more detailed discussion and analysis of the results.

\subsection{Background}

The survey was deployed into the Australian community as the national EHR is under development and perhaps coming to the attention of consumers through media reports. The secondary use of medical data context is rife with contradictions and vexing questions that arise from the pace of technological development and adoption by many stakeholders.

\subsubsection{Descriptive Statistics}

A total of 1,158 of the final Australian surveys were returned. The majority of respondents were female. This was not unexpected as Aora and McHorney (2000) previously reported that women want to participate in medical related decision making. 


\begin{tabular}{|r|r|r|}
\hline Gender & $\begin{array}{c}\text { Frequency } \\
(n)\end{array}$ & $\begin{array}{r}\text { \% of } \\
\text { Total }\end{array}$ \\
\hline Female & 759 & 66 \\
\hline Male & 369 & 32 \\
\hline Unknown & 30 & 2 \\
\hline TOTAL & 1158 & \\
\hline
\end{tabular}

\section{Gender}

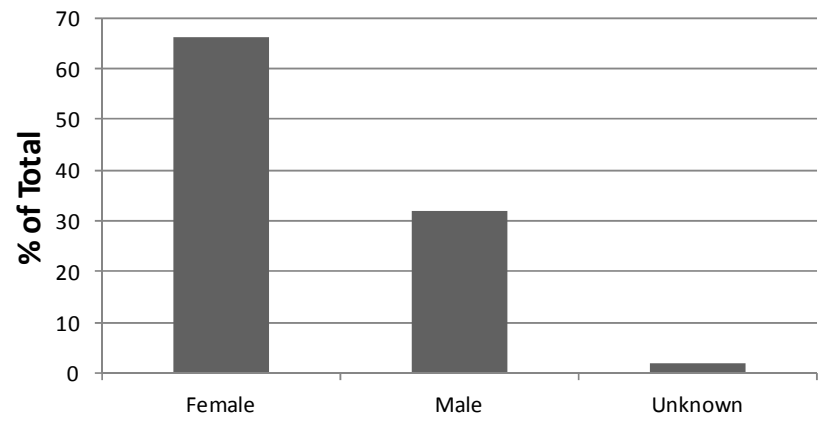

Figure 29: Australian respondent demographics, gender

Women also are more active in seeking healthcare and questioning of clinicians during visits (Nathanson 1977; Mechanic 1978). Figure 29 illustrates the percentage of respondents by gender.

\begin{tabular}{|r|r|r|}
\hline \multicolumn{1}{|c|}{ Age } & $\begin{array}{r}\text { Frequency } \\
(n)\end{array}$ & $\begin{array}{r}\text { \% of } \\
\text { Total }\end{array}$ \\
\hline $18-25$ & 32 & 3 \\
\hline $26-39$ & 149 & 13 \\
\hline $40-50$ & 259 & 23 \\
\hline $51-65$ & 424 & 37 \\
\hline $66-80$ & 214 & 19 \\
\hline Over 80 & 45 & 4 \\
\hline Unknown & 35 & 3 \\
\hline TOTAL & 1158 & \\
\hline & & \\
\hline
\end{tabular}

\section{Age}

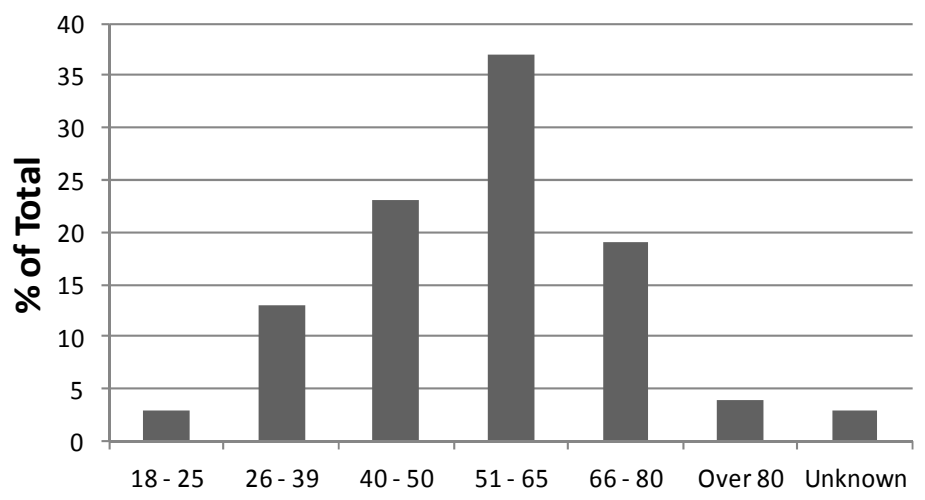

Figure 30: Australian respondent demographics, age

The majority of respondents provided the optional demographics and the largest age group to respond were respondents aged 51-65 years. It was pleasing to have 45 octogenarians respond to the survey; however, the number of responses from the 
youngest age group, 18-25, was disappointing. It is possible that social media and online surveys may be a better method to engage with this age group.

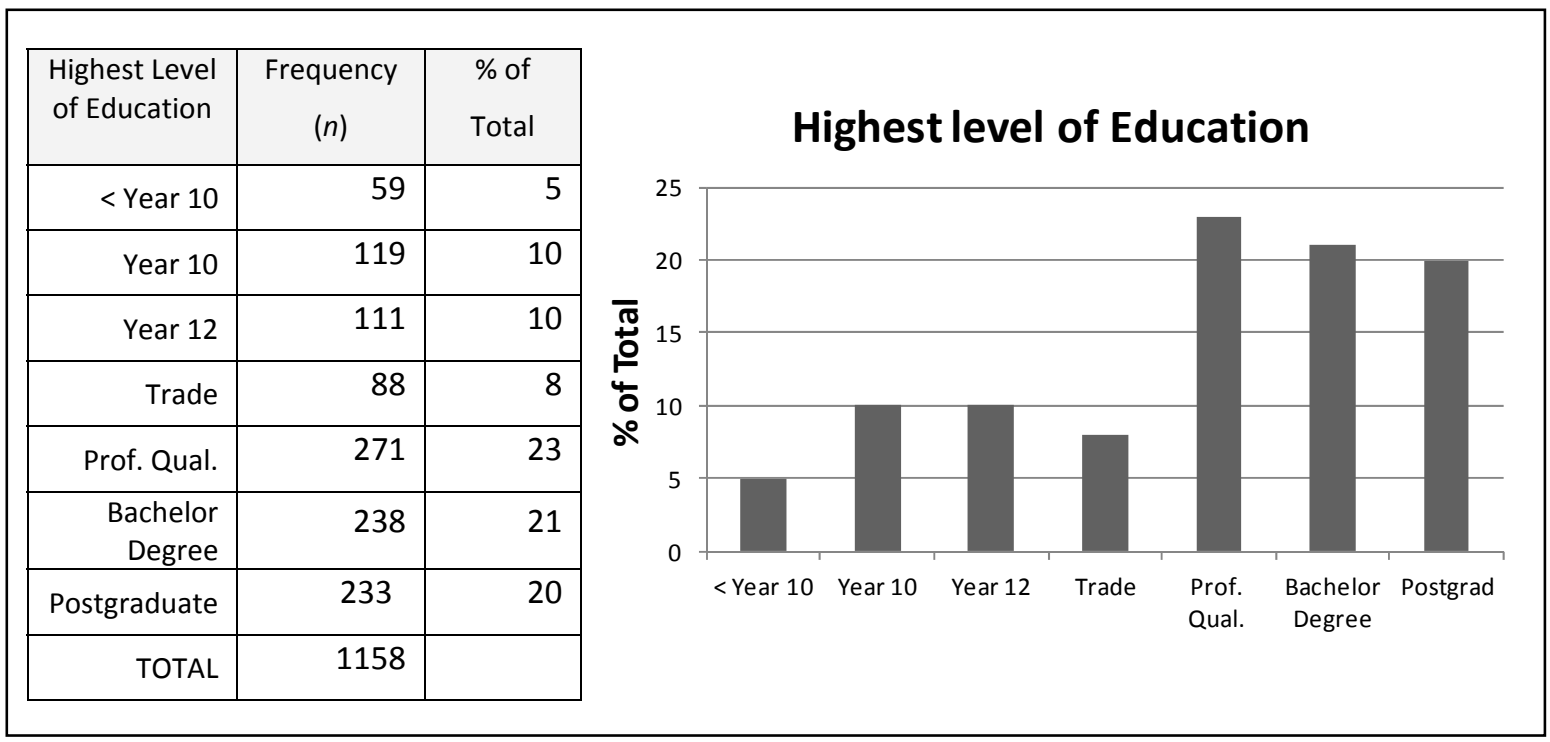

Figure 31: Australian respondent demographics, highest level of education

The majority (64\%) of respondents self-reported as holding professional or higher levels of education. In addition to dominating the quantitative survey responses this well educated group also provided the majority of qualitative comments (see Table 15). It was, however, pleasing to have 135 comments from respondents with trade and high school level education as the 'voice' of these respondents is that of the majority of the Australian community. This Chapter and the next two Chapters reveal statistically significant results across the highest level of respondent education which has implications for the management of privacy in the secondary use of medical data context.

Table 15: Frequency of open-ended comments by highest level of education

\begin{tabular}{|l|r|r|r|r|}
\hline $\begin{array}{c}\text { Highest Level of } \\
\text { Education }\end{array}$ & $\begin{array}{c}\text { Frequency of } \\
\text { Comment 1 }\end{array}$ & $\begin{array}{c}\text { \% of Total Number } \\
\text { of Comment 1 }\end{array}$ & $\begin{array}{l}\text { Frequency of } \\
\text { Comment 2 }\end{array}$ & $\begin{array}{c}\text { \% of Total } \\
\text { Number of } \\
\text { Comment 2 }\end{array}$ \\
\hline Post Grad & 84 & 25 & 47 & 24 \\
\hline Bachelor & 73 & 22 & 41 & 21 \\
\hline Professional & 77 & 23 & 57 & 5 \\
\hline Trade & 16 & 5 & 9 & 9 \\
\hline Year 12 & 34 & 10 & 17 & 6 \\
\hline Year 10 & 28 & 4 & 11 & 4 \\
\hline$<$ Year 10 & 13 & 4 & 7 & 197 \\
\hline
\end{tabular}


Respondents were invited to self-report if they had ever worked in the healthcare sector including the allied health sector. This is an important demographic as it provides an opportunity to look at a segment of the population who are often responsible for consumer (patient) privacy in both the delivery of healthcare and the secondary use of data. There are statistically significant differences in opinion between this group of respondents and the non- healthcare workers in terms of the 'concept' of privacy and the 'management' of privacy as described in this and following chapters.

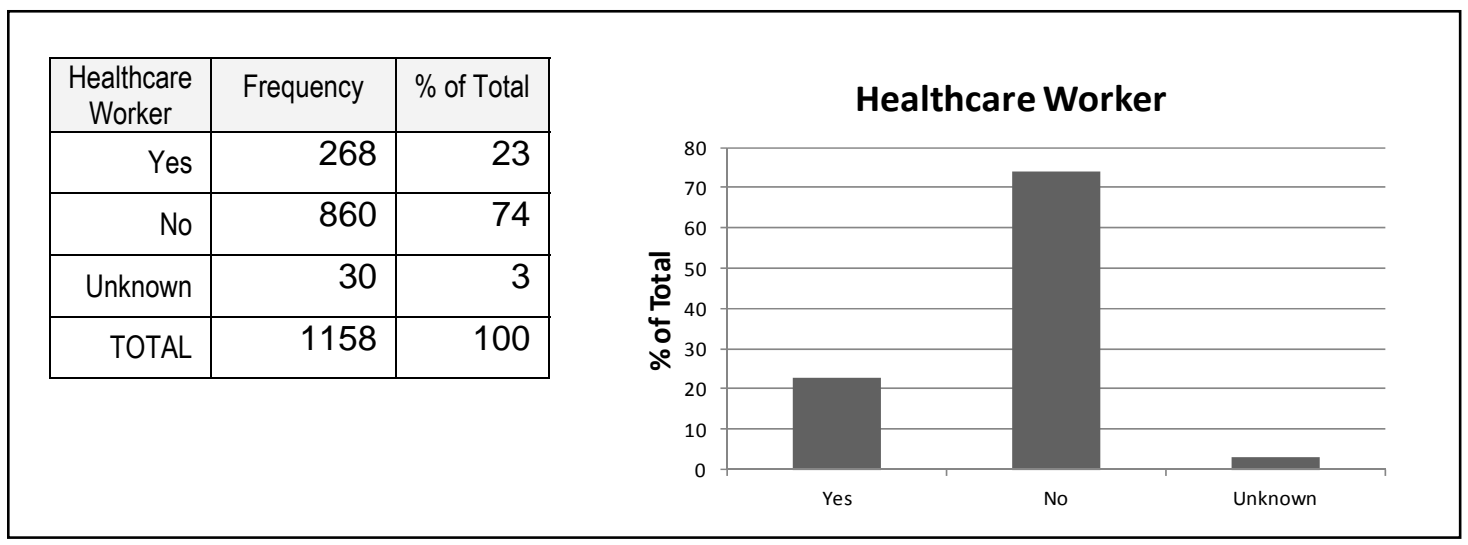

Figure 32: Australian respondent demographics, health sector worker

The Research Methodology chapter discussed the importance of determining internal reliability for the final surveys and Table 16 presents the results of internal reliability evaluations. All but one of the constructs falls above the threshold for this study i.e. $>0.60$. The Justification - balance construct, does not meet the expected threshold hence caution is required when analysing this construct. The comments made by citizens in response to the two open ended questions may provide some insight on this 'getting the balance right' issue.

Table 16: Reliability of scales

\begin{tabular}{|l|l|l|l|l|}
\hline $\begin{array}{l}\text { Tripartite } \\
\text { Component }\end{array}$ & Construct & Code & $\begin{array}{l}\text { Cronbach Alpha } \\
(\boldsymbol{\alpha})\end{array}$ & $\begin{array}{l}\text { Number of } \\
\text { items }\end{array}$ \\
\hline Concept & Anxiety & C-A & 0.691 & 6 \\
\hline & Limited Access & C-LA & 0.602 & 2 \\
\hline Justification & Rights based & J-RB & 0.644 & 3 \\
\hline & Balance & J-B & 0.159 & 3 \\
\hline Management & Control & M-C & 0.715 & 11 \\
\hline & Data Stewardship & M-DS & 0.617 & 5 \\
\hline
\end{tabular}




\subsubsection{Response Frequency}

This section presents the survey response frequencies in tabular and graphical format. The survey results are not presented in the order of appearance on the survey instrument but are rather grouped by the tripartite component to which they belong i.e. the 'concept' of privacy, 'justification' of privacy or 'management' of privacy. The table includes the statement number, text of the statement used in the survey, tabular presentation of response frequency, and percentage of valid responses.

Missing responses are included in the tabular results but are not represented in the bar charts. 'Don't know' was a response category on the Likert scale and such responses are presented on the bar charts. Table 17 presents the survey data that related to the concept of privacy with a focus on consumer anxiety and the medical community concept of privacy as being limited access as described in the literature review.

Analysis and discussion of these response frequencies is presented in the next Chapter. 
Table 17: Privacy tripartite component - concept of privacy, survey response frequency.

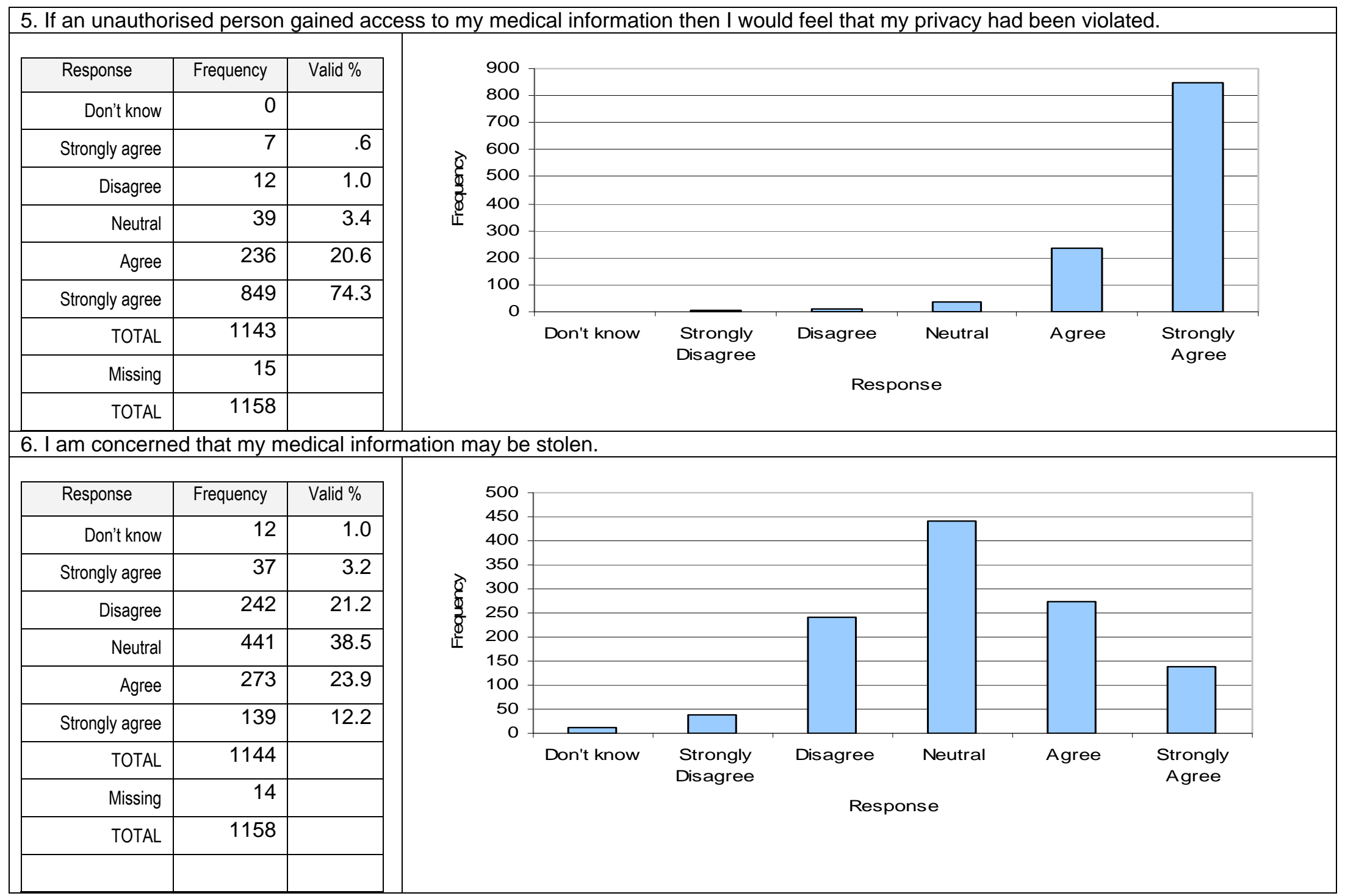




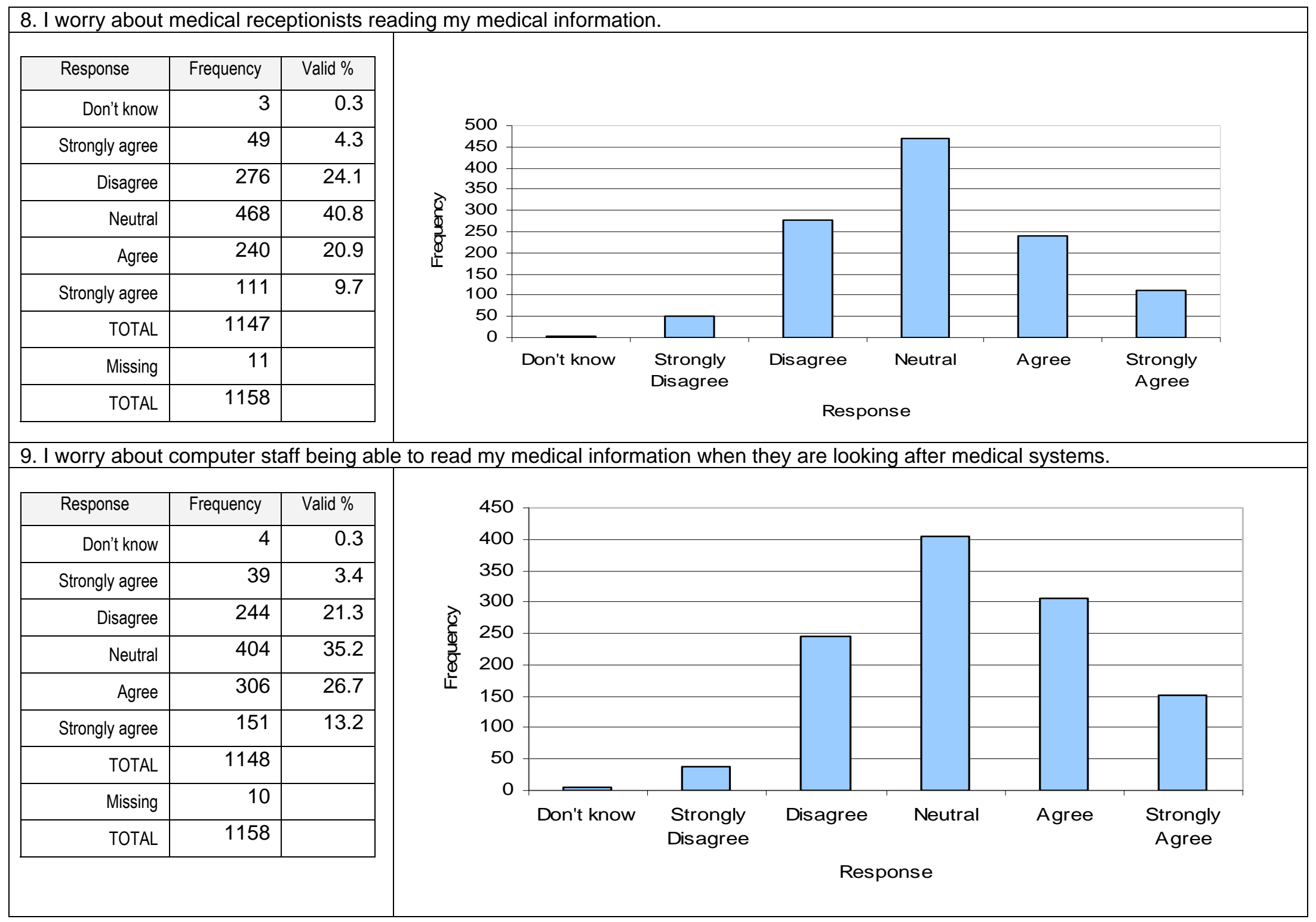




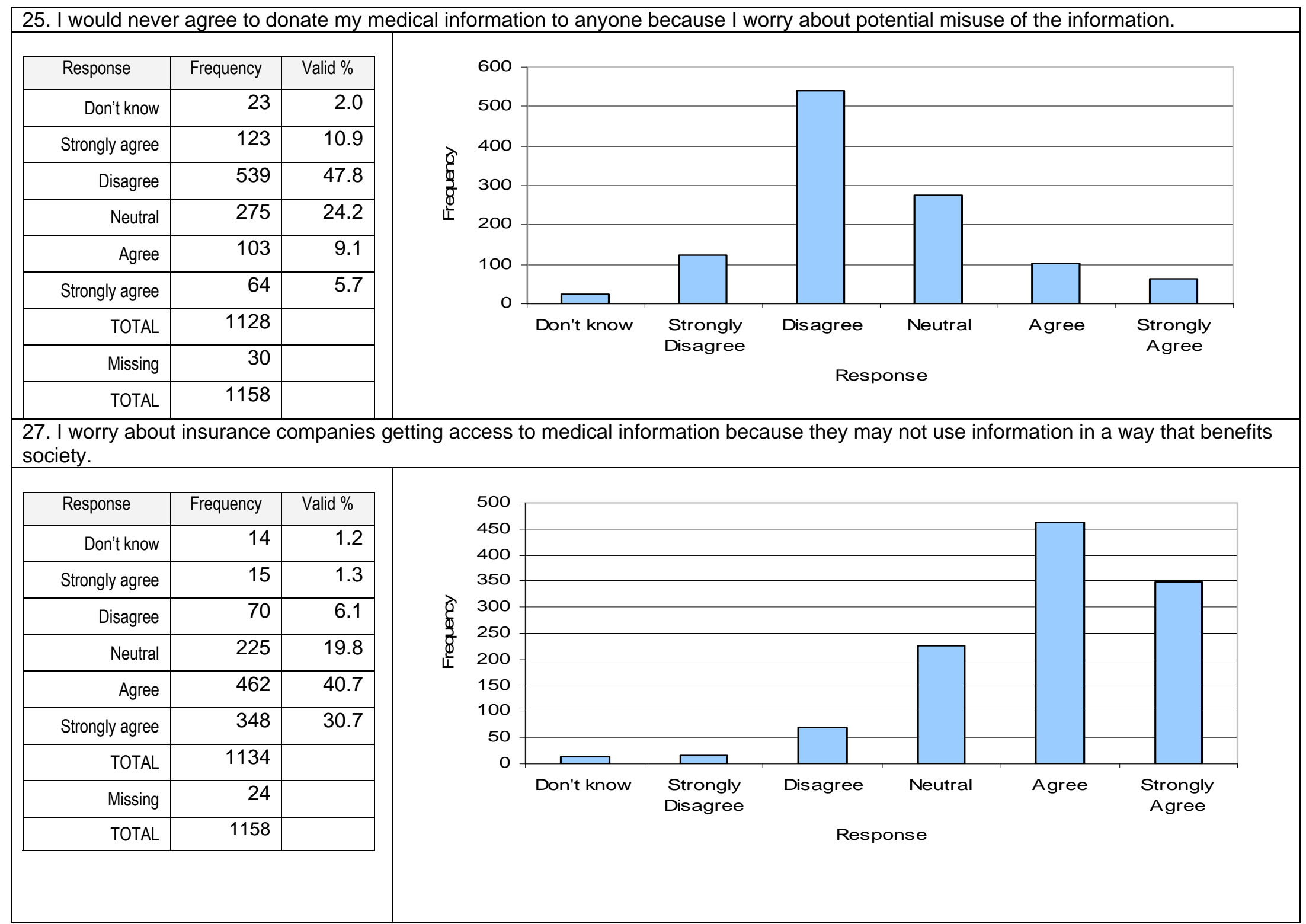




\begin{tabular}{|c|c|c|}
\hline Response & Frequency & Valid \% \\
\hline Don't know & 225 & 19.8 \\
\hline Strongly agree & 8 & 0.7 \\
\hline Disagree & 33 & 2.9 \\
\hline Neutral & 231 & 20.3 \\
\hline Agree & 518 & 45.5 \\
\hline Strongly agree & 124 & 10.9 \\
\hline TOTAL & 1139 & \\
\hline Missing & 19 & \\
\hline TOTAL & 1158 & \\
\hline
\end{tabular}

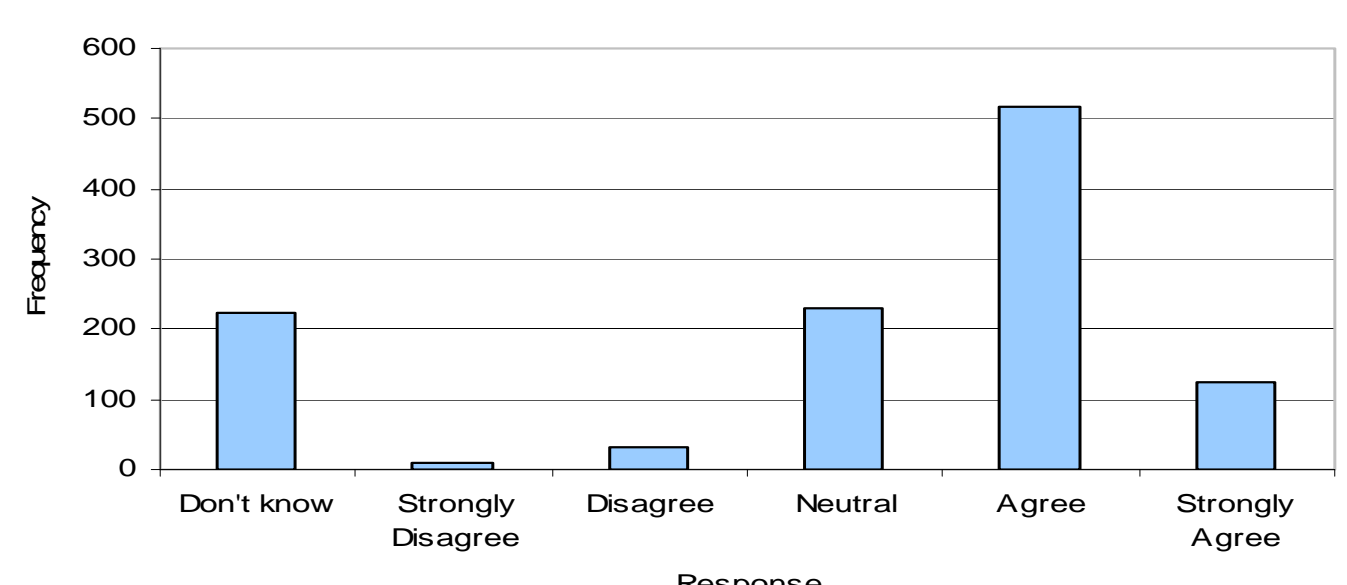

11. It seems that my healthcare providers feel that the fewer people who see my medical information the higher the level of privacy they have provided for me.

\begin{tabular}{|r|r|r|}
\hline \multicolumn{1}{|c|}{ Response } & Frequency & \multicolumn{1}{c|}{ Valid \% } \\
\hline Don't know & 223 & 19.7 \\
\hline Strongly agree & 4 & 0.3 \\
\hline Disagree & 45 & 3.9 \\
\hline Neutral & 289 & 25.6 \\
\hline Agree & 463 & 41 \\
\hline Strongly agree & 103 & 9.1 \\
\hline TOTAL & 1127 & \\
\hline Missing & 31 & \\
\hline TOTAL & 1158 & \\
\hline
\end{tabular}

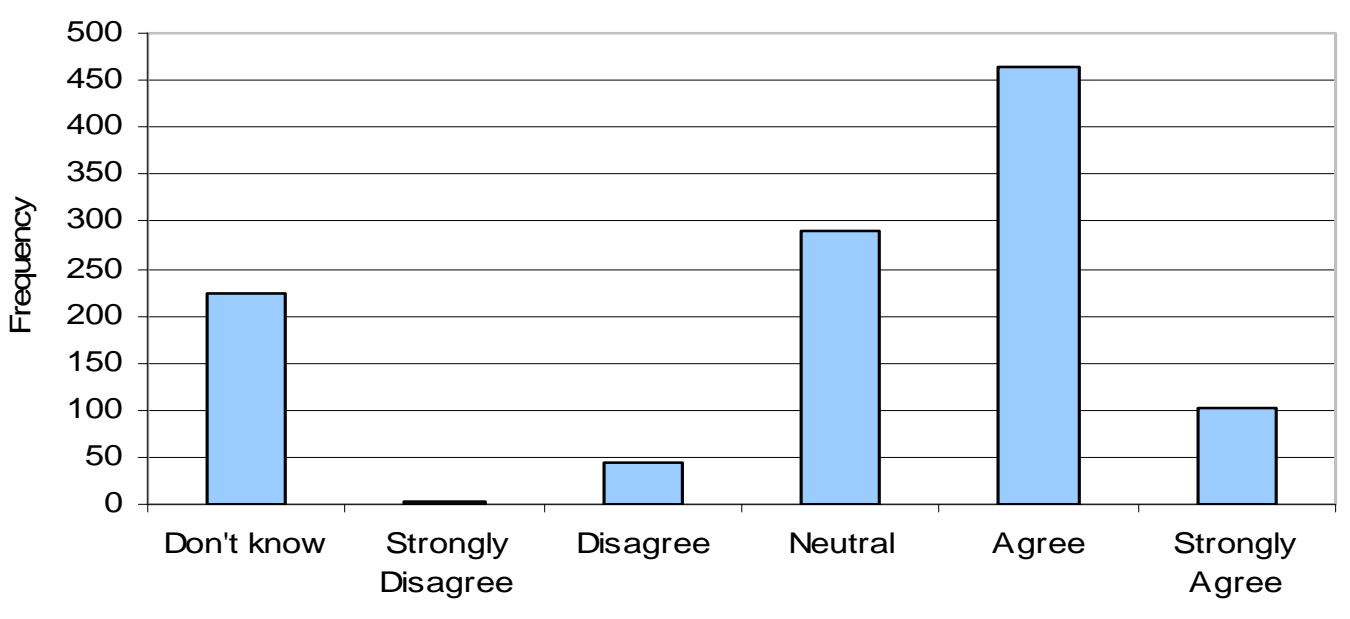

Response 
Table 18 presents response frequencies for statements that contribute to the second tripartite component, justification of privacy. These statements explore the consumers opinion regarding 'rights' based justifications for privacy and the balancing 'common good' against individual rights.

Table 18: Privacy tripartite component - justification of privacy, survey response frequency

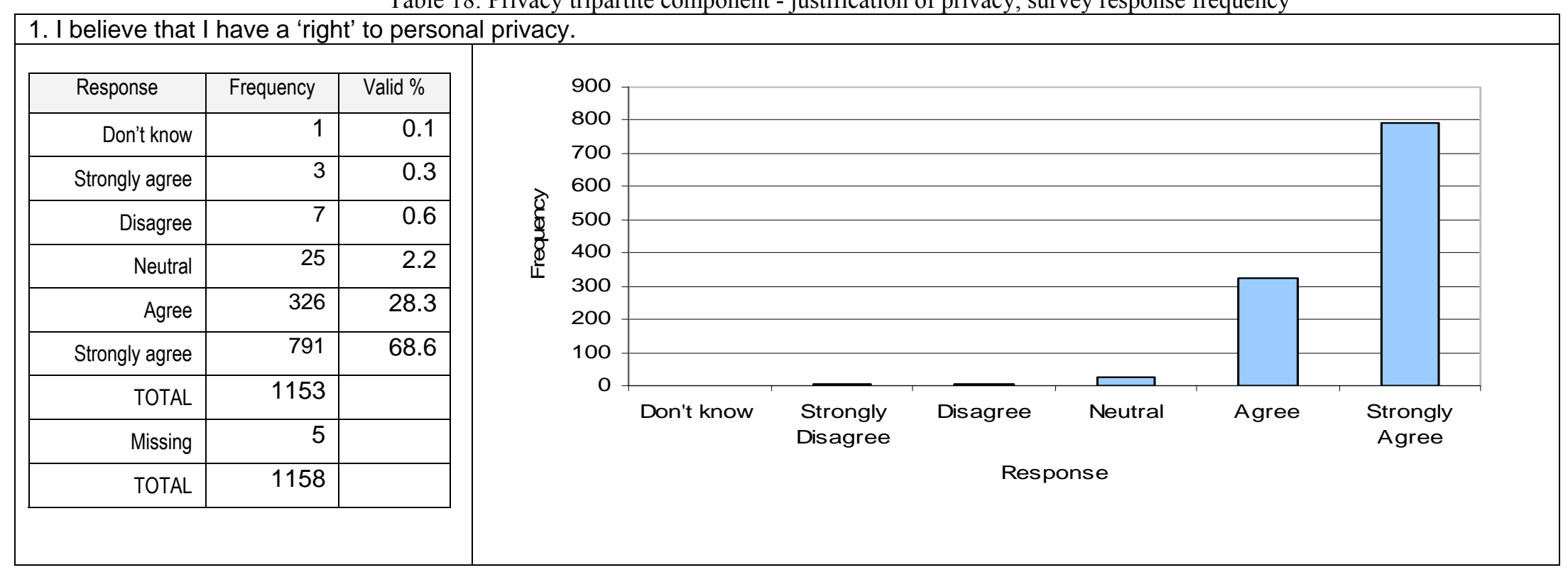


3. I have the 'right' to share my medical information with others.

\begin{tabular}{|r|r|r|}
\hline \multicolumn{1}{|c|}{ Response } & Frequency & \multicolumn{1}{c|}{ Valid \% } \\
\hline Don't know & 6 & 0.5 \\
\hline Strongly agree & 16 & 1.4 \\
\hline Disagree & 15 & 1.3 \\
\hline Neutral & 39 & 3.4 \\
\hline Agree & 509 & 44.5 \\
\hline Strongly agree & 558 & 48.8 \\
\hline TOTAL & 1143 & \\
\hline Missing & 15 & \\
\hline TOTAL & 1158 & \\
\hline 4. expect Australian laws and healthere gur
\end{tabular}

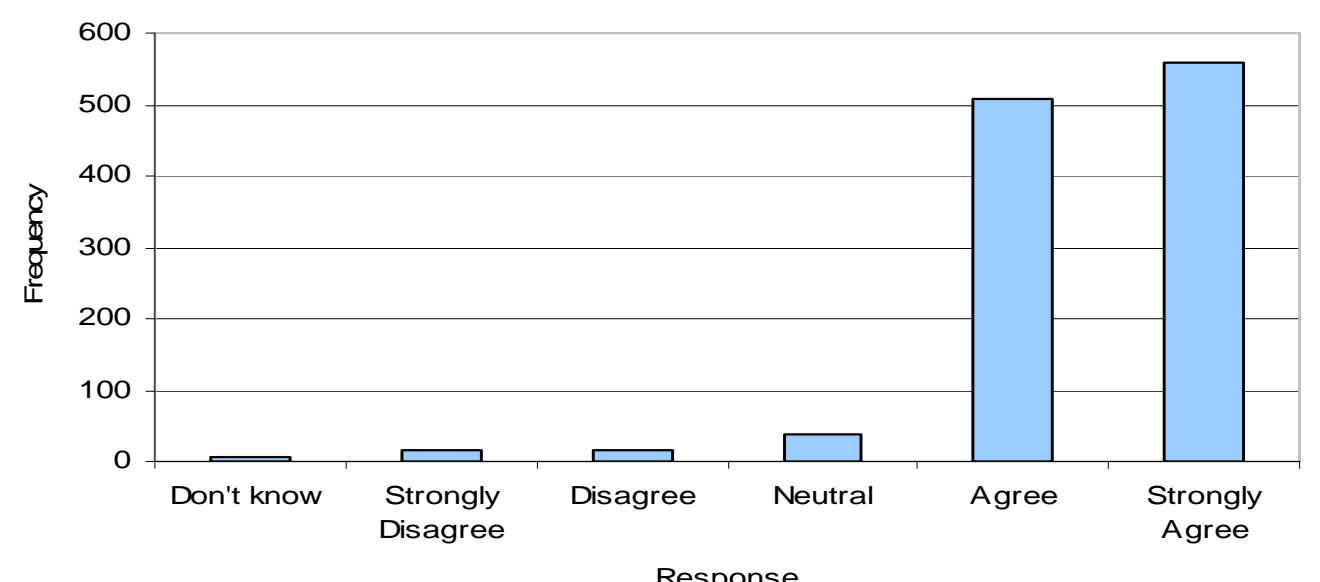

4. I expect Australian laws and healthcare guidelines to protect my personal privacy.

\begin{tabular}{|r|r|r|}
\hline \multicolumn{1}{|c|}{ Response } & Frequency & Valid \% \\
\hline Don't know & 2 & 0.2 \\
\hline Strongly agree & 3 & 0.3 \\
\hline Disagree & 3 & 0.3 \\
\hline Neutral & 17 & 1.5 \\
\hline Agree & 310 & 26.9 \\
\hline Strongly agree & 815 & 70.9 \\
\hline TOTAL & 1150 & \\
\hline Missing & 8 & \\
\hline TOTAL & 1158 & \\
\hline
\end{tabular}

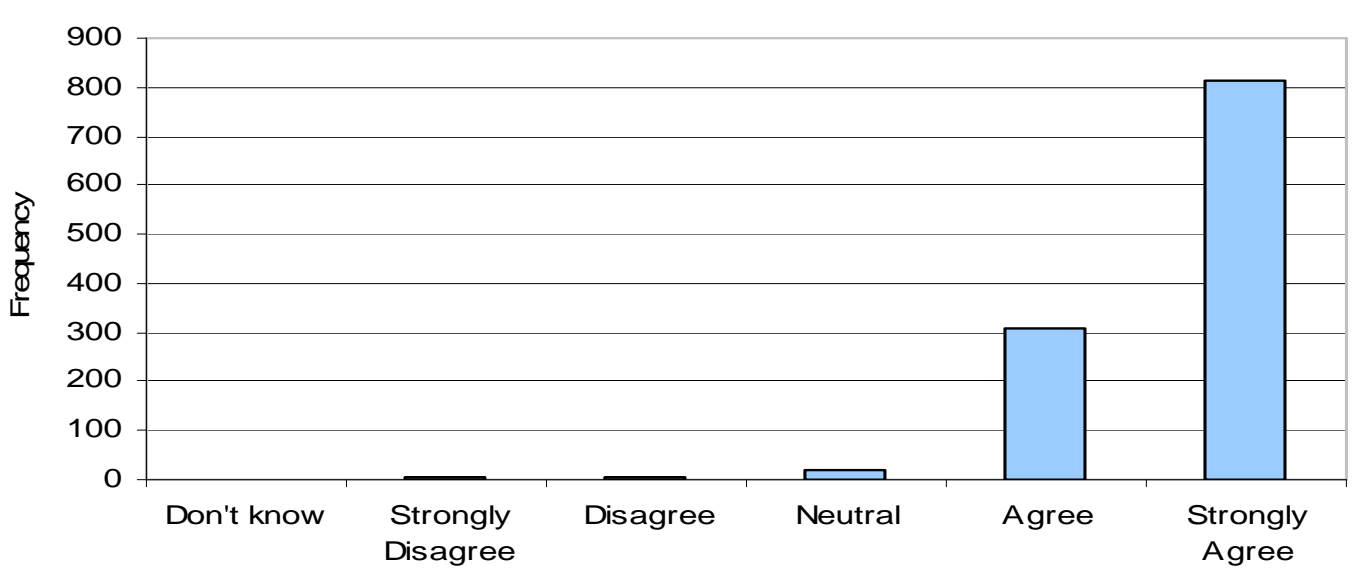

Response 
12. If information about my health can be used to help others who are suffering ill-health then I believe my information should be used to help those people.

\begin{tabular}{|r|r|r|}
\hline \multicolumn{1}{|c|}{ Response } & Frequency & \multicolumn{1}{|c|}{ Valid \% } \\
\hline Don't know & 18 & 1.6 \\
\hline Strongly agree & 27 & 2.4 \\
\hline Disagree & 71 & 6.2 \\
\hline Neutral & 160 & 14.0 \\
\hline Agree & 598 & 52.5 \\
\hline Strongly agree & 266 & 23.3 \\
\hline TOTAL & 1140 & \\
\hline Missing & 18 & \\
\hline TOTAL & 1158 & \\
\hline
\end{tabular}

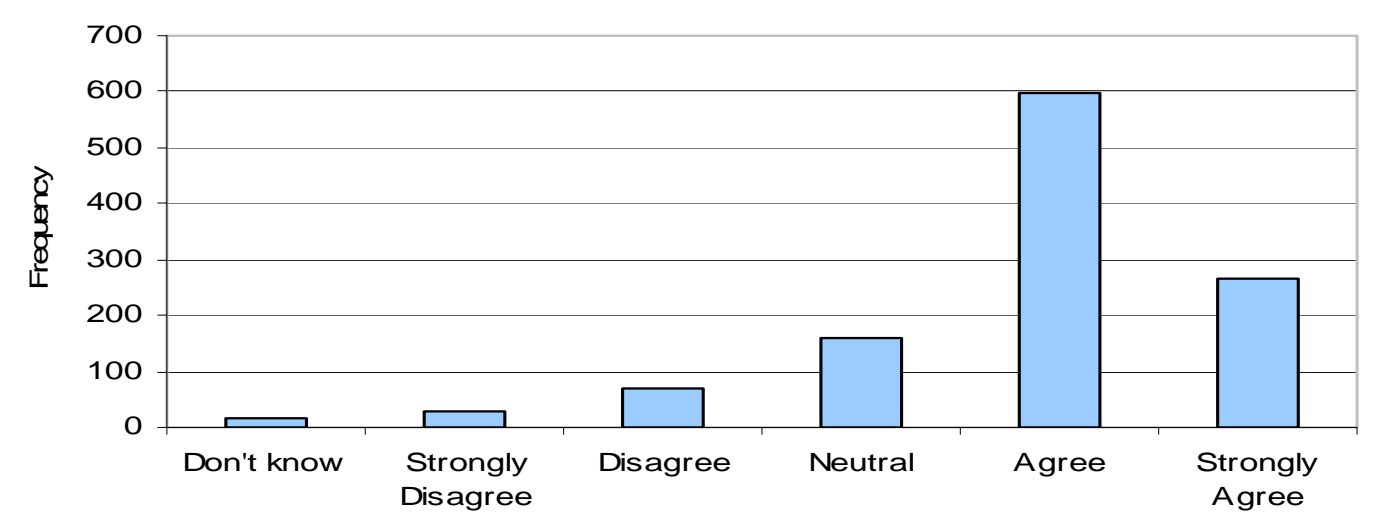

Response

26. I support the idea of medical information donation when the information is used in a way that benefits society.

\begin{tabular}{|r|r|r|}
\hline \multicolumn{1}{|c|}{ Response } & Frequency & \multicolumn{1}{c|}{ Valid \% } \\
\hline Don't know & 10 & 0.9 \\
\hline Strongly agree & 14 & 1.2 \\
\hline Disagree & 19 & 1.7 \\
\hline Neutral & 82 & 7.2 \\
\hline Agree & 648 & 57.2 \\
\hline Strongly agree & 360 & 31.8 \\
\hline TOTAL & 1133 & \\
\hline Missing & 25 & \\
\hline TOTAL & 1158 & \\
\hline
\end{tabular}

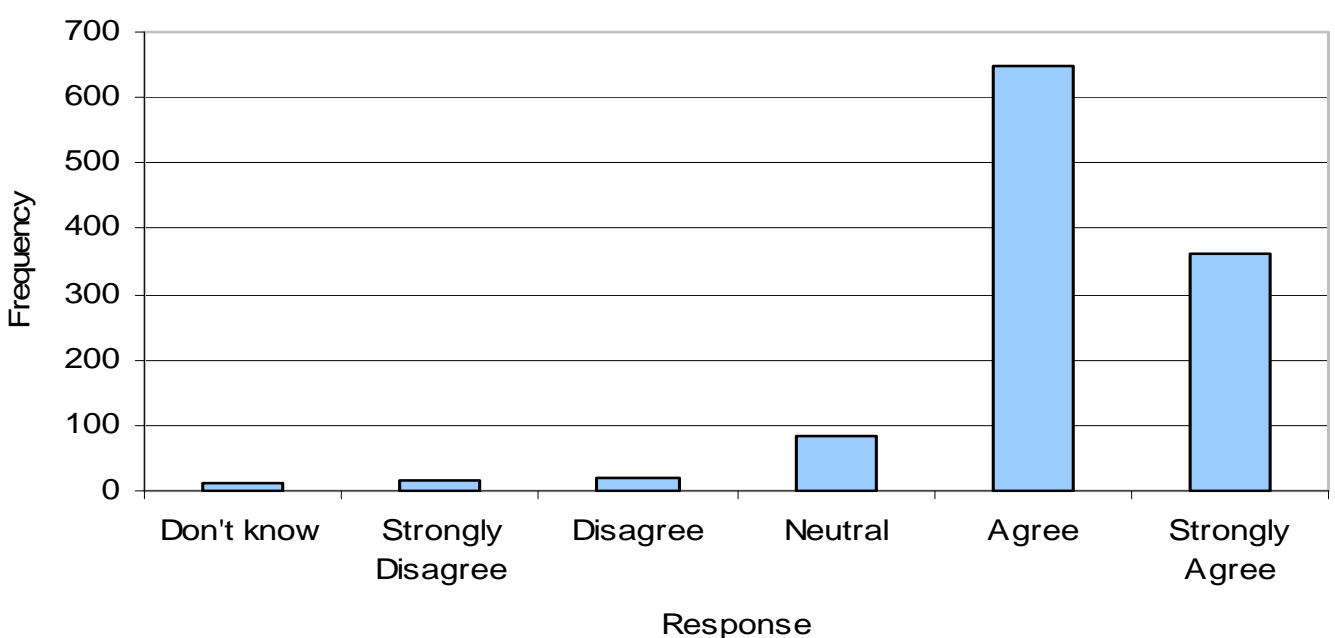




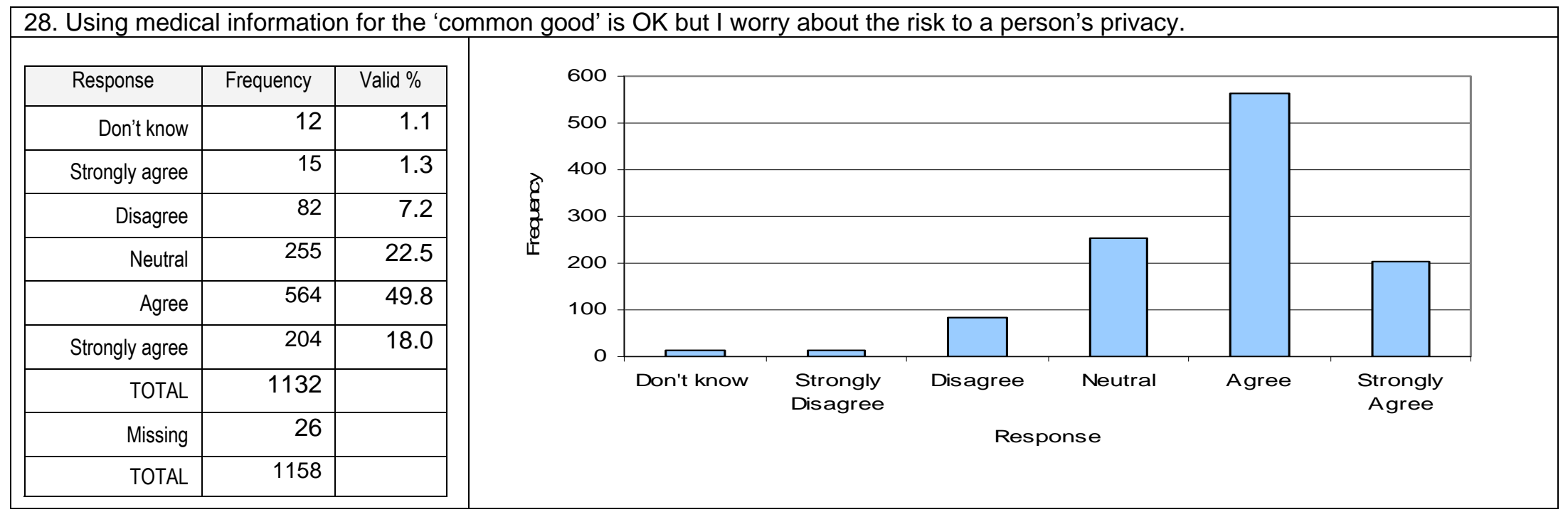

The final privacy tripartite component - Privacy Management, consumer survey response frequencies - are presented in Table 19. 
Table 19: Privacy tripartite component - privacy management, survey response frequency

2. I think my records belong to me - th
\begin{tabular}{|r|r|r|}
\hline \multicolumn{1}{|c|}{ Response } & Frequency & Valid \% \\
\hline Don't know & 0 & \\
\hline Strongly agree & 10 & 0.9 \\
\hline Disagree & 33 & 2.9 \\
\hline Neutral & 86 & 7.5 \\
\hline Agree & 362 & 31.5 \\
\hline Strongly agree & 658 & 57.3 \\
\hline TOTAL & 1149 & \\
\hline Missing & 9 & \\
\hline TOTAL & 1158 & \\
\hline
\end{tabular}

\section{When my medical information is stored on a computer owned by a healthcare provider they should not assume that they 'own' the} information.

\begin{tabular}{|r|r|r|}
\hline \multicolumn{1}{|c|}{ Response } & Frequency & \multicolumn{1}{|c|}{ Valid \% } \\
\hline Don't know & 5 & 0.4 \\
\hline Strongly agree & 8 & 0.7 \\
\hline Disagree & 20 & 1.7 \\
\hline Neutral & 52 & 4.5 \\
\hline Agree & 442 & 38.7 \\
\hline Strongly agree & 617 & 53.9 \\
\hline TOTAL & 1144 & \\
\hline Missing & 14 & \\
\hline TOTAL & 1158 & \\
\hline
\end{tabular}

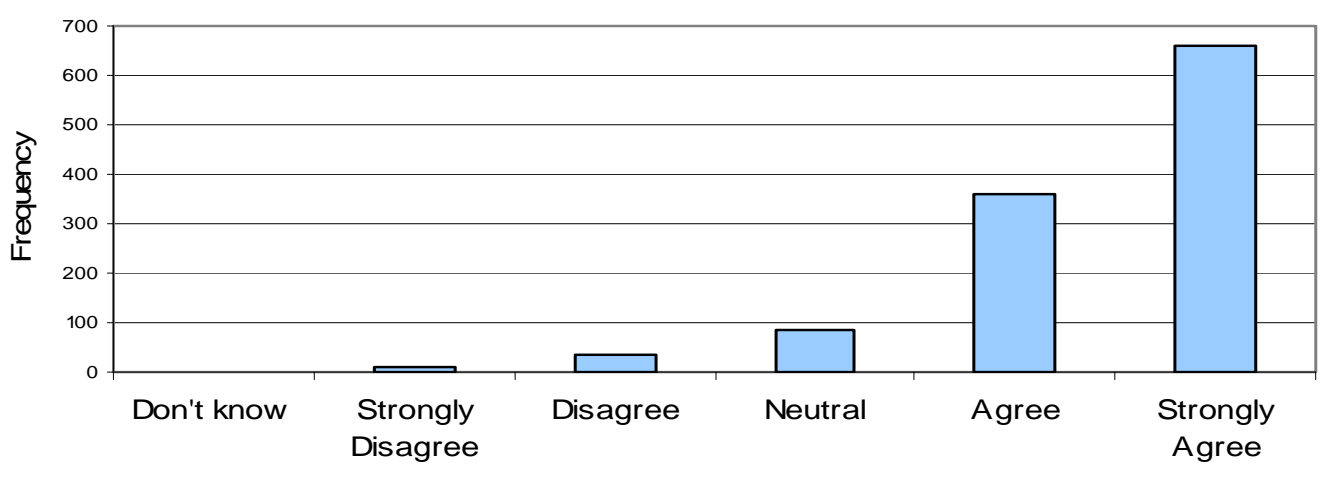

Response

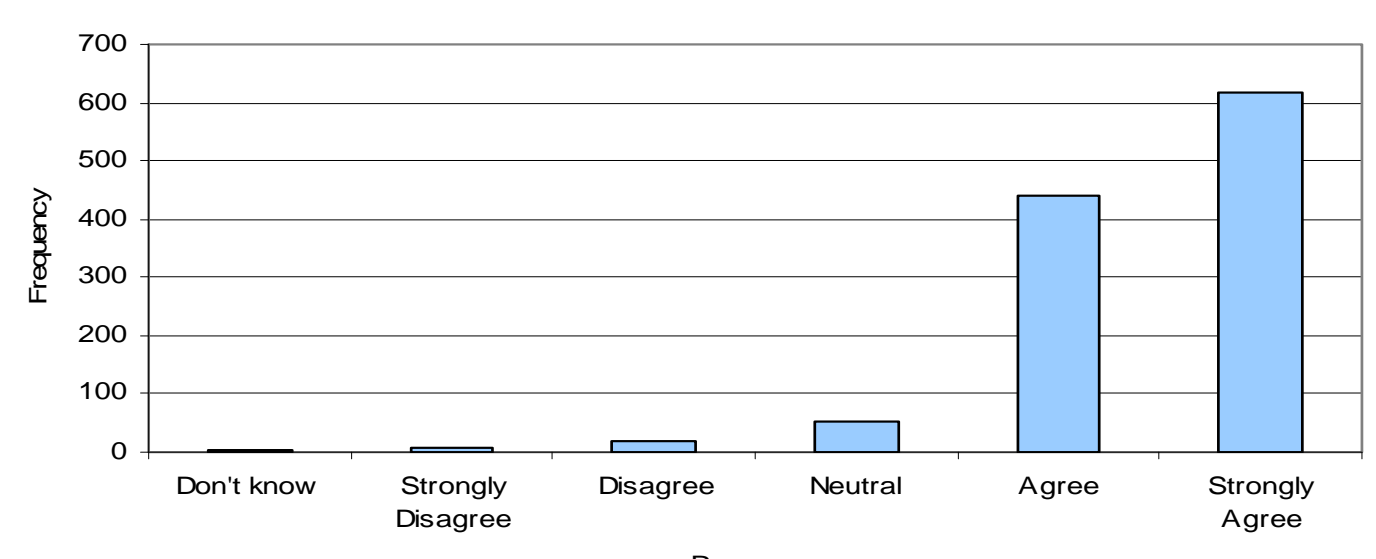

Response 
18. Any medical research groups who want to use 'donated' data must comply with the wishes of the person who has 'donated' the data.

\begin{tabular}{|r|r|r|}
\hline \multicolumn{1}{|c|}{ Response } & Frequency & \multicolumn{1}{c|}{ Valid \% } \\
\hline Don't know & 4 & 0.3 \\
\hline Strongly agree & 6 & 0.5 \\
\hline Disagree & 25 & 2.2 \\
\hline Neutral & 66 & 5.8 \\
\hline Agree & 425 & 37.2 \\
\hline Strongly agree & 617 & 54.0 \\
\hline TOTAL & 1143 & \\
\hline Missing & 15 & \\
\hline TOTAL & 1158 & \\
\hline \multicolumn{3}{|r}{} \\
\hline
\end{tabular}

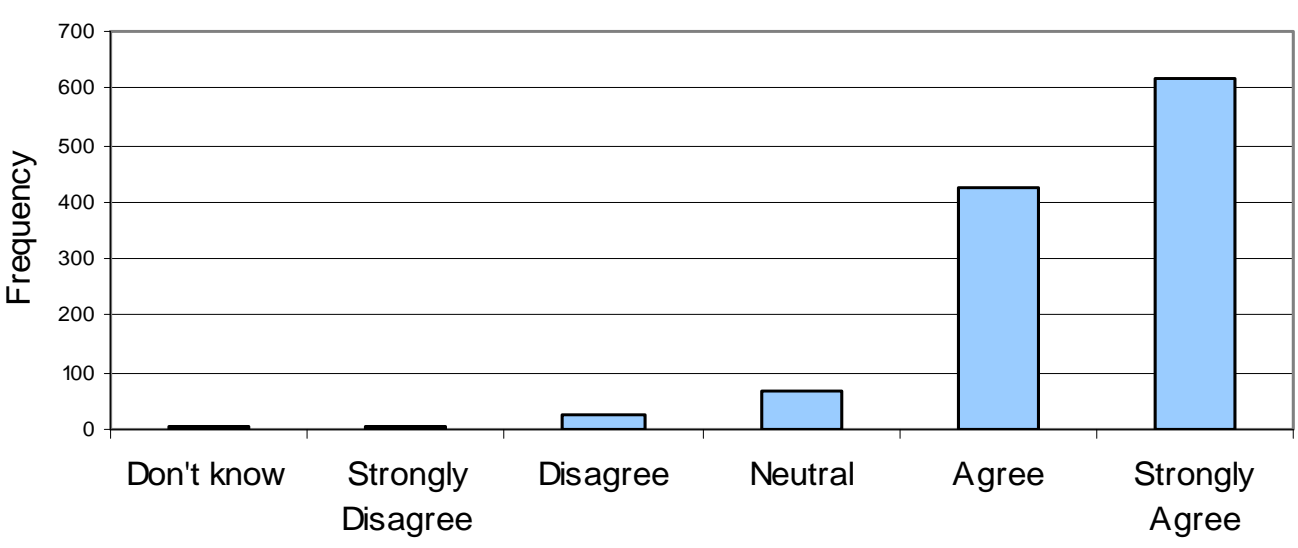

Response

24. I would be happy to let the Australian Government decide who can use my medical information.

\begin{tabular}{|r|r|r|}
\hline \multicolumn{1}{|c|}{ Response } & Frequency & \multicolumn{1}{c|}{ Valid \% } \\
\hline Don't know & 12 & 1.1 \\
\hline Strongly agree & 457 & 40.3 \\
\hline Disagree & 422 & 37.2 \\
\hline Neutral & 120 & 10.6 \\
\hline Agree & 83 & 7.3 \\
\hline Strongly agree & 40 & 3.5 \\
\hline TOTAL & 1134 & \\
\hline Missing & 24 & \\
\hline TOTAL & 1158 & \\
\hline
\end{tabular}

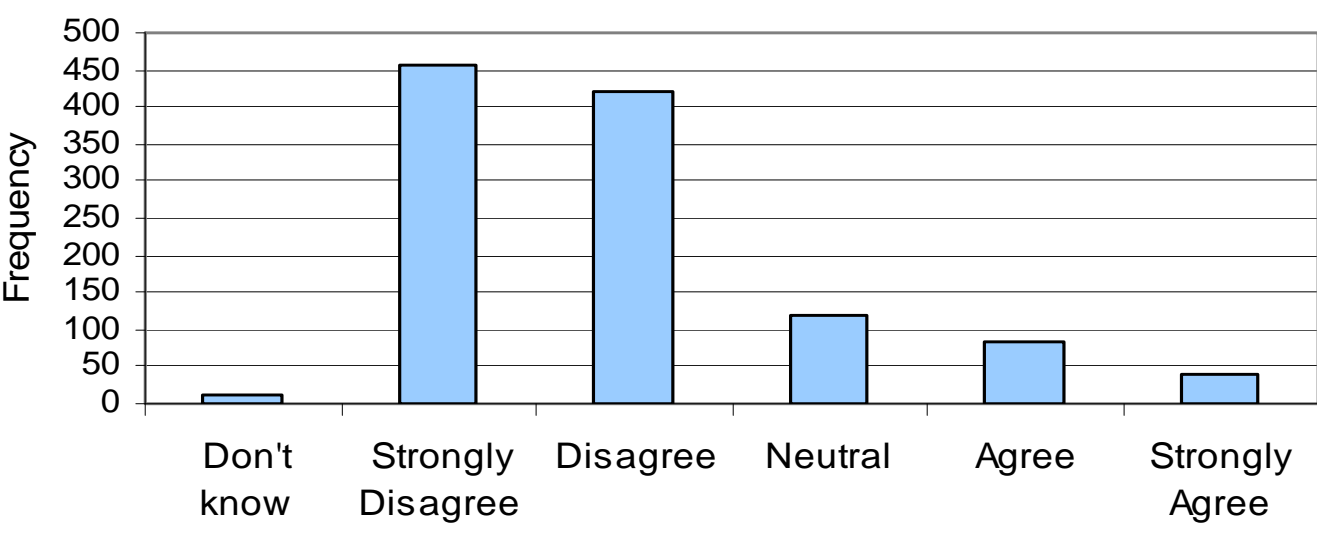

Response 
30. A legal judge in Australia decided that the notes written about a patient, by a Doctor, are owned by the Doctor not the patient. This decision seems reasonable to me.

\begin{tabular}{|r|r|r|}
\hline \multicolumn{1}{|c|}{ Response } & Frequency & \multicolumn{1}{c|}{ Valid \% } \\
\hline Don't know & 22 & 1.9 \\
\hline Strongly agree & 365 & 32.2 \\
\hline Disagree & 387 & 34.1 \\
\hline Neutral & 123 & 10.8 \\
\hline Agree & 164 & 14.4 \\
\hline Strongly agree & 74 & 6.5 \\
\hline TOTAL & 1135 & \\
\hline Missing & 23 & \\
\hline TOTAL & 1158 & \\
\hline \multicolumn{2}{|l}{} \\
\hline
\end{tabular}

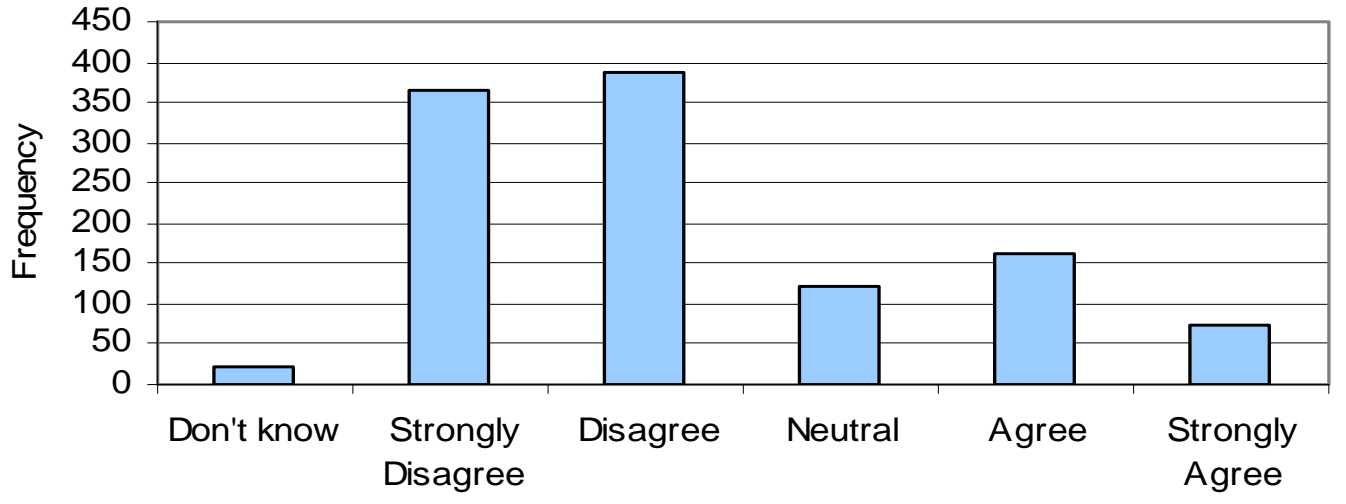

13. If my health information could be made anonymous by removing things like my name, address, phone number and Medicare number I would be more likely to agree for the information to be used for medical research.

\begin{tabular}{|r|r|r|}
\hline \multicolumn{1}{|c|}{ Response } & \multicolumn{1}{|c|}{ Frequency } & \multicolumn{1}{c|}{ Valid \% } \\
\hline Don't know & 3 & 0.3 \\
\hline Strongly agree & 8 & 0.7 \\
\hline Disagree & 25 & 2.2 \\
\hline Neutral & 68 & 5.9 \\
\hline Agree & 542 & 47.5 \\
\hline Strongly agree & 495 & 43.4 \\
\hline TOTAL & 1141 & \\
\hline Missing & 17 & \\
\hline TOTAL & 1158 & \\
\hline
\end{tabular}

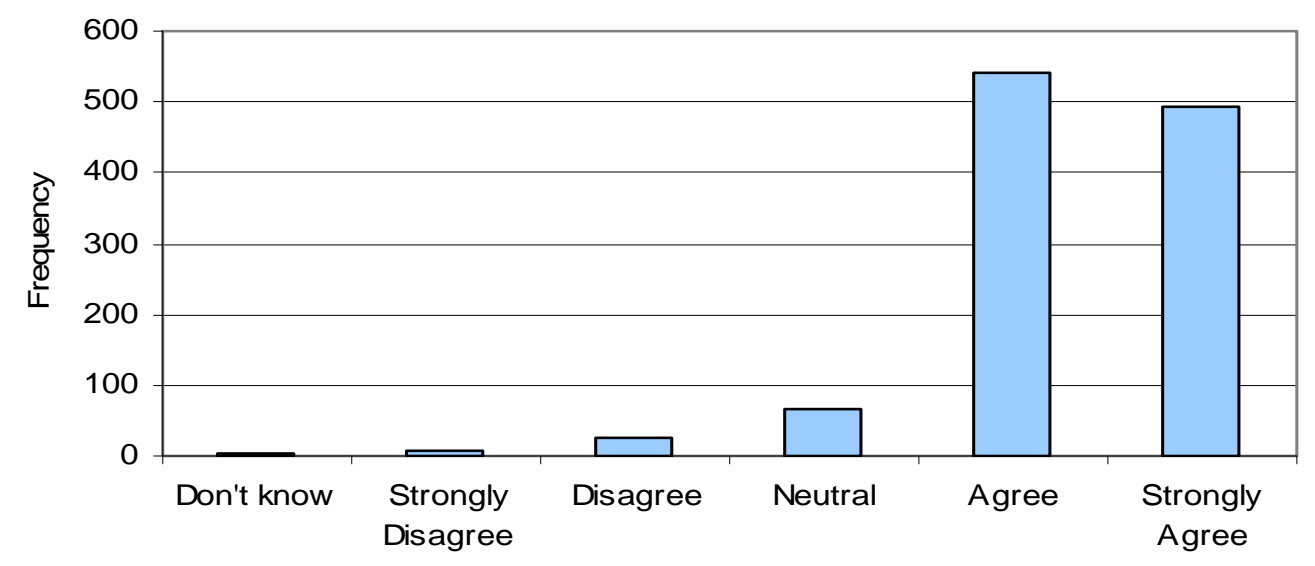

Response 
14. I feel that I continue to have privacy even when other people have access to my personal information if I am the one who has granted the other people access.

\begin{tabular}{|c|c|c|}
\hline Response & Frequency & Valid \% \\
\hline Don't know & 23 & 2.0 \\
\hline Strongly agree & 13 & 1.1 \\
\hline Disagree & 96 & 8.5 \\
\hline Neutral & 169 & 14.9 \\
\hline Agree & 607 & 53.4 \\
\hline Strongly agree & 228 & 20.1 \\
\hline TOTAL & 1136 & \\
\hline Missing & 22 & \\
\hline TOTAL & 1158 & \\
\hline
\end{tabular}

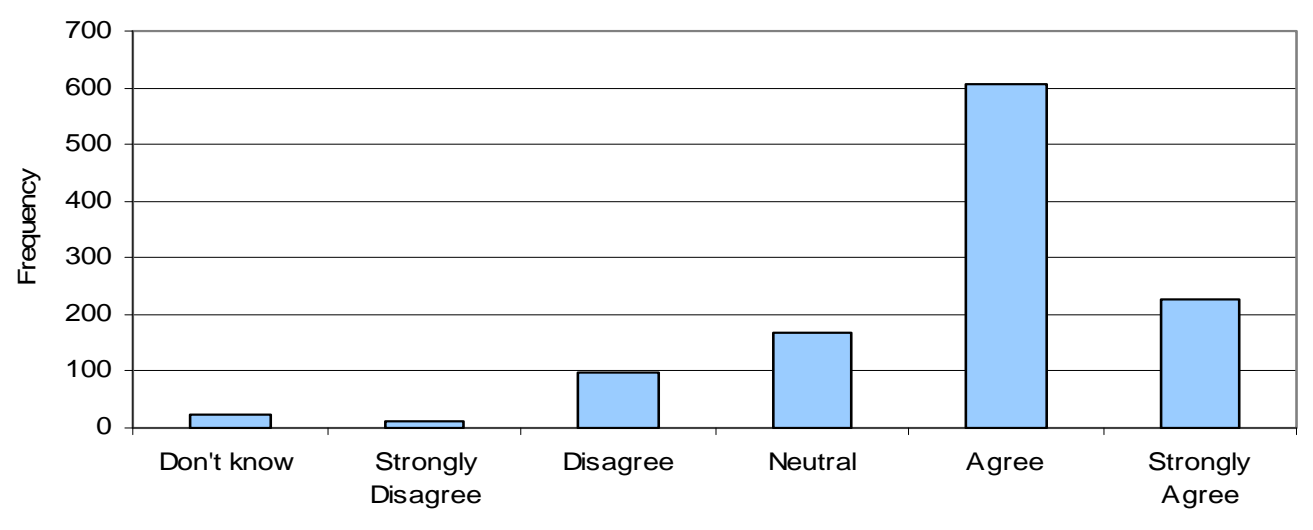

15. I support the idea of people being given a personal choice about 'donating' their medical information for research

\begin{tabular}{|r|r|r|}
\hline Response & Frequency & \multicolumn{1}{|c|}{ Valid \% } \\
\hline Don't know & 3 & 0.3 \\
\hline Strongly agree & 8 & 0.7 \\
\hline Disagree & 21 & 1.8 \\
\hline Neutral & 63 & 5.5 \\
\hline Agree & 595 & 52.1 \\
\hline Strongly agree & 453 & 39.6 \\
\hline TOTAL & 1143 & \\
\hline Missing & 15 & \\
\hline TOTAL & 1158 & \\
\hline
\end{tabular}

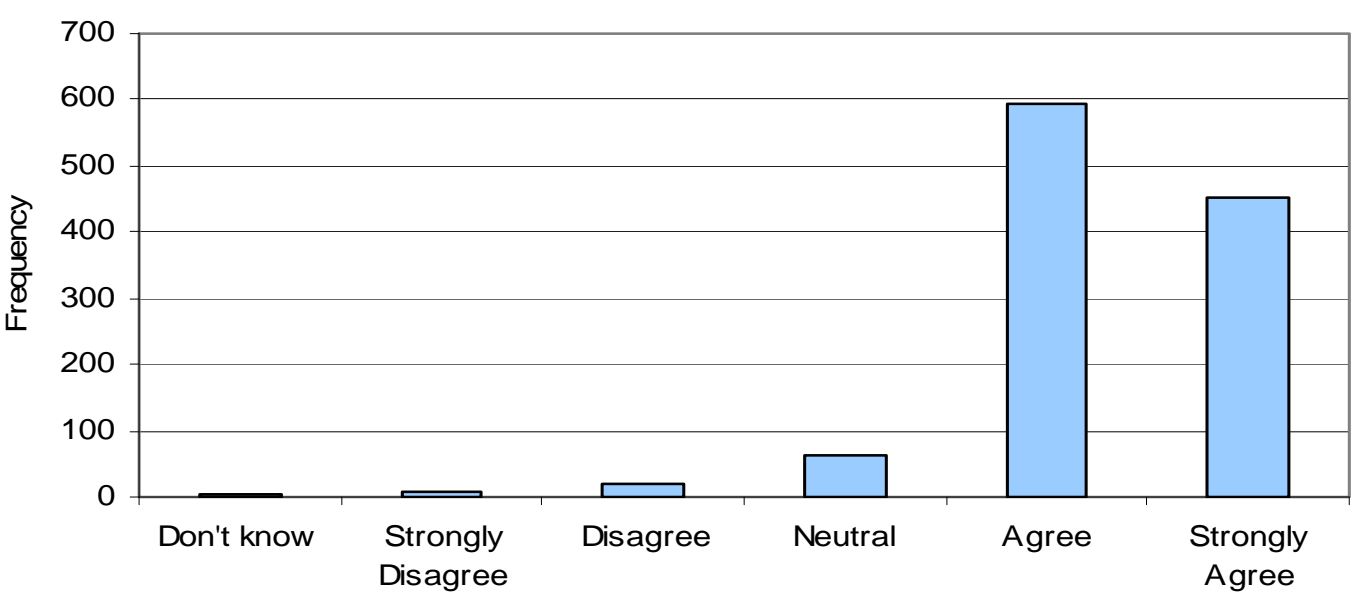

Response 
16. If I donated my medical information for research I would want to choose the level of privacy I required. For example I may choose (1) 'always anonymous' or (2) 'name and Medicare number can always be used'.

\begin{tabular}{|r|r|r|}
\hline \multicolumn{1}{|c|}{ Response } & Frequency & \multicolumn{1}{|c|}{ Valid \% } \\
\hline Don't know & 13 & 1.1 \\
\hline Strongly agree & 25 & 2.2 \\
\hline Disagree & 20 & 1.8 \\
\hline Neutral & 55 & 4.8 \\
\hline Agree & 523 & 46.1 \\
\hline Strongly agree & 499 & 44.0 \\
\hline TOTAL & 1135 & \\
\hline Missing & 23 & \\
\hline TOTAL & 1158 & \\
\hline
\end{tabular}

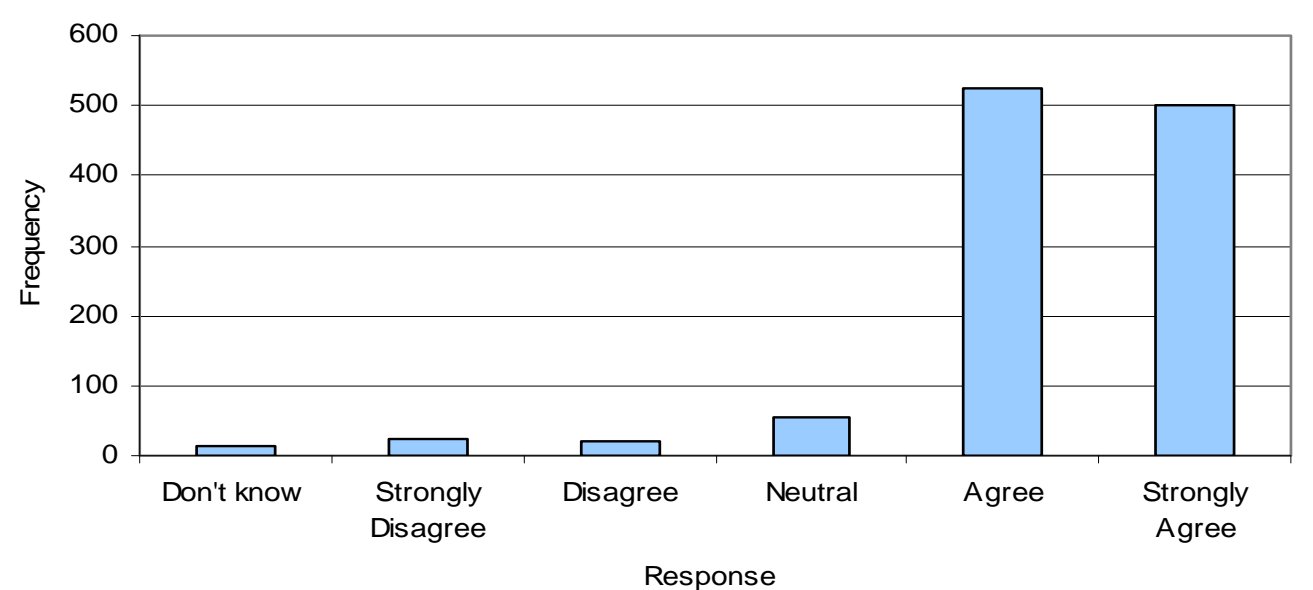

17. If I give consent for my health information to be used for research I want to be able to say who can use my information like 'medical researchers', 'drug companies', 'university researchers' or 'insurance companies'.

\begin{tabular}{|r|r|r|}
\hline \multicolumn{1}{|c|}{ Response } & Frequency & Valid \% \\
\hline Don't know & 6 & 0.5 \\
\hline Strongly agree & 11 & 1.0 \\
\hline Disagree & 44 & 3.9 \\
\hline Neutral & 116 & 10.1 \\
\hline Agree & 461 & 40.3 \\
\hline Strongly agree & 505 & 44.2 \\
\hline TOTAL & 1143 & \\
\hline Missing & 15 & \\
\hline TOTAL & 1158 & \\
\hline
\end{tabular}

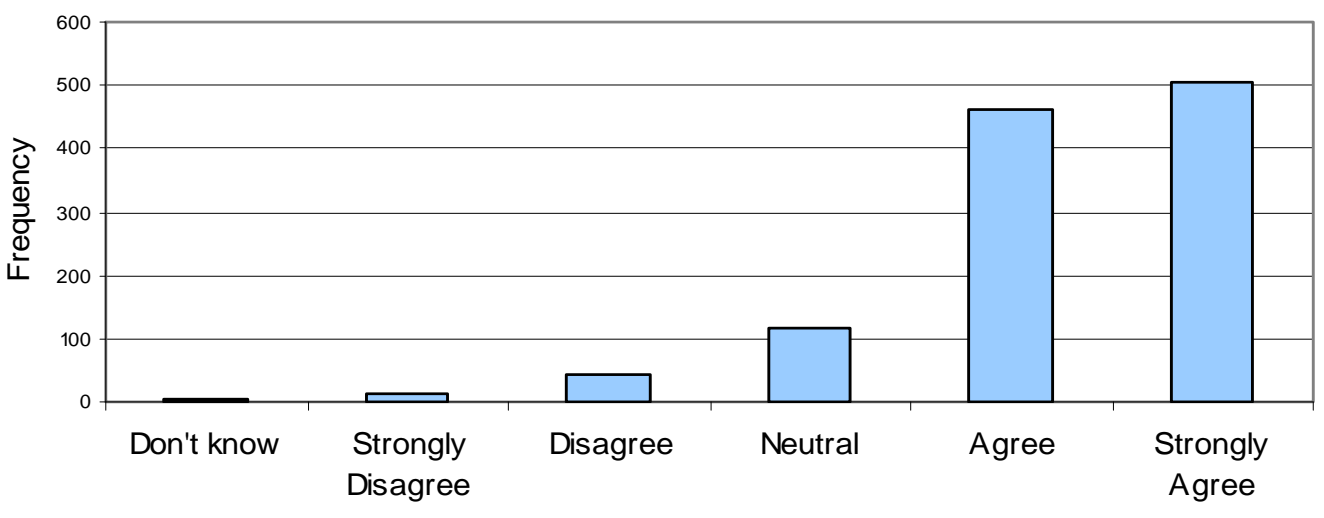

Response 
19. A person must be able to choose to keep their medical information private and never consent to release their medical information for any purpose.

\begin{tabular}{|r|r|r|}
\hline \multicolumn{1}{|c|}{ Response } & Frequency & \multicolumn{1}{|c|}{ Valid \% } \\
\hline Don't know & 9 & 0.8 \\
\hline Strongly agree & 24 & 2.1 \\
\hline Disagree & 117 & 10.3 \\
\hline Neutral & 126 & 11.1 \\
\hline Agree & 376 & 33.0 \\
\hline Strongly agree & 486 & 42.7 \\
\hline TOTAL & 1138 & \\
\hline Missing & 20 & \\
\hline TOTAL & 1158 & \\
\hline
\end{tabular}

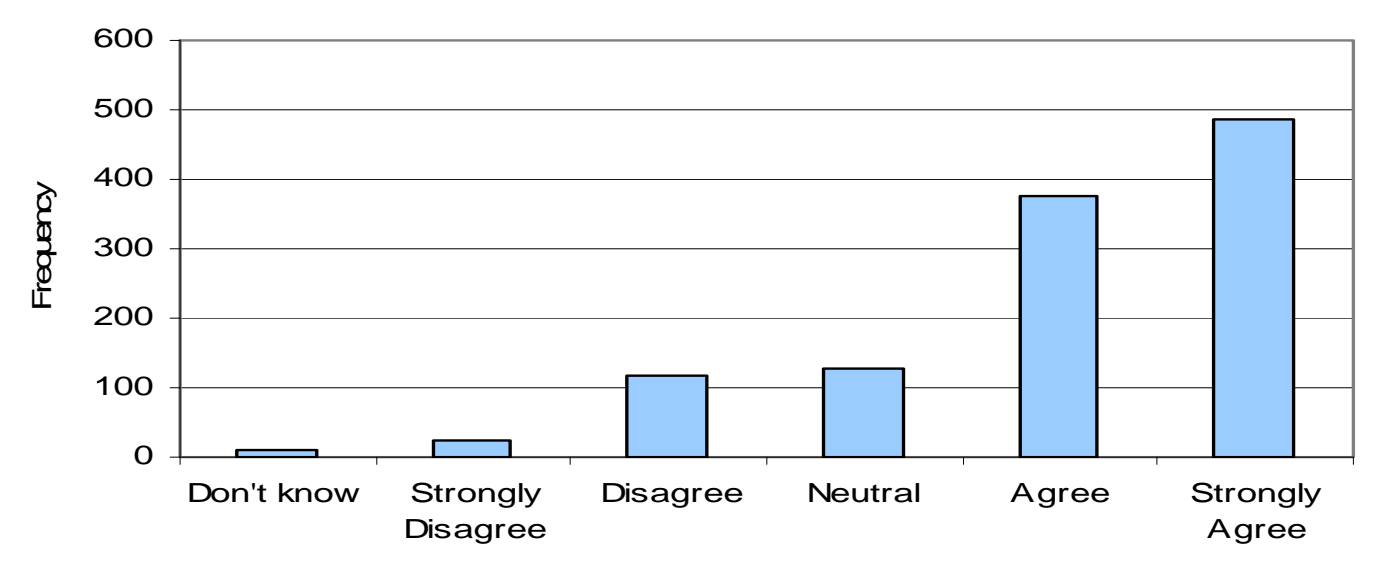

20. If I donated my medical information for research I would like to give my consent once - at the time of 'signing up' as a data donor.

\begin{tabular}{|r|r|r|}
\hline \multicolumn{1}{|c|}{ Response } & Frequency & \multicolumn{1}{|c|}{ Valid \% } \\
\hline Don't know & 24 & 2.1 \\
\hline Strongly agree & 57 & 5.0 \\
\hline Disagree & 164 & 14.4 \\
\hline Neutral & 160 & 14.1 \\
\hline Agree & 521 & 45.9 \\
\hline Strongly agree & 210 & 18.5 \\
\hline TOTAL & 1136 & \\
\hline Missing & 22 & \\
\hline TOTAL & 1158 & \\
\hline & & \\
\hline
\end{tabular}

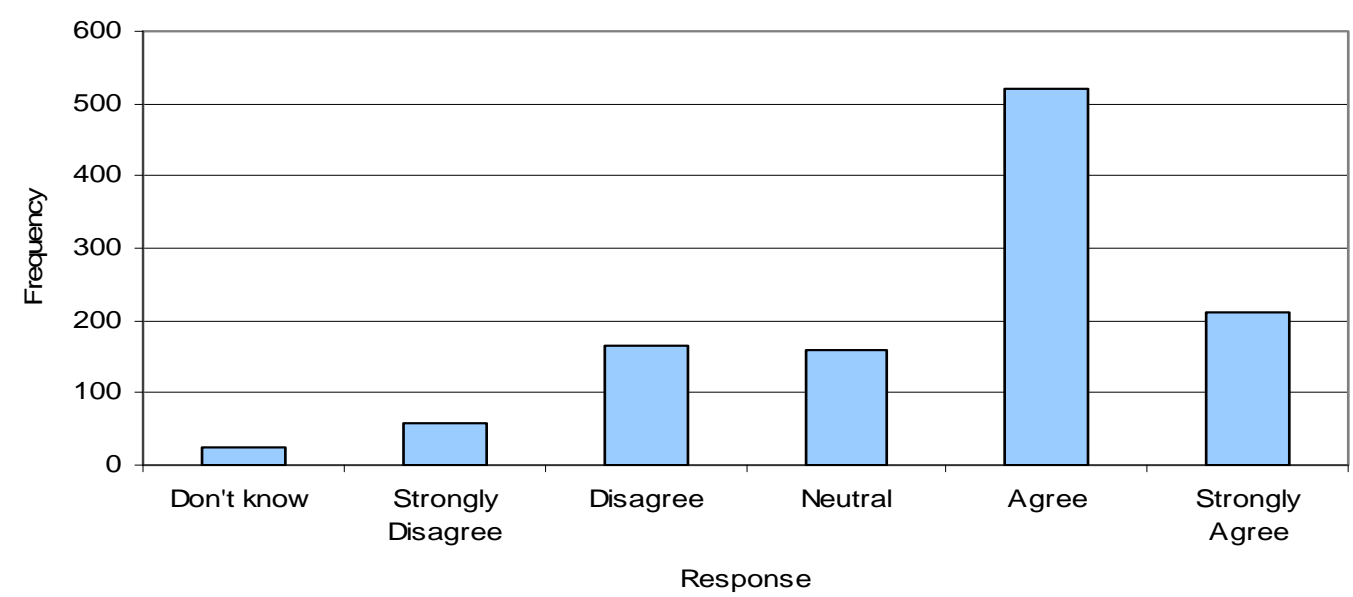


21. If people agree to donate their data for medical research there must be a way for them to stop the donation agreement at any time.

\begin{tabular}{|r|r|r|}
\hline \multicolumn{1}{|c|}{ Response } & Frequency & \multicolumn{1}{|c|}{ Valid \% } \\
\hline Don't know & 6 & 0.5 \\
\hline Strongly agree & 9 & 0.7 \\
\hline Disagree & 44 & 3.9 \\
\hline Neutral & 67 & 5.9 \\
\hline Agree & 493 & 43.2 \\
\hline Strongly agree & 522 & 45.7 \\
\hline TOTAL & 1141 & \\
\hline Missing & 17 & \\
\hline TOTAL & 1158 & \\
\hline
\end{tabular}

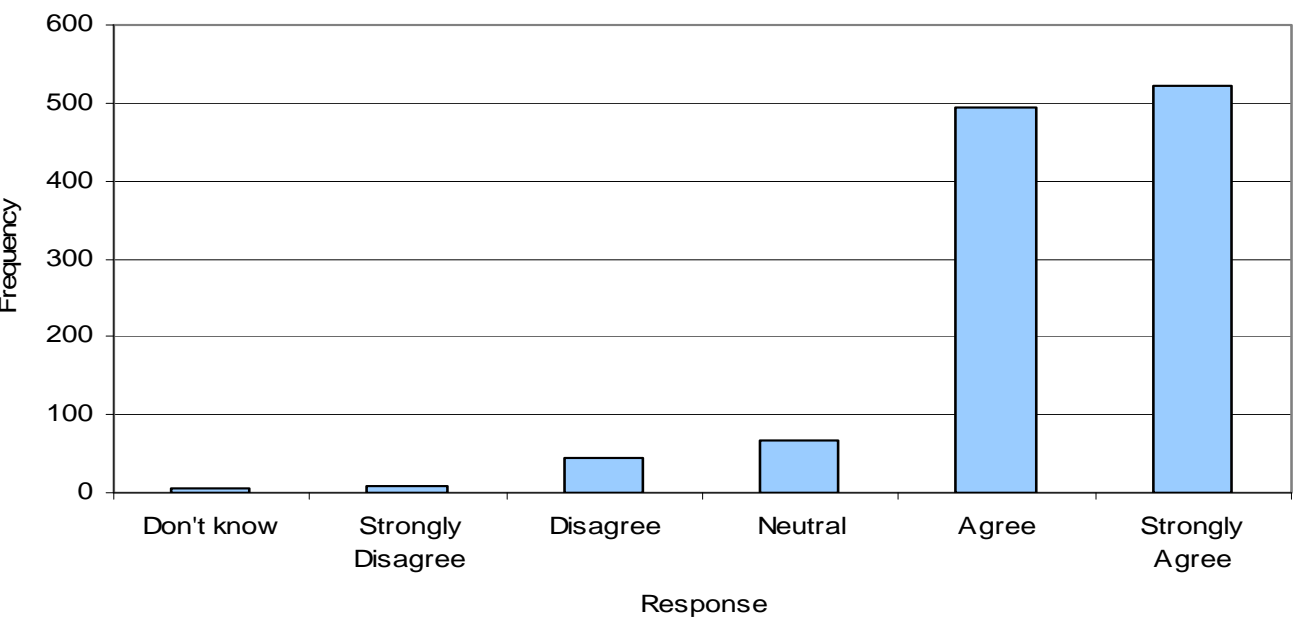

22. If people agree to donate their data for medical research from time to time they must be asked if they want to continue to donate.

\begin{tabular}{|r|r|r|}
\hline \multicolumn{1}{|c|}{ Response } & Frequency & \multicolumn{1}{c|}{ Valid \% } \\
\hline Don't know & 9 & 0.8 \\
\hline Strongly agree & 17 & 1.5 \\
\hline Disagree & 81 & 7.1 \\
\hline Neutral & 135 & 11.9 \\
\hline Agree & 506 & 44.5 \\
\hline Strongly agree & 390 & 34.3 \\
\hline TOTAL & 1138 & \\
\hline Missing & 20 & \\
\hline TOTAL & 1158 & \\
\hline
\end{tabular}

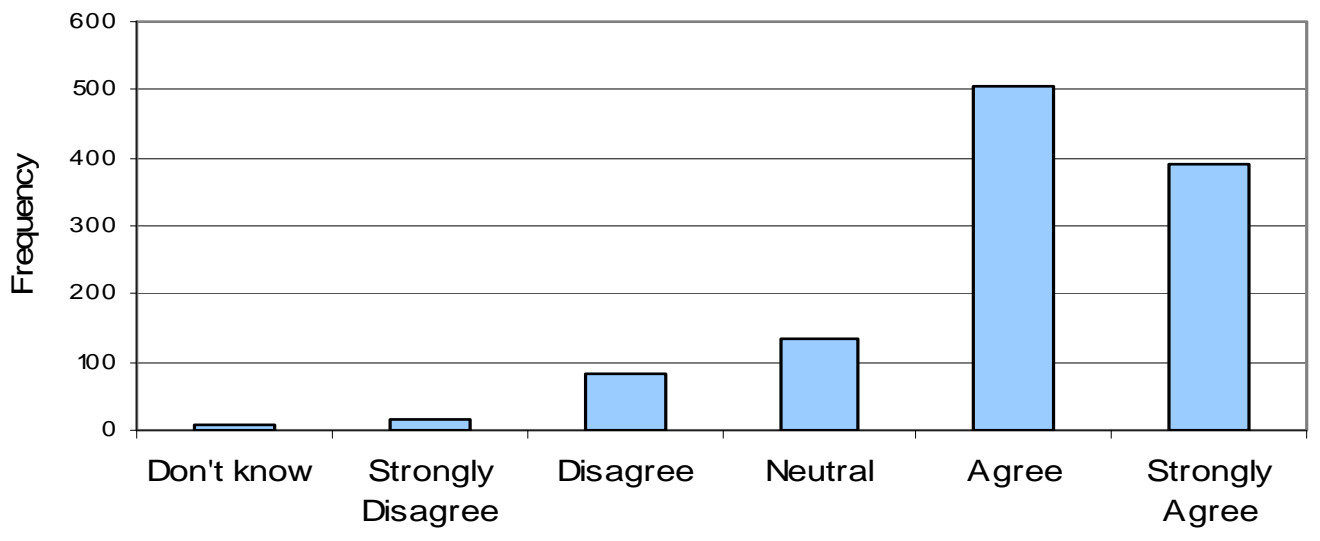

Response 
23. If I choose to donate my medical information then healthcare providers should release the information according to my instructions.

\begin{tabular}{|r|r|r|}
\hline \multicolumn{1}{|c|}{ Response } & Frequency & \multicolumn{1}{|c|}{ Valid \% } \\
\hline Don't know & 8 & 0.7 \\
\hline Strongly agree & 4 & 0.4 \\
\hline Disagree & 18 & 1.6 \\
\hline Neutral & 74 & 6.5 \\
\hline Agree & 554 & 48.9 \\
\hline Strongly agree & 475 & 41.9 \\
\hline TOTAL & 1133 & \\
\hline Missing & 25 & \\
\hline TOTAL & 1158 & \\
\hline
\end{tabular}

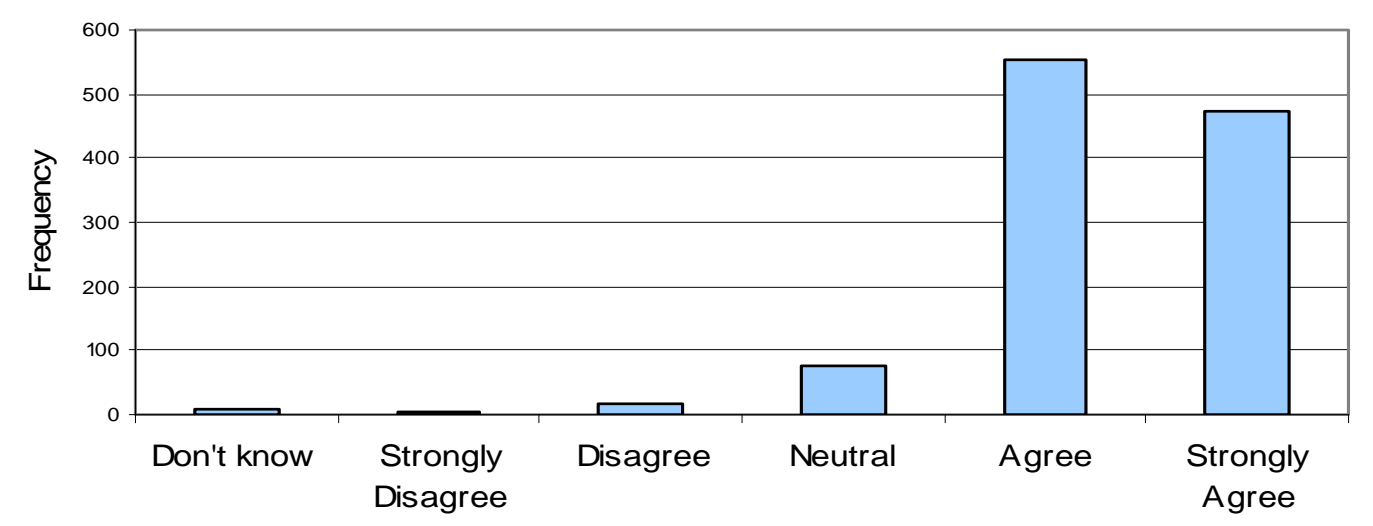

29. I should be able to see my medical information and it should be easy to correct any mistakes in the information.

\begin{tabular}{|r|r|r|}
\hline \multicolumn{1}{|c|}{ Response } & Frequency & Valid \% \\
\hline Don't know & 7 & 0.6 \\
\hline Strongly agree & 2 & 0.2 \\
\hline Disagree & 19 & 1.7 \\
\hline Neutral & 69 & 6.1 \\
\hline Agree & 477 & 42.1 \\
\hline Strongly agree & 560 & 49.4 \\
\hline TOTAL & 1134 & \\
\hline Missing & 24 & \\
\hline TOTAL & 1158 & \\
\hline
\end{tabular}

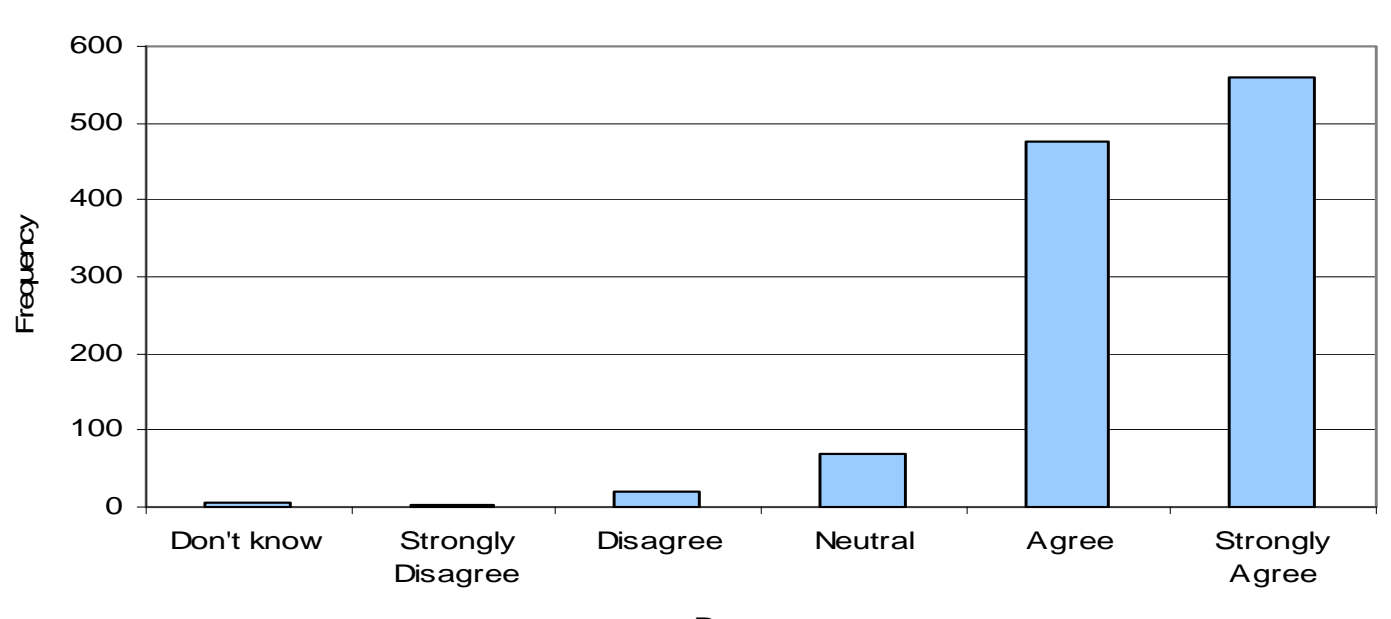

Response 


\subsubsection{Mixed Method Analysis}

This section reports the results of both quantitative and qualitative analysis.

QuantitativeChi-Square tests were performed on the gender, age, education level and self-reported healthcare worker demographics across all of the survey questions. Demographic characteristics containing null values have been removed prior to ChiSquare analysis. The 5 point Likert scale has been reduced to disagree, neutral and agree by combining 'strongly disagree' and 'disagree' into 'disagree' and 'strongly agree' and 'agree' into 'agree'. The 'Don't know' response was omitted from this aspect of analysis. The results presented in this section include only those Chi-Square tests where no more than $20 \%$ of the expected counts were less than five (Yates, Moore et al. 1999).

\section{Qualitative}

The qualitative comments provided by survey respondents were encoded, as described in the Research Method Chapter, within Moor and Tavani's tripartite privacy framework (2001). The results have been organised around the tripartite privacy framework to aid analysis of the consumer views regarding concept, justification and management of privacy. Wherever possible, divergent views as expressed through qualitative comments have been selected to illustrate the differences of opinion amongst respondents. Where only a segment of the qualitative response relates to the particular tripartite component a notation of three dots (...) has been adopted to indicate that part of the text is omitted.

A structured notation has been adopted to convey in a concise manner the demographics of the source respondent. The notation begins and ends with a square bracket [] followed by, survey number, gender (M or F), home State or Territory, age bracket (e.g. 18-25), highest education level ( e.g. <Yr 10), and a code to indicate if the respondent has worked in the healthcare sector (HW for healthcare worker and NHW for non healthcare worker). If partial demographics are available the known components are presented. Table 20 presents summary details of Australian States and Territories that may assist in interpreting the home geographic component of the structured notation attached to each qualitative comment. 
Table 20: Australian State and Territory Codes

\begin{tabular}{|c|c|c|}
\hline Code & State or Territory & Postcode initial digits \\
\hline ACT & Australian Capital Territory & 26 \\
\hline NSW & New South Wales & 08 \\
\hline NT & Northern Territory & 4 \\
\hline QLD & Queensland & 5 \\
\hline SA & South Australia & 7 \\
\hline TAS & Tasmania & 3 \\
\hline VIC & Victoria & 6 \\
\hline WA & Western Australia & \\
\hline
\end{tabular}

The survey results indicate that the consumers used the qualitative page to respond in a variety of ways - only sometimes containing themselves to the stimuli questions.

\subsubsection{Tripartite Component: Privacy Concept - Quantitative Analysis}

There are seven survey statements $(6,8,9,10,11,25,27)$ pertaining to the tripartite 'concept' component. Statistically significant differences were found regarding highest education level, age and self reported healthcare worker. Table 21 presents a matrix of the statements and demographics investigated via Pearson's Chi-Square with an $\mathrm{X}$ indicating where the statistically significant results were found.

Table 21: Privacy Concept Chi-Square statistically significant results.

\begin{tabular}{|c|c|c|c|c|c|}
\hline & Construct & Gender & Age & $\begin{array}{c}\text { Highest Education } \\
\text { Level }\end{array}$ & Healthcare Worker \\
\hline Statement 5 & Anxiety & & & & \\
\hline Statement 6 & Anxiety & & $x$ & $x$ & \\
\hline Statement 8 & Anxiety & & $x$ & $x$ & \\
\hline Statement 9 & Anxiety & & $x$ & $x$ & \\
\hline Statement 25 & Anxiety & & $x$ & $x$ & \\
\hline Statement 27 & Anxiety & & & & $x$ \\
\hline Statement 10 & $\begin{array}{l}\text { Limited } \\
\text { Access }\end{array}$ & & $\mathrm{X}$ & & \\
\hline Statement 11 & $\begin{array}{l}\text { Limited } \\
\text { Access }\end{array}$ & & & & $\mathrm{X}$ \\
\hline
\end{tabular}

In terms of the concept of privacy, no statistically significant difference was found between gender of respondents. The age of the respondent is statistically significant 
in $62.5 \%$ of the constructs used to investigate the privacy concept. Highest level of education was significant in $50 \%$ of the anxiety constructs; however, level of education did not have significance in terms of limited access. Healthcare workers versus non healthcare workers emerged as significant in two statements and all of the statistically significant results are presented in more detail and discussed in the next sections.

\subsubsection{Anxiety}

Ch-Square tests on respondent age for Statement 5 - If an unauthorised person gained access to my medical information then I would feel that my privacy had been violated, resulted in statistically significant differences between various age groups with $p$ value 0.051 , however 7 cells had expected count less than 5 indicating a poor situation for testing with Chi-Square, hence results are not reported here.

Chi-Square tests on Statement 6 - I am concerned that my medical information may be stolen revealed citizens' opinions differed by age $\left(\chi^{2}=49.75, \mathrm{df}=10, p<0.001\right)$. Citizens (<51years) tended to be less concerned about stolen medical information than expected and older citizens were more concerned as illustrated in Table 22.

Table 22: Statement 6 Pearsons Chi-Square statistically significant - Age

\begin{tabular}{|c|c|c|c|c|c|}
\hline AGE & Frequency & Disagree & Neutral & Agree & TOTAL \\
\hline $18-25$ & $\begin{array}{r}\text { Count } \\
\text { Expected Count }\end{array}$ & $\begin{array}{r}14 \\
8.1\end{array}$ & $\begin{array}{r}9 \\
12.4\end{array}$ & $\begin{array}{r}9 \\
11.5\end{array}$ & 32 \\
\hline $26-39$ & $\begin{array}{r}\text { Count } \\
\text { Expected Count }\end{array}$ & $\begin{array}{r}53 \\
36.8\end{array}$ & $\begin{array}{r}63 \\
56.7\end{array}$ & $\begin{array}{r}30 \\
52.6\end{array}$ & 146 \\
\hline $40-50$ & $\begin{array}{r}\text { Count } \\
\text { Expected Count }\end{array}$ & $\begin{array}{r}74 \\
65.2 \\
\end{array}$ & $\begin{array}{r}106 \\
100.5\end{array}$ & $\begin{array}{r}79 \\
93.2\end{array}$ & 259 \\
\hline $51-65$ & $\begin{array}{r}\text { Count } \\
\text { Expected Count }\end{array}$ & $\begin{array}{r}87 \\
103.5\end{array}$ & $\begin{array}{r}167 \\
159.5 \\
\end{array}$ & $\begin{array}{r}157 \\
148.0\end{array}$ & 411 \\
\hline $66-80$ & $\begin{array}{r}\text { Count } \\
\text { Expected Count }\end{array}$ & $\begin{array}{r}41 \\
52.4 \\
\end{array}$ & $\begin{array}{r}72 \\
80.7\end{array}$ & $\begin{array}{r}95 \\
74.9\end{array}$ & 208 \\
\hline Over 80 & $\begin{array}{r}\text { Count } \\
\text { Expected Count } \\
\end{array}$ & $\begin{array}{r}8 \\
11.1 \\
\end{array}$ & $\begin{array}{r}10 \\
17.1\end{array}$ & $\begin{array}{r}26 \\
15.8\end{array}$ & 44 \\
\hline TOTAL & Count & 277 & 427 & 396 & 1100 \\
\hline
\end{tabular}

Statistically significant results also resulted from Pearson's Chi-Square test of education level with Statement $6\left(\chi^{2}=33.548, \mathrm{df}=12, p<.001\right)$. As Table 23 illustrates, tertiary educated citizens tended to be less concerned with theft of medical information. 
Table 23: Statement 6 Pearsons Chi-Square statistically significant - Highest Level of Education

\begin{tabular}{|c|c|c|c|c|c|}
\hline $\begin{array}{c}\text { Highest } \\
\text { Education }\end{array}$ & Frequency & Disagree & Neutral & Agree & Total \\
\hline$<Y r 10$ & $\begin{array}{r}\text { Count } \\
\text { Expected }\end{array}$ & $\begin{array}{r}7 \\
15.0\end{array}$ & $\begin{array}{r}23 \\
22.8\end{array}$ & $\begin{array}{r}29 \\
21.3\end{array}$ & 59 \\
\hline 7 & $\begin{array}{r}\text { Count } \\
\text { Expected }\end{array}$ & $\begin{array}{r}22 \\
29.1\end{array}$ & $\begin{array}{r}40 \\
44.3\end{array}$ & $\begin{array}{r}53 \\
41.5\end{array}$ & 115 \\
\hline Yr12 & $\begin{array}{r}\text { Count } \\
\text { Expected }\end{array}$ & $\begin{array}{r}24 \\
27.6\end{array}$ & $\begin{array}{r}46 \\
42.0\end{array}$ & $\begin{array}{r}39 \\
39.3\end{array}$ & 109 \\
\hline Trade & $\begin{array}{r}\text { Count } \\
\text { Expected }\end{array}$ & $\begin{array}{r}16 \\
21.8\end{array}$ & $\begin{array}{r}36 \\
33.2\end{array}$ & $\begin{array}{r}34 \\
31.0\end{array}$ & 86 \\
\hline Prof & $\begin{array}{r}\text { Count } \\
\text { Expected }\end{array}$ & $\begin{array}{r}58 \\
66.9\end{array}$ & $\begin{array}{r}104 \\
101.8 \\
\end{array}$ & $\begin{array}{r}102 \\
95.3\end{array}$ & 264 \\
\hline Bachelor & $\begin{array}{r}\text { Count } \\
\text { Expected }\end{array}$ & $\begin{array}{r}73 \\
59.8\end{array}$ & $\begin{array}{r}96 \\
91.0\end{array}$ & $\begin{array}{r}67 \\
85.2\end{array}$ & 236 \\
\hline PostGrad & $\begin{array}{r}\text { Count } \\
\text { Expected }\end{array}$ & $\begin{array}{r}78 \\
57.8\end{array}$ & $\begin{array}{r}78 \\
87.9\end{array}$ & $\begin{array}{r}72 \\
82.3\end{array}$ & 228 \\
\hline TOTAL & Count & 278 & 423 & 396 & 1097 \\
\hline
\end{tabular}

Chi-Square tests on Statement 8 - I worry about medical receptionists reading my medical information revealed citizens opinion differing by age $\left(\chi^{2}=27.227, \mathrm{df}=10\right.$, $p=0.002)$ and highest education level $\left(\chi^{2}=35.606, \mathrm{df}=12, p<0.001\right)$. Citizens aged between 18 and 50 disagreed with Statement 8 more frequently than expected and citizens older than 50 agreed with the statement more frequently than expected (see Table 24).

Table 24: Statement 8 Pearsons Chi-Square statistically significant - Age

\begin{tabular}{|c|c|c|c|c|c|}
\hline Age & Frequency & Disagree & Neutral & Agree & Total \\
\hline $18-25$ & $\begin{array}{r}\text { Count } \\
\text { Expected Count }\end{array}$ & $\begin{array}{r}17 \\
9.2\end{array}$ & $\begin{array}{r}9 \\
13.1\end{array}$ & $\begin{array}{r}6 \\
9.7\end{array}$ & 32 \\
\hline 26-39 & $\begin{array}{r}\text { Count } \\
\text { Expected Count }\end{array}$ & $\begin{array}{r}52 \\
42.1\end{array}$ & $\begin{array}{r}56 \\
60.1\end{array}$ & $\begin{array}{r}39 \\
44.8\end{array}$ & 147 \\
\hline $40-50$ & $\begin{array}{r}\text { Count } \\
\text { Expected Count }\end{array}$ & $\begin{array}{r}88 \\
73.3\end{array}$ & $\begin{array}{r}91 \\
104.7\end{array}$ & $\begin{array}{r}77 \\
78.0\end{array}$ & 256 \\
\hline $51-65$ & $\begin{array}{r}\text { Count } \\
\text { Expected Count }\end{array}$ & $\begin{array}{r}108 \\
120.3\end{array}$ & $\begin{array}{r}183 \\
171.8\end{array}$ & $\begin{array}{r}129 \\
127.9\end{array}$ & 420 \\
\hline $66-80$ & $\begin{array}{r}\text { Count } \\
\text { Expected Count }\end{array}$ & $\begin{array}{r}44 \\
60.4\end{array}$ & $\begin{array}{r}95 \\
86.3\end{array}$ & $\begin{array}{r}72 \\
64.3 \\
\end{array}$ & 211 \\
\hline Over 80 & $\begin{array}{r}\text { Count } \\
\text { Expected Count }\end{array}$ & $\begin{array}{r}9 \\
12.6\end{array}$ & $\begin{array}{r}20 \\
18.0\end{array}$ & $\begin{array}{r}15 \\
13.4\end{array}$ & 44 \\
\hline TOTAL & Count & 318 & 454 & 338 & 1110 \\
\hline
\end{tabular}

Highest Education Level emerged as a statistically significant demographic. As illustrated in Table 25 tertiary educated Australians responded 'disagree' or 'strongly disagree' far more frequently than expected and all other groups responded more frequently than expected to 'strongly agree' or 'agree'. 
Table 25: Statement 8 Pearsons Chi-Square statistically significant - Highest Level of Education

\begin{tabular}{|c|c|c|c|c|c|}
\hline $\begin{array}{c}\text { Highest } \\
\text { Education }\end{array}$ & Frequency & Disagree & Neutral & Agree & Total \\
\hline$<Y r 10$ & $\begin{array}{r}\text { Count } \\
\text { Expected }\end{array}$ & $\begin{array}{r}9 \\
16.8\end{array}$ & $\begin{array}{r}32 \\
24.0\end{array}$ & $\begin{array}{r}18 \\
18.1\end{array}$ & 59 \\
\hline 7 & $\begin{array}{r}\text { Count } \\
\text { Expected }\end{array}$ & $\begin{array}{r}27 \\
33.7\end{array}$ & $\begin{array}{r}44 \\
48.1\end{array}$ & $\begin{array}{r}47 \\
36.2\end{array}$ & 118 \\
\hline Yr12 & $\begin{array}{r}\text { Count } \\
\text { Expected }\end{array}$ & $\begin{array}{r}33 \\
31.1\end{array}$ & $\begin{array}{r}47 \\
44.4\end{array}$ & $\begin{array}{r}29 \\
33.5\end{array}$ & 109 \\
\hline Trade & $\begin{array}{r}\text { Count } \\
\text { Expected }\end{array}$ & $\begin{array}{r}19 \\
24.8\end{array}$ & $\begin{array}{r}32 \\
35.4\end{array}$ & $\begin{array}{r}36 \\
26.7\end{array}$ & 87 \\
\hline Prof & $\begin{array}{r}\text { Count } \\
\text { Expected }\end{array}$ & $\begin{array}{r}61 \\
75.6\end{array}$ & $\begin{array}{r}111 \\
108.0\end{array}$ & $\begin{array}{r}93 \\
81.4 \\
\end{array}$ & 265 \\
\hline Bachelor & $\begin{array}{r}\text { Count } \\
\text { Expected }\end{array}$ & $\begin{array}{r}81 \\
67.4\end{array}$ & $\begin{array}{r}97 \\
96.1\end{array}$ & $\begin{array}{r}58 \\
72.5\end{array}$ & 236 \\
\hline PostGrad & $\begin{array}{r}\text { Count } \\
\text { Expected }\end{array}$ & $\begin{array}{r}86 \\
66.5\end{array}$ & $\begin{array}{r}88 \\
94.9\end{array}$ & $\begin{array}{r}59 \\
71.6\end{array}$ & 233 \\
\hline TOTAL & Count & 316 & 451 & 340 & 1107 \\
\hline
\end{tabular}

The Chi-Square testing on Statement 9 - I worry about computer staff being able to read my medical information when they are looking after medical systems, revealed citizens' opinion differing by age $\left(\chi^{2}=23.7, \mathrm{df}=10, p=0.008\right)$ and highest level of education $\left(\chi^{2}=46.6, \mathrm{df}=12, p<0.001\right)$. The $18-50$ years age group disagreed with this statement more frequently than expected and the respondents over 50 years of age 'strongly agree'/ 'agree' in larger numbers than expected. The number of 'neutral' responses from those over 50 years of age also exceeded expectations.

Postgraduate and Bachelor level educated citizens responded negatively to this statement more frequently than expected. Trades and Professionally qualified citizens 'strongly agree'/ 'agree' with the statement more frequently than expected and there is no discernable trend amongst respondents with Year 12 or less education.

Statement 25 - I would never agree to donate my medical information to anyone because I worry about potential misuse of the information. Chi-Square testing revealed one of the strongest $\chi^{2}$ results of the survey across education levels $\left(\chi^{2}=59.7, \mathrm{df}=12, p<0.001\right)$. Table 26 illustrates. Age was also important with strong results $\left(\chi^{2}=32.6, \mathrm{df}=10, p<0.001\right)$. 
Table 26: Statement 25 Pearsons Chi-Square statistically significant - Highest Level of Education

\begin{tabular}{|c|c|c|c|c|c|}
\hline $\begin{array}{c}\text { Highest } \\
\text { Education }\end{array}$ & Frequency & Disagree & Neutral & Agree & Total \\
\hline$<Y r 10$ & $\begin{array}{r}\text { Count } \\
\text { Expected }\end{array}$ & $\begin{array}{r}25 \\
33.7\end{array}$ & $\begin{array}{r}15 \\
13.8\end{array}$ & $\begin{array}{r}16 \\
8.5\end{array}$ & 56 \\
\hline Yr10 & $\begin{array}{r}\text { Count } \\
\text { Expected }\end{array}$ & $\begin{array}{r}49 \\
66.8\end{array}$ & $\begin{array}{r}41 \\
27.4\end{array}$ & $\begin{array}{r}21 \\
16.8\end{array}$ & 111 \\
\hline Yr12 & $\begin{array}{r}\text { Count } \\
\text { Expected }\end{array}$ & $\begin{array}{r}56 \\
63.2\end{array}$ & $\begin{array}{r}34 \\
25.9\end{array}$ & $\begin{array}{r}15 \\
15.9\end{array}$ & 105 \\
\hline Trade & $\begin{array}{r}\text { Count } \\
\text { Expected }\end{array}$ & $\begin{array}{r}37 \\
51.7\end{array}$ & $\begin{array}{r}26 \\
21.2\end{array}$ & $\begin{array}{r}23 \\
13.0\end{array}$ & 86 \\
\hline Prof & $\begin{array}{r}\text { Count } \\
\text { Expected }\end{array}$ & $\begin{array}{r}163 \\
157.6 \\
\end{array}$ & $\begin{array}{r}59 \\
64.7\end{array}$ & $\begin{array}{r}40 \\
39.7\end{array}$ & 262 \\
\hline Bachelor & $\begin{array}{r}\text { Count } \\
\text { Expected }\end{array}$ & $\begin{array}{r}159 \\
140.8\end{array}$ & $\begin{array}{r}55 \\
57.7\end{array}$ & $\begin{array}{r}20 \\
35.5\end{array}$ & 234 \\
\hline PostGrad & $\begin{array}{r}\text { Count } \\
\text { Expected }\end{array}$ & $\begin{array}{r}162 \\
137.2\end{array}$ & $\begin{array}{r}37 \\
56.3\end{array}$ & $\begin{array}{r}29 \\
34.6\end{array}$ & 228 \\
\hline TOTAL & Count & 651 & 267 & 164 & 1082 \\
\hline
\end{tabular}

Postgraduate educated respondents exceeded expected counts with 'strongly disagree'/ 'disagree' responses. Their 'neutral' responses are well below expected counts indicating little equivocation in relation to this statement by postgraduates. Those with Bachelor level education are following a similar, though less extreme, pattern of responses. High School and Trades qualified citizens are more 'neutral' to positive in their responses. Professionally qualified citizens hold space between the high school and tertiary citizens.

Age is, once again statistically significant with responses to this statement with citizens older than 66 years responding positively to the statement more frequently than expected and those younger than 66 years not meeting expected counts for 'strongly agree'/ 'agree'.

The Chi-Square test results for Statement 27 - I worry about insurance companies getting access to medical information because they may not use information in a way that benefits society, revealed statistically significant results for self-reported healthcare workers $\left(\chi^{2}=6.9, \mathrm{df}=2, p=0.032\right)$, as presented in Table 27 . 
Table 27: Statement 27 Pearson's Chi-Square - Statistically Significant - healthcare worker.

\begin{tabular}{|c|r|r|r|r|r|}
\hline $\begin{array}{c}\text { Healthcare } \\
\text { worker }\end{array}$ & Frequency & Disagree & Neutral & Agree & Total \\
\hline \multirow{2}{*}{ No } & Count & 65 & 184 & 593 & 842 \\
& Expected Count & 64.8 & 169.3 & 607.9 & 262 \\
\hline Yes & Count & 20 & 38 & 204 & 1104 \\
\hline \multirow{2}{*}{ TOTAL } & Expected Count & 20.2 & 52.7 & 189.1 & 797 \\
\hline
\end{tabular}

Self reported healthcare workers 'strongly agree'/ 'agree' with the statement more frequently than expected and non healthcare workers are more 'neutral' in their response than expected.

\subsubsection{Restricted Access}

Chi-Square tests on Statement 10 - In Australia my healthcare providers try to protect my privacy by restricting access to my medical information, revealed citizens' opinion's differing by age $\left(\chi^{2}=20.047, \mathrm{df}=10, p=0.029\right)$. Citizens aged less than 66 years did not 'strongly agree'/ 'agree' at expected frequencies and their 'neutral' frequency exceeded expected frequency. Positive responses from citizens aged 66 years and older exceeded expected frequencies.

Chi-Square tests on Statement 11 - It seems that my healthcare providers feel that the fewer people who see my medical information the higher the level of privacy they provide for me, revealed citizens' opinion's differing between those who self reported as healthcare workers and others $\left(\chi^{2}=8.767, \mathrm{df}=2, p=0.012\right)$. Healthcare workers responses were polarised with greater than expected frequency on both 'agree' and 'disagree' and less than expected on the central 'neutral' response as presented in Table 28.

Table 28: Statement 11 Pearsons Chi-Square statistically significant - Healthcare Worker

\begin{tabular}{|c|r|r|r|r|r|}
\hline $\begin{array}{c}\text { Healthcare } \\
\text { worker }\end{array}$ & Frequency & Disagree & Neutral & Agree & Total \\
\hline No & Count & 34 & 229 & 395 & 661 \\
& Expected Count & 35.8 & 211.1 & 414.1 & 225 \\
\hline Yes & Count & 14 & 54 & 157 & 886 \\
\hline \multirow{2}{*}{ TOTAL } & Expected Count & 12.2 & 71.9 & 140.9 & 555 \\
\hline
\end{tabular}


Non-healthcare workers provided 'neutral' responses more frequently than expected 'strongly agree'/'agree' responses less frequently than expected.

\subsubsection{Tripartite Component: Privacy Concept - Qualitative Analysis}

Table 29 presents the qualitative codes adopted and the frequency with which a theme was included in respondents comments to the two qualitative survey questions for deductive themes related to the tripartite Privacy Concept as described in the Research Method Chapter.

Table 29: Privacy Concept Deductive Encoding Summary

\begin{tabular}{|c|l|r|l|r|r|r|}
\hline Code & & $\begin{array}{l}\text { Sub } \\
\text { Code }\end{array}$ & Theme & $\begin{array}{l}\text { Comment 1 } \\
\text { Frequency }\end{array}$ & $\begin{array}{c}\text { Comment 2 } \\
\text { Frequency }\end{array}$ & Total \\
\hline 1 & $\begin{array}{l}\text { Privacy } \\
\text { Concept }\end{array}$ & A & Expressing anxiety & 31 & 114 \\
\hline & B & $\begin{array}{l}\text { Not anxious about secondary } \\
\text { use of data }\end{array}$ & 16 & 31 \\
\hline & C & $\begin{array}{l}\text { Consumer TRUST - Don't know } \\
\text { who has information - Lack of } \\
\text { transparency }\end{array}$ & 63 & 33 \\
\hline & D & $\begin{array}{l}\text { Not everyone who has access } \\
\text { has patients' best interests at } \\
\text { heart }\end{array}$ & 13 & 79 \\
\hline
\end{tabular}

Examples of the qualitative comments and demographics of the respondents are presented in Table 30 arranged under the deductive themes.

Table 30: Tripartite - Privacy Concept deductive themes

\begin{tabular}{|l|l|}
\hline \multicolumn{1}{|l|}{ Theme } \\
\hline 1A - Expressing anxiety \\
\hline & $\begin{array}{l}\ldots \text { I am very worried about the potential for misuse and privacy breaches... } \\
\text { [Survey595,F,NSW,18-25,Bach,NHW] }\end{array}$ \\
& $\begin{array}{l}\text {.. companies or organisations may gain access with intentions that are not } \\
\text { consistent with human rights and misuse data according to more profit making } \\
\text { mandates. [Survey725,M,NSW18-25,Yr12,HW] }\end{array}$ \\
\hline $\begin{array}{l}\text { Who uses it and why. Privacy. I would worry about me losing control of my info. } \\
\text { [Survey187,F,NT,26-39,Yr10,NHW] }\end{array}$ & $\begin{array}{l}\text { I was in a situation where I personally knew a medical clerk working at my } \\
\text { doctors surgery. I also knew she was a heroin addict. Her accessing my medical } \\
\text { records was a concern for me... [Survey476,F,VIC,26-39,Postgrad,NHW] }\end{array}$ \\
\hline $\begin{array}{l}\text { Yes ... even if companies are ethical, not all employees would be. } \\
{[\text { Survey602,F,NSW,51-65,Postgrad,NHW] }}\end{array}$ \\
\hline
\end{tabular}




\begin{tabular}{|c|c|}
\hline & $\begin{array}{l}\text { Would be exceedingly concerned about release of data that included things like } \\
\text { name, address, date of birth, medicare no. etc that might be potentially used for } \\
\text { identity theft [Survey377,M,NSW,51-65,Bach,HW] }\end{array}$ \\
\hline & $\begin{array}{l}\text { General concerns regarding who has access to the information, purposes and } \\
\text { possible negative impact on the patient eg. discrimination. [Survey561,F,NSW,51- } \\
65 \text { Trade,NHW] }\end{array}$ \\
\hline \multicolumn{2}{|r|}{ 1B - Not anxious about secondary use of data } \\
\hline & $\begin{array}{l}\text { Provided it has no detrimental impact on the individual, I don't have any } \\
\text { objections.[Survey476,F,VIC,26-39,Postgrad,NHW] }\end{array}$ \\
\hline & $\begin{array}{l}\text { I am not overly concerned regarding my personal records but understand the } \\
\text { concerns of others where sensitive information is contained...I would be only to } \\
\text { happy to support data donation... [Survey } 448, F, V I C, 40-50, B a c h, H W]\end{array}$ \\
\hline & $\begin{array}{l}\text { No. I feel confident that my doctor will respect my privacy and that records are } \\
\text { kept confidential. [Survey249,F,NSW,40-50,Postgrad,NHW] }\end{array}$ \\
\hline \multicolumn{2}{|r|}{ 1C - Consumer TRUST - Don't know who has information - Lack of transparency } \\
\hline & $\begin{array}{l}\text { Yes if it is anything like the phone numbers given out by Telstra there's no way of } \\
\text { knowing who will get your information, their purpose and their redistribution and } \\
\text { to whom. [Survey } 488, F, V I C, 40-50, P r o f, H W]\end{array}$ \\
\hline & $\begin{array}{l}\text {... I must admit I don't even know who has access to my information from my } \\
\text { medical visits. [Survey } 94, F, N S W, 26-39, B a c h, N H W]\end{array}$ \\
\hline & $\begin{array}{l}\text {... in theory it sounds a good idea but once information is given out anything can } \\
\text { happen to it... [Survey } 718, M, N S W, 66-80, \text { Prof,NHW] }\end{array}$ \\
\hline & $\begin{array}{l}\text { I do not trust my insurance company having access to medical records, but I trust } \\
\text { Doctors, nurses, healthcare staff and workers. [Survey190,M,NSW,51-65,Prof,NHW] }\end{array}$ \\
\hline & Trusting a system is important... [Survey700,F,NSr10,NHW] \\
\hline \multicolumn{2}{|c|}{ 1D - Not everyone who has access has patients' best interests at heart } \\
\hline & $\begin{array}{l}\text {...Unscrupulous employers may seek to misuse private medical information... } \\
\text { [Survey539,M,NSW,66-80,Postgrad,NHW] }\end{array}$ \\
\hline & $\begin{array}{l}\text { Concern re: recent offer of DNA testing and its possible effect on health } \\
\text { insurance premium charges and employment opportunities. [Survey191,F,NSW,66- } \\
80, \text { Postgrad,NHW] }\end{array}$ \\
\hline & $\begin{array}{l}\text { I wouldn't like my data to get into the hands of those outside the medical } \\
\text { profession. [Survey358,F,Unknown,>80,Yr10,NHW] }\end{array}$ \\
\hline & $\begin{array}{l}\text { No only that the information is collected respectfully and only distributed to } \\
\text { appropriate companies that will use the information in a way that does not just } \\
\text { benefit themselves. [Survey239,F,NSW,18-25,HSC,Unknown] }\end{array}$ \\
\hline & If it gets into the hands of the wrong people. [Survey459,F,VIC,26-39,Postgrad,NHW] \\
\hline & $\begin{array}{l}\text { Unscrupulous healthcare workers/companies eg. pharmaceutical are only in the } \\
\text { minority ... [Survey } 79, M, N S W, 51-65, P r o f, N H W]\end{array}$ \\
\hline \multicolumn{2}{|r|}{ 1E - Surveillance } \\
\hline & $\begin{array}{l}\text { As long as lam consulted, lam prepared to release most of my data/records to } \\
\text { most researchers-companies to assist them and even for 'status quo' figures but } \\
\text { definitely not for 'snooping' or spying by anyone. [Survey318,M,NSW,66-80,Prof,NHW] }\end{array}$ \\
\hline
\end{tabular}

4.2.5 Tripartite Component: Privacy Justification - Quantitative Analysis

There are six survey statements $(1,3,4,12,26,28)$ pertaining to the tripartite 'justification'. Statistically significant differences were found regarding gender, age, and highest education level. Table 31 presents a summary of statistically significant results. 
Table 31: Tripartite Privacy Justification Statistically Significant Results

\begin{tabular}{|l|c|c|c|c|l|}
\hline & Construct & Gender & Age & $\begin{array}{r}\text { Highest Education } \\
\text { Level }\end{array}$ & Healthcare Worker \\
\hline Statement 1 & Rights Based & $\mathrm{X}$ & & & \\
\hline Statement 3 & Rights Based & $\mathrm{X}$ & $\mathrm{X}$ & & \\
\hline Statement 4 & Rights Based & & & & \\
\hline Statement 12 & Balance & & $\mathrm{X}$ & $\mathrm{X}$ & \\
\hline Statement 26 & Balance & & & & \\
\hline Statement 28 & Balance & $\mathrm{X}$ & & & \\
\hline
\end{tabular}

Gender, age and education level are statistically significant for the rights based construct and gender, age and education level for the statements on using data for 'common good'. Each of these is discussed in more detail below.

\subsubsection{1 'Rights' based}

Chi-Square tests on Statement 1 - I believe that I have a 'right' to personal privacy, revealed citizens opinion differing by gender $\left(\chi^{2}=8.792, \mathrm{df}=2, p=0.012\right)$. Females responded positively more frequently than expected and males were more 'neutral' in their responses than expected.

Statement 3 - I have the 'right' to share my medical information with others, also found gender and age to be statistically significant through Pearson Chi-Square testing with results for gender of $\left(\chi^{2}=7.972, \mathrm{df}=2, p=0.019\right)$ and age of $\left(\chi^{2}=40.144, \mathrm{df}=2, p<0.001\right)$.

Males were less supportive than expected of this statement and females were more supportive than expected. In terms of age, the older citizens ( $>66$ years) were agreeing at lower rates than expected and those aged 26-50 were again expressing stronger support than expected. Citizens aged 66-80 disagreed with the statement at more than 2.5 times the expected frequency.

The Chi-Square test results for Statement 12 - If information about my health can be used to help others who are suffering ill-health then I believe my information should be used to help those people, revealed statistically significant results across age $\left(\chi^{2}=25.2, \mathrm{df}=10, p=0.005\right)$ and highest education level $\left(\chi^{2}=22.6, \mathrm{df}=12, p=0.031\right)$. 
Respondents older than 66 years responded more positively than expected and the majority of younger consumers (aged 26-65 years) did not meet the expected number of 'agree' responses, as illustrated in Table 32.

Table 32: Statement 12 Pearsons Chi-Square Statistically Significant - Age

\begin{tabular}{|c|c|c|c|c|c|}
\hline Age & Frequency & Disagree & Neutral & Agree & Total \\
\hline $18-25$ & $\begin{array}{r}\text { Count } \\
\text { Expected Count }\end{array}$ & $\begin{array}{r}0 \\
2.9\end{array}$ & $\begin{array}{r}6 \\
4.4\end{array}$ & $\begin{array}{r}26 \\
24.7\end{array}$ & 32 \\
\hline $26-39$ & $\begin{array}{r}\text { Count } \\
\text { Expected Count }\end{array}$ & $\begin{array}{r}12 \\
13.2\end{array}$ & $\begin{array}{r}25 \\
20.3\end{array}$ & $\begin{array}{r}110 \\
113.5\end{array}$ & 147 \\
\hline $40-50$ & $\begin{array}{r}\text { Count } \\
\text { Expected Count }\end{array}$ & $\begin{array}{r}25 \\
22.5\end{array}$ & $\begin{array}{r}43 \\
34.7\end{array}$ & $\begin{array}{r}183 \\
193.8 \\
\end{array}$ & 251 \\
\hline $51-65$ & $\begin{array}{r}\text { Count } \\
\text { Expected Count } \\
\end{array}$ & $\begin{array}{r}46 \\
37.0 \\
\end{array}$ & $\begin{array}{r}60 \\
57.0 \\
\end{array}$ & $\begin{array}{r}306 \\
318.1 \\
\end{array}$ & 412 \\
\hline $66-80$ & $\begin{array}{r}\text { Count } \\
\text { Expected Count } \\
\end{array}$ & $\begin{array}{r}12 \\
18.6 \\
\end{array}$ & $\begin{array}{r}14 \\
28.6 \\
\end{array}$ & $\begin{array}{r}181 \\
159.8 \\
\end{array}$ & 207 \\
\hline Over 80 & $\begin{array}{r}\text { Count } \\
\text { Expected Count }\end{array}$ & $\begin{array}{r}3 \\
3.9 \\
\end{array}$ & $\begin{array}{r}3 \\
5.9 \\
\end{array}$ & $\begin{array}{r}37 \\
33.2 \\
\end{array}$ & 43 \\
\hline TOTAL & Count & 98 & 151 & 843 & 1092 \\
\hline
\end{tabular}

Tertiary educated respondents did not meet 'strongly agree'/'agree' expected counts for Statement 12 with counts exceeded for both 'neutral' and negative responses as presented in Table 33.

Table 33: Statement 12 Pearson Chi-Square Statistically Significant - Education Level

\begin{tabular}{|c|c|c|c|c|c|}
\hline $\begin{array}{l}\text { Highest } \\
\text { Education }\end{array}$ & Frequency & Disagree & Neutral & Agree & Total \\
\hline$<Y r 10$ & $\begin{array}{r}\text { Count } \\
\text { Expected }\end{array}$ & $\begin{array}{r}3 \\
5.1\end{array}$ & $\begin{array}{r}3 \\
7.9\end{array}$ & $\begin{array}{r}51 \\
44.0\end{array}$ & 57 \\
\hline Yr10 & $\begin{array}{r}\text { Count } \\
\text { Expected }\end{array}$ & $\begin{array}{r}11 \\
10.5\end{array}$ & $\begin{array}{r}21 \\
16.1\end{array}$ & $\begin{array}{r}85 \\
90.3\end{array}$ & 117 \\
\hline Yr12 & $\begin{array}{r}\text { Count } \\
\text { Expected }\end{array}$ & $\begin{array}{r}5 \\
9.7\end{array}$ & $\begin{array}{r}10 \\
14.9\end{array}$ & $\begin{array}{r}93 \\
83.4\end{array}$ & 108 \\
\hline Trade & $\begin{array}{r}\text { Count } \\
\text { Expected }\end{array}$ & $\begin{array}{r}5 \\
7.8\end{array}$ & $\begin{array}{r}12 \\
12.0\end{array}$ & $\begin{array}{r}70 \\
67.2\end{array}$ & 87 \\
\hline Prof & $\begin{array}{r}\text { Count } \\
\text { Expected }\end{array}$ & $\begin{array}{r}25 \\
23.5\end{array}$ & $\begin{array}{r}26 \\
36.0\end{array}$ & $\begin{array}{r}210 \\
201.5\end{array}$ & 261 \\
\hline Bachelor & $\begin{array}{r}\text { Count } \\
\text { Expected }\end{array}$ & $\begin{array}{r}25 \\
20.9\end{array}$ & $\begin{array}{r}40 \\
32.0\end{array}$ & $\begin{array}{r}167 \\
179.1\end{array}$ & 232 \\
\hline PostGrad & $\begin{array}{r}\text { Count } \\
\text { Expected }\end{array}$ & $\begin{array}{r}24 \\
20.4\end{array}$ & $\begin{array}{r}38 \\
31.2\end{array}$ & $\begin{array}{r}164 \\
174.5\end{array}$ & 226 \\
\hline TOTAL & Count & 98 & 150 & 840 & 1088 \\
\hline
\end{tabular}

Respondents with less than Year 10 education level responded in higher frequency than expected. It is possible that the older ( $>66$ years), less formally educated respondents are influencing these results. As the demographics presented in Figure 
33 below illustrate, many older respondents have less than 10 years of formal education.

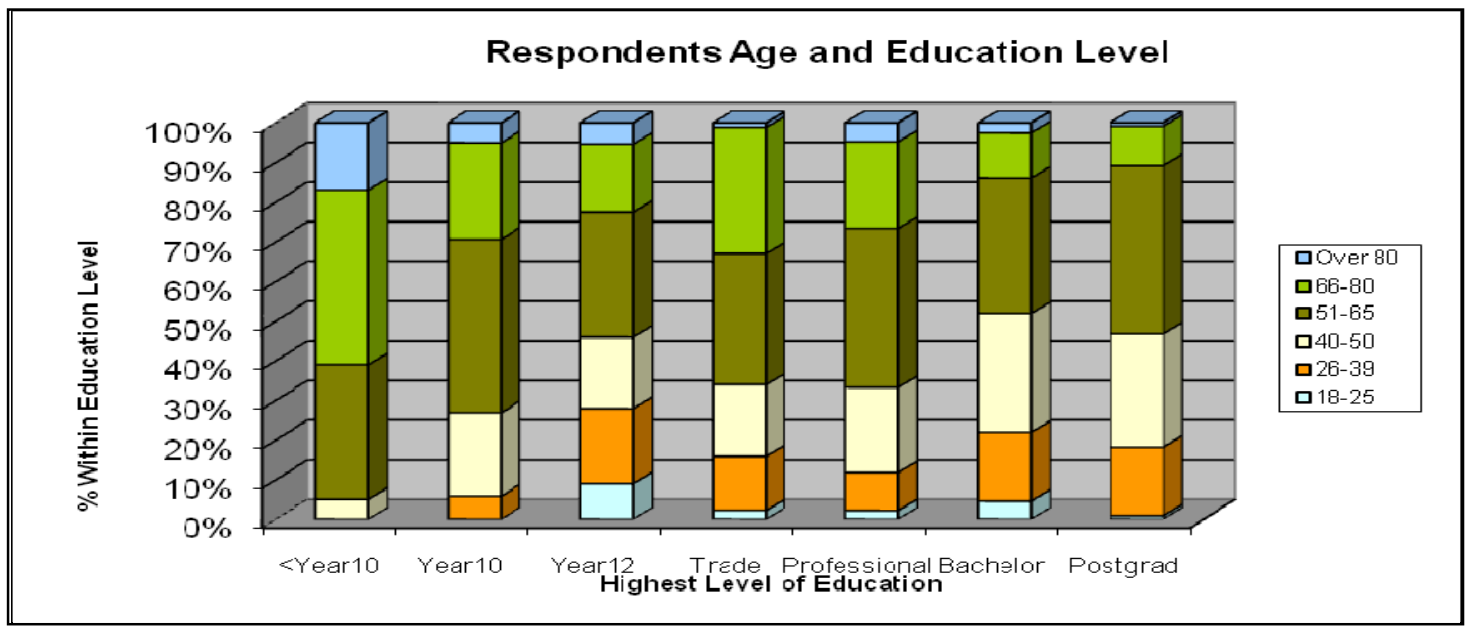

Figure 33: Respondents age group by Education Level

Statement 28 - Using medical information for the 'common good' is OK but I worry about the risk to a person's privacy. Chi-Square tests indicate statistically significant results across gender $\left(\chi^{2}=6.7, \mathrm{df}=2, p=0.035\right)$. Women chose 'strongly agree'/ 'agree' as their response more frequently than expected while men responded with 'disagree' or 'neutral' more frequently than expected as illustrated in Table 34.

Table 34:Statement 28 Pearsons Chi-Square Statistically Significant - Gender

\begin{tabular}{|c|r|r|r|r|r|}
\hline Gender & \multicolumn{1}{|c|}{ Frequency } & Disagree & Neutral & \multicolumn{1}{c|}{ Agree } & \multicolumn{1}{c|}{ Total } \\
\hline \multirow{2}{*}{ Female } & Count & 55 & 162 & 523 & 740 \\
& Expected Count & 64.4 & 169.1 & 506.5 & 363 \\
\hline \multirow{2}{*}{ Male } & Count & 41 & 90 & 232 & 1103 \\
\hline \multirow{2}{*}{ TOTAL } & Expected Count & 31.6 & 82.9 & 248.5 & \\
\hline
\end{tabular}

The next section presents consumers qualitative comments regarding the two Privacy Justification issues explored through the survey - that is the 'right' to privacy and balancing the needs of society in terms of secondary use of medical data.

4.2.6 Tripartite Component: Privacy Justification - Qualitative Analysis

Table 35 presents the summary of qualitative analysis. 
Table 35: Justification Qualitative Summary

\begin{tabular}{|c|c|c|l|c|c|c|}
\hline Code & & $\begin{array}{l}\text { Sub } \\
\text { Code }\end{array}$ & Theme & $\begin{array}{l}\text { Comment 1 } \\
\text { Frequency }\end{array}$ & $\begin{array}{c}\text { Comment 2 } \\
\text { Frequency }\end{array}$ & Total \\
\hline 2 & Justification & A & 'Right' to privacy & 8 & 6 & 14 \\
\hline & B & $\begin{array}{l}\text { Responsibility of citizens to } \\
\text { participate in secondary use. } \\
\text { Individual rights versus 'common } \\
\text { good' }\end{array}$ & 43 & 26 & 69 \\
\hline & C & $\begin{array}{l}\text { Personal data as a commercial } \\
\text { commodity; Commercial aspects } \\
\text { of data use }\end{array}$ & 48 & 16 & 64 \\
\hline & D & Ownership of data & 29 & 33 & 62 \\
\hline \multicolumn{2}{|l}{ Total number of consumer comments regarding privacy justification } & 128 & 81 & $\mathbf{2 0 9}$ \\
\hline
\end{tabular}

Examples of the qualitative comments and demographics of the respondents are presented in Table 36 arranged under the deductive themes.

Table 36: Tripartite model - Justification of Privacy - Deductive themes

\begin{tabular}{|c|c|}
\hline \multicolumn{2}{|l|}{ Theme } \\
\hline \multicolumn{2}{|c|}{ 2A - 'Right’ to Privacy } \\
\hline & $\begin{array}{l}\text { So called privacy in Australia is over the top. Information should be available to } \\
\text { improve society in this case health. [Survey } 36, M, N S W, 66-80, Y r 10, N H W]\end{array}$ \\
\hline & $\begin{array}{l}\text {... seeing a GP does not mean that I have handed over my right to privacy or my } \\
\text { choice to disclose or not! [Survey } 405, F, S A, 51-65, \text { Postgrad,HW] }\end{array}$ \\
\hline \multicolumn{2}{|r|}{$\begin{array}{l}\text { 2B - Responsibility of citizens to participate in secondary use. Individual rights versus } \\
\text { 'common good' }\end{array}$} \\
\hline & $\begin{array}{l}\text { With appropriate protocols and audit trails in place, I believe de-personalised } \\
\text { medical data can be used for worthwhile research purposes. [Survey1152,F,VIC,51- } \\
65, \text { Postgrad,HW] }\end{array}$ \\
\hline & $\begin{array}{l}\text { I understand the use of medical data is of utmost importance for research and } \\
\text { progress, but always have that fear of not being able to trust the powers that be. } \\
\text { But risks aside how will there ever be progress in research?... [Survey617,F,NSW,66- } \\
80, \mathrm{HSC}, \mathrm{NHW} \text { ] }\end{array}$ \\
\hline & $\begin{array}{l}\text { As tax payers we all contribute to everyone's healthcare - medicare, subsidies } \\
\text { (pensioners, unemployed etc), research, hospitals - as such, all info that can be } \\
\text { collected and used anonymously to improve treatments, diagnosis etc should be } \\
\text { available to all in the medical/research fields... [Survey493,F,NSW,66-80,Bach,NHW] }\end{array}$ \\
\hline & $\begin{array}{l}\text {... As a former federal bureaucrat (including in health department) I know } \\
\text { accidents can happen that result in breach of patient privacy - but I think the } \\
\text { "public good" resulting from medical research has to be seen as important enough } \\
\text { to outweigh the risk of privacy breach. [Survey } 988, F, A C T, 51-65, \text { Postgrad,NHW] }\end{array}$ \\
\hline \multicolumn{2}{|r|}{ 2C - Personal data as a commercial commodity - Commercial aspects of data use } \\
\hline & $\begin{array}{l}\text { Yes, intermediaries gather data and aggregate and sell this data. } \\
\text { [Survey375,M,NSW,51-65,Postgrad,NHW] }\end{array}$ \\
\hline & $\begin{array}{l}\text { My greatest concern is insurance companies accessing information that will then } \\
\text { 'allow' them to refuse certain people or increased premiums to an unreasonable } \\
\text { level. [Survey } 423, F, A C T, 51-65, B a c h, N H W]\end{array}$ \\
\hline & $\begin{array}{l}\text { Yes. I am concerned particularly about insurance companies and also the } \\
\text { extrapolation of that data towards my offspring. [Survey780,F,NT,51-65,Postgrad,HW] }\end{array}$ \\
\hline & $\begin{array}{l}\text {... Medical data used as a tool for research by non-profit organisations is fine. I } \\
\text { don't want to be giving big pharmaceutical companies the ability to make bigger }\end{array}$ \\
\hline
\end{tabular}




\begin{tabular}{|c|c|}
\hline & profits ... [Survey604,F,NSW,40-50,Bach,NHW] \\
\hline & $\begin{array}{l}\text {... Drug companies want this information as do research organisations. Healthcare } \\
\text { providers may see this as an opportunity to compile and sell their data on their } \\
\text { health files. Regulation of this activity is probably required at Federal Govt level. } \\
\text { [Survey1039,F,NSW,51-65,Bach,NHW] }\end{array}$ \\
\hline & $\begin{array}{l}\text { Concerns over theft of data for use for commercial purposes as was experienced } \\
\text { last year in India with British medical records Also concerned that employers and } \\
\text { others will discriminate if they have access to this info. [Survey } 489, F, A C T, 40-50, P r o f, N H W]\end{array}$ \\
\hline & $\begin{array}{l}\text { I do have concerns that health practitioners may 'sell' aggregated data from } \\
\text { patients of their practice [Survey } 1153, F, V I C, 40-50, \text { Prof,NHW] }\end{array}$ \\
\hline & $\begin{array}{l}\text { Life insurance companies and genetic testing - both sides of this argument have } \\
\text { merit and I'm not clear on how to resolve it. [Survey539,M,NSW,66-80,Postgrad,NHW] }\end{array}$ \\
\hline \multicolumn{2}{|c|}{ 2D - Ownership of Data } \\
\hline & $\begin{array}{l}\ldots \text { I think that both Doctor and myself should 'own' the information. } \\
{[\text { [Survey969,F,NSW,26-39,Postgrad,NHW] }}\end{array}$ \\
\hline & $\begin{array}{l}\text { The notes made by the doctor are for the doctors records, but the patient should } \\
\text { be able to access copies if requested. Why should the patient be denied notes } \\
\text { about their own health? [Survey262,M,SA,66-80,Prof,NHW] }\end{array}$ \\
\hline & $\begin{array}{l}\text { It's a disgrace that a doctor own 'notes' they write up on a person. [Survey4,F,NSW,26- } \\
39, \text { Prof,NHW] }\end{array}$ \\
\hline & $\begin{array}{l}\ldots \text { I would like to think that a wide range of medical data can be collected for the } \\
\text { benefit of all ie. medical research - they should not be the property of GPS. } \\
\text { [Survey23,F,NSW,51-65,Prof,HW] }\end{array}$ \\
\hline & $\begin{array}{l}\text { Re Q30 my opinion is that records should be 'jointly owned' by the Dr and patient } \\
\text { - after all the patient "pays" for the service - whether thru bulk bill or 'cash' doesn't } \\
\text { matter! [Survey91,F,NSW,40-50,HSC,NHW] }\end{array}$ \\
\hline & $\begin{array}{l}\text {...As a school teacher, I make notes/observations and record results constantly } \\
\text { about my pupils. They are NOT for publication in anyway and I never show them } \\
\text { to parents. However there is a constant system of reporting to parents using } \\
\text { bonafide channels of communication, including written reports and face-to-face } \\
\text { interviews. In the same way, I would expect that my Doctor makes notes to himself } \\
\text { regarding my treatment. They are HIS alone ... again not for publication in any } \\
\text { way. [Survey116,F,NSW,51-65,Bach,NHW] }\end{array}$ \\
\hline & $\begin{array}{l}\text {..."Ownership" and health records is debatable issue and as a healthcare provider } \\
\text { myself it is a dilemma as to who 'owns' the records - this is partly due to } \\
\text { differences in interpreting the purpose of the records. [Survey24,F,NSW,51-65,Postgrad,HW] }\end{array}$ \\
\hline
\end{tabular}

\subsubsection{Tripartite Component: Privacy Management - Quantitative Analysis}

There are sixteen survey statements $(2,7,13,14,15,16,17,18,19,20,21,22,23,24,29,30)$ pertaining to the tripartite 'privacy management' component. Statistically significant differences were found regarding gender, age, highest education level and healthcare workers and further details are provided in this section.

Table 37: Privacy Management statistically significant results.

\begin{tabular}{|l|c|c|c|c|c|}
\hline & Construct & Gender & Age & $\begin{array}{c}\text { Highest Education } \\
\text { Level }\end{array}$ & Healthcare Worker \\
\hline Statement 2 & Data Stewardship & $\mathrm{X}$ & & & $\mathrm{X}$ \\
\hline Statement 7 & Data Stewardship & & & & $\mathrm{X}$ \\
\hline Statement 18 & Data Stewardship & & & & \\
\hline Statement 24 & Data Stewardship & $\mathrm{X}$ & & & \\
\hline
\end{tabular}




\begin{tabular}{|l|c|c|c|c|c|}
\hline Statement 30 & Data Stewardship & & $\mathrm{X}$ & & $\mathrm{X}$ \\
\hline Statement 13 & Control & & & & \\
\hline Statement 14 & Control & & & & \\
\hline Statement 15 & Control & & & & \\
\hline Statement 16 & Control & $\mathrm{X}$ & $\mathrm{X}$ & & $\mathrm{X}$ \\
\hline Statement 17 & Control & $\mathrm{X}$ & & $\mathrm{X}$ & $\mathrm{X}$ \\
\hline Statement 19 & Control & $\mathrm{X}$ & & & \\
\hline Statement 20 & Control & & $\mathrm{X}$ & & $\mathrm{X}$ \\
\hline Statement 21 & Control & $\mathrm{X}$ & & $\mathrm{X}$ & \\
\hline Statement 22 & Control & $\mathrm{X}$ & & & $\mathrm{X}$ \\
\hline Statement 23 & Control & $\mathrm{X}$ & & & \\
\hline Statement 29 & Control & & & & \\
\hline
\end{tabular}

\subsubsection{Data Stewardship}

Chi-Square test results for Statement 2 - I think my medical records belong to me they don't just belong to my healthcare providers, indicate significant difference for gender $\left(\chi^{2}=5.8, \mathrm{df}=2, p=0.054\right)$ and healthcare workers $\left(\chi^{2}=11.2, \mathrm{df}=2, p=0.004\right)$. Females agreed or strongly agreed in higher frequencies than expected which contrasts with males who responded positively less frequently than expected. Males disagreed with the statement more frequently than expected.

Healthcare workers disagreed with Statement 2 at almost twice the expected frequency and did not meet expected frequency in supporting the statement. In contrast, non-medical workers exceeded expected frequency in 'agree' and 'strongly agree' responses (see Table 38).

Table 38: Statement 2 statistically significant - Healthcare worker

\begin{tabular}{|c|r|r|r|r|r|}
\hline $\begin{array}{c}\text { Healthcare } \\
\text { worker }\end{array}$ & Frequency & Disagree & Neutral & Agree & Total \\
\hline No & Count & 24 & 62 & 773 & 859 \\
& Expected Count & 33.0 & 63.6 & 762.4 & 262 \\
\hline Yes & Count & 19 & 21 & 222 & 1121 \\
\hline \multirow{2}{*}{ TOTAL } & Expected Count & 10.0 & 19.4 & 232.6 & 995 \\
\hline
\end{tabular}

The only statistically significant difference between citizens responses to Statement 7 - When my medical information is stored on a computer owned by a healthcare 
provider they should not assume that they 'own' the information, emerged for healthcare workers and non-healthcare workers $\left(\chi^{2}=18.586, \mathrm{df}=2, p<0.001\right)$. Self reported healthcare workers responded 'strongly disagree'/ 'disagree' more than twice as often as expected and the frequency of their positive response was less than expected. In contrast non-healthcare workers responded 'strongly agree'/ 'agree' more frequently than expected as illustrated in Table 39.

Table 39: Statement 7 statistically significant - Healthcare Worker

\begin{tabular}{|c|r|r|r|r|r|}
\hline $\begin{array}{c}\text { Healthcare } \\
\text { worker }\end{array}$ & Frequency & \multicolumn{1}{c|}{ Disagree } & \multicolumn{1}{c|}{ Neutral } & \multicolumn{1}{|c|}{ Agree } & Total \\
\hline \multirow{2}{*}{ No } & Count & 12 & 34 & 806 & 852 \\
& Expected Count & 20.7 & 38.3 & 793.0 & 260 \\
\hline Yes & Count & 15 & 16 & 229 & 1112 \\
\hline \multirow{2}{*}{ TOTAL } & Expected Count & 6.3 & 11.7 & 242.0 & 1035 \\
\hline
\end{tabular}

Chi-Square test results for Statement 30 - A legal judge in Australia decided that the notes written about a patient, by a Doctor, are owned by the Doctor not the patient. This decision seems reasonable to me, indicate significant difference for age $\left(\chi^{2}=40.160, \mathrm{df}=10, \quad p<0.001\right)$ and healthcare worker status $\left(\chi^{2}=9.419, \mathrm{df}=2\right.$, $p=0.009$ ). Citizens younger than 25 years and citizens older than 66 years 'strongly agree'/ 'agree' response frequency exceeded the expected counts (see Table 40). Healthcare workers responses were more polarised than expected with the 'neutral' response frequency lower than expected. Healthcare workers' positive response was more frequent than expected and their negative response frequency was less than expected.

Table 40: Statement 30 Pearson Chi-Square statistically significant - Age

\begin{tabular}{|c|c|c|c|c|c|}
\hline Age & Frequency & Disagree & Neutral & Agree & Total \\
\hline $18-25$ & $\begin{array}{r}\text { Count } \\
\text { Expected Count }\end{array}$ & $\begin{array}{r}18 \\
20.9\end{array}$ & $\begin{array}{r}4 \\
3.5\end{array}$ & $\begin{array}{r}9 \\
6.6\end{array}$ & 31 \\
\hline $26-39$ & $\begin{array}{r}\text { Count } \\
\text { Expected Count } \\
\end{array}$ & $\begin{array}{r}100 \\
100.4 \\
\end{array}$ & $\begin{array}{r}26 \\
16.8\end{array}$ & $\begin{array}{r}23 \\
31.9\end{array}$ & 149 \\
\hline $40-50$ & $\begin{array}{r}\text { Count } \\
\text { Expected Count }\end{array}$ & $\begin{array}{r}182 \\
169.1\end{array}$ & $\begin{array}{r}33 \\
28.2 \\
\end{array}$ & $\begin{array}{r}36 \\
53.7\end{array}$ & 251 \\
\hline $51-65$ & $\begin{array}{r}\text { Count } \\
\text { Expected Count }\end{array}$ & $\begin{array}{r}293 \\
278.9\end{array}$ & $\begin{array}{r}36 \\
46.5 \\
\end{array}$ & $\begin{array}{r}85 \\
88.6 \\
\end{array}$ & 414 \\
\hline $66-80$ & $\begin{array}{r}\text { Count } \\
\text { Expected Count } \\
\end{array}$ & $\begin{array}{r}123 \\
138.8 \\
\end{array}$ & $\begin{array}{r}18 \\
23.2 \\
\end{array}$ & $\begin{array}{r}65 \\
44.1 \\
\end{array}$ & 206 \\
\hline Over 80 & $\begin{array}{r}\text { Count } \\
\text { Expected Count } \\
\end{array}$ & $\begin{array}{r}21 \\
29.0 \\
\end{array}$ & $\begin{array}{r}6 \\
4.8 \\
\end{array}$ & $\begin{array}{r}16 \\
9.2 \\
\end{array}$ & 43 \\
\hline TOTAL & Count & 737 & 123 & 234 & 1094 \\
\hline
\end{tabular}




\subsubsection{Control}

Pearson Chi-Square testing on Statements 13,14 and 15 did not yield statistically significant differences. Chi-Square test results for Statement 16 - If I donated my medical information for research I would want to choose the level of privacy I required. For example I may choose (1) 'always anonymous' or (2) 'name and Medicare number can always be used' indicate significant difference for gender $\left(\chi^{2}=19.984, \mathrm{df}=2, p<0.001\right)$ and age $\left(\chi^{2}=70.314, \mathrm{df}=10, p<0.001\right)$. The frequency of females responding 'strongly agree'/'agree' exceeded expected frequency and, in contrast, frequency of males responding positively was less than expected. Citizens younger than 66 years responded 'strongly agree'/'agree' more frequently than expected. In contrast, citizens 66 years and older responded positively less frequently than expected as presented in Table 41.

Table 41: Statement 16 Pearson Chi-Square statistically significant - Age

\begin{tabular}{|c|c|c|c|c|c|}
\hline Age & Frequency & Disagree & Neutral & Agree & Total \\
\hline $18-25$ & $\begin{array}{r}\text { Count } \\
\text { Expected Count }\end{array}$ & $\begin{array}{r}0 \\
1.2\end{array}$ & $\begin{array}{r}2 \\
1.5\end{array}$ & $\begin{array}{r}29 \\
28.3\end{array}$ & 31 \\
\hline $26-39$ & $\begin{array}{r}\text { Count } \\
\text { Expected Count }\end{array}$ & $\begin{array}{r}4 \\
5.7\end{array}$ & $\begin{array}{r}3 \\
6.9\end{array}$ & $\begin{array}{r}139 \\
133.3\end{array}$ & 146 \\
\hline $40-50$ & $\begin{array}{r}\text { Count } \\
\text { Expected Count }\end{array}$ & $\begin{array}{r}0 \\
10.2\end{array}$ & $\begin{array}{r}8 \\
12.3\end{array}$ & $\begin{array}{r}251 \\
236.5\end{array}$ & 259 \\
\hline $51-65$ & $\begin{array}{r}\text { Count } \\
\text { Expected Count }\end{array}$ & $\begin{array}{r}15 \\
16.3\end{array}$ & $\begin{array}{r}12 \\
19.7\end{array}$ & $\begin{array}{r}388 \\
378.9\end{array}$ & 415 \\
\hline $66-80$ & $\begin{array}{r}\text { Count } \\
\text { Expected Count }\end{array}$ & $\begin{array}{r}19 \\
8.0\end{array}$ & $\begin{array}{r}21 \\
9.7\end{array}$ & $\begin{array}{r}163 \\
185.4\end{array}$ & 203 \\
\hline Over 80 & $\begin{array}{r}\text { Count } \\
\text { Expected Count }\end{array}$ & $\begin{array}{r}5 \\
1.5\end{array}$ & $\begin{array}{r}6 \\
1.9\end{array}$ & $\begin{array}{r}28 \\
35.6\end{array}$ & 39 \\
\hline TOTAL & Count & 43 & 52 & 998 & 1093 \\
\hline
\end{tabular}

Statement 17 - If I give consent for my health information to be used for research I want to be able to say who can use my information like 'medical researchers', 'drug companies', 'university researchers' or 'insurance companies'. Pearsons Chi-Square testing resulted in statistically significant differences by gender $\left(\chi^{2}=10.805, \mathrm{df}=2\right.$, $p=0.005)$ and healthcare worker $\left(\chi^{2}=9.099, \mathrm{df}=2, p=0.011\right)$. In terms of positive response of 'strongly agree'/ 'agree', females responded more frequently than expected and males less frequently than expected. Interestingly, self reported healthcare workers responded 'strongly agree'/ 'agree' more frequently than expected and non-medical workers responded positively less frequently than expected. Table 42 presents these results and it is clear that medical workers are less 
frequently 'neutral' or negative regarding this statement whereas non-medical workers responded more frequently to 'neutral' or 'strongly disagree'/'disagree' than expected.

Table 42: Statement 17 Pearsons Chi-Square statistically significant - Healthcare Worker

\begin{tabular}{|c|r|r|r|r|r|}
\hline $\begin{array}{c}\text { Healthcare } \\
\text { worker }\end{array}$ & Frequency & Disagree & Neutral & Agree & Total \\
\hline \multirow{2}{*}{ No } & Count & 47 & 96 & 707 & 850 \\
& Expected Count & 42.1 & 85.7 & 722.2 & 261 \\
\hline Yes & Count & 8 & 16 & 237 & 1111 \\
\hline \multirow{2}{*}{ TOTAL } & Expected Count & 12.9 & 23.3 & 221.8 & 944 \\
\hline
\end{tabular}

Chi-Square test results for Statement 19 - A person must be able to choose to keep their medical information private and never consent to release their medical information for any purpose, yielded statistically significant results for gender $\left(\chi^{2}=13.647, \mathrm{df}=2, \quad p=0.001\right)$ and highest education level $\left(\chi^{2}=27.625, \mathrm{df}=12\right.$, $p=0.006$ ). Males responded negatively to this statement more frequently than expected. Females responded negatively to this statement less frequently than expected. 'Neutral' responses from both genders were as expected. Tertiary educated citizens (Bachelor or Post Graduate) and citizens with less than 10 years of education did not respond positively at the expected frequency.

Chi-Square test results for Statement 20 - If I donated my medical information for research I would like to give my consent once - at the time of 'signing up' as a data donor, yielded statistically significant results for age $\left(\chi^{2}=28.773, \mathrm{df}=10, p=0.001\right)$, highest education level $\left(\chi^{2}=28.800, \mathrm{df}=12, p=0.004\right)$ and healthcare worker $\left(\chi^{2}=6.109, \mathrm{df}=2, \quad p=0.047\right)$. Citizens aged $40-65$ years responded 'strongly disagree'/'disagree' more frequently than expected. Citizens with professional and tertiary education expressed negative responses to this statement more frequently than expected. Healthcare workers responded 'strongly disagree'/'disagree' more frequently than expected.

Chi-Square test results for Statement 21 - If people agree to donate their data for medical research there must be a way for them to stop the donation agreement at any time, yielded statistically significant results for gender $\left(\chi^{2}=7.617, \mathrm{df}=2, p=0.022\right)$. In 
terms of positive responses of 'strongly agree'/'agree', females frequency exceeded expectations and male frequency of response was less than expected.

Chi-Square test results for Statement 22 - If people agree to donate their data for medical research from time to time they must be asked if they want to continue to donate, yielded statistically significant results for gender $\left(\chi^{2}=20.050, \mathrm{df}=2\right.$, $p<0.001)$, education level $\left(\chi^{2}=24.274, \mathrm{df}=12, p=0.019\right)$ and healthcare worker $\left(\chi^{2}=6.611, \mathrm{df}=2, p=0.037\right)$. In terms of positive responses of 'strongly agree'/'agree' female frequency exceeded expectations and male frequency of response was less than expected. Citizens without tertiary education responded 'strongly agree'/'agree' greater than or equal to the expected level. Citizens holding tertiary education qualifications did not respond 'strongly agree'/'agree' at expected frequency and their level of negative response exceeded the expected values (see Table 43). Healthcare workers responded 'strongly disagree'/'disagree' more frequently than expected.

Table 43: Statement 22 Pearsons Chi-Square statistically significant - Age

\begin{tabular}{|c|c|c|c|c|c|}
\hline Age & Frequency & Disagree & Neutral & Agree & Total \\
\hline $18-25$ & $\begin{array}{r}\text { Count } \\
\text { Expected Count }\end{array}$ & $\begin{array}{r}4 \\
5.0\end{array}$ & $\begin{array}{r}8 \\
7.0\end{array}$ & $\begin{array}{r}45 \\
45.0\end{array}$ & 57 \\
\hline $26-39$ & $\begin{array}{r}\text { Count } \\
\text { Expected Count }\end{array}$ & $\begin{array}{r}5 \\
10.4\end{array}$ & $\begin{array}{r}8 \\
14.3\end{array}$ & $\begin{array}{r}104 \\
92.3\end{array}$ & 117 \\
\hline $40-50$ & $\begin{array}{r}\text { Count } \\
\text { Expected Count }\end{array}$ & $\begin{array}{r}9 \\
9.7\end{array}$ & $\begin{array}{r}16 \\
13.5\end{array}$ & $\begin{array}{r}85 \\
86.8\end{array}$ & 110 \\
\hline $51-65$ & $\begin{array}{r}\text { Count } \\
\text { Expected Count } \\
\end{array}$ & $\begin{array}{r}5 \\
7.6 \\
\end{array}$ & $\begin{array}{r}5 \\
10.5\end{array}$ & $\begin{array}{r}76 \\
67.9\end{array}$ & 86 \\
\hline $66-80$ & $\begin{array}{r}\text { Count } \\
\text { Expected Count }\end{array}$ & $\begin{array}{r}23 \\
23.4\end{array}$ & $\begin{array}{r}26 \\
32.3\end{array}$ & $\begin{array}{r}215 \\
208.3\end{array}$ & 264 \\
\hline Over 80 & $\begin{array}{r}\text { Count } \\
\text { Expected Count }\end{array}$ & $\begin{array}{r}29 \\
20.6\end{array}$ & $\begin{array}{r}32 \\
28.4\end{array}$ & $\begin{array}{r}171 \\
183.1\end{array}$ & 232 \\
\hline TOTAL & Count & 97 & 134 & 864 & 1095 \\
\hline
\end{tabular}

Chi-Square testing on Statement 23 - If I choose to donate my medical information then healthcare providers should release the information according to my instructions, revealed that respondents gender was significant $\left(\chi^{2}=6.590, \mathrm{df}=2\right.$, $p=0.037)$. In terms of positive responses of 'strongly agree'/ 'agree', female frequency exceeded expectations and male frequency of response was less than expected. 
Chi-Square testing on Statement 29 - I should be able to see my medical information and it should be easy to correct any mistakes in the information, revealed that healthcare worker was significant $\left(\chi^{2}=7.475, \mathrm{df}=2, p=0.024\right)$. Healthcare workers did not reflect a positive response. They had lower than expected 'strongly agree'/'agree' response frequencies and higher 'neutral' and negative responses.

\subsubsection{Tripartite Component: Privacy Management - Qualitative Analysis}

The qualitative analysis for Privacy Management are presented in Table 44 .

Table 44: Management Qualitative Summary

\begin{tabular}{|c|c|c|c|c|c|c|}
\hline Code & & $\begin{array}{l}\text { Sub } \\
\text { Code }\end{array}$ & Theme & $\begin{array}{l}\text { Comment } 1 \\
\text { Frequency } \\
\end{array}$ & $\begin{array}{l}\text { Comment } 2 \\
\text { Frequency }\end{array}$ & Total \\
\hline \multirow[t]{14}{*}{3} & Management & $A$ & $\begin{array}{l}\text { Good data stewardship required } \\
\text { and consumers need confidence } \\
\text { in arrangements underpinning } \\
\text { secondary use }\end{array}$ & 31 & 14 & 45 \\
\hline & & $B$ & $\begin{array}{l}\text { Consumers as research partners } \\
\text { not research subjects }\end{array}$ & 10 & 1 & 11 \\
\hline & & $\mathrm{C}$ & Consumer control of data issues & 57 & 21 & 78 \\
\hline & & $\mathrm{D}$ & $\begin{array}{l}\text { Restricted access to consumer } \\
\text { data issues }\end{array}$ & 11 & 17 & 28 \\
\hline & & $E$ & De-identification of data & 53 & 13 & 66 \\
\hline & & $\mathrm{F}$ & Consent & 49 & 12 & 61 \\
\hline & & G & Payment for use of data & 6 & 1 & 7 \\
\hline & & $\mathrm{H}$ & $\begin{array}{l}\text { Legal system to protect } \\
\text { consumers }\end{array}$ & 12 & 8 & 20 \\
\hline & & I & $\begin{array}{l}\text { Consumers to provide input on } \\
\text { data stewardship - including } \\
\text { being able to decline to participate }\end{array}$ & 23 & 7 & 30 \\
\hline & & $\mathrm{J}$ & Role of Government & 19 & 6 & 25 \\
\hline & & $\mathrm{K}$ & $\begin{array}{lcr}\text { Secondary } & \text { use mechanisms: } \\
\text { Human Research Ethics } \\
\text { Committees; computer technology }\end{array}$ & 8 & 2 & 10 \\
\hline & & L & $\begin{array}{l}\text { Comments in support of } \\
\text { secondary use }\end{array}$ & 78 & 26 & 104 \\
\hline & & $\mathrm{M}$ & $\begin{array}{l}\text { Comments about sensitivity of } \\
\text { different types of information eg. } \\
\text { Sexual health, mental health }\end{array}$ & 18 & 15 & 33 \\
\hline & & $\mathrm{N}$ & $\begin{array}{l}\text { Comments about the purpose of } \\
\text { data use e.g. OK for research but } \\
\text { not OK for commercial secondary } \\
\text { use }\end{array}$ & 89 & 19 & 108 \\
\hline \multicolumn{4}{|c|}{ Total number of consumer comments regarding privacy management } & 464 & 162 & 626 \\
\hline
\end{tabular}

Examples of the qualitative comments and demographics of the respondents are presented in Table 45 arranged under the deductive themes. 
Table 45: Tripartite - Management of Privacy - deductive themes

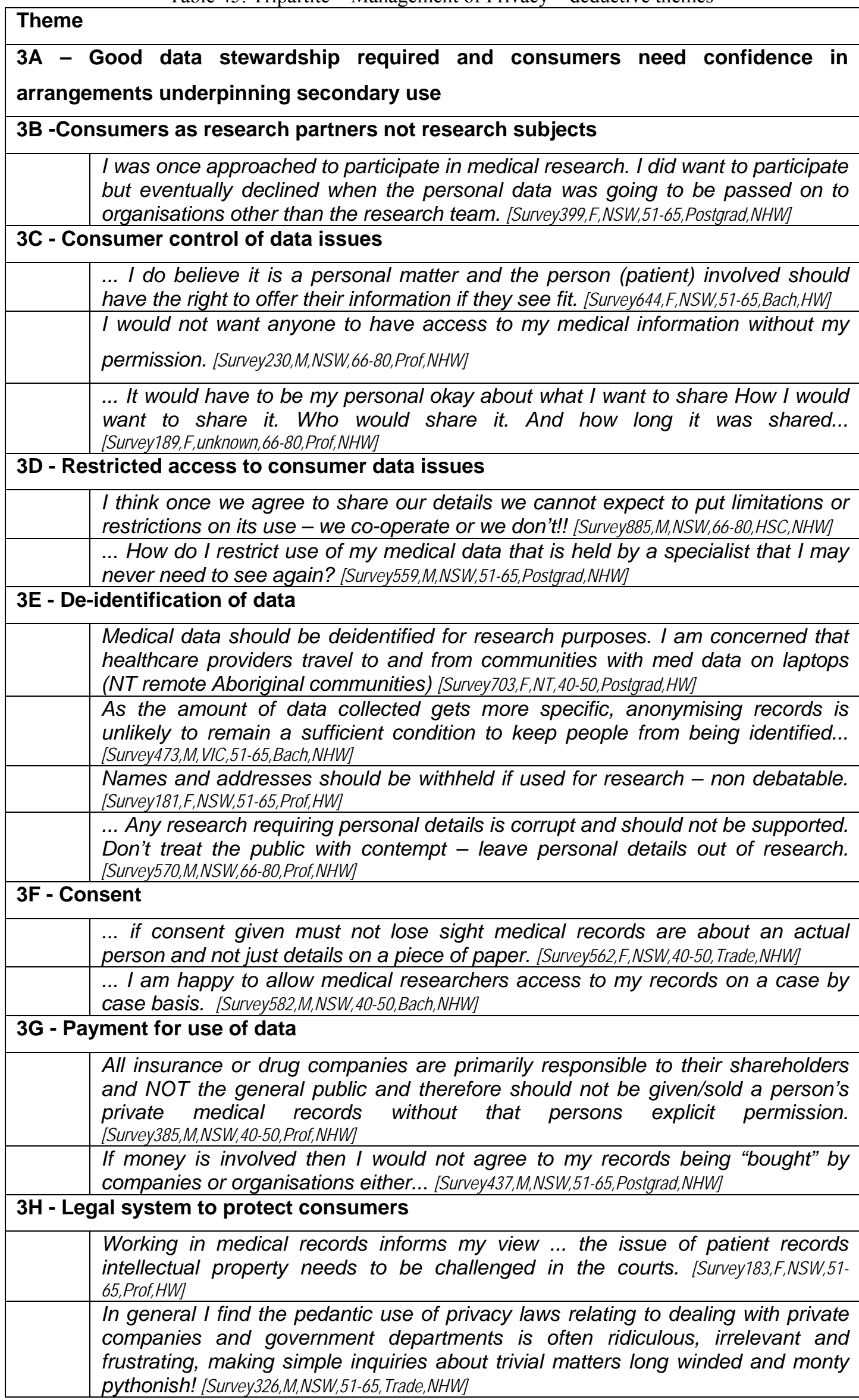




\begin{tabular}{|c|c|}
\hline & $\begin{array}{l}\text { Do not want lay people ie. the State, making decisions regarding my records - } \\
\text { not even the justice system who are not qualified to determine the issue. } \\
\text { [Survey189,F,unknown,66-80,Prof,NHW] }\end{array}$ \\
\hline \multicolumn{2}{|r|}{$\begin{array}{l}\text { 3I - Consumers to provide input on data stewardship - including being able to } \\
\text { decline to participate }\end{array}$} \\
\hline & $\begin{array}{l}\text { Should never be made available without prior discussion and approval. } \\
\text { [Survey1019,F,NSW,51-65,Prof,NHW] }\end{array}$ \\
\hline & $\begin{array}{l}\text { No. I would have no issue sharing me medical data as long as it was used } \\
\text { correctly to benefit society, it was anonymous and I gave permission. } \\
\text { [Survey491,F,NSW,26-39,Prof,NHW] }\end{array}$ \\
\hline \multicolumn{2}{|c|}{ 3J - Role of Government } \\
\hline & $\begin{array}{l}\text { I would worry about what government officials may do with the medical data - } \\
\text { could the data be used against people in an individual sense. [Survey250,F,NSW,51- } \\
65, \text { Bach,NHW] }\end{array}$ \\
\hline \multicolumn{2}{|r|}{$\begin{array}{l}\text { 3K - Secondary use mechanisms: Human Research Ethics Committees; computer } \\
\text { technology }\end{array}$} \\
\hline & $\begin{array}{l}\text {... It raises other questions - what about information about children, the elderly, } \\
\text { mentally ill? We need to know their privacy is protected. Who speaks for them? } \\
{[\text { [Survey,F,NSW,40-50,Postgrad,HW] }}\end{array}$ \\
\hline \multicolumn{2}{|c|}{ 3L - Comments in support of secondary use } \\
\hline & $\begin{array}{l}\text { I think the idea of donating medical information is a great ic } \\
\text { who may not want to donate a part of themselves to resear } \\
\text { still give something to medicine.... hopefully in the near fut } \\
\text { for a medical information donation plan! [Survey239,F,NSW,18-25,H }\end{array}$ \\
\hline \multicolumn{2}{|r|}{$\begin{array}{l}\text { 3M - Comments about sensitivity of different types of information eg. Sexual health, } \\
\text { mental health }\end{array}$} \\
\hline & $\begin{array}{l}\ldots \text { I feel I should (and others should) have the right to keep their medical } \\
\text { information private unless (i) it is used statistically (but anonymously) (ii) there is } \\
\text { a condition present that could negatively affect other eg. AIDS, genetic problem. } \\
\text { Through my desire for privacy I should not be allowed to give negative } \\
\text { consequences to others. [51-65, reuse concern] }\end{array}$ \\
\hline & $\begin{array}{l}\text {... some misgivings regarding mental health issues getting (scary) info into the } \\
\text { wrong hands. Information travels so quickly and is so potable with digital } \\
\text { systems... [Survey189,F,unknown,66-80,Prof,NHW] }\end{array}$ \\
\hline & $\begin{array}{l}\text { ntial for sensitive info } \\
d \text { admin to maintain }\end{array}$ \\
\hline \multicolumn{2}{|r|}{$\begin{array}{l}3 \mathrm{~N} \text { - Comments about the purpose of data use eg. OK for research but not OK for } \\
\text { commercial secondary use }\end{array}$} \\
\hline & $\begin{array}{l}\text { I would be happy for information to be used for research that would help the } \\
\text { community. I would not feel comfortable on this information being used by } \\
\text { commercial entities such as drug companies where the results built corporate } \\
\text { profits rather than social, health etc outcomes. [Survey825,F,SA,40-50,Postgrad,NHW] }\end{array}$ \\
\hline & $\begin{array}{l}\text { Don't like the idea of insurance/drug/advertising companies getting it, but I have } \\
\text { no problem with it being used for legitimate medical purposes. [Survey467,M,VIC,40- } \\
50, \text { Bach,NHW] }\end{array}$ \\
\hline & $\begin{array}{l}\text { Yes - once information is available for re-use it will be virtually impossible to stop } \\
\text { access by insurance companies + commercial medical researchers/drug } \\
\text { companies and others. Having said that, I support the THEORY that information } \\
\text { should be available, with permission, for not for profit medical research to assist } \\
\text { with identifying treatment and cures. [Survey667,F,NSW,40-50,Postgrad,NHW] }\end{array}$ \\
\hline & It all depends on the use of the data and who has collected the data. \\
\hline
\end{tabular}




\begin{tabular}{|l|l|}
\hline & $\begin{array}{l}\text { [Survey99,F,NSW,66-80,Yr10,NHW] } \\
\text { A prime concern would be the release of medical info to companies possibly } \\
\text { related to the research bodies but not actively involved in research. } \\
{[\text { Survey6,M,NSW,51-65,Bach,NHW] }}\end{array}$ \\
\hline $\begin{array}{l}\text { Not if it is to be used for research; the only problem I have is if it is to be used by } \\
\text { insurance companies against people. [Survey1013,F,NSW,51-65,Bach,HW] }\end{array}$ \\
$\begin{array}{l}\text { I am much more interested in medical research and university research in the } \\
\text { area of medicine. I am not interested in research for insurance companies etc } \\
\text { [Survey101,M,NSW,66-80,Bach,NHW] }\end{array}$ \\
\hline
\end{tabular}

\subsection{Emergent Qualitative Themes}

A deductive approach was taken to the encoding of qualitative comments with existing literature providing the areas of focus. Issues arose through the survey qualitative material that were not anticipated through the deductive process. These are listed here as themes that emerged through inductive process of analysis:

- Organ donation comments

- Primary care delivery recommendations for improvements

- Broad data management issues

- Accessing medical data for purposes of solving crime

The Australian pilot survey included public opinion statements regarding altruism and explored this theme with quantitative opinion statements regarding financial donations to support medical research and blood donation. The qualitative comments on the pilot survey included comments regarding organ donation. The altruism statements were not included in the final survey and hence the feedback on organ donations was less expected in the larger survey. These are important themes and the qualitative comments gathered by the Australian survey may inform future research into these matters. 


\subsection{Further Consideration of Results}

Section 4.1 of this Chapter presented quantitative and qualitative results for the tripartite components of Privacy Concept, Privacy Justification and Privacy Management.

Table 46 presents further details of results from Pearsons Chi-Square testing. The summary tables in Section 4.1 used an $\mathrm{X}$ to indicate statistically significant results.

Where Chi-Square testing results fall within the normal statistically significant range but expected counts fewer than 5 exceeded the $20 \%$ threshold, these are included with appropriate annotations in Table 46.

Some of the Privacy Management results are at 22.2\% of expected cell counts with fewer than five counts which puts them just outside the threshold. Future research with larger sample sizes may provide the number of responses required to bring these into the acceptable range. They are provided here for interest and no claims are made regarding statistical significance. In addition, three tests have been included where $p$ values are just outside the significant range, these are tagged 'Special inclusions' and results will be discussed below without claiming any statistical significance. 
Table 46: Further consideration of quantitative results

\begin{tabular}{|c|c|c|c|c|c|}
\hline & Construct & Gender & Age & Highest Education Level & Healthcare Worker \\
\hline \multicolumn{6}{|c|}{ PRIVACY CONCEPT } \\
\hline Statement 5 & Anxiety & & & & \\
\hline Statement 6 & Anxiety & & $\left(\chi^{2}=49.7, \mathrm{df}=10, p<0.001\right)$ & $\left(\chi^{2}=33.5, \mathrm{df}=12, p=0.001\right)$ & \\
\hline Statement 8 & Anxiety & & $\left(\chi^{2}=27.2, \mathrm{df}=10, p=0.002\right)$ & $\left(\chi^{2}=35.6, \mathrm{df}=12, p<0.001\right)$ & \\
\hline Statement 9 & Anxiety & & $\left(\chi^{2}=23.7, \mathrm{df}=10, p=0.008\right)$ & $\left(\chi^{2}=46.6, \mathrm{df}=12, p<0.001\right)$ & \\
\hline Statement 25 & Anxiety & & $\left(\chi^{2}=32.6, \mathrm{df}=10, p<0.001\right)$ & $\left(\chi^{2}=59.7, \mathrm{df}=12, p<0.001\right)$ & \\
\hline Statement 27 & Anxiety & & & & $\left(\chi^{2}=6.899, \mathrm{df}=2, p=0.03\right)$ \\
\hline Statement 10 & $\begin{array}{l}\text { Limited } \\
\text { Access }\end{array}$ & & $\left(\chi^{2}=20.1, \mathrm{df}=10, p=0.03\right)$ & & \\
\hline Statement 11 & $\begin{array}{l}\text { Limited } \\
\text { Access }\end{array}$ & & & & $\left(\chi^{2}=8.8, \mathrm{df}=2, p=0.012\right)$ \\
\hline \multicolumn{6}{|c|}{ PRIVACY JUSTIFICATION } \\
\hline Statement 1 & Rights Based & $\left(\chi^{2}=8.8, \mathrm{df}=2, p=0.012\right)$ & $\begin{array}{c}\left(\chi^{2}=21.0, \mathrm{df}=10, p<0.001\right) \\
5 \text { cells }(55.6 \%) \text { expected } \\
\text { count fewer than } 5\end{array}$ & & \\
\hline Statement 3 & Rights Based & $\left(\chi^{2}=8.0, \mathrm{df}=2, p=0.019\right)$ & $\left(\chi^{2}=40.1, \mathrm{df}=10, p=0.008\right)$ & $\begin{array}{c}\left(\chi^{2}=27.4, \mathrm{df}=12, p=0.007\right) \\
8 \text { cells }(38.1 \%) \text { expected } \\
\text { count fewer than } 5\end{array}$ & \\
\hline Statement 4 & Rights Based & $\begin{array}{c}\left(\chi^{2}=15.1, \mathrm{df}=2, p=0.001\right) \\
2 \text { cells }(33.3 \%) \text { expected } \\
\text { count fewer than } 5\end{array}$ & & & \\
\hline Statement 12 & Balance & & $\begin{array}{c}\left(\chi^{2}=25.161, \mathrm{df}=10\right. \\
p=0.005)\end{array}$ & $\left(\chi^{2}=22.6, \mathrm{df}=12, p=0.031\right)$ & \\
\hline
\end{tabular}




\begin{tabular}{|c|c|c|c|c|c|}
\hline & Construct & Gender & Age & Highest Education Level & Healthcare Worker \\
\hline Statement 26 & Balance & & & & \\
\hline Statement 28 & Balance & $\left(\chi^{2}=6.7, \mathrm{df}=2, p=0.035\right)$ & & & \\
\hline \multicolumn{6}{|c|}{ PRIVACY MANAGEMENT } \\
\hline Statement 2 & $\begin{array}{c}\text { Data } \\
\text { Stewardship }\end{array}$ & $\left(\chi^{2}=5.8, \mathrm{df}=2, p=0.05\right)$ & $\begin{array}{c}\left(\chi^{2}=26.1, \mathrm{df}=10, p=0.004\right) \\
4 \text { cells }(22.2 \%) \text { expected } \\
\text { count fewer than } 5\end{array}$ & & $\left(\chi^{2}=11.2, \mathrm{df}=2, p=0.004\right)$ \\
\hline Statement 7 & $\begin{array}{c}\text { Data } \\
\text { Stewardship }\end{array}$ & & & & $\left(\chi^{2}=18.6, \mathrm{df}=2, p<0.001\right)$ \\
\hline Statement 18 & $\begin{array}{c}\text { Data } \\
\text { Stewardship }\end{array}$ & & & $\begin{array}{c}\left(\chi^{2}=22.6, \mathrm{df}=12, p=0.031\right) \\
6 \text { cells }(28.6 \%) \text { expected } \\
\text { count fewer than } 5\end{array}$ & $\begin{array}{c}\left(\chi^{2}=5.8, \mathrm{df}=2, p=0.056\right) \\
\text { Special inclusion }\end{array}$ \\
\hline Statement 24 & $\begin{array}{c}\text { Data } \\
\text { Stewardship }\end{array}$ & $\begin{array}{c}\left(\chi^{2}=5.8, \mathrm{df}=2, p=0.056\right) \\
\text { Special inclusion }\end{array}$ & $\begin{array}{c}\left(\chi^{2}=48.2, \mathrm{df}=10, p<0.001\right) \\
4 \text { cells }(22.2 \%) \text { expected } \\
\text { count fewer than } 5\end{array}$ & & \\
\hline Statement 30 & $\begin{array}{c}\text { Data } \\
\text { Stewardship }\end{array}$ & & $\left(\chi^{2}=40.2, \mathrm{df}=10, p<0.001\right)$ & $\begin{array}{c}\left(\chi^{2}=20.7, \mathrm{df}=12, p=0.055\right) \\
\text { Special inclusion }\end{array}$ & $\left(\chi^{2}=9.4, \mathrm{df}=2, p=0.009\right)$ \\
\hline Statement 13 & Control & & & & \\
\hline Statement 14 & Control & & & & \\
\hline Statement 15 & Control & & & & \\
\hline Statement 16 & Control & $\left(\chi^{2}=20.0, \mathrm{df}=2, p<0.001\right)$ & $\begin{array}{c}\left(\chi^{2}=70.3, \mathrm{df}=10, p<0.001\right) \\
4 \text { cells }(22.2 \%) \text { expected } \\
\text { count fewer than } 5\end{array}$ & $\begin{array}{c}\left(\chi^{2}=32.6, \mathrm{df}=12, p=0.001\right) \\
6 \text { cells }(28.6 \%) \text { expected } \\
\text { count fewer than } 5\end{array}$ & \\
\hline Statement 17 & Control & $\left(\chi^{2}=10.8, \mathrm{df}=2, p=0.005\right)$ & & & $\left(\chi^{2}=9.1, \mathrm{df}=2, p=0.011\right)$ \\
\hline Statement 19 & Control & $\left(\chi^{2}=13.6, \mathrm{df}=2, p=0.001\right)$ & & $\left(\chi^{2}=27.6, \mathrm{df}=12, p=0.006\right)$ & \\
\hline Statement 20 & Control & & $\left(\chi^{2}=28.8, \mathrm{df}=10, p=0.001\right)$ & $\left(\chi^{2}=28.8, \mathrm{df}=12, p=0.004\right)$ & $\left(\chi^{2}=6.1, \mathrm{df}=2, p=0.047\right)$ \\
\hline
\end{tabular}




\begin{tabular}{|l|c|c|c|c|c|}
\hline & Construct & Gender & Age & Highest Education Level & Healthcare Worker \\
\hline Statement 21 & Control & $\left(\chi^{2}=7.6, \mathrm{df}=2, p=0.022\right)$ & & & \\
\hline Statement 22 & Control & $\left(\chi^{2}=20.1, \mathrm{df}=2, p<0.001\right)$ & & $\left(\chi^{2}=24.3, \mathrm{df}=12, p=0.019\right)$ & $\left(\chi^{2}=6.6, \mathrm{df}=2, p=0.037\right)$ \\
\hline Statement 23 & Control & $\left(\chi^{2}=6.5, \mathrm{df}=2, p=0.037\right)$ & & \\
\hline Statement 29 & Control & & $\begin{array}{c}\left(\chi^{2}=21.0, \mathrm{df}=10, p=0.021\right) \\
7 \text { cells }(38.9 \%) \text { expected } \\
\text { count fewer than 5 }\end{array}$ & & $\left(\chi^{2}=7.5, \mathrm{df}=2, p=0.024\right)$ \\
\hline
\end{tabular}


Given the narrow margin of the 'special inclusions' from the acceptable threshold established for this research, they do provide some insight that could be further explored in subsequent research.

Statement 30 - A legal judge in Australia decided that the notes written about a patient, by a Doctor, are owned by the Doctor not the patient. This decision seems reasonable to me, Chi-Square testing returned a result concerning highest education level that was just outside the threshold for significance $\left(\chi^{2}=20.7, \mathrm{df}=12, p=0.055\right)$. Opinion was diverse across education levels in response to this statement. Table 47 provides details regarding expected and actual counts.

Table 47:Statement 30 Chi-Square test results by highest education level

\begin{tabular}{|c|c|c|c|c|c|}
\hline $\begin{array}{c}\text { Highest } \\
\text { Education }\end{array}$ & Frequency & Disagree & Neutral & Agree & Total \\
\hline$<Y r 10$ & $\begin{array}{r}\text { Count } \\
\text { Expected }\end{array}$ & $\begin{array}{r}33 \\
39.1\end{array}$ & $\begin{array}{r}5 \\
6.5\end{array}$ & $\begin{array}{r}20 \\
12.5\end{array}$ & 58 \\
\hline Yr10 & $\begin{array}{r}\text { Count } \\
\text { Expected }\end{array}$ & $\begin{array}{r}84 \\
78.8\end{array}$ & $\begin{array}{r}8 \\
13.1\end{array}$ & $\begin{array}{r}25 \\
25.1\end{array}$ & 117 \\
\hline Yr12 & $\begin{array}{r}\text { Count } \\
\text { Expected }\end{array}$ & $\begin{array}{r}68 \\
71.4\end{array}$ & $\begin{array}{r}10 \\
11.9\end{array}$ & $\begin{array}{r}28 \\
22.8\end{array}$ & 106 \\
\hline Trade & $\begin{array}{r}\text { Count } \\
\text { Expected }\end{array}$ & $\begin{array}{r}61 \\
57.9\end{array}$ & $\begin{array}{r}9 \\
9.6\end{array}$ & $\begin{array}{r}16 \\
18.5\end{array}$ & 86 \\
\hline Prof & $\begin{array}{r}\text { Count } \\
\text { Expected }\end{array}$ & $\begin{array}{r}184 \\
178.4\end{array}$ & $\begin{array}{r}31 \\
29.7\end{array}$ & $\begin{array}{r}50 \\
56.9\end{array}$ & 265 \\
\hline Bachelor & $\begin{array}{r}\text { Count } \\
\text { Expected }\end{array}$ & $\begin{array}{r}152 \\
154.9\end{array}$ & $\begin{array}{r}38 \\
25.7\end{array}$ & $\begin{array}{r}40 \\
49.4\end{array}$ & 230 \\
\hline PostGrad & $\begin{array}{r}\text { Count } \\
\text { Expected }\end{array}$ & $\begin{array}{r}152 \\
153.5\end{array}$ & $\begin{array}{r}21 \\
25.5\end{array}$ & $\begin{array}{r}55 \\
48.9\end{array}$ & 228 \\
\hline TOTAL & Count & 734 & 122 & 234 & 1090 \\
\hline
\end{tabular}

Statement 24 - I would be happy to let the Australian Government decide who can use my medical information, Chi-Square testing returned a result concerning highest education level that was just outside the threshold for significance $\left(\chi^{2}=5.8, \mathrm{df}=2\right.$, $p=0.056$ ). Females did not respond as positively as expected and males 'strongly agree/'agree' more frequently than expected.

Statement 18 - Any medical research groups who want to use 'donated' data must comply with the wishes of the person who has 'donated' the data, Chi-Square testing returned a result concerning healthcare workers that was just outside the threshold for significance $\left(\chi^{2}=5.8, \mathrm{df}=2, p=0.056\right)$. Healthcare workers responded more 
positively than expected and were less 'neutral' in their opinion as illustrated in Table 48 .

Table 48:Statement 18 Chi-Square test results by healthcare worker.

\begin{tabular}{|c|c|c|c|c|c|}
\hline $\begin{array}{c}\text { Healthcare } \\
\text { worker }\end{array}$ & Frequency & Disagree & Neutral & Agree & Total \\
\hline No & $\begin{array}{r}\text { Count } \\
\text { Expected Count }\end{array}$ & $\begin{array}{r}22 \\
23.8\end{array}$ & $\begin{array}{r}55 \\
47.5\end{array}$ & $\begin{array}{r}776 \\
781.7\end{array}$ & 853 \\
\hline Yes & $\begin{array}{r}\text { Count } \\
\text { Expected Count }\end{array}$ & $\begin{array}{r}9 \\
7.2\end{array}$ & $\begin{array}{r}7 \\
14.5\end{array}$ & $\begin{array}{r}244 \\
238.3\end{array}$ & 260 \\
\hline TOTAL & Count & 31 & 62 & 1020 & 1113 \\
\hline
\end{tabular}

The 'Special inclusion' Chi-Square test results are further discussed in the next Chapter.

Statement 16 - If I donated my medical information for research I would want to choose the level of privacy I required. For example I may choose (1) 'always anonymous' or (2) 'name and Medicare number can always be used', Chi-Square testing returned the strongest $\chi^{2}$ result of all tests at $\left(\chi^{2}=70.3, \mathrm{df}=10, p<0.001\right)$ across respondent age. The problem with this result is that 4 cells $(22.2 \%)$, have expected counts fewer than 5 .

\subsection{Chapter Summary}

This chapter reported the results of the Australian consumer survey. Demographic details and response rates were reported. Responses were received from every State and Territory across Australia and from urban, regional and remote locations. Response frequencies for each statement were presented in tabular and graphical format with each 5 point Likert scale response frequency included.

Results of empirical tests for instrument reliability were presented with all but one construct resulting in Cronbach Alpha $>0.6$ which falls within the exploratory research satisfactory range as suggested by Nunnally (1978) and is similar to those used on satisfaction surveys deployed by the National Health Service in Britain (McKinley, Manku-Scott et al. 1997). Instrument face and content validity were also reported. 
Pearsons Chi-Square tests were conducted across the categorical demographics data and ordinal responses to statements resulting in 38 statistically significant results allowing rejection of the null hypothesis:

$\mathrm{H}_{0}$ : There is no significant difference between groups of consumers as expressed through responses to the public opinion survey used in this study where $p<=0.05$.

Frequency and expected count tables were presented for those results showing strongest $\chi^{2}$ results. The rejection of the null hypothesis makes it clear that there is a statistically significant variation in consumer opinion on matters investigated through the consumer survey. This has implications for any proposal that attempts to satisfy consumers' expectations in the secondary use of medical data.

Qualitative comments were classified and reported based on assessment by two coders following Miles and Huberman recommended approach (1994). The summary counts for theme occurrence in survey responses were presented along with sample comments from a diverse set of survey respondents. These qualitative results complemented the quantitative results and were co-presented within the tripartite framework.

The results of this survey have provided the starting point to documenting Australian consumer expectations regarding secondary use of their medical data. This is the first study that has attempted to elicit this information from Australian consumers and, as described in the Introduction chapter, the consumers are important stakeholders whose requirements should be included in conceptualising the secondary use of the data contained in their EHRs. The next chapter provides analysis of the survey results presented in this chapter. 


\section{AUSTRALIAN CONSUMER PUBLIC OPINION SURVEY ANALYSIS AND INTERPRETATION OF RESULTS}

\subsection{Introduction}

The overall aim of this research study is "To better understand consumer's views of secondary uses of medical data with a particular focus on privacy matters". The specific research questions are:

\section{Research Question 1}

What are consumer's expectations and concerns regarding secondary uses of their medical data, particularly with respect to privacy matters?

Research Question 2

Does the RALC theory (Tavani and Moor 2001) and the framework for contextual integrity (Nissenbaum 2010) offer privacy concepts that can: (1) be applied in the secondary use of medical data context and (2) gain support from interested consumers?

The Australian survey results presented in the previous chapter will be arranged and analysed in this chapter in a manner that helps answer the above research questions. Chapter 7 will use the outcomes of the consumer focussed research questions to aid in the design of a flexible secondary use of medical data framework.

The survey results pertaining to the tripartite components Privacy Concept and Privacy Justification provide data to address Research Question 1. The tripartite Privacy Management component, also explored through the consumer survey, contributes towards addressing Research Question 2.

Key findings include:

- $\quad 11,6$ and 21 statistically significant Chi-Square results across demographics related to the concept, justification and management of privacy respectively 
- 5, 4 and 14 dominant qualitative themes resulted from responses to openended questions for the concept, justification and management of privacy respectively

- No statistically significant gender differences emerged concerning the concept of privacy

- No statistically significant differences emerged between healthcare workers and non-healthcare workers regarding the justification of privacy

- Regarding privacy management women expect more control over re-use of their data

- Healthcare workers attitudes towards medical data stewardship and consumer correction of data differ from the broader community

- Australian consumers do not support the Australian Government taking a data stewardship role over consumers medical data

- The RALC and Contextual Integrity privacy theories could be applied to secondary use of medical data context

This chapter includes Figures that provide multiple bar charts condensed for comparison and discussion purposes. The y-axis in the bar charts represents the number of consumer responses and the $\mathrm{x}$-axis is the dichotomised opinion results. The green bars represent the actual counts of respondents and the grey bars represent the expected counts from the Chi-Square calculations. This data was initially presented in tabular format in the previous Chapter and a selection of results is provided here in graphical format to facilitate discussions.

\subsection{Research Question 1}

The results of the public opinion survey provide some insight into consumers' 'expectations' and 'concerns' regarding secondary uses of their medical data, particularly pertaining to privacy matters. The focus of this section will be on analysing the quantitative and qualitative results of the Privacy Concept and Privacy Justification aspects of the survey. When statistically significant results are introduced these will be clearly identified. Where appropriate the Australian public opinion survey results will be supplemented by results of prior research to provide the most comprehensive descriptions possible to address the Research Questions. 


\subsubsection{Tripartite Privacy Concept and Justification of Privacy}

The concept of privacy is a large topic and it was only possible to explore two key aspects via the survey - consumer anxiety and consumer understanding of the frequently considered 'limited access' concept. The first qualitative question - Do you have any concerns regarding the collection and re-use of medical data, took a very direct approach to investigating Research Question 1; specifically the matter of consumer concern. The deductive themes apparent in both the literature review and the comments expressed by Australians were predominantly general anxiety, trust and lack of transparency issues, questionable intent of some parties with access to medical data, and the concept of surveillance. The quantitative survey responses received from the Australian public indicate attitudes and opinions varying in statistically significant ways according to the age and education level of the respondent. On the whole, citizens aged over 50 tend to express more concern or anxiety regarding privacy. Citizens with higher levels of education tend to express less anxiety regarding privacy issues with high school and trades educated consumers more concerned.

Considering the quantitative survey results there were no statistically significant differences across gender related to consumer expectations and anxiety or concern. This contrasts with the age and education level demographic with strong $\chi^{2}$ test results ranging from 20.1 to 59.7 as displayed in Table 21 in the previous Chapter. Healthcare workers opinions were also statistically significant on two statements. These are key survey results because they allow an improved understanding of the similarity between male and female opinions on the concept of privacy. In contrast the improved understanding gained through these survey results suggest that age and education level result in different opinions. Rather than generalising Australian consumers as a broad group when referring to privacy matters we can stratify the consumer group and refer to the different opinions held by different parts of the community. The next section provides further analysis of these matters.

\subsubsection{Consumer Concerns and Expectations}

The quantitative responses to Statements 5,6,8,9,25 and 27 relate to consumer anxiety or concern regarding privacy in the secondary use context as reported in the 
previous Chapter. The quantitative responses indicate concerns amongst consumers with many statistically significant results.

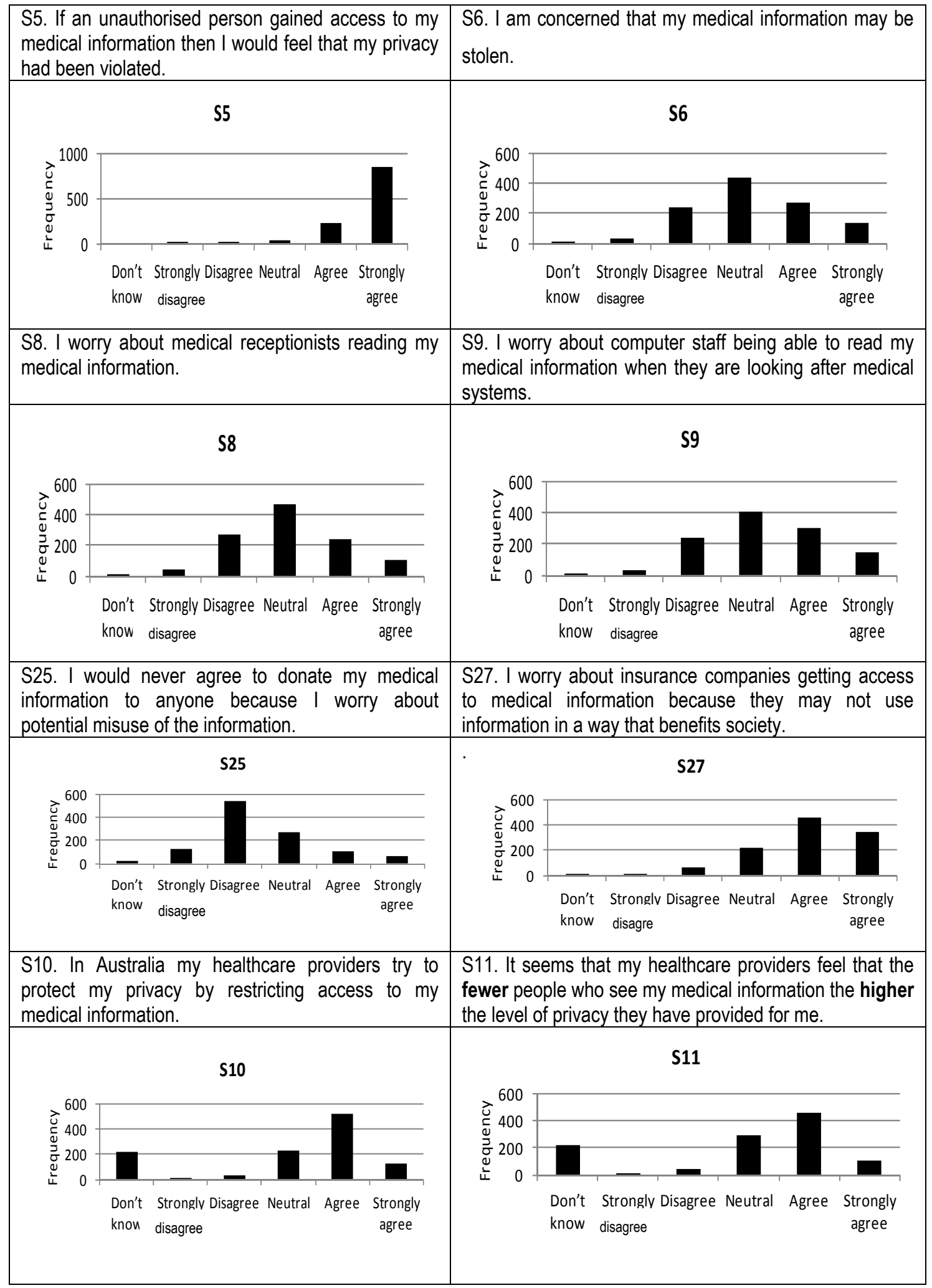

Figure 34: Consumer Concern and Expectations Part 1 


\subsubsection{Consumer Concern and Expectations Part 1}

Survey results regarding the respondents feeling of violation resulting from unauthorised access are homogenous with consumers overwhelmingly concerned, as apparent in the Statement 5 results in Figure 34. With the vast majority of respondents selecting the 'Strongly agree' response there is little room for doubt regarding the strength of the sample populations' opinion on the issue of unauthorised access being a violation of privacy. This has implications for the primary care health domain as well as the secondary use context. The consumer's voices here are clear and in accord.

The survey results for the next four statements $(6,8,9,25)$ are not as homogenous as those for Statement 5. Attitudes are diverse across age groups and highest education level of respondents. These are further considered below.

The investigation of consumers' expectations of limited access as part of the concept of privacy provides surprising results. A large number of respondents selected 'don't know' as their Likert scale response. The healthcare community perceives the concept of privacy to be one of limiting access, as documented in the Literature Review. Yet it is clear from the survey responses to statements 10 and 11 that the general public are not necessarily thinking about healthcare privacy in this manner. This is also surprising given the focus on privacy matters in front-line healthcare delivery over recent years and with publication of privacy policies and guidelines for consumer consumption. According to the survey results, the general public are not overwhelmingly recognising/understanding the healthcare sector attempts to explain privacy matters about restricted access to information to them. This outcome warrants further research into the effectiveness of current health sector privacy campaigns.

The pattern emerging from the statistically significant results of statements regarding concern about privacy is that older Australians express concern at higher rates than do younger Australians. The results presented in Chapter 4 for statements 6, 8, 9 and 25 show that older respondents are more concerned than expected regarding theft of medical information, medical receptionists and IT professionals accessing 
information, and misuse of donated information. Younger Australians did not respond with the same frequency of concern as did older citizens. The threshold for concern shifts between 51 years and 66 years depending on the privacy issue being considered as described in thesis Section 4.2.3.

The data gathered with the survey instrument does not allow investigation of the causes of more concern over the privacy concept amongst older Australians. This is an open research area that could benefit from further more targeted research investigating the causal factors. It is interesting to note that even though the younger respondents are not strident regarding the concept of privacy the results of the tripartite Privacy Management component of the survey indicate younger Australians are open to participating in decisions regarding secondary use of their medical data. These contrasting outcomes are intriguing.

\subsubsection{Influence of Highest Level of Education on Concern for Privacy}

It is clear that the higher the level of formal education the less concerned citizens are regarding the theft of medical information (see Figure 35). Respondents with Year 10 or less than Year 10 level of education expressed agreement with the statement more frequently than expected while Postgraduate and Bachelor education level respondents disagreed more frequently than expected.

The real world implications of these differences arise when considering the majority of healthcare professionals who make decisions regarding privacy of medical information are tertiary educated. The results of this survey suggest that these individuals may hold more relaxed views regarding medical information theft than do the majority of the population who have not undertaken tertiary education. These more relaxed views may influence the formulation of policy and guidelines surrounding management of medical information matters and inadequately deal with the broader consumer base fears in regard to the impact of perceived anxiety about medical information theft. The work of Croll and Morarji (2006) emphasised the importance of managing consumer perception as much as reality and the results of this survey Statement 6 provide support for Croll's work on management of perception - in this case perceived concern over theft. 


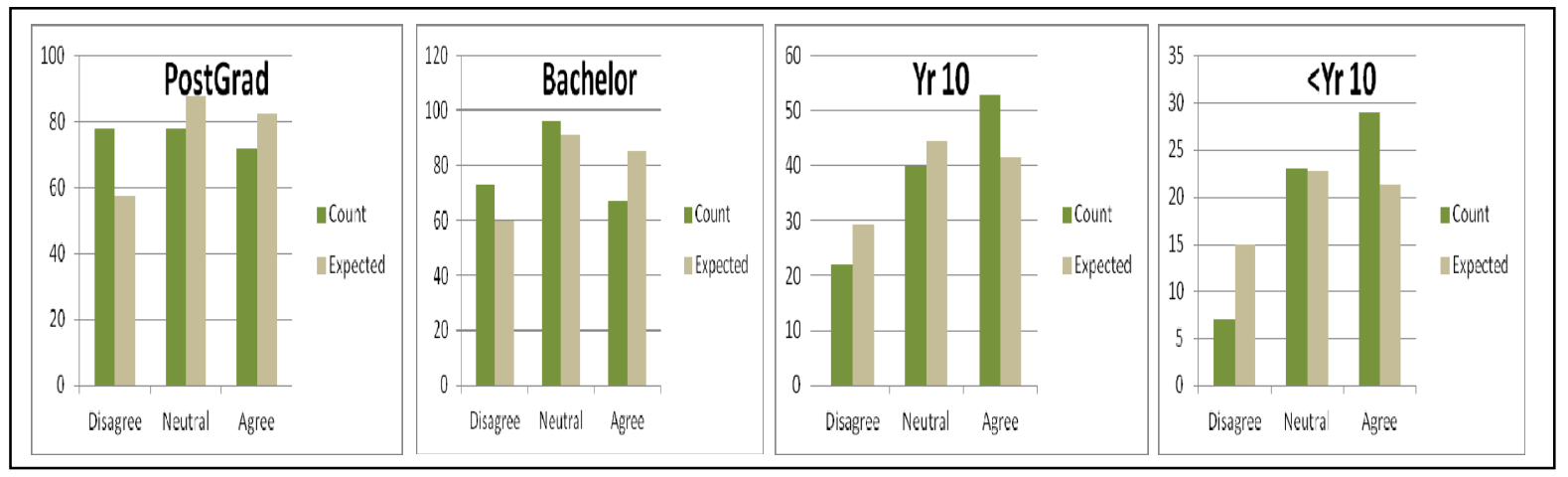

Figure 35: Statement 6 - I am concerned that my medical information may be stolen, selected education level responses.

Higher levels of education also led to less concern regarding access to information, Statement 8 - I worry about medical receptionists reading my medical information, (see Figure 35), with the Trades and Year 10 educated citizens more concerned than tertiary educated citizens about medical receptionists reading information. These results support and refine an earlier study (Willison, Keshavjee et al. 2003) where Canadian respondents also indicated concern about medical receptionists access to medical records. The study results presented in this thesis have refined the Willison et al. approach by adding the dimension of education level to the analysis. The statistically significant impact of education level $\left(\chi^{2}=35.606, \mathrm{df}=12, p<0.001\right)$, is clearly illustrated in Figure 36.

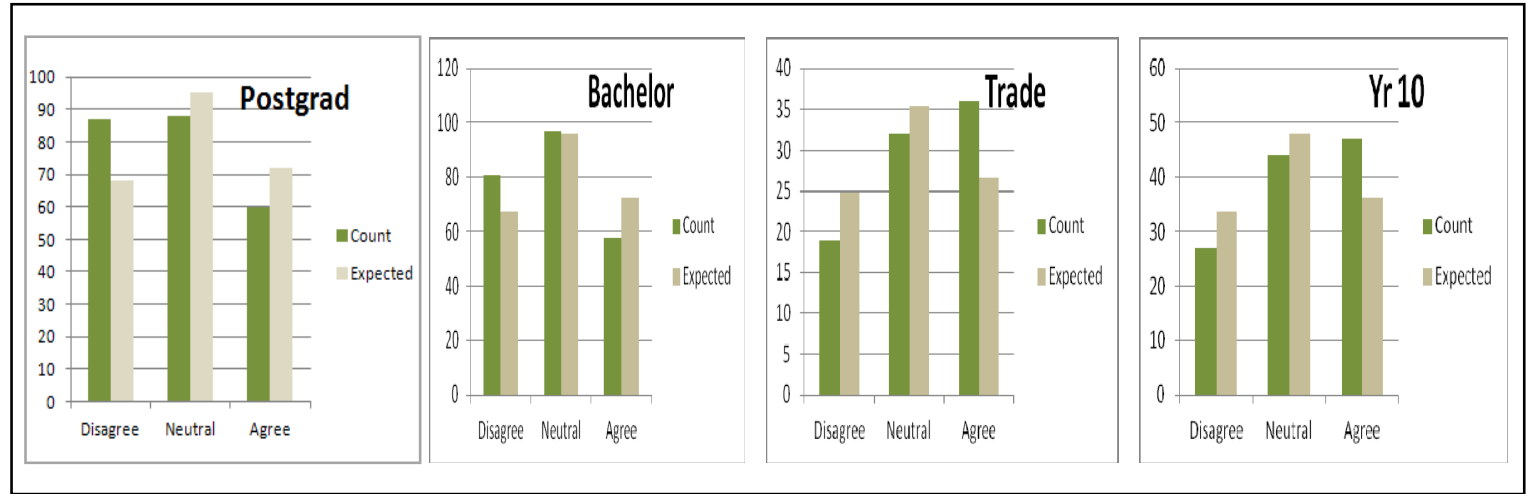

Figure 36: Statement 8 - I worry about medical receptionists reading my medical information, selected education level responses.

The earlier Canadian research also explored consumer attitudes towards computer professionals accessing personal medical information and Statement 9 - I worry about computer staff being able to read my medical information when they are 
looking after medical systems, was included in the Australian survey to give an opportunity to build on the prior research. Canadian research (EKOS Research Associates 2007) found that consumers were concerned about information technology professionals having access to medical information and as Figure 37 illustrates Australians are also concerned however there is stratification across levels of education $\left(\chi^{2}=36.6, \mathrm{df}=12, p<0.001\right)$ as previously described.

On the whole Australian consumers may not be aware of the number of information technology (IT) professionals who have access to medical information in the day-today execution of their system support roles. The respondents to this survey showed more concern about IT professional access than medical receptionist access, as illustrated in Figure 37. The implications of this into the future must be considered as the shift to electronic health records across Australia necessarily will require an increase in the number of IT staff with access to sensitive information. The long held healthcare profession principle of patient confidentiality may not be as widely appreciated by the IT staff who are not located on the 'front-line' of delivering patient care. The well established tradition of patient confidentiality that stretches back hundreds of years in the nursing and medicine professions, as discussed in the literature review, is under pressure in the information age and the IT professionals are the agents of change the Australian general public are concerned about.

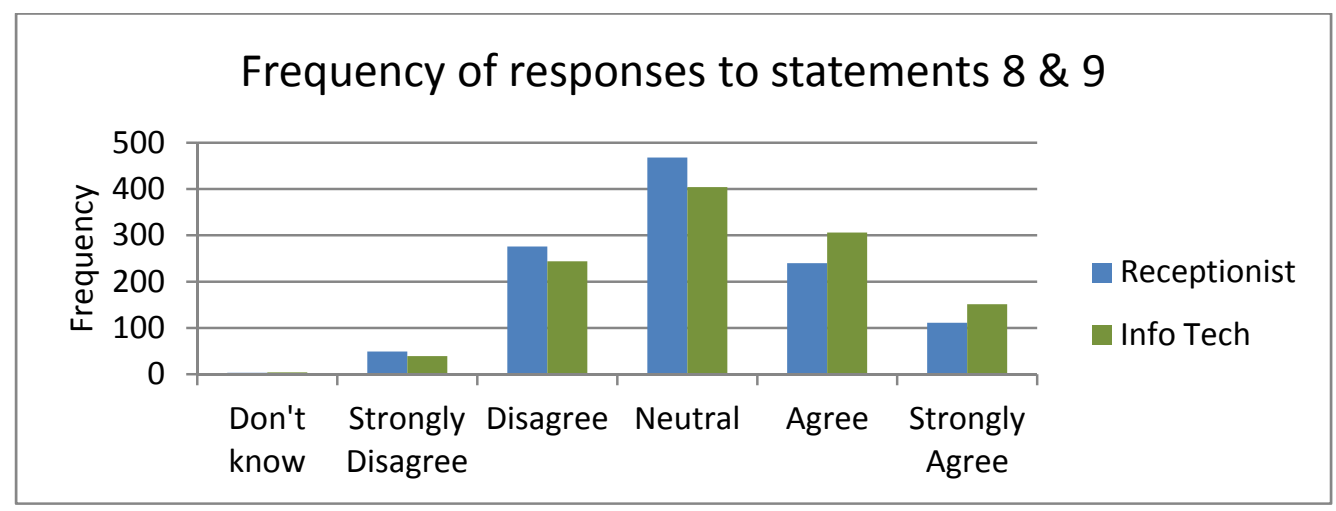

Figure 37: Frequency of responses for statements regarding concern over medical receptionist $(\mathrm{n}=1,147)$ and IT professional $(\mathrm{n}=1,148)$ access to consumer medical information.

The 'behind-the-scenes' nature of the IT professional prevents the consumers from adequately conceptualising the role they play and may contribute to the disquiet regarding their role. In contrast, medical receptionist roles are better understood by 
consumers and the qualitative comments provided in response to the survey provide more insight into consumer experiences and concerns about the role of medical receptionists and privacy and confidentiality. Consumers expressed concern specifically about medical receptionists in the qualitative comments including:

- "I worry about receptionists etc. (not nursing or medical personnel) and whether they totally understand confidentiality and the importance of it." [Survey 941,F,NSW,40-50,Prof,HW]

- "Lack of privacy when medical receptionists give results over the phone which is heard by those in waiting room." [Survey 211,F,NSW,40-50,Prof,NHW]

- "I was in a situation where I personally knew a medical clerk working at my doctor's surgery. I also knew she was a heroin addict. Her accessing my medical records was a concern for me...” [Survey476,F,VIC,26-39,Postgrad,NHW]

\subsubsection{Consumer Concern Regarding Insurance Sector Secondary Use}

Statement 27 sought to engage consumers in the controversial area of secondary use of data by the insurance sector. A provocative statement was provided that, based on concerns in the literature, suggested that the insurance sector secondary use of medical data may not benefit society. The majority of respondents selected the 'strongly agree'/'agree' response with 225 opting for a 'neutral' response. There was no statistically significant difference between gender, age or education level in these results indicating a reasonably homogenous response from respondents. The responses of consumers who self identified as healthcare workers were statistically significant.

The insurance sector was particularly targeted in the consumer comments. It should be noted that no background information was provided to the survey respondents about secondary uses of data within the insurance industry. Respondents drew on their own knowledge and experience in commenting on these matters. Thoughtful consumer comments of concern regarding the insurance sector included:

- "My main concern about the collection and re-use of medical data is that the data may be wrongly used against the interests of the patient eg. by various insurance companies who may deny cover and/or benefits." [Survey 250,F,NSW,51-65,Bach,NHW] 
- "Only concern is that insurance companies could take advantage of information for their own benefit." [Survey 392,F,WA,51-65, $<$ Yr10,NHW]

- "My greatest concern is Insurance Companies accessing information that will then 'allow' them to refuse certain people or increase premiums to an unreasonable level." [Survey 423,F,NSW,51-65,Bach,NHW]

- "Instances where insurance companies or the Government can access data to manipulate health policies or levels of insurance does concern me yet if the information was to be used to assist research into medicine I would be only too happy to support data donation.” [Survey448,F,VIC,40-50,Bach,HW]

The comment from this female, a healthcare worker who resides in Victoria, highlights the capacity for consumers to make the distinction between secondary use for research into medicine versus secondary use by insurance sector and different levels of concern in each instance.

- "Yes. I am concerned particularly about Insurance Companies and also the extrapolation of that data towards my offspring." [Survey780,F,NT,5165,Postgrad,HW]

This female healthcare worker from the Northern Territory indicated how alarming the secondary use by the insurance sector is to consumers with her concern for future generations. This consumer is looking beyond 'the-here-and-now' and is imagining disadvantages that may arise in the future due to secondary use of medical data.

- "Would have some concerns about studies etc would want them to be ethical (rather than insurance companies or similar trying to use the information for their own purposes rather than to improve the healthcare of others)." [Survey 969,F,NSW,26-39,Postgrad,NHW]

This postgraduate educated female from New South Wales is getting to the core issue mentioned by many respondents where altruistic use of medical information is viewed far more favourably than is commercial use.

- "Yes- particularly if used by drug companies who sometimes behave unethically and more so if used by insurance co's. to raise premiums for some or exclude some from insurance, or not pay out etc." [Survey1100,F,NSW,51-65,Postgrad,NHW]

This female consumer from New South Wales is raising the issue of insurance organisations choosing to exclude future policy holders or to raise premiums for 
higher risk customers based on business intelligence acquired through secondary data use.

The results regarding wariness, anxiety or concern amongst consumers when it comes to insurance industry involvement echoes results of earlier research that investigated sources of research funding (Willison, Keshavjee et al. 2003). As reported by Willison et al. the consumers were specifically concerned due to possible attempts by insurance companies to deny coverage for consumers. The patients participating in this earlier Canadian study were reported as being generally opposed to selling personal data to another researcher for profit. The consumers in Willison's study had given little thought about the use of their medical information for secondary purposes however the consumers had conceptualised secondary use by the insurance industry.

The results this Australian consumer survey are consistent with the findings of Perera, Holbrook et al. (2011) where it was found that $67 \%$ of patients and $70 \%$ of physicians did not want private insurance companies to access medical data.

The Australian survey developed and deployed for this study explored these anxieties further and a statistically significant result was found for healthcare workers' responses to Statement 27 - I worry about insurance companies getting access to medical information because they may not use information in a way that benefits society, $\left(\chi^{2}=6.90, \mathrm{df}=2, p=0.032\right)$. Healthcare workers' responses indicated concern regarding insurance industry secondary use of consumers' medical information. The healthcare workers concept of privacy was challenged by the idea of use of their patient's medical records to meet profit driven insurance industry goals. The content of the 2010 Healthcare Identifiers Act supports the view held by the surveyed healthcare workers and contains specific provisions to exclude the passing of medical data to insurance industry organisations. This contrasts with the approach adopted in the United States and Canada, as described in the Literature Review.

The role of Australian health insurance providers is somewhat grey as they gather vast volumes of detailed medical information about individuals through transaction 
processing systems supporting payments for health services. This data becomes 'fuel for the engine' of business intelligence and data mining tools identifying patterns and predictions for likely health outcomes. There are many qualitative responses to the Australian survey that indicate consumer disquiet with this practice - yet by purchasing private health insurance Australians are contributing their personal information for such secondary purposes.

The qualitative comments provided by some survey respondents are unambiguous and emphatic in terms of insurance industry secondary uses - these uses are not supported by the Australian respondents. Broadly speaking, many of the qualitative comments indicated that if de-identified data was used the consumers would be less concerned about secondary use. This concession was not extended to the insurance industry. Some consumer comments indicated they were not prepared to support anonymised release of data to the insurance industry as they were cognisant of the potential impact of refused insurance policies or raised premiums based on intelligence garnered from the secondary use of medical data. In this matter a number of consumers indicated some depth of understanding of these matters and their concern was apparent, for example:

- “... organisations such as insurance companies or even drug companies are often less than above reproach and are notorious for employing tactics and policies which are immoral beyond expression. I would be most distressed to learn that my own data had contributed to the formation of such policies. On a larger scale such disreputable organisations obtaining vast quantities of information or databases, especially when the information was not originally given for their use is far more troubling given the power of information when collected enmass in this way." [Survey 135,F,NHW]

The issues that this female, non-healthcare worker raised included lack of trust in insurance companies and desire to ensure that her medical information makes no contribution to such secondary use. She highlights that the information was originally collected for another, more primary purpose and she reflects on the computational potential of such large datasets. In this way she is reflecting the published literature. 
- "Yes, insurance companies are already using medical information to 'genetisize' potential future applicants for health insurance. Someday they will 'cluster' them and come up with the argument that since all applicants will die, there are some that will die sooner in certain clusters and ultimately everyone will either have exclusion clauses in their policy or premium loadings, not because they are necessarily a higher risk, but because they belong to a certain genetic or illness cluster." [Survey520,M,NSW,5165 ,Postgrad,HW]

This postgraduate educated male from New South Wales, has a well elucidated view of future health industry secondary use of medical information and his concern is apparent. He also raised the issue of genetic data.

Genetic data was not specifically raised in this survey however some consumers highlighted specific concerns regarding this very special type of data. These have been identified as emergent themes and there is potential for future research regarding the implication of genetic data. Other consumer comments regarding genetic data include:

- "Life insurance companies and genetic testing - both sides of this argument have merit and I'm not clear on how to resolve it." [Survey539,M,NSW,6680,Postgrad,NHW]

- "Genetic testing and potential use by insurance companies to deny cover is a concern. For this reason I would not be tested as by my understanding of the law I would be obliged to share any results with insurance providers." [Survey681,F,NT,40-50,Postgrad,NHW]

\subsubsection{Consumer Concerns and Expectations Part 2}

The next section continues to explore consumers' expectations and concerns with a focus on the 'rights' based justifications of privacy. The consumer concerns and expectations regarding the healthcare sector justification of data re-use as finding a 'balance' between the needs of society versus individual expectations of privacy is also investigated. Figure 38 presents the frequency response charts for statements associated with these issues. The opening statement in the survey investigated consumer attitudes about privacy as a 'right'. Qualitative comments provided by two respondents indicated that the introduction of the 'rights' based approach to privacy did not rest well with them. Both of the citizens were aged 51-65 years and reside on 
opposite sides of Australia with a postgraduate educated female from WA and a professional male from NSW. Apart from these two consumers the remainder of the respondents wrote frequently of their perceived 'rights' regarding their privacy. The quantitative results show the majority of consumers 'strongly agree'/'agree' they have a 'right' to personal privacy with statistically significant differences between gender $\left(\chi^{2}=8.8, \mathrm{df}=2, p=0.012\right)$. Females responded positively more frequently than expected and males were more 'neutral' in their responses than expected. One female respondent from South Australia provided a very concise comment, “... seeing a GP does not mean that I have handed over my right to privacy or my choice to disclose or not!”

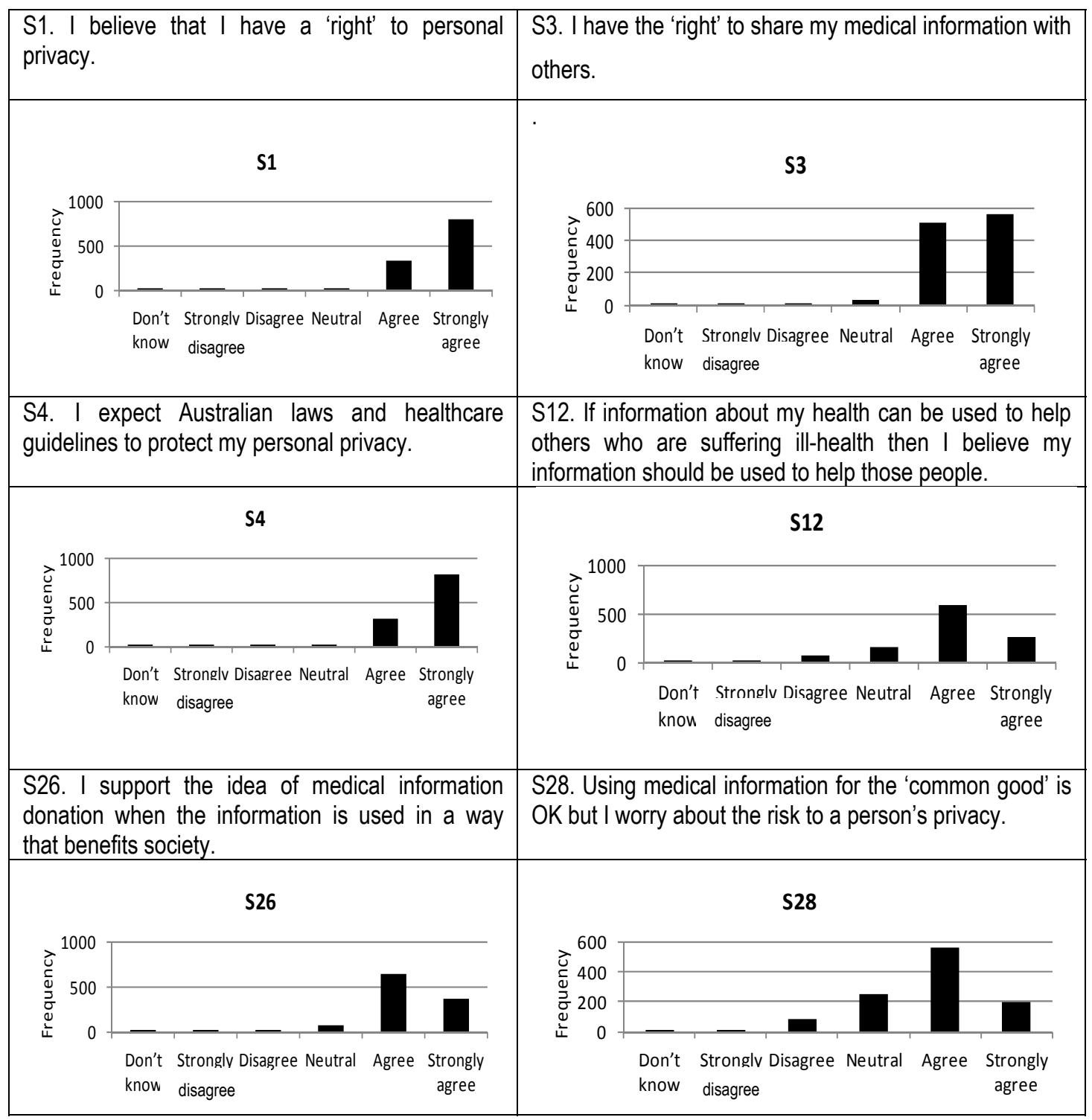

Figure 38: Consumer Concerns and Expectations Part 2 
Gender differences continued $\left(\chi^{2}=8.0, \mathrm{df}=2, p=0.019\right)$ with responses to Statement 3 - I have a 'right' to share my medical information with others. Again women responded more positively than expected and men did not meet positive expectations and selected 'neutral' and negative responses more frequently than expected. These gender differences regarding expectations and 'rights' based views are a precursor to the far more statistically significant differences between gender that are described below. This emergent gender difference grows in importance throughout the remainder of this Chapter.

The older Australian respondents, aged 66-80 years disagreed with Statement 3, with 2.5 times the expected frequency of disagreement whereas the 26-50 year olds expressed stronger support for this statement than expected. The Chi-Square test results reflected these differences $\left(\chi^{2}=40.1, \mathrm{df}=10, p=0.008\right)$. The statement is very broad and was an initial step to exploring the notion of empowered consumers who have some 'right' over the movement of their medical information. Older respondents are likely to be more compliant with the notion that sharing medical information belongs in the doctors' domain rather than with the patients. There is insufficient data available through this survey to confirm this proposition and future research could explore this generational shift in attitude further.

The younger respondents are overwhelmingly positive in their responses to Statement 3 indicating an expectation that sharing medical data is their 'right'. This will likely have implications on secondary use of medical data in the future. For example, in a future scenario where a research group called XYZ may call for contributions of medical data to investigate disease $\mathrm{ABC}$ - possibly using social networking tools or the like to 'get-the-word-out' - young Australians may see it as their 'right' to decide if their data will be used to contribute towards the study. If the data is housed on a health service providers IT infrastructure the young Australian consumer may send a 'share my data with $X Y Z$ ' instruction to the health service provider and actually expect the provision of their data to the XYZ research group to support research into disease ABC. Who 'owns' this data - the consumer or the health service provider? Is it reasonable for consumers to expect to be able to respond to 'calls for data donations' from research group XYZ? Are there suitable 
ethics approvals in place? Should the doctor decide who the consumer can 'share' their medical data with? The survey used in this study explores many of these questions.

The results from Statement 3 - I have the 'right' to share my medical information with others, are perhaps the first from an investigation into this type of issue. Further research where consumers are presented with forward thinking scenarios, similar to the one above, can assist in anticipating and planning for boundary pushing secondary use scenarios. The generational shift apparent in responses to this statement could sound a warning that the established 'doctor decides' paradigm may come under future pressure in the secondary context.

Statement 4 gauged the expectation of consumers regarding how Australian law combined with healthcare guidelines, which interpret the law, protects their privacy. There were no statistically significant differences between consumers on this matter. The consumers do overwhelmingly expect legal protection. The 2008 Australian Law Reform Commission's (ALRC) recommendations described in the literature review would enhance consumer privacy protection. At the time of finalising this thesis the Australian Government had yet to act on the ALRC Privacy recommendations regarding medical information privacy.

Statements 12, 26 and 28 explored consumer attitudes regarding the often used healthcare sector justification for secondary data use as seeking a 'balance' between broad societal good and privacy needs of individuals. When viewed through the medical researchers' lens, as discussed in the literature review, the medical data gathered during the delivery of healthcare is an increasingly valuable resource for retrospective observational studies. Statements 12 and 26 explore the consumers' responses to suggestions that their data should be used to help other humans suffering ill-health and tests attitudes with a statement about medical information donation being useful when some benefit to society is the outcome. The consumer response, refer S12 and S26 in Figure 38, is positive however not to the same extent as the statements regarding 'rights' to privacy. 
Chi-Square testing on statement 12 - If information about my health can be used to help others who are suffering ill-health then I believe my information should be used to help those people, revealed statistically significant results across age $\left(\chi^{2}=25.2, \mathrm{df}=10, p=0.005\right)$ and highest level of education $\left(\chi^{2}=22.6, \mathrm{df}=12, p=0.031\right)$. Citizens 66 years and older were responding positively to this statement more frequently than expected and those younger than 66 years did not meet expected counts for positive responses, thus resulting in the $\chi^{2}$ result.

Respondents with tertiary education responded less positively to this statement than expected and the negative responses were more frequent than expected. There is no clear trend amongst the other education levels. This is probably not the sort of response that the healthcare community would have hoped for from tertiary educated consumers. Future research could investigate this area further and the use of background materials and a vignette to garner responses may enhance the understanding of consumer attitudes on this issue.

There were no statistically significant difference amongst respondents to statement 26 - I support the idea of medical information donation when the information is used in a way that benefits society, and there were fewer 'neutral' responses to this statement than to S12. Qualitative responses provided more insight into consumer views which were largely supportive, for example:

- “... I'm very healthy so far. Don't think I'd worry anyway, if it would help others.” [Survey 1143,F,VIC,66-80,Prof,NHW]

- "I think there should be some balance sought between the rights of patients and doctors and the broader societal good..." [Survey 1137, F,VIC,4050,Postgrad,NHW]

- “... I believe the health benefits of access to patient records potentially outweigh the cost associated with less personal privacy..." [Survey 1118, F,VIC,51-65,Postgrad,HW]

- "I believe the sharing of data if used for the common good is totally reasonable..." [Survey1005,M,NSW,51-65,Prof,NHW] 
- "... there should be some form of monitoring or policing the release of data. Self-regulation is insufficient for an issue as sensitive as this." [Survey972,M,NSW,51-65,Yr12,HW]

- "I would be happy for information to be used for research that would help the community. I would not feel comfortable on this information being used by commercial entities such as drug companies where the results built corporate profits rather than social health etc. outcomes." [Survey825,F,SA,4050,Postgrad,NHW]

The last statement above from the South Australian female leads back to the concerns previously described regarding insurance industry access for purposes that consumers may not perceive as necessarily of benefit to society. There are numerous similar consumer comments focussing on pharmaceutical organisations. During the conduct of this study interested members of the healthcare sector, including medical specialists, informally argued the case regarding the contribution made by pharmaceutical organisations to the overall welfare of society through the development of new drugs; a process which may involve secondary use of medical data. None of the 1,158 Australians who responded to this survey made the same argument in the qualitative feedback. Examples of comments include:

- "I think most people have some concern. I certainly do. Drug companies want this sort of information as do research organisations. Healthcare providers may see this as an opportunity to compile and sell data on their health files. Regulation of this activity is probably required at Federal Govt. level." [Survey1039,F,51-65,Bachelor,NHW]

There was no reference to on-selling of medical data in the survey material, yet this consumer is informed and aware of the practice.

- "We have concerns re the holders of information i.e. our medical records selling for profit, especially to drug companies, marketers and potential employers." [Survey173]

- "Once information is available for re-use it will be virtually impossible to stop access by insurance companies + commercial medical researchers/drug companies and others. Having said that, I support the THEORY that information should be available, with permission, for not for profit medical research to assist with identifying treatment and cures." [Survey667,F,NSW,4050,Postgrad,HW] 
- "My age, life experiences, education and employment in the health industry cause me to be very cautious about sharing personal health information. I would be concerned also about the agendas of drug companies being provided with such information..." [Survey889,F,NSW,40-50,Postgrad,HW]

- "All insurance or drug companies are primarily responsible to their shareholders and NOT the general public and therefore should not be given/sold a person's private medical records without that person's explicit permission.” [Survey385,M,NSW,40-50,Prof,NHW]

The final statement exploring consumer concerns and expectations is Statement $28-$ Using medical information for the 'common good' is OK but I worry about the risk to a person's privacy, resulted in Chi-Square statistically significant results across gender $\left(\chi^{2}=6.7, \mathrm{df}=2, p=0.035\right)$. In a manner consistent with many of the other expectations and concerns, female respondents 'strongly agree'/'agree' responses exceeded expected counts and males positive responses failed to meet expected counts. This is another outcome that emphasises the gender differences in attitude.

The research reported by Parkin and Paul (2011) indicated that consumers supported the secondary use of medical data, including identifiable (rather than anonymous) data, for utilitarian purposes. The consumer responses to Statements 12, 26 and 28 in this survey are similarly generally supportive of secondary use for utilitarian purposes. An important point of difference however is this surveys statements did not explore the specific use of identifiable data.

\subsection{Summary of Research Question 1 Findings}

The first research question driving this study is "What are consumer's expectations and concerns regarding secondary uses of their medical data, particularly pertaining to privacy matters?” In summary, the findings of Research Question 1 relate to the attitudes of the adult Australians who responded to this survey with findings including:

1. Consumers are expressing concern regarding secondary use of medical data and associated privacy issues; particularly regarding potential data use by insurance and pharmaceutical sectors. 
2. There are statistically significant differences across age groups, education levels of respondents and self-reported healthcare workers regarding these privacy concerns.

3. There are statistically significant gender and age differences regarding consumer's expectations of a 'right' to privacy.

4. There are many consumers who are not aware of the healthcare sector concept of privacy related to 'limited access'.

5. There are statistically significant differences across education level and age regarding the privacy concept of 'Getting-the-balance-right' to deliver benefit to society through secondary use of data.

\subsection{Research Question 2}

The second research question asks Does the RALC theory (Tavani and Moor 2001) and the framework for contextual integrity (Nissenbaum 2010) offer privacy concepts that can: (1) be applied in the secondary use of medical data context and (2) gain support from interested consumers?" This part of the Chapter looks more closely at consumers' attitudes towards the 'management' of privacy which is the third component of the tripartite model.

Specific recommendations discussed by Moor and Tavani were investigated through opinion statements in the consumer survey. These included individual control for the management of privacy in possibly three ways: choice, consent and correction. The survey focussed more on consent because "Consent is a means of control that manages privacy and justifies what without it would be an invasion of privacy" (Tavani and Moor 2001, p. 8). The notion of consent also has great import in the medical community and this convergence influenced the number of survey statements that focussed on 'real world' aspects of operationalising consent for secondary use of medical data.

Beyond the quantitative aspects of the survey instrument many respondents expanded their description of attitude through the two optional open ended questions. The frequency counts associated with each tripartite Privacy Management construct in the survey provide insight into the level of support that may be offered by consumers. Never before have Australian consumers been asked to respond to such detailed queries regarding their expectation of privacy management of the secondary 
use of medical data. The normative zones of privacy surrounding vast volumes of stored medical data are under pressure with the shift to electronic health records. Stewardship of this data, with more interest and participation by consumers, challenges the restricted access account of privacy. Therefore some of the questions in the Privacy Management section of the survey engaged consumers in stewardship matters. Table 49 recaps and summarises the consumer responses to stewardship statements. The wording of Statements 2 and 7 was quite provocative to respondents with experience with the existing healthcare sector data stewardship paradigm where healthcare providers have provided unchallenged stewardship of consumers' medical information.

Table 49: Consumer Data Stewardship

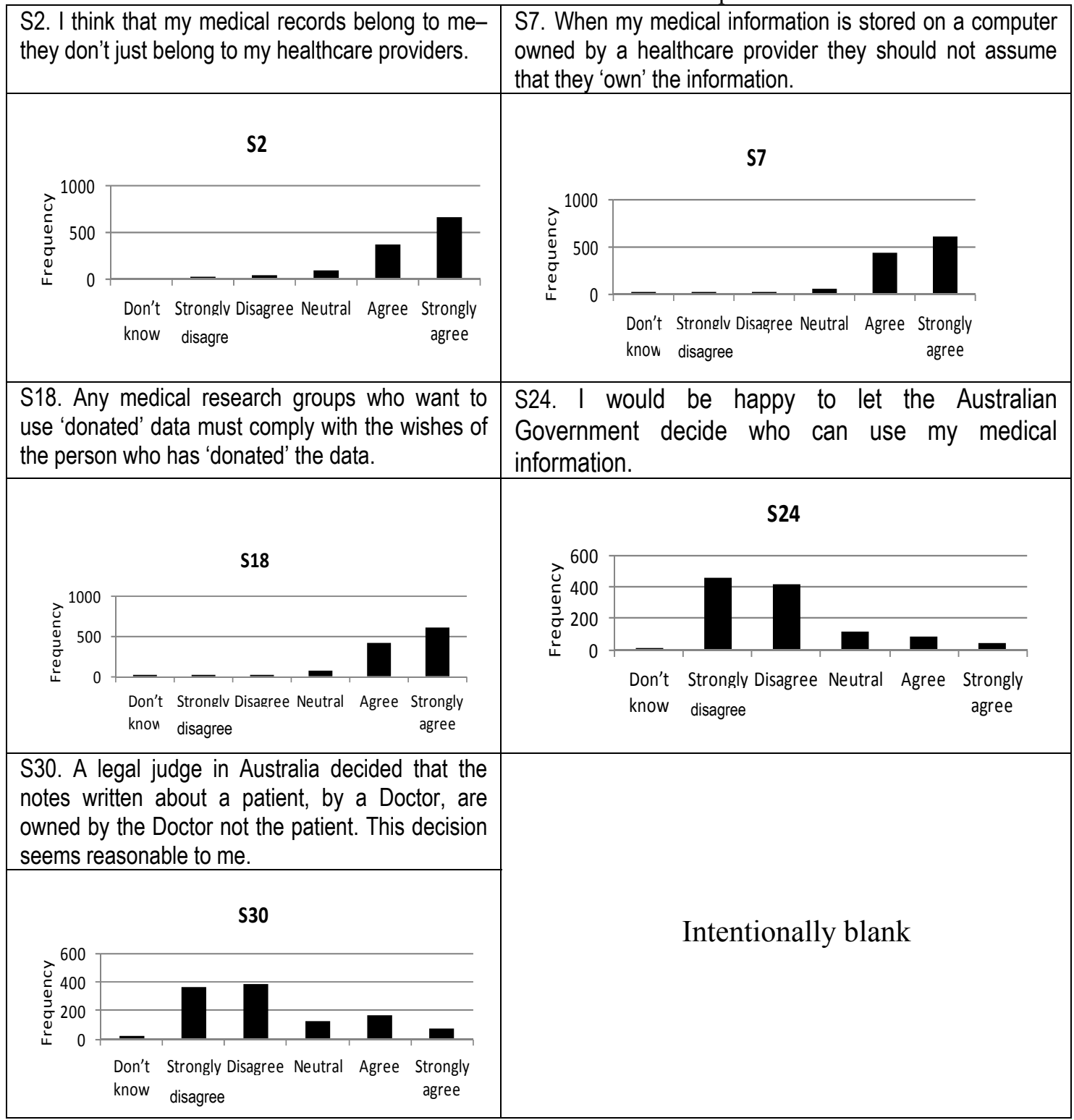


As described above the restricted access approach to privacy is challenged because this privacy theory alone is inadequate in dealing with secondary use of medical data in the Information Age. As the Literature Review presented, the medical community have, and continue to rely heavily on, the restricted access approach to patient privacy. Therefore it is not surprising that three of the five survey statements related to data stewardship reveal statistically significant differences for self-reported healthcare workers and S18 Chi-Square results just outside the statistically significant threshold at $p=0.056$.

This is the first time that metrics have been available to quantify healthcare worker attitudes and allow contrast to the attitudes held by the broader community. The different attitudes have implications for the future as a shift away from tight healthcare sector sole stewardship of data with more engagement with consumers is apparent in the survey results on both data stewardship and consumer choice and consent as shown in Table 50.

The Australian responses to Statement 7 link to the research published by Buckley, Murphy et al. (2011) regarding a survey of the Irish public. The Irish survey found that $68 \%$ of patients were unwilling to allow General Practitioners to decide which researchers could access patient identifiable data. The strong response from Irish respondents could be interpreted as an unwillingness to delegate 'ownership' of data to their General Practitioner.

Introduction of the 2010 Healthcare Identifiers in Australia, to be administered by a Government agency, is the preliminary step to having integrated medical information available for the Australian Government to adopt a stewardship role over, as foreshadowed by Magnusson (2002).

This is the background to Statement 24 and it is apparent that Australian consumers do not endorse Government data stewardship. On this issue healthcare workers and the broader community are in accord with no significant differences in the overwhelmingly negative response to Statement $24-I$ would be happy to let the Australian Government decide who can use my medical information. This is an 
interesting result when compared to the research of Perera et al. (2011) where only $40 \%$ of patients indicated they did not support government access to medical data.

Statement 30 explored consumer views to the Breen Vs. Williams case, described in the Literature Review, and qualitative consumer feedback was diverse ranging from criticism such as:

- "It's a disgrace that a doctor own 'notes' they write up on a person".[Survey4,F,NSW,26-39,Prof,NHW]

- "Regarding Q30, the judges determination does not seem reasonable to me because a doctors notes are written in collaboration with the patient ie. They are partly based on information supplied by the patient, therefore the patient has claim to these notes." [Survey465,M,NSW,51-65,Bach,NHW]

to support from professionals outside the healthcare sector who could find parallels between the teaching profession and that of medical doctors in terms of note taking:

- "My overriding belief is that my medical record is mine but is distinct from doctors notes eg. Like a teacher's notes compiled before writing a student's report. I should have complete access to these and be the sole person who decides who has access to these." [Survey48,F,NSW,26-39,Postgrad,NHW]

- "As a school teacher, I make notes/observations and record results constantly about my pupils. They are NOT for publication in any way and I never show them to parents. However, there is a constant system of reporting to parents using bonafide chanels of communication, including written reports and face-to-face interviews. In the same way, I would expect that my Doctor makes notes to himself regarding my treatment. They are HIS alone ... Again, not for publication in anyway. The actual record of my medical history treatments are mine upon request (or should be)." [Survey116,F,NSW,5165,Prof,NHW].

Similar to many of the other survey responses the Statement 30 results were statistically significant across age with the over 66 years of age citizens again supporting S30 in larger numbers than expected. This older age group is again indicating attitudes that the doctor should have stewardship of patient medical information. The 51-65 year olds are the transition age where expected positive counts are narrowly missed but 'strongly disagree'/'disagree' responses exceed the expected count. The consumers younger than 51 years are not responding positively to the legal decision re-enforcing stewardship by the healthcare provider. This outcome is similar to the findings of Mulligan (2001) where statistically significant 
differences were found across age groups regarding confidence in health sector data storage.

These initial data stewardship research findings add to the emerging picture of consistently different attitudes to the concept, justification and management of privacy across generations of Australian survey respondents. The data stewardship findings reported here are an early warning of changing expectations amongst the Australian community and planning will be required to effectively manage the transition to ensure that the nation has an agreed strategy on stewardship of health data as it is rapidly accumulated in many health information systems around the country.

Relying on the traditional compliance of consumers regarding health data stewardship will be inadequate in the future. If the Australian Government expected to fill the void by becoming the national data steward consumers' responses to Statement 24 indicate this would not be an acceptable strategy from citizens' points of view. A forward looking secondary data stewardship strategy is required for Australian consumers' medical information.

The next section moves to considering the tripartite Privacy Management issues of choice, consent and correction. Table 50 includes a recap of the consumer responses to Privacy Management statements that revealed statistically significant results across gender. 
Table 50: Consumer Privacy Management Part 1

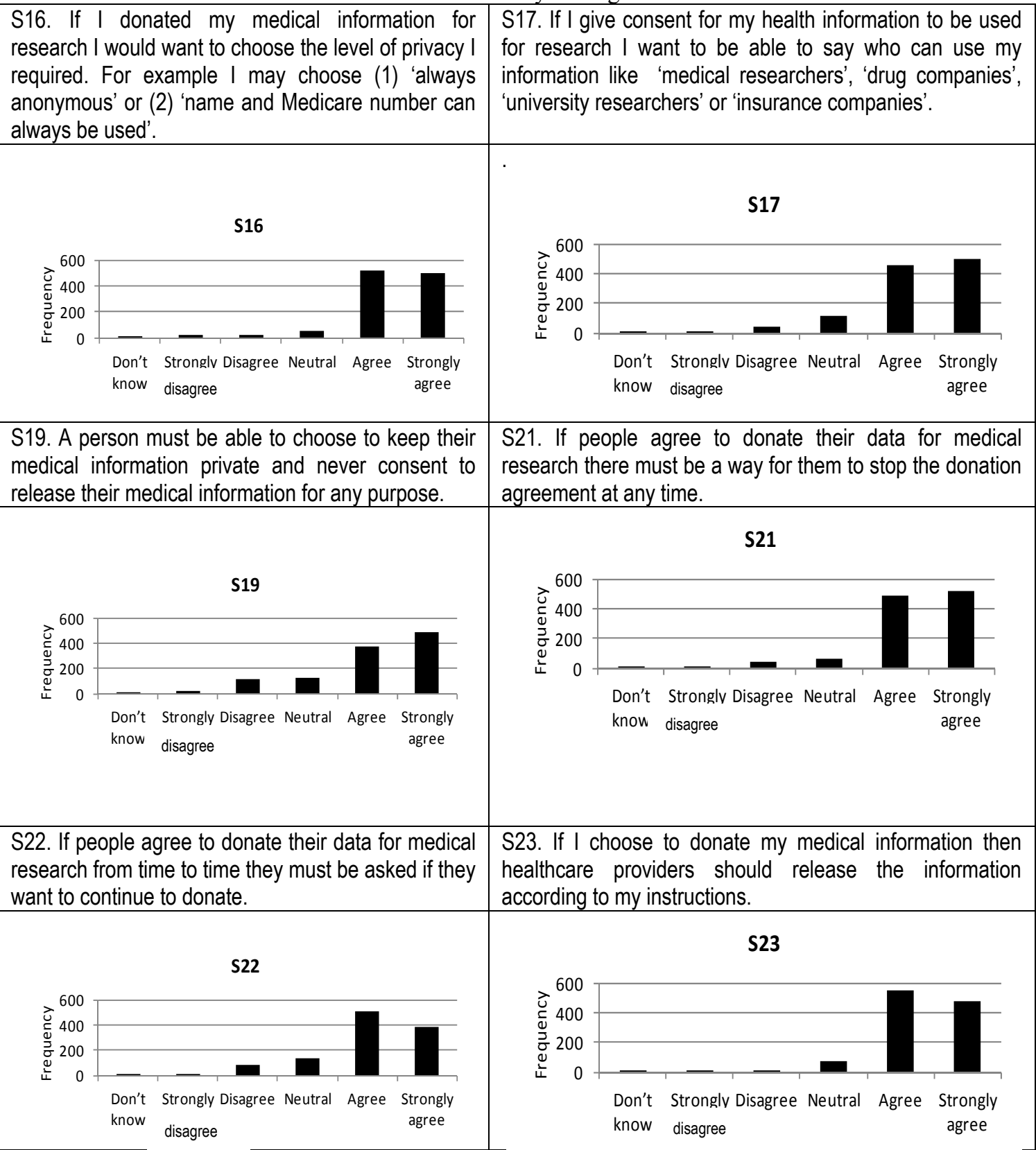

Statistically significant results between genders are clear on the issue of consumer control within the management of privacy domain. The frequency of women expressing a desire for various aspects of control over secondary use of their medical data is consistent through the Chi-Square expected count frequencies for survey Statements 16, 17, 19, 21, 22, and 23. In contrast, men did not meet expected counts (See Table 51) and with respect to the control of use of their data, men hence do not 
express the same level of expectation as do women. This reflects the gender differences findings of Research Question 1.

Table 51: Gender Differences Regarding Management of Privacy - Control.

\begin{tabular}{|c|c|c|c|}
\hline Statement & \multicolumn{3}{|c|}{ Strongly Agree/Agree } \\
\hline $\begin{array}{l}\text { 16. If I donated my medical information for research I would want to } \\
\text { choose the level of privacy I required. For example I may choose } \\
\text { (1) 'always anonymous' or (2) 'name and Medicare number can } \\
\text { always be used'. }\end{array}$ & $\begin{array}{l}\text { Count } \\
\text { Expected Count }\end{array}$ & $\begin{array}{l}\text { Female } \\
694 \\
675.1\end{array}$ & $\begin{array}{l}\text { Male } \\
310 \\
328.9\end{array}$ \\
\hline $\begin{array}{l}\text { 17. If I give consent for my health information to be used for } \\
\text { research I want to be able to say who can use my information like } \\
\text { 'medical researchers', 'drug companies', 'university researchers' or } \\
\text { 'insurance companies'. }\end{array}$ & $\begin{array}{l}\text { Count } \\
\text { Expected Count }\end{array}$ & $\begin{array}{l}\text { Female } \\
655 \\
636.7\end{array}$ & $\begin{array}{l}\text { Male } \\
289 \\
307.3\end{array}$ \\
\hline $\begin{array}{l}\text { 19. A person must be able to choose to keep their medical } \\
\text { information private and never consent to release their medical } \\
\text { information for any purpose. }\end{array}$ & $\begin{array}{l}\text { Count } \\
\text { Expected Count }\end{array}$ & $\begin{array}{l}\text { Female } \\
589 \\
569.5\end{array}$ & $\begin{array}{l}\text { Male } \\
255 \\
274.5\end{array}$ \\
\hline $\begin{array}{l}\text { 21. If people agree to donate their data for medical research there } \\
\text { must be a way for them to stop the donation agreement at any } \\
\text { time. }\end{array}$ & $\begin{array}{l}\text { Count } \\
\text { Expected Count }\end{array}$ & $\begin{array}{l}\text { Female } \\
680 \\
666.7\end{array}$ & $\begin{array}{l}\text { Male } \\
312 \\
325.3\end{array}$ \\
\hline $\begin{array}{l}\text { 22. If people agree to donate their data for medical research from } \\
\text { time to time they must be asked if they want to continue to donate. }\end{array}$ & $\begin{array}{l}\text { Count } \\
\text { Expected Count }\end{array}$ & $\begin{array}{l}\text { Female } \\
615 \\
586.6\end{array}$ & $\begin{array}{l}\text { Male } \\
259 \\
287.4\end{array}$ \\
\hline $\begin{array}{l}\text { 23. If I choose to donate my medical information then healthcare } \\
\text { providers should release the information according to my } \\
\text { instructions. }\end{array}$ & $\begin{array}{l}\text { Count } \\
\text { Expected Count }\end{array}$ & $\begin{array}{l}\text { Female } \\
689 \\
679.3\end{array}$ & $\begin{array}{l}\text { Male } \\
324 \\
333.7\end{array}$ \\
\hline
\end{tabular}

As noted at the end of the previous Chapter, Statement 24 Chi-Square test results return $p=0.056$, just outside the statistically significant range, and responses to this statement regarding the Australian Government controlling access to medical data for secondary uses attracts support from males and greater than expected opposition from females.

This finding supports those of recent Australian studies that indicated women were more engaged in healthcare matters. A 2010 report from CSC (Pettigrew, Roman et al. 2010) found Australian women are generally more engaged than men when it comes to in their personal healthcare management. In particular, the CSC report (p. $23)$ states that: more women $(83 \%)$ keep test results and x-ray images than men (72\%), more women (60\%) keep educational documentation than men (47\%), and more women $(46 \%)$ than men $(39 \%)$ shared personally held medical information 
with healthcare providers. In addition, it supports an early Canadian study into secondary uses of medical information for research found that women required more detail than men regarding research that used their data (Willison, Keshavjee et al. 2003).

A reasonable conclusion to draw is that women would be more responsive to requests to join as research partners in research using medical information provided they were offered a genuine opportunity to partner. It is also reasonable to conclude that women would demand more control than men would over the nature of the secondary use. This has implications for future systematic approaches to tackling the secondary use of medical data and may provide some insight for human research ethics committees in deliberations regarding medical data usage. If a consumer is prepared to be fully engaged and give instruction regarding secondary use of their medical data perhaps ethics committee's no longer need to make judgements regarding the use of consumer data for secondary purposes - the consumer instructions could be followed.

It is interesting to note that based on the results from the part of this survey that investigated the 'concept' of privacy there was no statistically significant difference between women and men in terms of anxiety regarding privacy. Women are no more concerned about privacy than are men so it is not likely that the anxiety over privacy is driving the desire for more control over secondary use of their data. The reason behind the women's desire for more control over secondary uses is an interesting open research area.

Tertiary educated respondents did not meet expected positive counts for Statement 19 - A person must be able to choose to keep their medical information private and never consent to release their medical information for any purpose. Consumers with less than Yr10 education also failed to meet expected counts for 'strongly agree'/'agree' while the remainder exceeded expected counts for positive responses.

This is an important survey question as it attempts to draw out the views on maximising personal privacy through withdrawal from secondary use initiatives. 
Why are tertiary educated consumers, in particular, not more agreeable to this notion? This warrants further analysis and details are described below. What emerges are diverse attitudes that reflect some of the perspectives described in the Literature Review. It is outstanding to have such examples illustrating the various competing points of view regarding secondary use from our own citizens.

The qualitative comments for respondents with $<$ Year 10 or with Bachelor or Postgrad education who selected 'strongly disagree'/'disagree' responses for Statement 19 were reviewed to find some elaboration of the attitudes behind responses to this statement. There were no relevant elaborating comments from the $<$ Year 10 educated respondents so no further insight into their attitudes could be gained.

Of the tertiary educated respondents who selected 'strongly disagree'/'disagree' for S19, the following are comments that elaborate their attitudes in a useful way:

- "I think it is important that medical data is available for ethical and valid research which could be beneficial to all Australians."[Survey677,F,ACT,5165,Bach,HW]

This is a response from a healthcare worker who is not endorsing the opportunity for a consumer to withdraw from having their medical data used for secondary purposes. What we read in the above comment is an endorsement of the 'common good' argument often used by the healthcare sector as justification for using an individual's medical data. The next elaborating comment is from a female resident of the ACT who debunks concerns regarding society surveillance and argues for compulsory consumer participation for the 'common good'. She also raises the spectre of deidentified data and the next section of the Chapter discusses anonymity matters.

- "Medical break throughs could be made with better access to nonidentifiable data. Any system will be criticized by those who fear a "bigbrother" campaign by Govt. so voluntary data input might not be comprehensive. A legislated compulsory system would be better for the 
common good, as it would enable a more complete picture of health issues in the community."[Survey776,F,ACT,26-39,Bach,NHW]

An intriguing comment came from a male, non-healthcare worker in Victoria who commented:

- "Brin has written about privacy issues in the "Transparent Society" Any legal or administrative systems put in place should be designed to cope with the challenges of the Moore's law like decrease in security costs, both as an opportunity and a further pressure." [Survey473,M,VIC,51-65,NHW]

This respondent is referring to a non-fiction book "The Transparent Society" written by David Brin (1998) who considers a world with social transparency and far less privacy. Another comment took a very economic rationalist approach to addressing why an individual should not be allowed to 'opt-out':

- "As tax payers we all contribute to everyone's healthcare - Medicare, subsidies(pensioners, unemployed etc.), research, hospitals - as such, all info that can be collected and used anonymously to improve treatments, diagnosis etc. should be available to all in the medical/research fields. It is through the sharing of information that improvements occur and prevents duplication of research and gives larger data base thereby hastening developments. "[Survey493,F,NSW,66-80,NHW]

The analysis of the negative responses to Statement 19 did not elicit any points of view that have not been acknowledged in the Literature Review component of this study. Having the response to this statement held within a relational database with the demographics was ideal as the development of SQL queries to drill-down into the responses and comments to quickly develop a profile of attitudes was speedy and straight forward.

Statements 21, 22 and 23 explored the level of control and frequency of consent renewal expected by consumers when their medical information is being used for a secondary purpose. Healthcare workers responded positively to the idea of consumers having an opportunity to re-affirm consent for secondary use of their data. 
There were mixed responses from the sample population with tertiary educated citizens responding in the negative more frequently than expected. Analysis of these responses indicates a diversity of views with no clear pattern apart from the gender differences already considered.

Analysis of S20 responses, as illustrated in Table 52 below, indicates that consumers also have mixed attitudes towards the provision of one consent for data donation. The Irish consumer survey (Buckley, Murphy et al. 2011) found that $89.5 \%$ of respondents would agree to an ongoing consent without the need for consent for individual studies. Considering the impact of age (10 year increments) the Irish survey found a significant association between age and increased likelihood of agreeing to ongoing consent.

This Australian survey also found statistically significant differences across age $\left(\chi^{2}=28.773, \mathrm{df}=10, \quad p=0.001\right)$ with citizens aged 40-65 responding 'strongly disagree/disagree' more frequently than expected. Buckley, Murphy et al (2011) suggest that employment security influences citizens willingness to share their medical information.

Combining the results of S22 and S20 delivers a range of views on the issue of timing and frequency of consent. The implications of this for future implementations of consent associated with any secondary use of medical data is that flexible arrangements will be required to accommodate diverse consumer expectations. 
Table 52: Consumer Privacy Management Part 2

\begin{tabular}{l}
$\begin{array}{l}\text { S13. If my health information could be made anonymous } \\
\text { by removing things like my name, address, phone number } \\
\text { and Medicare number I would be more likely to agree for } \\
\text { the information to be used for medical research. }\end{array} \begin{array}{l}\text { S14. I feel that I continue to have privacy even when other people } \\
\text { have access to my personal information if I am the one who has } \\
\text { granted the other people access. }\end{array}$ \\
\hline
\end{tabular}

The results of Statement 13 indicate positive consumer attitudes towards the use of anonymous medical data for research purposes. There are no statistically significant differences across respondents on this statement. This positive response to the use of anonymised data is similar to that reported by an earlier Canadian study (EKOS Research Associates 2007) where 84\% of respondents indicated agreement with use of data for research if names and addresses were first removed.

It is acknowledged that deciding on a suitable approach to de-identifying data is a complex matter however the issue of best approach to de-identification, or anonymising, medical data is beyond the scope of this study. Too often information technology studies have tackled de-identification as if it alone was the answer to all 
things privacy related. The point of this study is to investigate matters well beyond de-identification challenges. The consumer response to this question cannot be interpreted as carte blanche agreement with any third party use of de-identified data. The consumer responses to this entire survey indicated that a nuanced, sophisticated understanding of secondary use that requires a less blunt instrument than simply deidentifying data prior to secondary use.

Statement 29 explores the 'correction' component of Privacy Management suggested by Tavani and Moor. Statistically significant results were revealed across Healthcare Workers attitudes with these consumers responding negatively or 'neutral' more frequently than expected which contrasts with the rest of the respondents who are 'positive' more frequently than expected.

Further analysis, similar to that described above for S19, was conducted to gain insight into consumers who did not support consumers seeing and correcting information, the following comment was informative:

- “...Drs comments on file are not written to be viewed ie. Situations of patients with mental illness - personal comments on patient's condition should remain with Dr - NOT AVAILABLE FOR VIEWING..." [Survey392,F,WA,51-65, $<\operatorname{Yr} 10, N H W]$

Unfortunately the healthcare workers who selected 'strongly disagree'/'disagree' did not elaborate on the issue of consumers viewing and correcting information in qualitative comments hence no further insight could be gained. Perhaps as the long held practice has been for patients to not necessarily view their medical information the negative healthcare worker responses were 'status quo' without needing elaboration. The majority of respondents are supportive of the view and correction notion hence endorsing this aspect of RALC theory. The comment from the West Australian consumer above gives an illustrative example of difficulties with some consumers. The scope of this study is specifically about health service provider held medical information hence looking towards applying this aspect of RALC is challenging. 
Statement 14 aims at the core of the restricted access/limited control (RALC) hybrid privacy theory. The response from consumers indicates that they understood the statement i.e. few 'don't know' responses. This is a good start because composing a statement to pose this core RALC concept of Privacy Management was an iterative task due to the intangible and slippery privacy concepts at play. This statement combines the notion of 'restricted access' in that normative privacy would ordinarily exclude some people from having access to personal information. However, if the subject of the information (in this case consumer/patient) is the authority who has granted access, then through this exercise of some control by the subject a sense of privacy is maintained. The consumer response to this statement is affirmation of a foundation construct of RALC privacy theory and bodes well for translation into real world operations, such as secondary use contexts.

Summary of Privacy Management findings:

- Statistically significant results indicate that women expect more control over re-use of their data.

- Healthcare Workers attitudes towards medical data stewardship and consumer correction of data differ from those attitudes of the broader community.

- The advantages of using anonymised data are universally acknowledged by all consumers.

- Initial investigations suggest that Australian consumers do not support the Australian Government taking on a data stewardship role over consumers' medical information.

- The diverse 'lens' approach taken to developing the literature review of this study is reflected in consumer comments, particularly responses to Statement 19. 


\subsection{Summary of Research Question 2 Findings}

The second research question driving this study is:

"Do the RALC and contextual integrity privacy theory offer privacy concepts that can: (1) be applied in the secondary use of medical data context and (2) gain support from interested consumers?"

In summary, the findings of Research Question 2 are:

- The outcomes from the investigation into Privacy Concept, Privacy Justification and Privacy Management components through the Australian Public Opinion Survey Regarding Secondary Use of Medical Data indicates that the RALC and contextual integrity privacy theory could be applied in the secondary use of medical data context.

As consumers completed the surveys there was no expectation that respondents would conceptualise the tripartite components of the privacy theory. Each of the carefully selected attitudinal statements, many first trialled in the pilot surveys, sought to engage consumers on one particular tripartite component. The tripartite component classification was transparent to the respondents and relied upon the researcher to compile constructs appropriately as discussed for the pilot survey in thesis section 3.5.3.2 and for the final survey in thesis section 3.5.5. The consumers who responded to the survey were able to engage with the attitudinal statements and the analysis of quantitative results, classified according to privacy 'concept' or 'justification' or 'management', provided reliable results as discussed in thesis section 3.5.2.

Without specifically defining these theoretical constructs for survey respondents, it was possible to identify Contextual Integrity components within Australian and Canadian consumer survey respondent's open-ended comments. The survey comments identified different actors (e.g. not-forprofit medical researchers and for-profit commercial actors), different 
attributes (e.g. sexual health, mental health and family history) and transmission principles (e.g. consumer consent requirements and consumer feedback requirements on instances of secondary data use).

- Given the satisfactory response rate to the Australian survey and the clarity and volume of quantitative and qualitative survey data gathered, support for operationalising RALC (Tavani and Moor 2001) and Nissenbaum's (2010) contextual integrity to support secondary use of medical data would likely gain support from interested consumers.

\subsection{Conclusion}

Research Questions 1 and 2 have been addressed in this Chapter. In addition to these research questions the rejection of the null hypothesis:

$\mathrm{H}_{0}$ : There is no significant difference between groups of consumers as expressed through responses to the public opinion survey used in this study where $p<=0.05$.

indicates that a one-size-fits all approach to representing Australian consumer opinions and expectations regarding secondary use of their medical data would be inadequate. Any further work needs to acknowledge and accommodate the diversity of consumer opinion. There is an opportunity to further explore the application of the RALC and Chapter 7 focuses on the challenges of developing a privacy framework for secondary uses of medical data. The importance of this framework is apparent when reflecting on the generational shift that has emerged from the analysis presented in this chapter. Other complex issues that need to be addressed by the framework are the healthcare workers well established data stewardship practices. The role of women in establishing the secondary use framework is important as the results of the Australian survey indicate that they are more likely to engage productively in this endeavour. 


\section{CANADIAN CONSUMER PUBLIC OPINION SURVEY RESULTS AND COMPARISON TO AUSTRALIAN RESULTS AND ANALYSIS}

\subsection{Introduction}

The survey was deployed into the Canadian community where the introduction of electronic health records is further progressed than in Australia. The survey instrument used in Australia was used in the English speaking parts of Canada with little change beyond that which was needed to customise to local healthcare arrangements, as described in the Research Method Chapter. Hence the survey constructs are not reproduced here. This Chapter presents the Canadian survey results and discussion including comparison to the Australian survey results.

\subsubsection{Descriptive Statistics}

In total, 203 Canadians responded to the consumer survey. Table 53 presents the demographics of Canadian respondents and for comparison selected Australian demographics are also provided.

Table 53: Canadian Survey Respondents Demographics

\begin{tabular}{|r|r|r|r|}
\hline \multicolumn{1}{|c|}{ Respondent characteristics } & $\begin{array}{c}\text { Canadian } \\
\text { Frequency } \\
\text { (n) }\end{array}$ & $\begin{array}{c}\text { Canadian } \% \\
\text { of total }\end{array}$ & $\begin{array}{c}\text { Australian \% } \\
\text { of Total }\end{array}$ \\
\hline Gender & 111 & 54.7 & 65.5 \\
\hline Female & 81 & 39.9 & 31.9 \\
\hline Male & 11 & 5.4 & 2.6 \\
\hline specified & 2 & 1.0 & 12.9 \\
\hline $18-25$ & 22 & 10.8 & 23.1 \\
\hline $26-39$ & 50 & 24.6 & 36.6 \\
\hline $40-50$ & 80 & 39.4 & 18.5 \\
\hline $51-65$ & 30 & 14.8 & 3.9 \\
\hline $66-80$ & 10 & 4.9 & 3.0 \\
\hline Over 80 & 9 & 4.4 & \\
\hline Unknown & & & 2.8 \\
\hline
\end{tabular}




\begin{tabular}{|r|r|r|r|}
\hline \multicolumn{1}{|c|}{ Respondent characteristics } & $\begin{array}{c}\text { Canadian } \\
\text { Frequency }(\boldsymbol{n})\end{array}$ & $\begin{array}{c}\text { Canadian \% } \\
\text { of total }\end{array}$ & $\begin{array}{c}\text { Australian \% } \\
\text { of Total }\end{array}$ \\
\hline Highest Level of Education & 28 & 13.8 & 10.3 \\
\hline Secondary school & 30 & 14.8 & 9.6 \\
\hline College & 6 & 3.0 & 7.6 \\
\hline Trade Qualification & 20 & 9.9 & 12.4 \\
\hline Professional Qualification & 47 & 23.2 & 20.6 \\
\hline Bachelor Degree & 62 & 30.5 & 20.1 \\
\hline Postgraduate & 10 & 4.9 & 3.3 \\
\hline Unknown & & & 23.1 \\
\hline Yorked in healthcare sector & 38 & 18.7 & 74.3 \\
\hline Yes & 156 & 76.8 & 2.6 \\
\hline Unknown & 0 & 0 & \\
\hline & & & \\
\hline
\end{tabular}

\subsubsection{Survey Psychometrics}

This section investigates the validity of the Canadian consumer public opinion survey instrument using the same approach adopted with the Australian survey.

Table 54 presents the survey constructs, organised within appropriate tripartite privacy components, for the Canadian consumer survey scales. The Cronbach alpha $(\alpha)$ calculations were conducted using SPSS 17.0 and, as with the Australian survey, the alpha values were in the exploratory research range with the exception of Privacy Justification - 'finding-a-balance'.

Table 54: Canadian Survey Internal Reliability

\begin{tabular}{|l|l|l|r|r|c|}
\hline \multirow{2}{*}{$\begin{array}{c}\text { Tripartite } \\
\text { Component }\end{array}$} & \multicolumn{1}{|c|}{ Construct } & \multirow{2}{*}{ Code } & \multicolumn{2}{|c|}{ Cronbach Alpha (a) } & \multirow{2}{*}{$\begin{array}{c}\text { Number of } \\
\text { items }\end{array}$} \\
\cline { 4 - 5 } & & & Canada & Australia & \\
\hline Concept & Anxiety & C-A & 0.748 & 0.691 & 6 \\
\hline & Limited Access & C-LA & 0.561 & 0.602 & 2 \\
\hline Justification & Rights based & J-RB & 0.676 & 0.644 & 3 \\
\hline & Balance & J-B & 0.481 & 0.159 & 3 \\
\hline Management & Control & M-C & 0.690 & 0.715 & 11 \\
\hline & Data Stewardship & M-DS & 0.579 & 0.617 & 5 \\
\hline
\end{tabular}


Face validity was conducted by the University of Ontario Institute of Technology (UOIT) Research Ethics Board (REB) and student members of Health Informatics Research centre who were untrained in terms of survey instrument design or content of the survey. Content validity was addressed by Australian researchers and reviewed by the Canada Chair in Health Informatics at UOIT.

The survey instrument performed consistently when moved from the Australian context to the Canadian context which aids claims of instrument validity.

\subsubsection{Response Frequency and Comparison}

This section presents the survey response frequencies in tabular and graphical format. The survey results are not presented in the order of appearance on the survey instrument but rather they are grouped by the tripartite component to which they belong i.e. Privacy Concept, Privacy Justification or Privacy Management. Table 55 includes the statement number and text of the statement used in the survey and tabular presentation of Canadian response frequencies and percentage of valid responses. Australian response frequencies are provided in tabular format. The bar charts present the percentage of Canadian and Australian responses within each Likert scale valid response which includes the 'don't know' option.

Despite the difference in sample size between Australia and Canada, there is value in comparing the two survey results as the proportions of consumers within demographic groups are similar, as illustrated in Table 53. The Cronbach Alpha $(\alpha)$ internal reliability is higher for the Canadian survey than for the Australian survey on issues of consumer anxiety and perception of individual 'rights' to privacy. The Cronbach Alpha $(\alpha)$ measure on the Privacy - Justification 'getting-the-balanceright' construct was higher on the Canadian survey than the Australian survey, however this continues to be outside the accepted range for exploratory research. Any future research using this survey instrument needs to redesign the statements pertaining to the 'getting-the-balance-right' between the 'common good' of society perceptions of individual rights to get higher internal reliability. 
To aid in the comparison between Australian and Canadian survey results a null hypothesis was generated:

$\mathrm{H}_{0}$ : There is no significant difference between Canadian and Australian consumer opinion as expressed through responses to the public opinion survey used in this study where $p<0.05$.

The Mann-Whitney $U$ test was used to investigate the null hypothesis. Where the test results were statistically significant, and the null hypothesis was rejected, a note appears in Table 55 along with the asymptotic significance (2 tailed). The MannWhitney $U$ test results are non-parametric and hence cannot provide definitive metrics for the differences between the Canadian and Australian samples. By reviewing the bar charts in Table 55 it is possible to gain a broad sense of the differences in opinion however no confidence intervals can be stated. Despite this limitation, high level insight can be gained as presented in Table 55 below. Further research would enable a more precise calculation of the opinion differences between Australians and Canadians, however for the purpose of this initial study the MannWhitney $U$ test and frequency bar charts were sufficient. 
Table 55: Canadian and Australian Survey Response Frequency and Statistically Significant Mann-Whitney U test results.

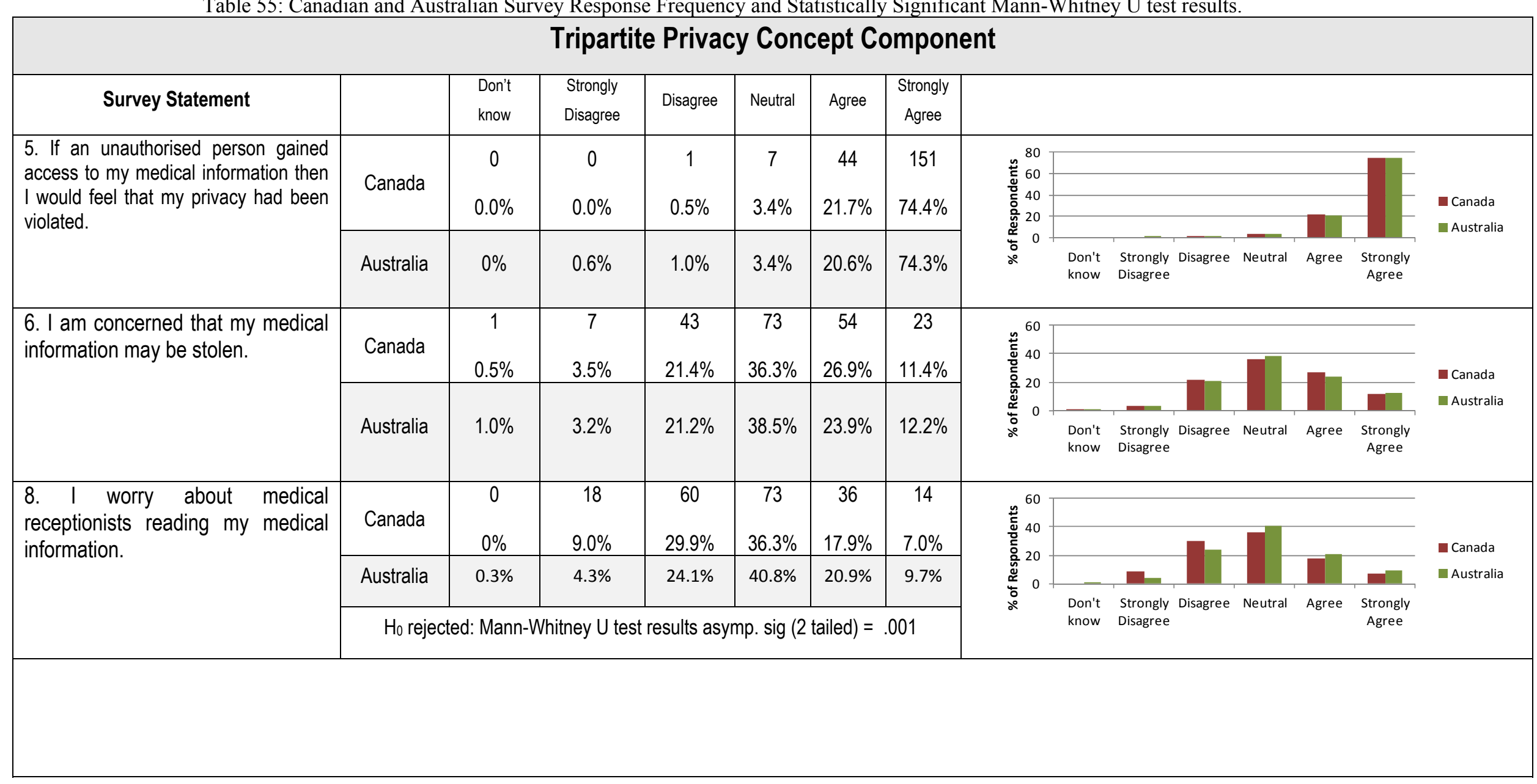




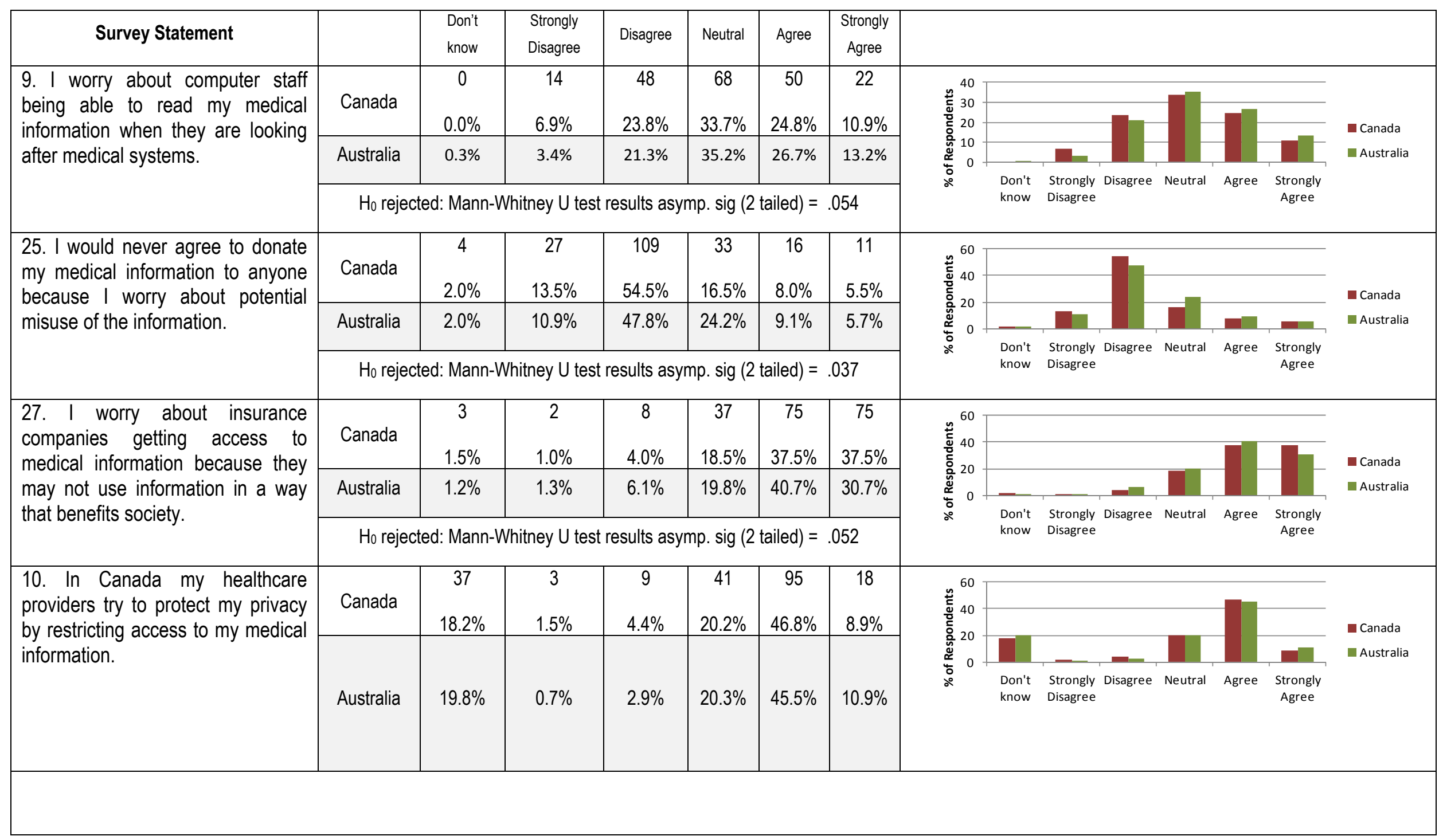




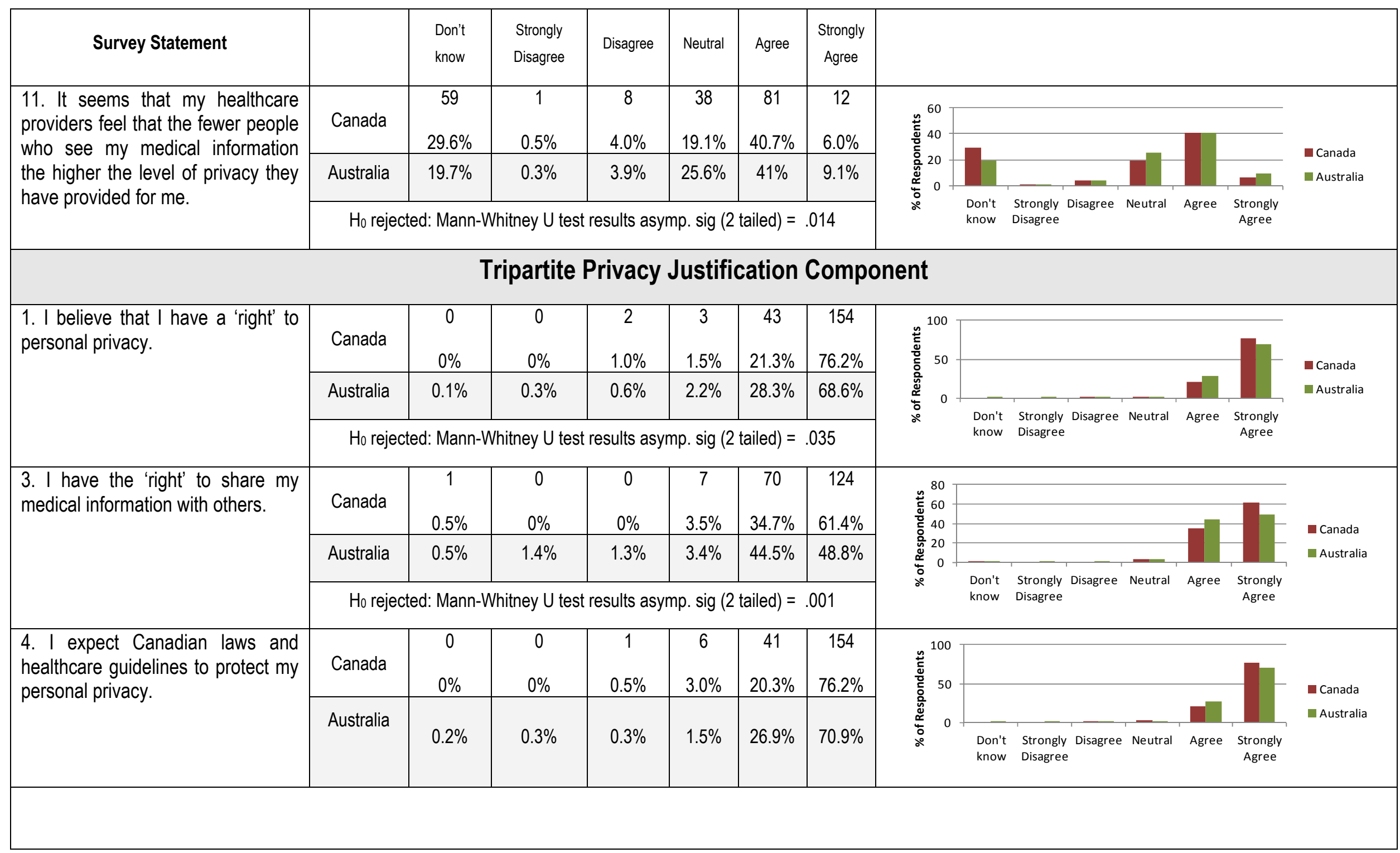




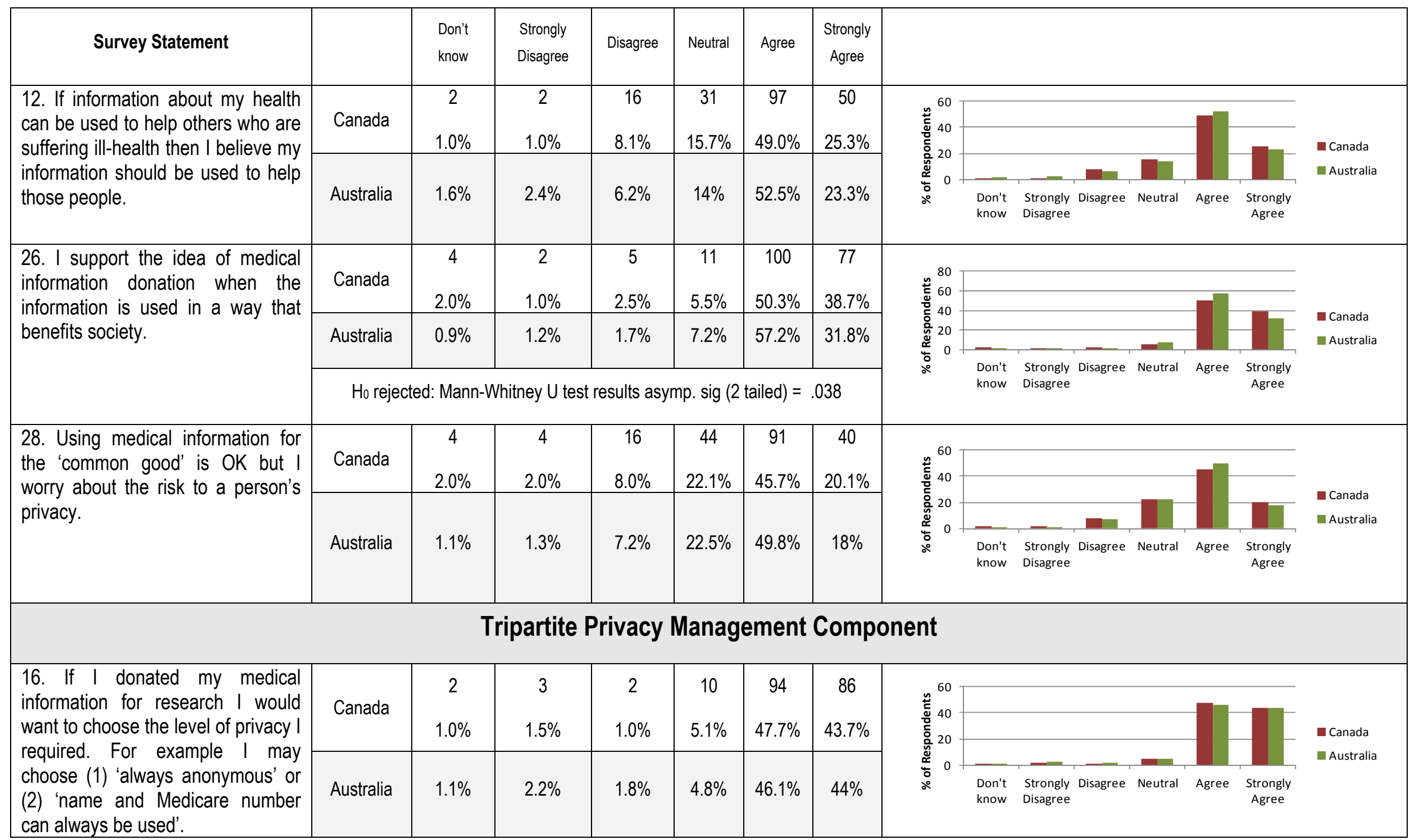




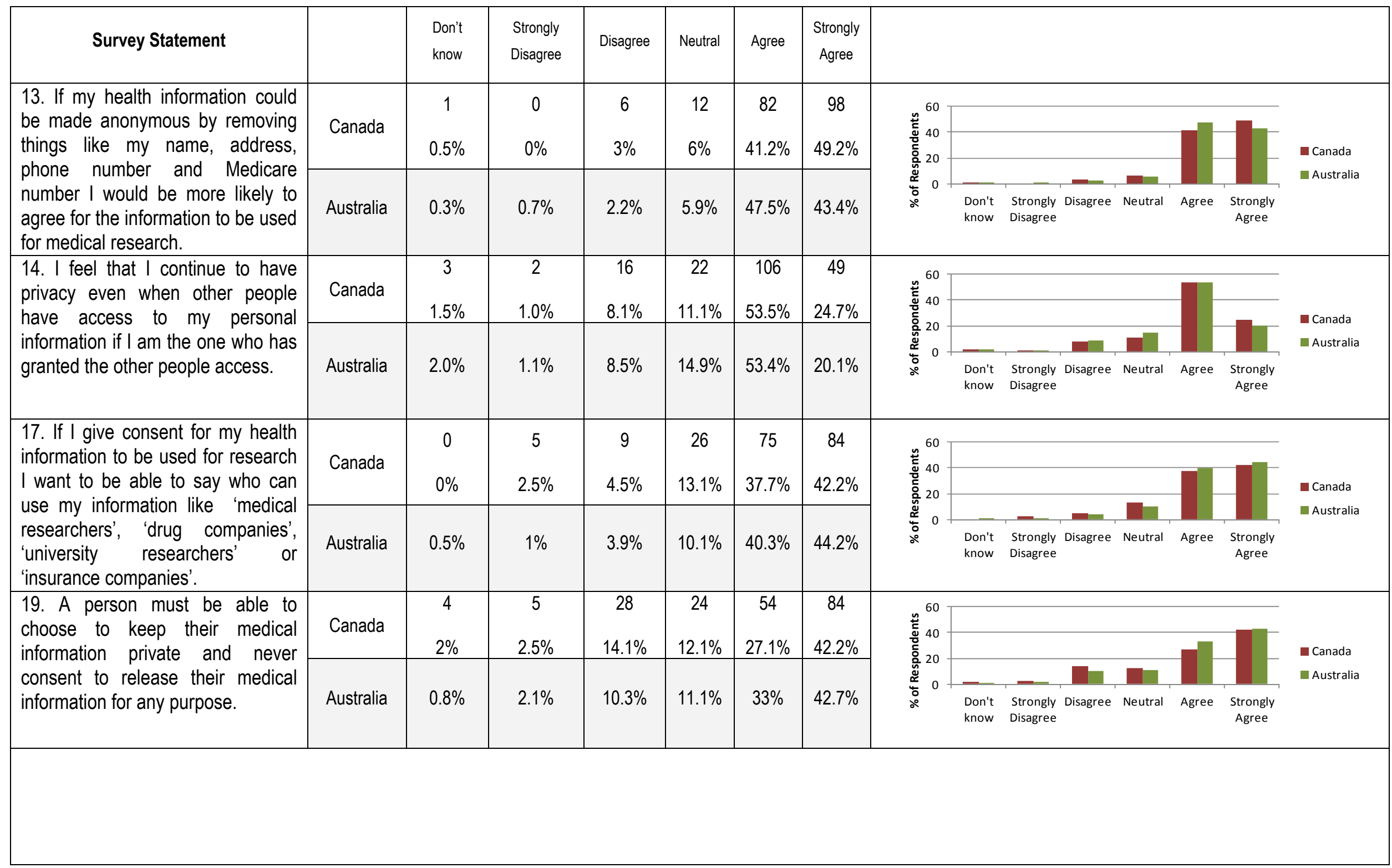




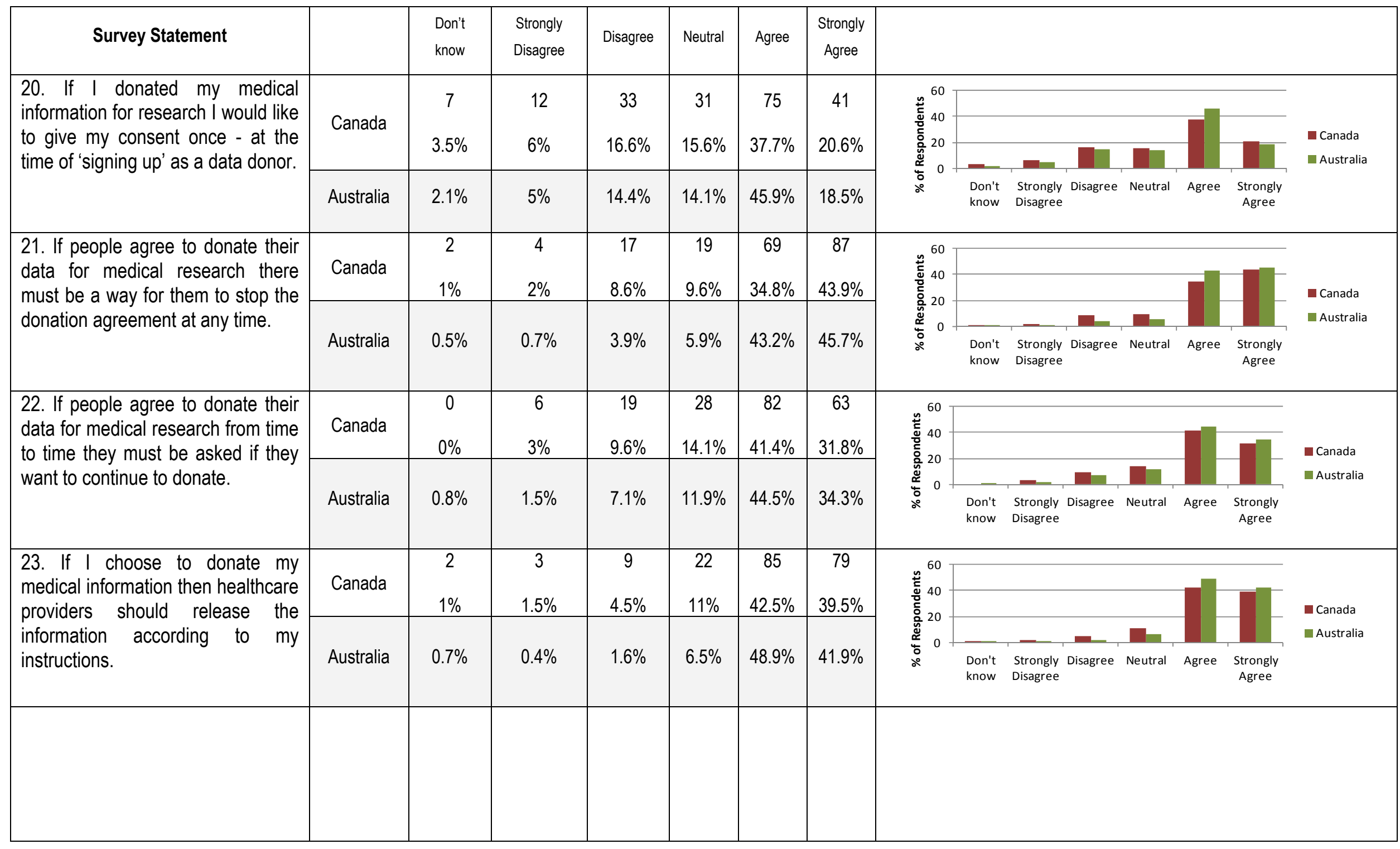




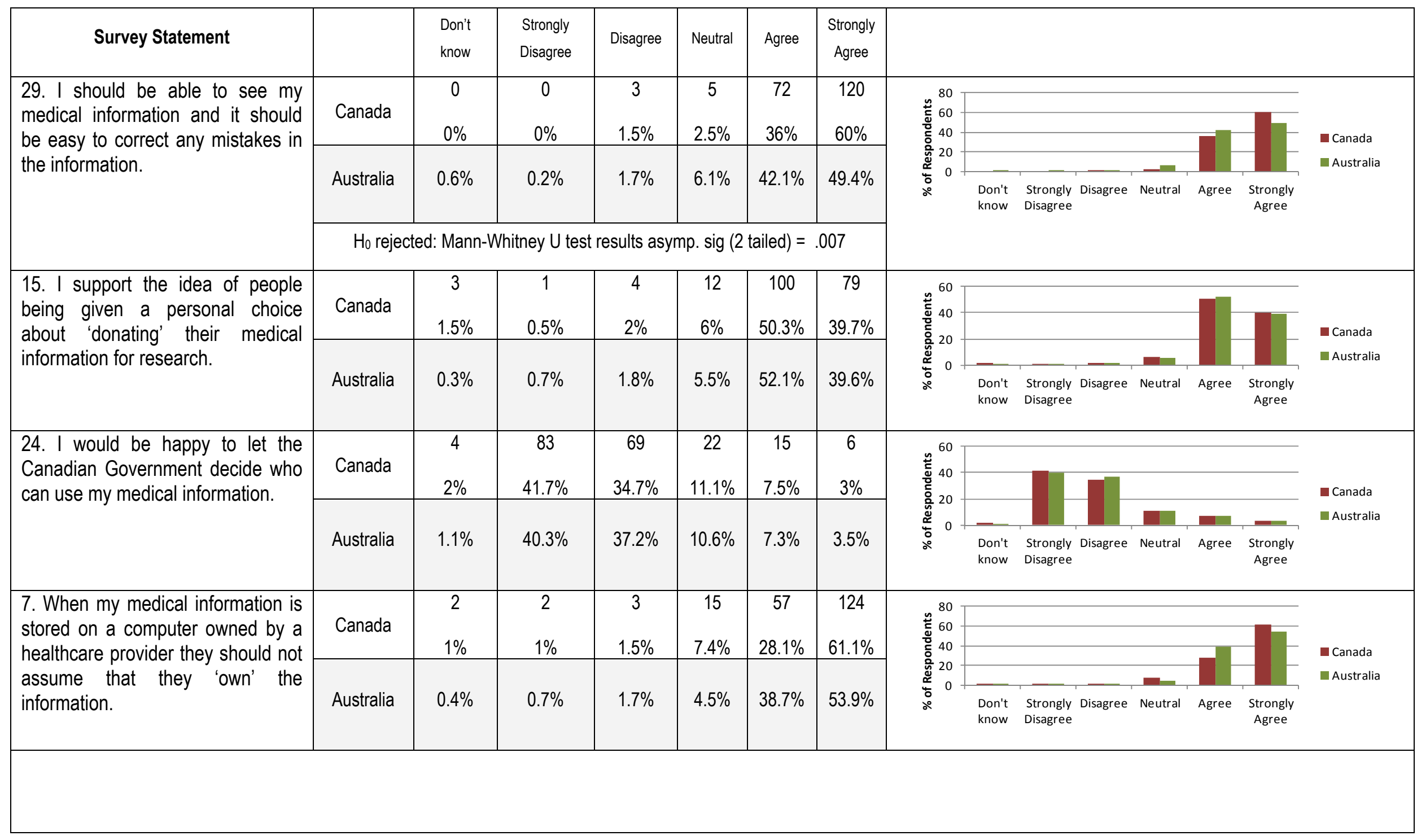




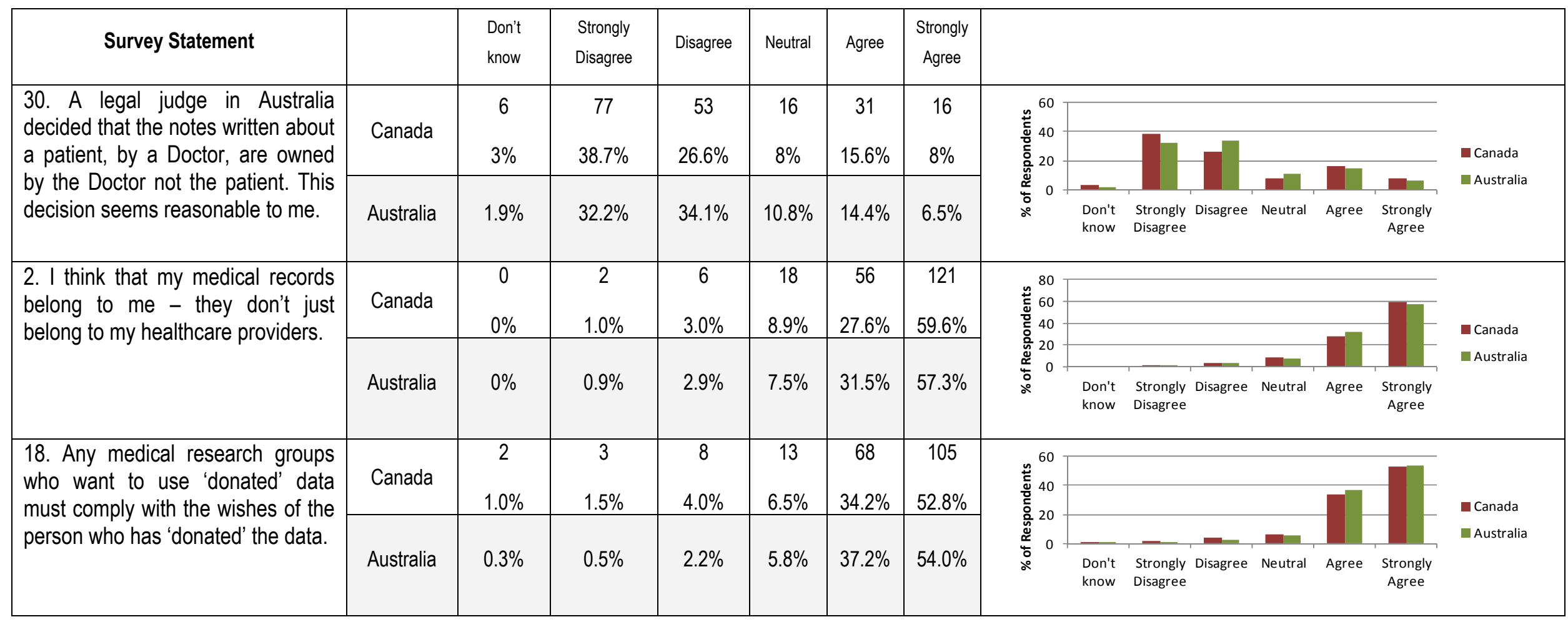


The next section discusses the results from the Canadian survey with an emphasis on comparison with Australian results including the Mann-Whitney $\mathrm{U}$ test and statistically significant Chi-Square test results.

\subsubsection{Analysis}

Data pre-processing was undertaken on the Canadian survey responses in exactly the same manner as that described for the Australian surveys in the Chapter 4. The qualitative comments have been encoded in the same manner as the Australian survey using the same coding scheme with an adjustment to highest level of education to include "College". The Canadian survey is smaller than the Australian survey with 203 and 1,158 returned surveys respectively. The frequencies with which themes arise in the qualitative comments have been tabulated as with the Australian survey and sample respondents comments are provided.

In an approach similar to the analysis of the Australian quantitative data, the Pearson Chi-Square $\left(x^{2}\right)$ test was used with the Canadian survey results. The Canadian sample size is much smaller than the Australian sample size and the results of Chi-Square tests on small samples are not as reliable as results from larger samples. As with the Australian results, where the Canadian expected count of Chi-Square results is less than five the result was excluded. This left just two statistically significant Chi-Square test results; on Statement 9 and Statement 20. These results are discussed in the appropriate tripartite material below.

\subsubsection{Tripartite Component - Privacy Concept}

The eight statements considering the concept of privacy, including anxiety and limited access approaches, revealed that amongst Canadian respondents there was only one statistically significant difference and this related to Statement 9. The Chi-Square tests on Statement 9 - I worry about computer staff being able to read my medical information when they are looking after medical systems, revealed citizens opinion differing according to highest level of education $\left(\chi^{2}=18.365, \mathrm{df}=10, p=0.049\right)$ with post graduate educated citizens responding 
negatively more frequently than expected in contrast to college and professional educated citizens who responded more positively.

This result is similar to the Australian responses to Statement 9 where ChiSquare testing also revealed opinion varying across education level $\left(\chi^{2}=46.6, \mathrm{df}=12, p<0.001\right)$. The difference in the degrees of freedom is expected as the Canadian education demographics include fewer categories than Australia. Tertiary educated (Bachelor and Postgraduate) Australians and Postgraduate educated Canadians are responding in a more negative way than expected to the Statement, thus indicating less anxiety regarding the involvement of IT professionals in managing health information systems than are other citizens.

The null hypothesis regarding no difference between Canadian and Australian consumers opinion was rejected for half the statements that relate to the tripartite Concept of Privacy Component (see Table 55). These are Statements $8,9,25,27$ and 11 and results for each are incorporated into discussions below.

Statement 8 explored consumers' anxiety regarding medical receptionists reading consumer medical information and Australians indicated that they worry about medical receptionists more than do Canadians. This sentiment is also apparent via the greater number of Canadians who responded 'strongly disagree' or 'disagree' to Statement 8.

Statement 9 explored consumer concern regarding IT professional access to medical information and the Chi-Square testing discussed above revealed differences within national samples. In addition there were differences between Canadian and Australian consumers. Echoing the results of Statement 8, Australians were again more anxious about IT professionals' access than were Canadians. Canadians selected 'strongly disagree' and 'disagree' more frequently than Australians. 
Not donating medical information because of concern about misuse was the focus of Statement 25. Australians were more neutral on this matter than were Canadians. Canadians outstripped Australians in negative responses thus indicating a stronger opinion about not wanting to withhold information due to potential misuse.

Statement 27 gathered public opinion regarding worry about insurance companies gaining access because their uses may not benefit society. Here Canadians strongly agreed more at a higher percentage than did Australians.

Restricted access concepts of privacy were explored in Statement 11 and Canadians responded 'don't know' more frequently than Australians. Slightly more Australians selected 'strongly agree' and 'neutral' than did Canadians. The previous Chapter considered why so many survey respondents chose 'don't know' and similar analysis could be applied here regarding because many Canadians did not know that the healthcare sector relies on limited access for privacy. The literature coming from the healthcare community is strong in promoting the limited access approach to privacy and yet a large percentage of Canadian and Australian citizens are unsure of this practice.

The same structured notation has been adopted for this Chapter as was used to attach demographic characteristics to Australian qualitative comments.

Table 56 provides a summary of Canadian codes needed to interpret demographics for qualitative comments.

Table 56: Canadian Province Codes

\begin{tabular}{|c|c|}
\hline Code & Province \\
\hline$A B$ & Alberta \\
\hline BC & British Columbia \\
\hline MB & Manitoba \\
\hline NB & New Brunswick \\
\hline NS & Nova Scotia \\
\hline ON & Ontario \\
\hline SK & Saskatchewan \\
\hline YT & Yukon Territory \\
\hline
\end{tabular}


Table 57 presents the qualitative codes adopted and the frequency with which a theme was included in Canadian respondents comments to the two qualitative survey questions for deductive themes related to the tripartite Privacy Concept (as described in the Research Method Chapter, Table 14).

Table 57: Tripartite Component - Privacy Concept, Canada- Qualitative Comment Count

\begin{tabular}{|c|l|r|l|r|r|}
\hline Code & \multicolumn{1}{|c|}{$\begin{array}{l}\text { Sub } \\
\text { Code }\end{array}$} & Theme & $\begin{array}{l}\text { Comment 1 } \\
\text { Frequency }\end{array}$ & $\begin{array}{r}\text { Comment 2 } \\
\text { Frequency }\end{array}$ \\
\hline 1 & $\begin{array}{l}\text { Privacy } \\
\text { Concept }\end{array}$ & A & Expressing anxiety & 9 & 9 \\
\hline & B & $\begin{array}{l}\text { Not anxious about secondary use } \\
\text { of data }\end{array}$ & 1 & 2 \\
\hline & C & $\begin{array}{l}\text { Consumer TRUST - Don't know } \\
\text { who has information - Lack of } \\
\text { transparency }\end{array}$ & 2 & 0 \\
\hline & D & $\begin{array}{l}\text { Not everyone who has access has } \\
\text { patients' best interests at heart }\end{array}$ & 12 & 7 \\
\hline & E & Surveillance & 1 & 1 \\
\hline
\end{tabular}

Examples of the diverse qualitative comments related to the tripartite Privacy Concept are provided below with demographic characteristics of the respondents.

"What do people have to hide? If you want to use OHIP you must comply with the rules that may compromise personal privacy." [Survey31,unknown]

The Ontario Health Insurance Plan (OHIP) is a government supported program for residents of Ontario with funding sources including taxes and Canadian Government contributions. This consumer is expressing an opinion that is based on an argument that if an individual wants to take advantage of the OHIP services they are not meeting all the costs of healthcare themselves and should be prepared to trade some of their privacy as a consequence. Some Australian respondents expressed similar economics-based rationale for forgoing privacy in return for heavily subsidised services.

"It must never be made available to insurance companies!”[Survey134,F,AB,5165,College,HW] 
"I don't sit around and 'worry' about 'where' is my healthcare information. Actually computers are not my forte but I do understand that "hackers" could access the info - what would they do with the info? Sell to insurance companies now that would worry me!" [Survey135,F,AB,66-80,Prof,HW]

"I am concerned about big pharma using data for their own financial benefit and insurance companies using data to exclude some people for healthcare coverage.” [Survey9,M,ON,40-50,Postgrad,NHW]

"I have concerns about the use of individuals medical data and potential for abuse by employers, insurance companies and other groups we haven't even considered at this point. There is huge potential for discrimination - and discrimination that is hidden is impossible to deal with. There are also other potential harms than discrimination - who knows how this information could be used?” [Survey4,F,ON,51-65,Postgrad,NHW]

These four comments re-enforce the Canadians Likert responses to Statement 27 expressing strong opinion regarding the insurance industry in a way sufficiently different to Australians that the difference was identified by the Mann-Whitney U test as described above.

"As with problems related to " $3^{\text {rd }}$ Party" access to daily emails and telephone numbers, personal information is being transferred to others who may not have the best interest of the donor. Instructions for use and storage may be compromised as the information descends through a long process of $3^{\text {rd }}$ party collectors.” [Survey136,F,BC,51-65,Postgrad,NHW]

“During my career I was involved with a number of studies based on personal information from surveys where the respondents had been promised confidentiality. I have yet to meet a researcher who took this promise seriously. I have seen confidential databases entrusted to a researcher who in turn delegated grad students who in turn share it with research groups! The research community does not seem to take the promise of confidentiality at all 
seriously. I basically have very little faith in promises of confidentiality." [Survey192,M,ON,66-80,Postgrad,NHW]

These two comments express concern about the journey of an individual's medical information beyond the bounds of primary care delivery. Survey 192 is particularly concerning as the respondent declared awareness of inappropriate data management from his professional experience. This is similar to an Australian medical researcher who was very frank in her assessment of 'what really goes' on in managing consumers data and is repeated here for comparison:

"Having worked in medical research for the past 8 years, I have been amazed to see the difference in systems used at the different hospitals - some very strict \& completely not - patient/client and others not seeming to care at all. Given the very sensitive nature of this data (mental health files) I was shocked to say the least with the latter. I now work in research management and review all ethics applications for my department. We now ensure that clients are fully aware of the potential for data (including medical files) to be re-used/analysed at later stages and most studies ask to recontact clients if this happens, but also ask if they want this at the initial consulting. I believe it is vital, especially in vulnerable populations that this area is fully and clearly explained to clients/patients as it is often confusing and these populations should not be taken advantage of.” [AustralianSurvey1142,F,VIC,26-39,Postgrad,HW]

The next two comments relate to an emerging theme in the Canadian survey and relate to the storage of data outside the jurisdiction of Canada:

"Data stored outside the country of origin i.e. Canadian data stored in the U.S. integrated database projects such as one at $U$ of Manitoba." [Survey10,M,ON,66-80,Bachelor,NHW]

"My concern is that computerised records are accessed in other countries with different or no sense of privacy protection (i.e. in US and India.)” [Survey84,F,MB,51-65,Postgrad,HW] 
Only one Australian out of the 390 individuals who provided qualitative comments raised the issue of offshore data storage. To have two Canadians out of the 67 individuals who provided comments raise this issue may be an indication this matter has more import in the Canadian community. This requires further research to determine if this early, small indication is valid. These cross border privacy and data management comments are very pertinent and there is activity underway across many societies in diverse sectors including law, healthcare and information systems struggling with these matters. This is likely to be a growing area of both research and industry attention in the future.

\subsubsection{Tripartite Component - Privacy Justification}

The Chi-Square test results for the Canadian survey statements related to tripartite Privacy Justification component did not give rise to any statistically significant results. The Mann-Whitney $U$ test comparing Canadian and Australian consumer opinions found asymptotic significant results on three statements and enabled rejection of the null hypothesis on Statements 1, 3 and 26.

As illustrated in Table 55 Canadians' responses to Statement 1 and Statement 3 indicate they 'strongly agree' more frequently than do Australians on matters related to the 'right' to privacy.

The Mann-Whitney $U$ test results indicate a difference between nations on the issue of using medical information in a way that benefits society. As illustrated through Statement 26 responses in Table 55. Canadians argued, through qualitative comments, for the 'getting-the-balance-right' debate. Some of the comments move from 'getting-the-balance-right' to issues of consent which, for the purposes of this study, are considered in the Privacy Management section. Rather than disjoint the consumers comments the consent matters have been retained in those included below. 
Table 58 presents the qualitative codes adopted, and the frequency with which a theme was included, in respondent comments to the two qualitative survey questions for deductive themes.

Table 58: Tripartite Component - Justification of Privacy, Canada - Qualitative Comment Count

\begin{tabular}{|c|c|c|l|c|c|}
\hline Code & & $\begin{array}{l}\text { Sub } \\
\text { Code }\end{array}$ & Theme & $\begin{array}{c}\text { Comment 1 } \\
\text { Frequency }\end{array}$ & $\begin{array}{c}\text { Comment 2 } \\
\text { Frequency }\end{array}$ \\
\hline 2 & Justification & A & 'Right' to privacy & 2 & 3 \\
\hline & B & $\begin{array}{l}\text { Responsibility of citizens to } \\
\text { participate in secondary use. } \\
\text { Individual rights versus 'common } \\
\text { good' }\end{array}$ & 4 \\
\hline & C & $\begin{array}{l}\text { Personal data as a commercial } \\
\text { commodity; Commercial aspects } \\
\text { of data use }\end{array}$ & 10 \\
\hline & D & Ownership of data & 7 & 10 \\
\hline
\end{tabular}

Examples of the qualitative comments related to the tripartite component Privacy Justification are provided below with demographic characteristics of the respondents.

"It is essential that researchers gain access to health records and data conveying morbidities etc. - but they cannot use it in ways that violates a person's confidentiality. There is little reason a researcher should want to focus on an individual case but information on individuals should be kept from other organisations such as insurance companies with a vested interest in a particular outcome”. [Survey59,M,BC,40-50,Bachelor,HW]

"I strongly believe that most people would consent to medical data use when used for good of all people and they would be even more willing if our laws provided and ensured accountability." [Survey118,M,unknown,51-65,College,NHW]

“Essentially I think a balance is required. Consent to use data is a must - ALL data needs to be voluntarily granted under conditions of informed consent. 
Data that has been anonymized does not in my opinion, belong to the subjects anymore - and he/she has no right to direct if/how it might be used." [Survey190,M,NS,40-50,Postgrad,NHW]

"From a utilitarian perspective the greater good of society must trump individual privacy. Most statistical data may remain anonymous as the name etc of the subjects isn't needed to come to conclusions people will benefit from the research. People who feel free to use OHIP must make full disclosure." [Survey31,unknown]

It is interesting to note the importance Canadians placed on their 'rights' to justify privacy yet very few of the qualitative comments elaborated on the matter of a person's 'rights'. In contrast, the respondents were more likely to elaborate on their desire to 'get-the-balance-right' with the case well put for medical information to be available for health research. The Cronbach Alpha (a) metric on constructs for 'getting-the-balance-right' was much better on the Canadian (0.481) survey than the Australian (0.159) survey. Initial analysis suggested that the wording of Statements for this construct was poor and led to the unsatisfactory internal reliability on this construct of the survey. The Canadian ( $\alpha$ ) is much better than the Australian and the Mann-Whitney U test identified cross-national differences on one relevant statement and the Canadian qualitative comments in this area are well articulated. This may be indicators of a difference in opinion between Australia and Canada on the veracity of these 'getting-the-balance-right' arguments; however the data available via this study is unable to definitively state this is a substantial difference. Further research could build on these early findings and explore the future implications (if there are any) of Australians perhaps not being as accepting of this utilitarian paradigm. The healthcare systems in Australia and Canada have some fundamental differences that may be a factor influencing this comparison. Australia has a mixed private-public system with cost sharing arrangements where private insurance plays a role. In contrast Canada has a universal public insurance plan (Blendon, Schoen et al. 2002). The delivery of universal care for Canadian citizens may engender a more positive response to survey Statement 26. 


\subsubsection{Tripartite Component - Privacy Management}

Chi-Square testing revealed statistically significant differences on only one Statement in those related to Privacy Management. Differences across gender were found on Statement 20 - If I donated my medical information for research I would like to give my consent once - at the time of 'signing up' as a data donor, with Chi-Square results $\left(\chi^{2}=8.041, \mathrm{df}=2, p=0.018\right)$ where Canadian women were less likely to 'strongly agree'/'agree' with this statement than expected and men were more likely to agree (see Table 59).

Table 59: Statement 20 Pearsons Chi-Square statistically significant - Gender

\begin{tabular}{|l|r|r|r|r|r|}
\hline \multicolumn{1}{|c|}{ Gender } & \multicolumn{1}{c|}{ Frequency } & \multicolumn{1}{c|}{ Disagree } & Neutral & \multicolumn{1}{c|}{ Agree } & Total \\
\hline \multirow{2}{*}{ Female } & Count & 31 & 16 & 56 & \multirow{2}{*}{103} \\
\hline \multirow{2}{*}{ Male } & Expected Count & 23.2 & 16.4 & 63.4 & \multirow{2}{*}{79} \\
\hline \multirow{2}{*}{ TOTAL } & Count & 10 & 13 & 56 & \multirow{2}{*}{182} \\
\hline
\end{tabular}

This result is similar to the Australian women who were found, via ChiSquare testing, to be expressing different opinions to men across a number of the Privacy Management statements. Given the small sample size and challenges associated with Chi-Square with expected counts fewer than five it is not surprising that very few Chi-Square statistically significant results could be found in the Canadian results, however there was sufficient data to allow this gender issue to emerge.

The Mann-Whitney U test result for Statement 29 - I should be able to see my medical information and it should be easy to correct any mistakes in the information found asymptotic significant differences between Australian and Canadian consumer opinion. A review of the bar chart in Table 55 reveals that Canadians 'strongly agree' with this statements more frequently than do Australians. This statement was included to explore the 'correction' aspects of Moor and Tavani's Restricted Access Limited Control (RALC) Theory. This theory suggests that the subject of information (in this context consumers/patients) should be able to see and correct any information that is held by a health service provider. The reason for the stronger view from 
Canadians may be because they are further advanced with the implementation of electronic health records (EHR) and Canadian consumers may be feeling some shared angst over their lack of ability to see and correct their electronic health record. As yet Australia has not completed the introduction of electronic health records and hence Australian consumer may not be as informed about the issue as are Canadians. The Australian implementation of electronic health records has emphasised the personally controlled aspects which contrasts with the Canadian approach to EHRs which has not emphasised consumer controlled aspects.

Table 60: Tripartite Component - Management of Privacy- Qualitative Comment Count

\begin{tabular}{|c|c|c|c|c|c|}
\hline Code & & $\begin{array}{l}\text { Sub } \\
\text { Code }\end{array}$ & Theme & $\begin{array}{l}\text { Comment } 1 \\
\text { Frequency }\end{array}$ & $\begin{array}{l}\text { Comment } 2 \\
\text { Frequency }\end{array}$ \\
\hline \multirow[t]{14}{*}{3} & Management & $A$ & $\begin{array}{l}\text { Good data stewardship } \\
\text { required and consumers need } \\
\text { confidence in arrangements } \\
\text { underpinning secondary use }\end{array}$ & 2 & 0 \\
\hline & & B & $\begin{array}{l}\text { Consumers as research } \\
\text { partners not research subjects }\end{array}$ & 0 & 0 \\
\hline & & $C$ & $\begin{array}{l}\text { Consumer control of data } \\
\text { issues }\end{array}$ & 2 & 9 \\
\hline & & $\mathrm{D}$ & $\begin{array}{l}\text { Restricted access to } \\
\text { consumer data issues }\end{array}$ & 0 & 0 \\
\hline & & $E$ & De-identification of data & 12 & 4 \\
\hline & & $F$ & Consent & 6 & 0 \\
\hline & & G & Payment for use of data & 0 & 0 \\
\hline & & $\mathrm{H}$ & $\begin{array}{l}\text { Legal system to protect } \\
\text { consumers }\end{array}$ & 0 & 3 \\
\hline & & $\mathrm{I}$ & $\begin{array}{l}\text { Consumers to provide input } \\
\text { on data stewardship - } \\
\text { including being able to decline } \\
\text { to participate }\end{array}$ & 1 & 0 \\
\hline & & $\mathrm{J}$ & Role of Government & 1 & 0 \\
\hline & & $\mathrm{K}$ & $\begin{array}{l}\text { Secondary use mechanisms: } \\
\text { Human Research Ethics } \\
\text { Committees; computer } \\
\text { technology }\end{array}$ & 0 & 1 \\
\hline & & $\mathrm{L}$ & $\begin{array}{l}\text { Comments in support of } \\
\text { secondary use }\end{array}$ & 7 & 0 \\
\hline & & $\mathrm{M}$ & $\begin{array}{l}\text { Comments about sensitivity of } \\
\text { different types of information } \\
\text { eg. Sexual health, mental } \\
\text { health }\end{array}$ & 0 & 0 \\
\hline & & $\mathrm{N}$ & $\begin{array}{l}\text { Comments about the purpose } \\
\text { of data use eg. OK for } \\
\text { research but not OK for } \\
\text { commercial secondary use }\end{array}$ & 15 & 2 \\
\hline \multicolumn{4}{|c|}{ TOTAL } & 46 & 19 \\
\hline
\end{tabular}


Examples of the qualitative comments related to the tripartite component Privacy Management are provided below along with demographic characteristics of the respondents.

"Personal medical data is a private matter and would not exist if there was not a person having that data collected. Information about a medical history is a result of a person being diagnosed in a professional manner. Access or use of a persons medical data, without full consent, in a context of informed use of such data is equivalent to THEFT.” [Survey97,F,NS,51-65,Postgrad,NHW]

“My husbands medical information was stolen at an H1N1 clinic. The computer stick was taken. Not great!!” [Survey109,F,ON,51-65,Bach,NHW]

These two Canadians are sharing opinions that indicate they are troubled by the theft of medical information. This echoes similar qualitative concerns from Australians.

"I believe medical practitioners need to be trained (and retrained) about releasing and discussing the details with the patient. There is a very 'paternalistic' attitude that permeates the profession - and I am dealing with a mid-age female doctor and I am mid-age female. This attitude is very common and therefore I have resigned myself to this attitude and trying to work around it - this wastes time and doesn't allow me to be proactive and self-directed.” [Survey136,F,BC,51-65,Bach,NHW]

As described in the Literature Review of this thesis, struggling with perceptions and the reality of medical paternalism is a complex issue that is apparent in both the primary care context and spills over into the secondary use context. The recent calls to adopt a research partnering approach with consumers/patients would overcome some of the paternalism and empower consumers. None of the Australian or Canadian consumers' qualitative comments directly mentioned partnering for future research however the sentiment expressed by the Canadian woman from British Columbia, who made the above comment, does focus on paternalism and negative associations. 
"Access to medical history - generally agree ASSUMING personal information is kept ANONYMOUS.” [Survey181,M,ON,51-65,Postgrad,NHW]

"Use of data for research is OK if information, imaging studies etc. are anonymized but this doesn't always happen. I've seen cases at meetings where CT scans are shown (case exchanges) and patient identifying info is still visible." [Survey50,F,NS,4050,Postgrad,HW]

The anonymising, or de-identifying, of consumers data also emerged as an important issue in the Australian consumers' qualitative comments. There are some interesting comments from Australians and Canadians who state that once data has been anonymised the consumer should not have any control over the secondary use. Other opinions indicate that even when anonymised the consumer should have some influence over data use.

"A persons medical information is their own personal property and should never be used without consent. A persons medical information should only be used for purposes that the patient has specified it be used for and nothing else." [Survey118,M,unknown,51-65,College,NHW]

This College educated Canadian male is arguing the case for medical information to be considered the property of the consumer with the consumer making decisions regarding re-use.

\subsection{Emergent Qualitative Themes}

As with the Australian survey, the Canadian survey adopted a deductive approach to the encoding of qualitative comments with existing literature providing the areas of focus. There are emergent issues that arose through the survey qualitative material that was not anticipated through the deductive process. These emergent Canadian themes are listed here as the themes that emerged via an inductive process of analysis:

- Offshore data storage issues e.g. United States and India

- Shared experiences from healthcare workers and researchers who witnessed poor privacy management during their careers 


\subsection{Summary of Comparative Findings}

The comparison of results from the Canadian and Australian surveys found statistically significant results, via Mann-Whitney $U$ testing, regarding the Privacy Concept, Privacy Justification and Privacy Management as summarised below:

\section{Privacy Concept}

- Anxiety about medical receptionists and IT professionals accessing personal medical information differs between Canadian and Australian respondents.

- Withholding medical information due to concern about potential for misuse varies between the Canadian and Australian respondents.

- Canadian and Australian respondents vary on the anxiety regarding insurance sector use of medical data.

Privacy Justification

- The strength of Canadian consumers' opinions regarding a person's 'rights' vary from Australian consumers.

- Differences exist between the Canadian and Australian survey respondents regarding the donation of medical information for use that benefits society.

Privacy Management

- Differences exist between Canadian and Australian consumers regarding the consumers' ability to see and correction medical information.

\subsection{Chapter Summary}

This chapter reported the results of the Canadian consumer survey and provided comparison with the Australian survey results. Responses were received from urban, regional and remote locations including the Yukon, Ontario, Manitoba, British Columbia, Nova Scotia, Alberta and New Brunswick. Response frequencies for each statement were presented in tabular and graphical format with each Likert scale.

Results of empirical tests for instrument reliability were presented with all but one construct resulting in Cronbach Alpha $>0.5$, which falls within the exploratory 
research satisfactory range. Pearsons Chi-Square tests were conducted across the categorical demographics data and ordinal responses to statements resulted in two statistically significant results. To aid in the comparison with Australian consumer survey results a null hypothesis was generated:

$\mathrm{H}_{0}$ : There is no significant difference between Canadian and Australian consumer opinion as expressed through responses to the public opinion survey used in this study where $p<=0.05$.

The Mann-Whitney $U$ test was employed to investigate the differences between Australian and Canadian citizens' attitudes and the null hypothesis was rejected on six statements.

As with the Australian surveys, qualitative comments were classified and reported based on assessment by two coders following Miles and Huberman recommended approach (1994). The same two qualitative researchers who coded the Australian survey also coded the Canadian survey. The summary counts for theme occurrence in survey responses were presented along with sample comments from a diverse set of survey respondents. These qualitative results complement the quantitative results and were co-presented within the tripartite framework.

This Chapter concludes the material that relates directly to the Canadian and Australian consumer surveys. Chapter 7 introduces a privacy framework for secondary use of medical data and Chapter 8 presents study conclusions. 


\section{A PRIVACY FRAMEWORK FOR SECONDARY USE OF MEDICAL DATA}

\subsection{Introduction}

In this Chapter a Privacy Framework for secondary use of medical data is proposed which builds on existing privacy theory (Tavani and Moor 2001; Nehf 2003; Moor 2005; Tavani 2007b; Nissenbaum 2010) and is informed by the opinion of consumers as described in Chapters 4,5 and 6 and other consumer research (Willison, Keshavjee et al. 2003; Willison, Schwartz et al. 2007; Willison, Emerson et al. 2008). The results of the survey chapters indicated statistically significant differences between groups of consumer. To accommodate the vast diversity of consumer opinion is a primary goal in developing the Privacy Framework. A flexible framework will be required. The expectations of the medical research community are also acknowledged and provided for within the proposed privacy framework.

This Chapter begins by using a series of figures to illustrate the construction of the proposed privacy framework drawing on elements of existing privacy theory and associated concepts for the secondary use of medical data context. Once the broad structure or 'skeleton' of the framework is in place the consumer views are used to refine the details of the framework.

The proposed Privacy Framework is not a detailed attempt to anticipate every possible permutation and combination of some consumer desires to apply restrictions to parts of their Electronic Health Records (EHR). The proposed Privacy Framework does not attempt to meticulously offer an ever increasing list of potential third party data users to consumers to consider if they are in or out of their approved list of data receivers. In the real world such a framework would rapidly become unwieldy and it would be difficult to maintain consumer engagement with such an onerous approach.

The proposed privacy framework for secondary use of medical data is a conceptual model which deliberately avoids introducing aspects of physical information systems design. The importance of establishing a conceptual or logical design independent of, and prior to, physical design is a core principle of information systems analysis and 
design as discussed in the Introduction chapter. Moving to physical system designs with inadequate consideration of the important conceptual design matters often leads to unsuccessful or inadequate information systems. The focus here remains on development of a conceptual model incorporating the requirements of the often over looked stakeholder - the consumer.

The next section introduces the 'skeleton' of the privacy framework, and once all parts have been introduced, more detailed discussion regarding the framework is provided including choices made regarding what should be included and excluded from the privacy framework for the secondary use of medical data.

\subsection{The Initial 'Skeleton' of the Framework}

Construction of the 'skeleton' of the privacy framework will be described in a staged approach with the first stage involving the incorporation of Nissenbaums' framework for Contextual Integrity as depicted in Figure 39. In Stage 2 (see Figure 40) Moor and Tavani's influence is added.

Nissenbaum's research into privacy from the perspective of context provides very useful insight and the abstract privacy elements she describes include Context, Actors, Attributes and Transmission Principles as described in the Literature review Chapter. Figure 39 illustrates the core elements of Nissenbaums' framework for contextual integrity and the introduction of these core elements into the privacy framework for secondary use of medical data which is depicted in the right hand box in Figure 39. The arrowed lines indicate the mapping and interpretation of each of Nissenbaum's core elements to the associated element in the privacy framework. Each of the arrowed lines is labelled A, B, C, D for ease of reference and the transition of each of Nissenbaums' elements to the privacy framework for secondary use of medical data is described here.

\section{Component A - Context}

The context for this model is Australian society where the struggle with privacy in the digital age is on-going. Specifically, the context for the proposed Privacy Framework is the secondary use of medical data with engagement with consumers to deliver improved privacy. 
Component B - Actors

The actors playing a role in any context include those who are sending information, those who are receiving information, and the subjects of the information. In the secondary use of medical data context the 'senders' of information are most likely to be healthcare providers. In this context the 'receivers' include medical researchers, health service researchers, commercial data 'harvesting' organisations, Government organisations, insurance sector stakeholders, and other stakeholders we cannot yet anticipate. The 'subjects' of the information are patients/consumers.

\section{Component $\mathrm{C}$ - Attributes (Information Types)}

The Attributes (Information Types) in this context includes a diverse range of physiological measurements, diagnoses, family histories, medication histories, mental health attributes, diseases and conditions experienced by the consumers. The data types are equally diverse including, but not limited to images, text, numeric, encoded physiological data, unstructured, narrative text, data streams and multimedia entries (Kalra 2006). The sensitivity levels of each attribute vary with the most sensitive being mental and sexual health. The attributes are represented in the privacy framework as a matrix of consumer data attributes and default sensitivity settings. The granularity of the contents of the data attributes and default sensitivity settings matrix are determined by the consumers. Chapters 4,5 and 6 of this thesis provide insight into consumers' expectations regarding the granularity expected and, as already emphasised, women are likely to expect finer levels of granularity in this matrix than are men.

\section{Component D - Transmission Principles}

Nissenbaum's Transmission Principles describe the context specific 'terms' and 'conditions' under which information may flow between actors. The transmission principles are a key component of the privacy framework proposed here.

The Transmission Principles in Nissenbaum's framework are interpreted here as a matrix of terms and conditions which will be applied to any information flows within 
the secondary use of medical data context. Consumer specific expectations regarding these terms and conditions are derived from Chapters 4, 5 and 6 of this thesis and material from the Literature Review. The inclusion of the consumer expectations in defining the transmission principles is one of the most innovative aspects of the privacy framework as previously consumers were not empowered to participate in determining such transmission principles. Frequently human research ethics committees and/or health sector leaders and clinicians make decisions regarding acceptable terms and conditions surrounding flow of consumer medical information. Inclusion of the consumers as actors determining the terms and conditions of data flow is an important aspect of the privacy framework for secondary use of medical data.

Consumer opinions and other stakeholders' expectations, including human research ethics committees, will be used to guide the contents of the matrix for Terms and Conditions for data flow in the privacy framework. The privacy framework for secondary use of medical data is not static; rather it is continually evolving and the Terms and Conditions suggested in this initial privacy framework are merely a starting point. On-going vigilance and maintenance will be required to ensure that consumers remain engaged in defining their expectations regarding the matrix. The granularity of the contents of the Terms and Conditions matrix is determined by the consumers. Similar to Component C, Chapters 4, 5 and 6 of this thesis provide insight into consumers' expectations regarding the granularity expected. 


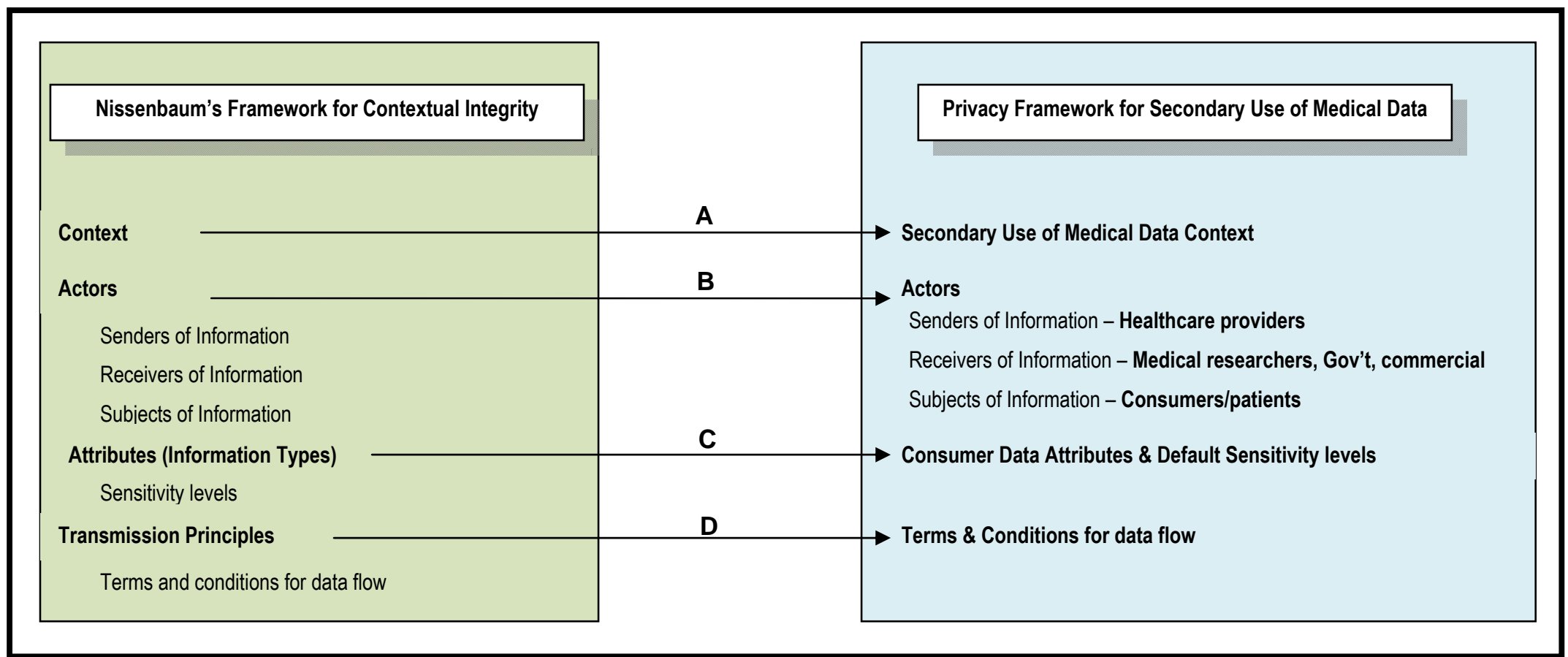

Figure 39: Constructing the Privacy Framework Stage 1

Construction of the Privacy Framework moves to Stage 2 where the theoretical contribution made by Moor and Tavani is adapted for the privacy framework - particularly the RALC concepts. Components E, F and G are added to the Privacy Framework in Stage 2 as illustrated in Figure 40: Constructing the Privacy Framework Stage 2. These theoretical components are enhanced and refined for this context by the results of the Australian and Canadian consumer surveys. 


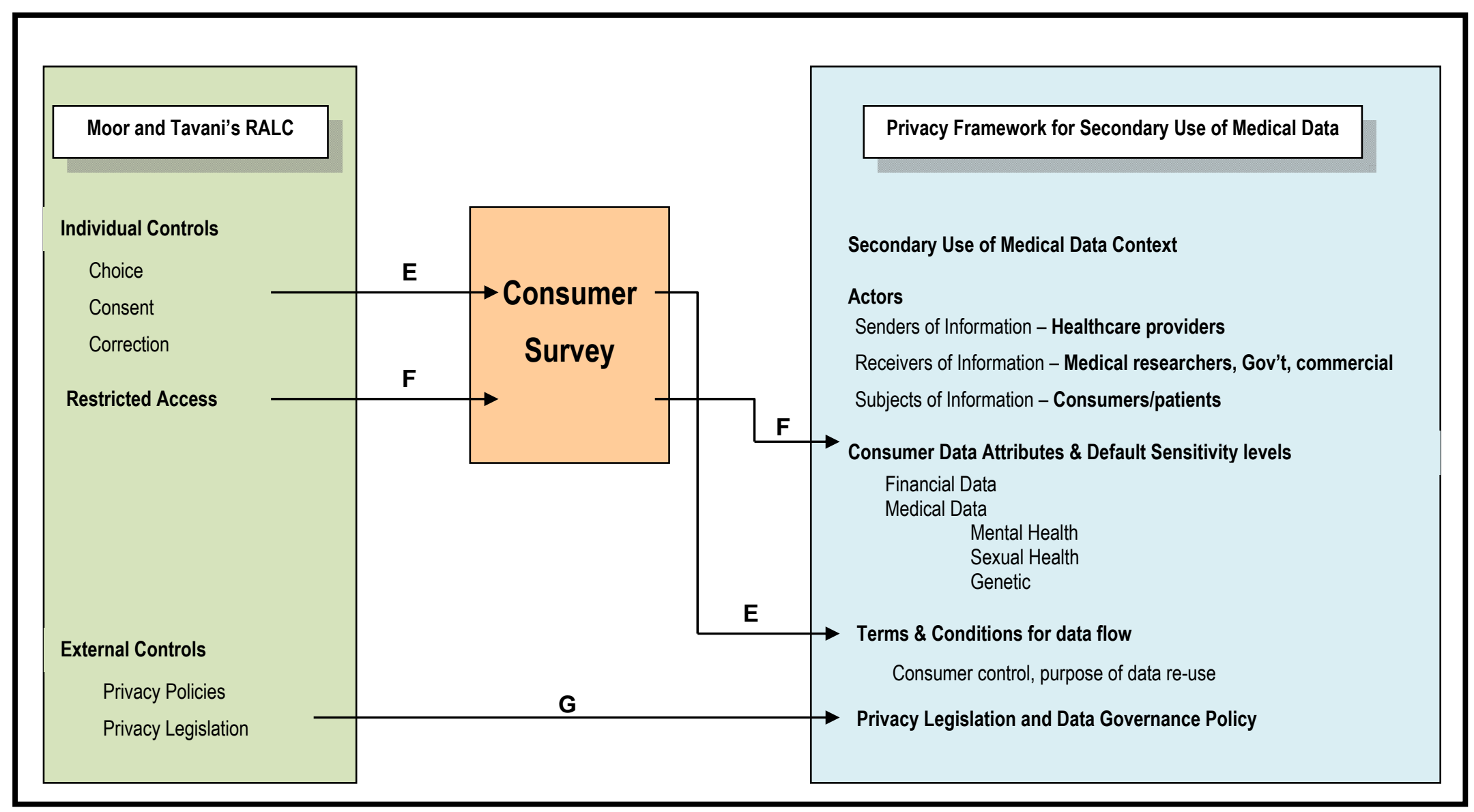

Figure 40: Constructing the Privacy Framework Stage 2 


\subsection{Incorporating Consumers Expectations into the Framework}

This section describes the conceptualisation of consumers engagement and moves to the inclusion of consumers expectations in the initial skeleton of the Privacy Framework.

\subsubsection{Conceptualising Levels of Consumer Engagement}

Meticulously capturing and maintaining details of consumer privacy expectations across the numerous dimensions of their EHR is a simplistic and likely unsustainable approach to addressing privacy concerns. The results of the consumer surveys indicate a capacity for the general public to engage in secondary use and privacy matters. What is required is a new approach to conceptualising these matters in a manner that leads to a physical information systems solution that can be embedded in revised, supportive business processes in the secondary use of medical data. The conceptual Privacy Framework thus informs both the information system design and a shift in the privacy paradigm operating in the secondary use context.

The consumer survey results in Chapters 4-6 indicate there are various levels of interest amongst the community regarding matters pertaining to secondary use of medical data. There are likely to be members of the community who have no interest in considering secondary use matters. There are also citizens who place enormous value on their personal privacy and their engagement in secondary use matters may vary from removing themselves entirely to looking for opportunities for maximum influence and authority over the secondary use of their data.

There are also varying individual capacities to engage in secondary matters. For example, citizens living with severe mental health issues, minors and dementia suffering or very elderly citizens, may not have the capacity to engage in secondary use and privacy matters. This was raised by a member of the survey design focus group and some of the consumers responding to the qualitative parts of the surveys.

There are infinite combinations of citizens with varying levels of 'interest' and 'capacity' to engage in secondary use of medical data matters. If an individual has 
low or minimal capacity to engage in decision making regarding secondary use of their medical data it is irrelevant how much interest they may show in secondary use matters as they are incapable of making necessary decisions.

There are other citizens who have sufficient capacity to engage in secondary matters but low levels of interest in becoming engaged. There are comments in the Australian and Canadian consumer surveys from citizens who would fit this group.

There are other citizens who may, over time, have increased interest in secondary use of their data if a 'trigger' was involved. For example, if a member of their family suffered from a disease, say lymphoma, and there was an opportunity for family members' data to be used for secondary purposes specific to lymphoma research, the interest level in secondary use of data may rise in the family members. The 'trigger' in this case is the lymphoma diagnosis for their family member. Other 'triggers' such as media reports of profiteering from the re-sale of medical data accrued through the delivery of primary care may have a mitigating effect. There are numerous comments in the Canadian and Australian survey results with consumers indicating they would not support commercial secondary use of their medical data. The 'trigger' here may have an impact on the level of consumer interest in engaging in matters about secondary data use. Alternatively this anti-commercial 'trigger' may lead to further interest as the consumer moves to protect their medical data from commercial secondary uses by engaging more in privacy matters.

The final broad group to consider are citizens who have both the capacity and interest in secondary use matters enabling them to fully engage in decision making regarding the secondary uses of their medical data. Figure 41 depicts the suggested broad groupings of citizens along the axes of capacity to engage and level of interest in secondary use matters. 


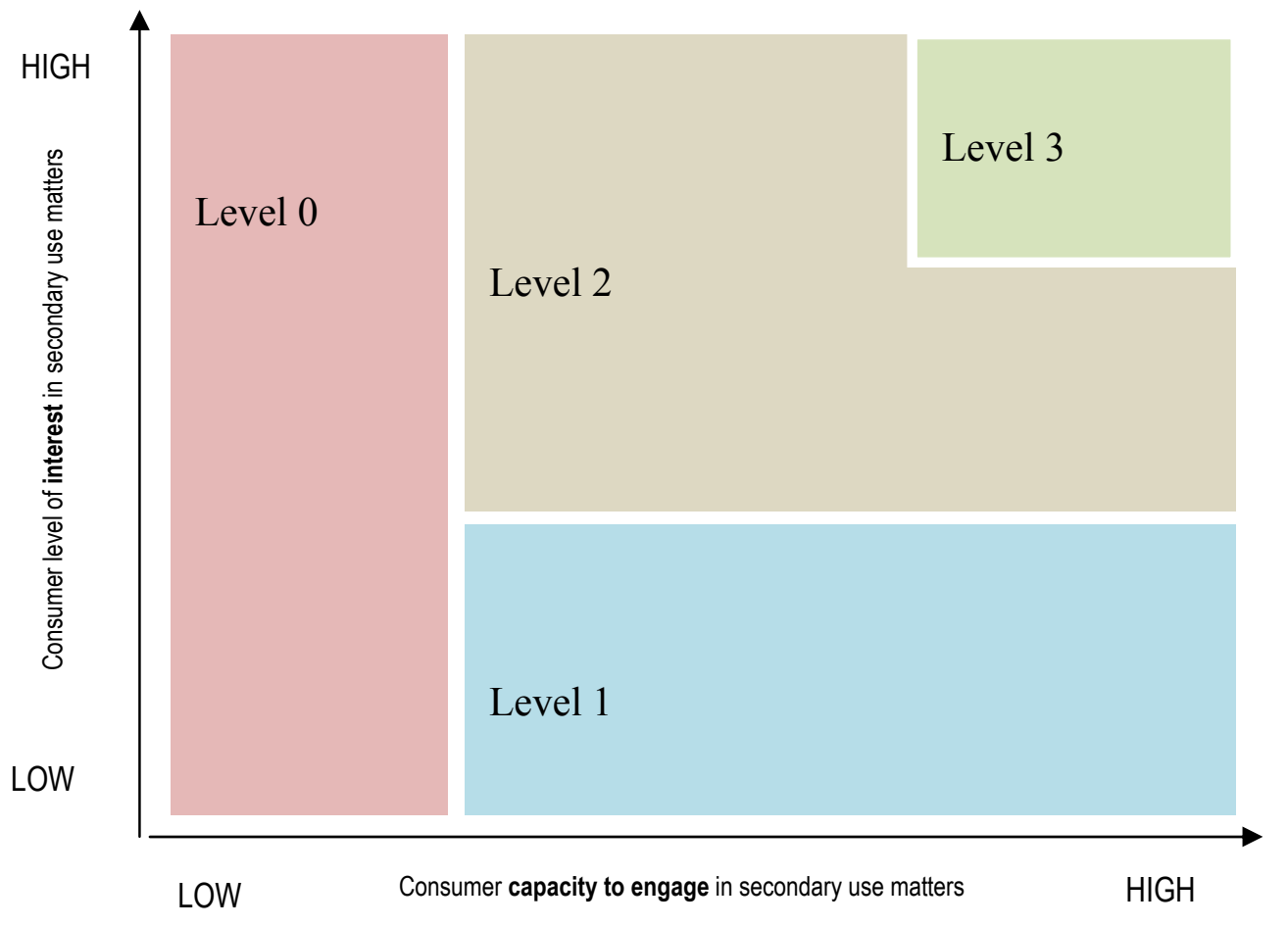

Figure 41: Consumer engagement scenario 1

Four levels of engagement amongst consumers are depicted in Figure 41. Zones have been blocked out in this figure however no metrics have been applied as it is not possible, with available knowledge, to predict the end of one grouping and the beginning of the next. White buffer zones have been included in the diagram, lying between each of the zones or groups, to emphasise that the boundaries of each group are ill defined. This figure assists in conceptualising the various levels of concurrent interest and capacity to engage amongst consumers. Figure 41 presents a scenario with arbitrary definition of the boundaries of levels of interest and capacity to engage.

Figure 42 presents an alternative scenario depicting more citizens with the necessary level of interest and capacity to engage fully in secondary use matters. This scenario moves towards the privacy advocates view of maximising consumer engagement and autonomy on secondary use of medical data matters. 


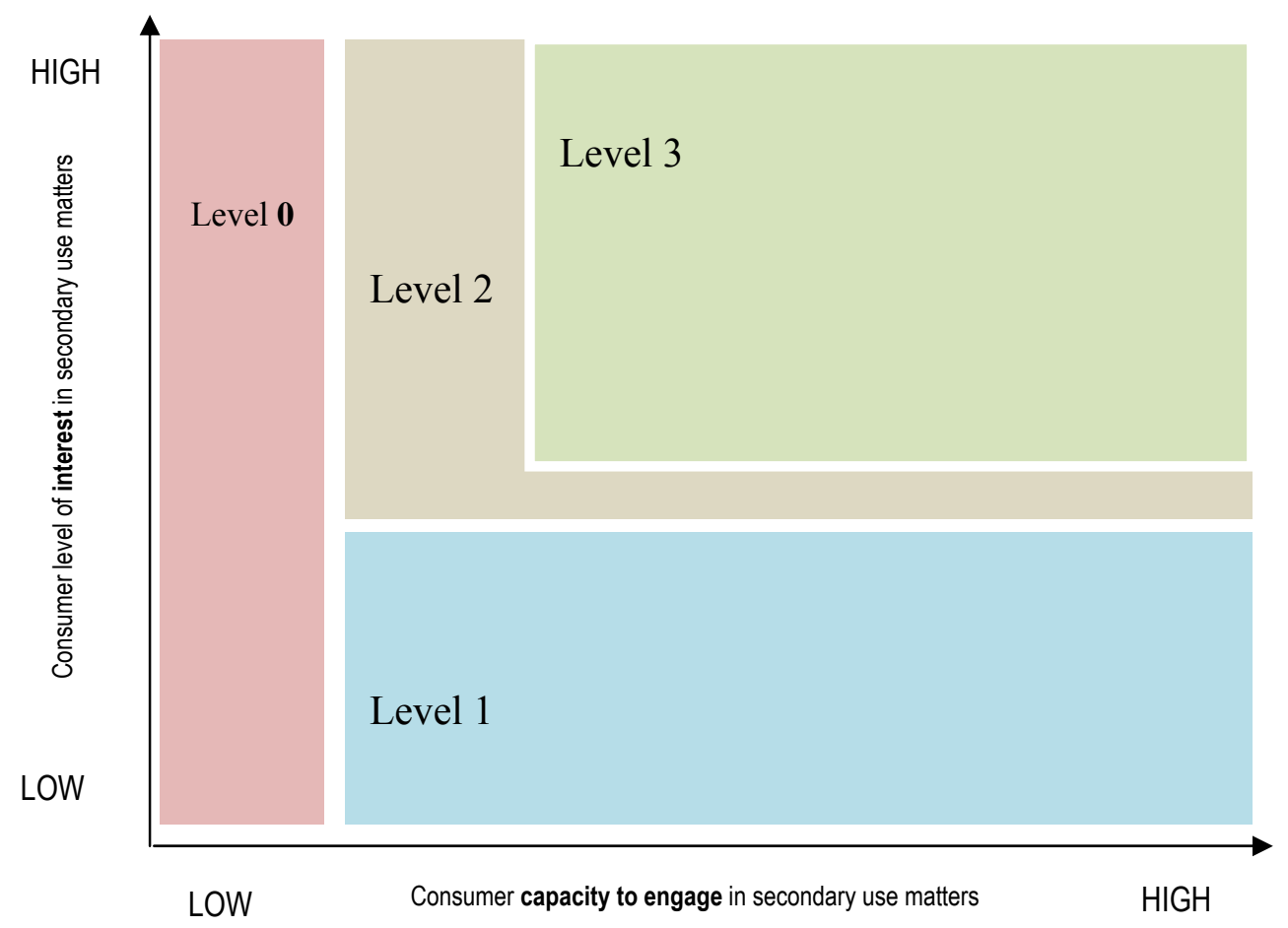

Figure 42: Consumer engagement scenario 2

In contrast Figure 43 presents an alternate scenario where the vast majority of consumers are considered to be incapable of engaging (Level 0) and with no autonomy for consumers. This moves closer to the scenario argued for by some public health researchers where they suggest that benefits of secondary data use to society far outweigh any individual privacy considerations. Each of these secondary use scenarios has been considered in the Chapter 2 Literature Review. The scenario figures are presented to provide a conceptualisation tool that leads into the further discussions about the Privacy Framework for secondary use of medical data. 


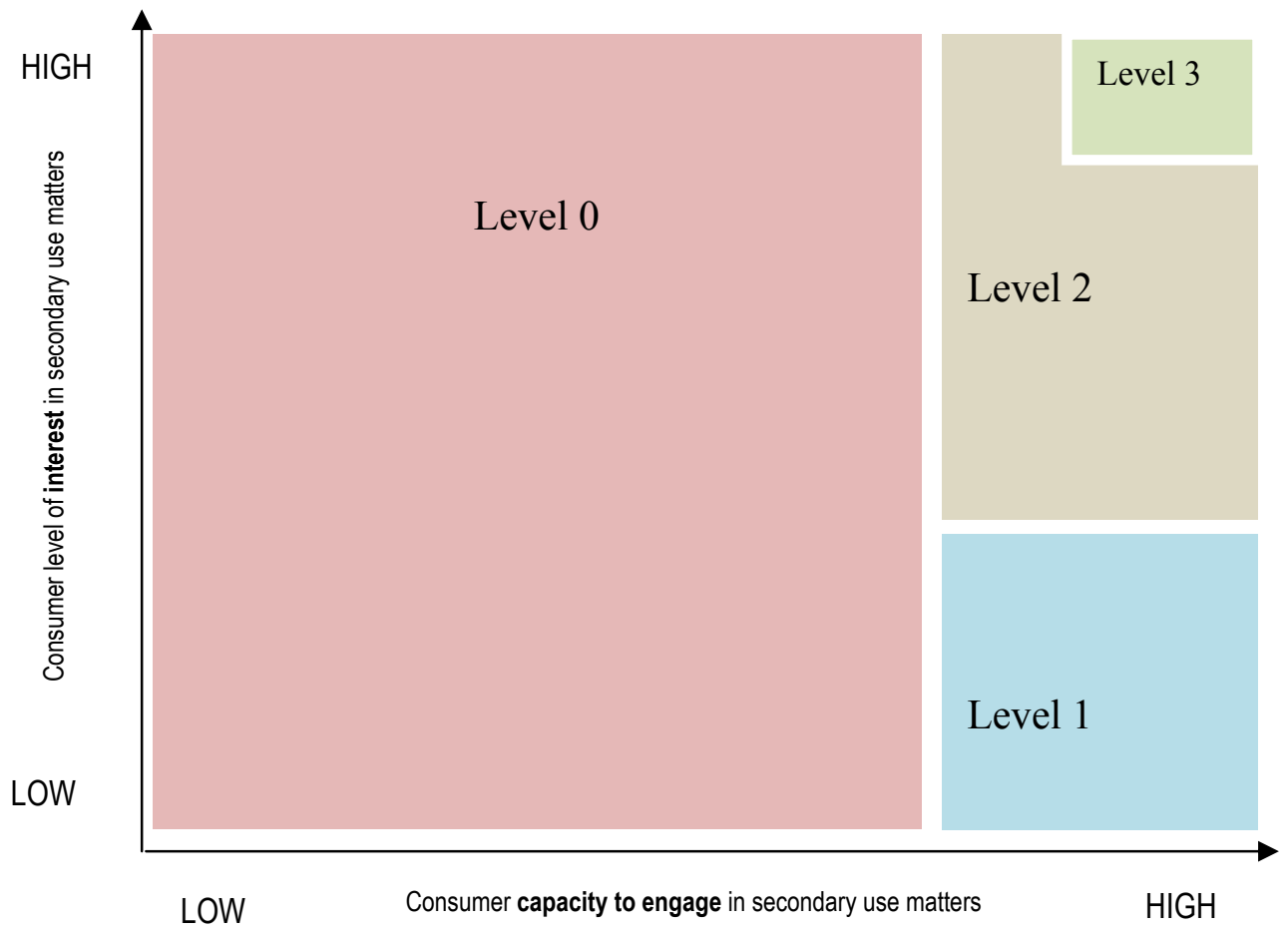

Figure 43: Consumer engagement scenario 3

The consumer engagement Levels $0-3$ assist in broadly grouping consumers into segments that have differing expectations on all matters related to the secondary use of their medical data. A capable citizen may choose to join the Level 0 group where limited opportunities would exist for consumer engagement in secondary data use matters. This is a choice that the Privacy Framework would provide to consumers. In contrast, if a consumer was not capable of deciding levels of engagement - even if they wanted to join the Level 3 group - the Privacy Framework would limit their engagement to Level 0. 
Table 61: Elaboration of Consumer Engagement Level 0 and Level 1

\begin{tabular}{|c|c|c|c|}
\hline $\begin{array}{c}\text { Engagement } \\
\text { Level }\end{array}$ & \multicolumn{2}{|c|}{ Brief description } & Australian Consumer Comments \\
\hline \multirow{6}{*}{ Level 0} & \multirow{6}{*}{\multicolumn{2}{|c|}{$\begin{array}{l}\text { Status Quo: Existing Human Research } \\
\text { Ethics Committee approvals and } \\
\text { protections apply without additional } \\
\text { direction or authority from consumers } \\
\text { regarding secondary uses }\end{array}$}} & $\begin{array}{l}\text { Anything in my not particularly fascinating medical history that } \\
\text { is any use to anyone else - help yourselves. }\end{array}$ \\
\hline & & & $\begin{array}{l}\text { The age and mental health of a person can affect the use of } \\
\text { medical data. }\end{array}$ \\
\hline & & & $\begin{array}{l}\text { What about information about children, the elderly, mentally ill? } \\
\text { We need to know their privacy is protected. Who speaks for } \\
\text { them? }\end{array}$ \\
\hline & & & $\begin{array}{l}\text { Common good overrides preferences if it gives a better } \\
\text { understanding of illness in general. }\end{array}$ \\
\hline & & & $\begin{array}{l}\text { It doesn't concern me that some people have access to my } \\
\text { records. }\end{array}$ \\
\hline & & & $\begin{array}{l}\text {... medical privacy is not something that occupies much of my } \\
\text { attention. I tend to take a fairly fatalistic approach: what } \\
\text { happens and may happen in the future is largely beyond my } \\
\text { control. }\end{array}$ \\
\hline \multirow{12}{*}{ Level 1} & \multirow{4}{*}{\multicolumn{2}{|c|}{$\begin{array}{l}\text { Consumer provides high level direction } \\
\text { regarding authorised secondary uses } \\
\text { including: } \\
\text { - NO to secondary use } \\
\text { - YES to secondary use } \\
\text { specifics eg.: }\end{array}$}} & $\begin{array}{l}\text { I am much more interested in medical research and university } \\
\text { research in the area of medicine. I am not interested in } \\
\text { research for insurance companies etc. }\end{array}$ \\
\hline & & & $\begin{array}{l}\text { The patient should have the opportunity to approve or } \\
\text { disapprove of the collection and re-use of data. }\end{array}$ \\
\hline & & & $\begin{array}{l}\text { Individuals should have the right to decide who their medical } \\
\text { records are given to for medical research. }\end{array}$ \\
\hline & & & $\begin{array}{l}\text { If anonymous age-sex-history then we may end up with better } \\
\text { health funds and insurance products as well as better hospitals } \\
\text { and treatment!! }\end{array}$ \\
\hline & \multirow[t]{8}{*}{$x_{0}$} & \multirow{8}{*}{$\begin{array}{l}\text { Level of anonymity } \\
\text { For-profit medical } \\
\text { research } \\
\text { Not for-profit medical } \\
\text { research } \\
\text { 'data brokers' } \\
\text { Commercial } \\
\text { organisations such as } \\
\text { the insurance and } \\
\text { pharmaceutical } \\
\text { sectors } \\
\text { Identify particular } \\
\text { areas of focus e.g. } \\
\text { diabetes, cancer, } \\
\text { schizophrenia } \\
\text { research etc. }\end{array}$} & $\begin{array}{l}\text { Names and addresses should be withheld if used for research } \\
\text {-non debatable. }\end{array}$ \\
\hline & & & $\begin{array}{l}\text { All insurance or drug companies are primarily responsible to } \\
\text { their shareholders and NOT the general public and therefore } \\
\text { should not be given/sold a person's private medical records } \\
\text { without that person's explicit permission. }\end{array}$ \\
\hline & & & $\begin{array}{l}\text { If money is involved then I would not agree to my records } \\
\text { being "bought" by companies or organisations either. }\end{array}$ \\
\hline & & & $\begin{array}{l}\text { There is absolutely no reason why any research requires the } \\
\text { name or address attached to the medical records. It is certain } \\
\text { that any requirement to personal details is not for research... } \\
\text { any research requiring personal details is corrupt and should } \\
\text { not be supported - leave personal details out of research. }\end{array}$ \\
\hline & & & Commercial operations should pay for data ... \\
\hline & & & $\begin{array}{l}\text { I would be happy to have my medical information used at any } \\
\text { time - preferably on an anonymous basis. }\end{array}$ \\
\hline & & & $\begin{array}{l}\text { In my opinion the patient owns his/her records and the re-use } \\
\text { of medical data can only be at the discretion of the patient. }\end{array}$ \\
\hline & & & $\begin{array}{l}\text { I believe that I the patient should be the only person capable of } \\
\text { authorising the use of my records for research. }\end{array}$ \\
\hline
\end{tabular}

Table 61 provides an introductory description of Level 0 and Level 1 Comments from the Australian consumer surveys that support the operation of the corresponding Level of engagement are also provided. Table 62 provides the same details for consumer engagement at Levels 2 and 3. 
Table 62: Elaboration of consumer engagement at Level 2 and Level 3

\begin{tabular}{|c|c|c|}
\hline $\begin{array}{l}\text { Engagement } \\
\text { Level }\end{array}$ & Brief description & Australian Consumer Comments \\
\hline \multirow[t]{9}{*}{ Level 2} & \multirow{9}{*}{$\begin{array}{l}\text { Consumer provides medium level } \\
\text { direction regarding authorised } \\
\text { secondary uses including: } \\
\text { - All Level } 1 \text { directions } \\
\text { PLUS } \\
\text { - Consent type e.g. per study, per } \\
\text { annum }\end{array}$} & $\begin{array}{l}\text { I would not want anyone to have access to medical information } \\
\text { without my permission. }\end{array}$ \\
\hline & & $\begin{array}{l}\text { Happy to have medical info in database with access by } \\
\text { consent. }\end{array}$ \\
\hline & & $\begin{array}{l}\text {... it is my choice to disclose my personal information - it } \\
\text { BELONGS to me - not to anyone else - seeing a GP does not } \\
\text { mean that I have handed over my right to privacy or my choice } \\
\text { to disclose or not! }\end{array}$ \\
\hline & & $\begin{array}{l}\text { Informed consent is important but I must admit I have no real } \\
\text { guarantee that any information I provide will not be handed to } \\
\text { insurance companies and similar misanthropic organisations. }\end{array}$ \\
\hline & & $\begin{array}{l}\text { It is my decision and mine alone as to who has access of my } \\
\text { records. }\end{array}$ \\
\hline & & $\begin{array}{l}\text { I think a person's consent should be sought BEFORE it is used } \\
\text { anywhere else. }\end{array}$ \\
\hline & & $\begin{array}{l}\text { I would like to think my medical information would help with } \\
\text { research to help others, but only with my express approval and } \\
\text { if I change my mind I would have the right to revoke the } \\
\text { decision. }\end{array}$ \\
\hline & & $\begin{array}{l}\text { I don't believe any of my info should be used for research or } \\
\text { any other purpose without my consent. Ever. I would consider } \\
\text { it unethical if this occurred. }\end{array}$ \\
\hline & & $\begin{array}{l}\text { If an individual wants to share information disclosure should be } \\
\text { voluntary, possibly consent for an individual purpose not a } \\
\text { general sharing of all info with a single consent. }\end{array}$ \\
\hline \multirow[t]{7}{*}{ Level 3} & \multirow{7}{*}{$\begin{array}{l}\text { Consumer provides detailed taxonomy } \\
\text { of authorisations including: } \\
\text { - All Level } 1 \text { \& Level } 2 \text { directions } \\
\text { PLUS } \\
\text { - Feedback/reporting requirements } \\
\text { on studies using consumers } \\
\text { personal data } \\
\text { - Willingness to be further } \\
\text { contacted regarding secondary } \\
\text { use matters }\end{array}$} & $\begin{array}{l}\text { Do not want lay people i.e. The State, making decisions } \\
\text { regarding my records not even the justice system who are not } \\
\text { qualified to determine the issues. It would have to be my } \\
\text { personal okay about what I share. How I want to share it. Who } \\
\text { would share it. And how long they shared it. }\end{array}$ \\
\hline & & $\begin{array}{l}\text { I believe my medical data is my data and owned by me. Not } \\
\text { owned by doctor, hospital, Medicare, Government, insurance. } \\
\text { Co etc }\end{array}$ \\
\hline & & Feedback on use of information should be followed through. \\
\hline & & $\begin{array}{l}\text { I feel my information is mine, not healthcare providers or } \\
\text { governments so I must make the choices about the data. }\end{array}$ \\
\hline & & $\begin{array}{l}\text { All medical information should be used or controlled by the } \\
\text { patient. }\end{array}$ \\
\hline & & $\begin{array}{l}\text { The approval should be sent every time the information is } \\
\text { requested. }\end{array}$ \\
\hline & & $\begin{array}{l}\text { Would like to be aware who is using my information at all } \\
\text { times. Do not like the idea of 'once' only authority. I should be } \\
\text { asked every time some organisation, including the } \\
\text { government, wants to use my history for any form of research. }\end{array}$ \\
\hline
\end{tabular}


Level 0 is similar to the current operation of Australian Human Research Ethics Committees (HRECs) where the committee members make decisions about the release of consumers medical data and may or may not request that researchers obtain informed consent from information subjects - i.e. patients/consumers. The role of HREC would be to provide approval for the overall study and to give instructions regarding data issues. It is possible at Level 0 engagement that HRECs may authorise the release of a consumer's data without any regard to the consumers wishes about secondary use matters. This may be appropriate if the citizen has been officially deemed incapable of making decisions e.g. citizens with diminished mental capacity. If consumers have not provided any secondary use directives the Level of engagement is defaulted to Level 0 . This maintains the status quo with HREC making decisions regarding the necessary approvals that consumers/patients are required to provide prior to any third party accessing personal medical data. This situation would not satisfy consumers with concerns regarding personal privacy and such citizens should be encouraged to move to Level 1 engagement and record a "No" directive on secondary use or alternatively they could move to Level 3 engagement where they achieve greater autonomy and control.

Level 1 provides consumers with an opportunity to give some high level guidance on the availability of their data for secondary purposes. The intent is for this to not be project specific consent but rather a broad "Yes" or "No" to the use of an individual's data for any kind of secondary purpose. If a consumer registers a "No" at this Level of engagement then their personal medical data should not be used for any secondary purpose. If consumers want to give project specific consent they need to move to Level 2 engagement. At Level 1 engagement consumers may, if they wish, refine the "Yes" response by nominating if their data is to be available for commercial and /or non-commercial uses. In addition the consumer also specifies the level of anonymity they require. The provision of Level 1 engagement with consumers could also speed up the pace at which data could be available for secondary use as consideration of data access issues by HREC would not be required if capable consumers had given informed consent through the Privacy Framework operating at Level 1. This would be of benefit to the many researchers who report delays in approval and lack of 
consistency between HRECs. The role of HREC would be to provide approval for the overall study but to limit the instructions regarding data issues to the secondary directives provided by the consumers. The consumers Level 1 instructions would be permanently stored with their electronic medical record.

Level 2 enables consumers to provide Level 1 direction plus further refinements concerning types of consent, consent renewal frequency and mechanisms for withdrawing consent. Consumer consent for secondary use may be provided for each study or the consumer may provide a pre-approval for studies that meet particular requirements. The latter approach would reduce the number of times a consumer would be contacted to seek consent and expedite the availability of data. It is important to reflect on the hierarchical nature of these Levels of engagement. If at Level 1 a consumer indicated that they were not interested in having their data used for commercial secondary uses it would not be possible, within the operation of this Privacy Framework, for such consumers to be asked to provide Level 2 study specific consent for a commercial secondary study. The only consumers who should be approach for such a study would be those who, at Level 1, indicated "yes" they support secondary uses of a commercial nature and at Level 2 indicated a wish to give study specific consent.

Some of the consumers responding to the public opinion survey, as presented in Chapters 4-6, provided qualitative feedback indicating they would not be satisfied with a single consent option and would prefer to provide consent for each study. Other respondents were happier with the notion of a single, re-useable consent. Level 2 engagement satisfies these diverse opinions by providing a flexible framework where consumers are able to select various consent profiles. Level 2 also provides consumers with an opportunity to select specific areas that they would like to support by making their data available for secondary purposes. For example they may choose to support particular focus areas of research such as breast cancer, diabetes, depression, schizophrenia or renal disease research.

The frequency of consent renewal is an important matter where consumers can provide direction. Annual consent renewal may be appropriate or a consumer may be 
prepared to allow consent to require less frequent renewal, to perhaps three years or longer.

If consumers wish to remove their consent for secondary use they must be able to do so at any time. This issue was explored through the consumer survey and further consideration is needed regarding the implementation of such 'withdraw' directives. However, it is essential that this capability be included in the privacy framework. As already emphasised, this is a conceptual framework that leads to physical implementation where technical solutions will be developed in accordance with the conceptual design. Rather than saying at this stage 'How are we going to effectively implement that?' and dropping this requirement from the privacy framework this challenge must remain and move forward towards physical implementation.

The consumers Level 1 and Level 2 secondary use instructions would be permanently stored with their electronic medical record.

Level 3 enables consumers to provide Level 2 (which includes Level 1) direction plus further refinement to take the engagement to the finest granularity available. At Level 3 engagement consumers have an opportunity to state their expectations regarding feedback on secondary use of their data. For example, consumers may request an annual report on each study or a higher level aggregated summary of all studies that used their data. Consumers may expect to be informed not only about the studies that have used their data but also the 'outcomes' from the studies. Amongst the qualitative comments from Australian consumers a number shared their experience of participating in studies and were very appreciative of the efforts researchers had put in to informing the study participants about progress and outcomes. This information was greatly appreciated by the participants and encouraged them to continue participation; therefore this practice has been included in the Privacy Framework for the most engaged citizens. Level 3 engagement also gives consumers an opportunity to 'put their hand up' and allow themselves to be identified and available for further contact on secondary use matters. 


\subsubsection{Consumer data attributes and default sensitivity settings}

Component $\mathrm{C}$ in Figure 39 relates to Nissenbaum's data attributes and sensitivity settings. This Privacy Framework does not propose that consumers consider each and every one of the attributes of their EHR and decide if they wish to have the data available for secondary use and if so who can use it and for what purpose. This would be an unmanageable approach due to the complexity involved in specification and maintenance of consumer views regarding the 'nitty-gritty' of their EHR. The Levels of consumer engagement described in the previous section are sufficient to enable consumers to provide secondary use and privacy directives across the large number of data attributes which comprise dynamic, always evolving EHRs.

Moor and Tavani's Restricted Access privacy concept, represented by Component F in Figure 40, contributes to the construct of data attributes and sensitivity settings in the proposed Privacy Framework. These are intangible concepts that are incorporated into the Privacy Framework as principles upon which the framework has been designed. The following scenarios illustrate the inclusion of restricted access concepts in the Privacy Framework. It should be noted that the consumers are empowered through the restricted access concept rather than excluded from involvement, in the way that restricted access has traditionally been adopted in the provision of patient confidentiality (with healthcare professionals restricting information access to primarily the care givers).

Generally sexual health, mental health and genetic data attributes are considered to be very sensitive data attributes of an electronic health record. Despite the fact that the Privacy Framework does not ask citizens to consider each of these sensitive areas and explicitly state their privacy expectations the use of the engagement Levels 0-3 does offer citizens an opportunity to secure any part of their electronic health record from unwanted secondary use. 


\subsubsection{Combining the Skeleton of the Privacy Framework and the Levels of Consumer Engagement}

This section seeks to illustrate the manner in which the skeleton of the Privacy Framework, adapted from Nissenbaum and Tavani and Moor, combines with the levels of consumer engagement as depicted in Figure 44

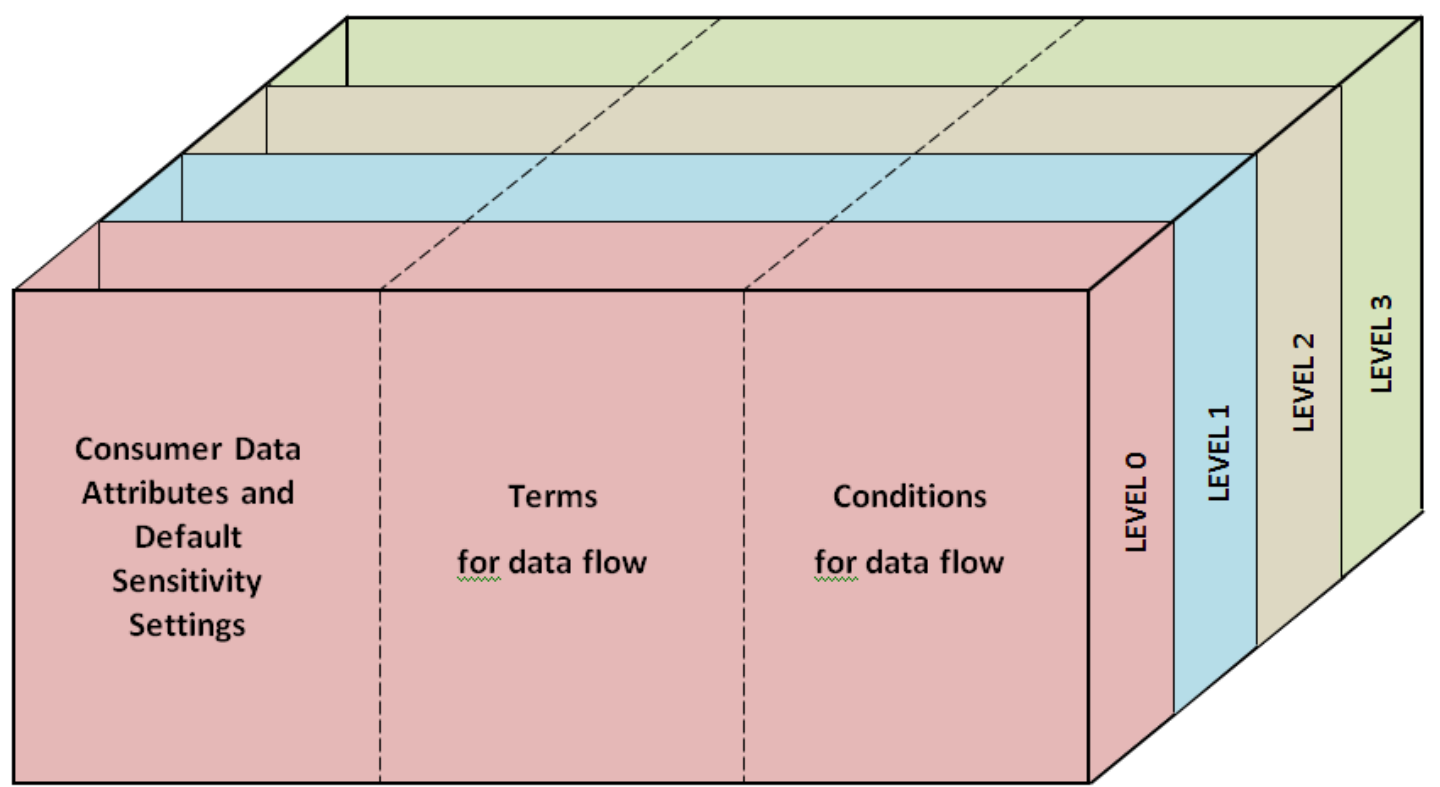

Figure 44: Privacy Framework combined with the Consumer Engagement Concept 
The consumer data attributes, default sensitivity settings, and terms and conditions for data flow run through all levels of engagement. Taking a shallow vertical slice through the cube is equivalent to the Level 0 engagement. By slicing deeper into the cube more of the data attributes, and terms and conditions for data flow are encountered. This is equivalent to a higher level of consumer engagement.

The context in which the privacy framework operates is also an essential aspect and Figure 45 illustrates the addition of the broad cap or cover of the context.

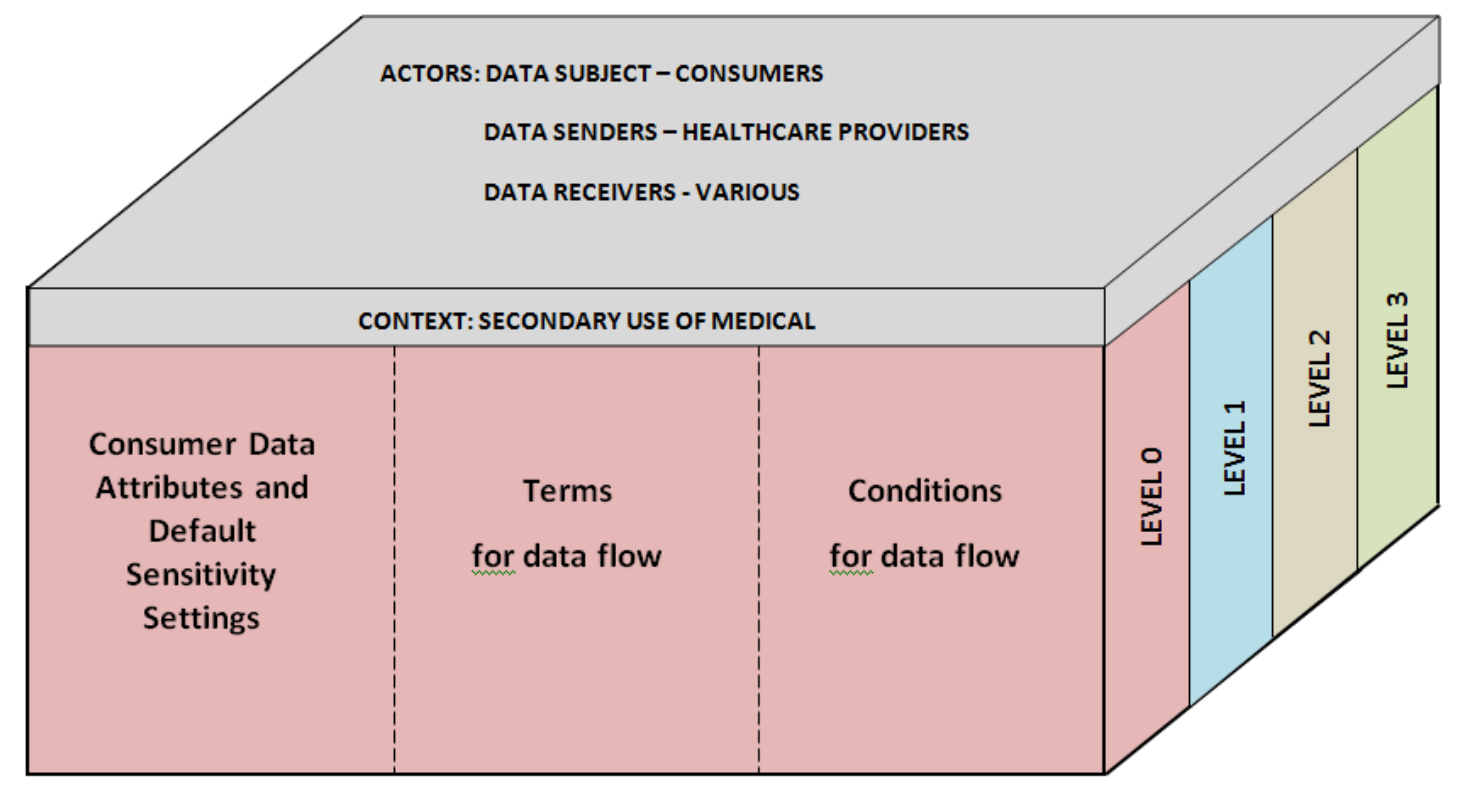

Figure 45: Addition of the context to the Privacy Framework 
In addition to the above figures three scenarios will be used here to illustrate the operation of the Privacy Framework incorporating the consumer level of engagement concept. The following scenarios are based on comments made by consumers in responding to the qualitative component of the surveys deployed in this research study:

Scenario 1 - Consumer A is a female rape victim who does not want any part of her EHR used for secondary use by any organisation or individual.

\section{Privacy Framework support for Consumer A in Scenario 1:}

If Consumer A leaves her engagement level at Level 0 then there will be data receivers who can gain access to de-identified data sets, and possibly identifiable datasets, containing Consumer A's EHR or part thereof. To meet the total privacy called for by Consumer A she needs to move to Level 1 and record "NO" against the measure for consumer agreement for secondary use.

Scenario 2 - Consumer B is a female who has multiple family members afflicted with diabetes and she would like to 'donate' data to any sort of medical research to do with diabetes. Consumer B is prepared to release her identified data and would like to receive feedback on any secondary use that included her medical information and she is prepared to be contacted about secondary use of medical data matters. Consumer B does not want to be contacted to provide consent for every study that uses her data she is satisfied to provide an annual renewal of consent that covers research studies approved by HRECs.

\section{Privacy Framework support for Consumer B in Scenario 2:}

This consumer needs to register at Level 1 indicating she is prepared to have her data used for secondary purposes. She needs to indicate that both for-profit and not-for-profit medical research into diabetes can access her data and she needs to indicate that use of identifiable data is acceptable. At Level 2 
she needs to indicate that her preference is to provide an annual consent that will cover multiple studies and she would only like to be contacted once per year to renew this consent. At Level 3 she needs to identify herself as being interested in further contact regarding secondary use of her medical data for diabetes research and she needs to record her instruction about the receipt of feedback on each of the studies her data has been included in.

Scenario 3 - Consumer $\mathrm{C}$ is a male recently diagnosed with a genetic disorder that in all likelihood will shorten his life by many decades. Consumer $\mathrm{C}$ is concerned that knowledge of this disorder may have a negative impact on his life insurance arrangements. At the same time Consumer $\mathrm{C}$ is very concerned because two of his children have also been diagnosed with the disorder and he would like to support any research that addresses this disorder as this may be beneficial to him and his children.

\section{Privacy Framework support for Consumer C in Scenario 3:}

Using the Privacy Framework Consumer $\mathrm{C}$ needs to register "Yes" at Level 1 to indicate his intention to permit secondary use of his data. At Level 1 he needs to set his anonymity level to "anonymous". Consumer C needs to avoid selecting commercial re-use thus precluding the insurance sector and data brokers from access. By selecting only not-for-profit medical research Consumer $\mathrm{C}$ facilitates the use of his anonymous data for the secondary use he wants to support i.e. medical research.

\subsubsection{The matrix for terms and conditions of data flows}

The matrix for terms and conditions for data flow is a development based on Nissenbaum's Transmission Principles, represented by Component D in Figure 39, combined with Tavani and Moors' Individual Control concepts, represented by Component E in Figure 40. The consumer surveys explored Moor and Tavani's RALC and results of the surveys indicate the purpose of the secondary use of their data influenced consumers' views about the terms and conditions of their agreement to support (or not to support) a particular secondary use. Hence the 'data re-use 
purpose' has been included in this interpretation of Nissenbaum's transmission principles. In addition, the transmission principles have been organised by consumer engagement level. As previously discussed these stratify consumers. Data subject, sender, and receiver are as defined by Nissenbaum.

The data flow conditions are very specific to the secondary use of medical data context - as anticipated by Nissenbaum. Data flow conditions depend on a number of factors including clear approval to proceed with the information flow from the 'approving authority' and such approvals are accompanied by a 'level of anonymity' which is, at its most simple, a dichotomy of 'identifiable' or 'anonymous'. It is acknowledged that a substantial body of work surrounds this concept of anonymity and de-identification however those issues are not the focus here. Healthcare providers have made assumptions regarding consumers' expected level of anonymity based on their narrow interpretation of what is meant by privacy. This Privacy Framework challenges those assumptions and empowers consumers engaged at Levels 1-3 to self-determination of privacy. The consumer survey results revealed some consumers were agreeable to the use of identifiable data and this can add substantial depth and opportunity to some areas of medical research which have previously been denied via blanket denial of identifiable datasets. The qualitative comments in consumer surveys also revealed an expectation of feedback to consumers when their data has been used for a secondary purpose. This has led to the inclusion of the 'Feedback to Consumer on Outcomes of Secondary Use' as one of the data flow conditions. Consumers engaged at Levels 1 and 2 do not provide instructions regarding feedback and hence this data flow condition does not apply for those consumers. Consumers with Level 3 engagement do provide instructions regarding feedback and hence the flow of their data is dependent on a data receiver meeting the Level 3 feedback condition imposed by the consumer. The next section presents the terms and condition matrix for each of the engagement levels and highlights the privacy advances for consumers at each engagement level. The data reuse purposes included in Table 63, Table 64, Table 65 and Table 66 represent broad categories of secondary use purposes that emerged from the literature review conducted for this study. 
Level 0 is the 'status quo' engagement level with current terms and conditions of secondary use continuing. The data re-use purposes have been broadly summarised and it is apparent that consumers have little opportunity to engage regarding the data flow conditions applying to each data re-use purpose. The HREC may refer to consumers for consent however there is no guarantee this will occur. At Level 0 there is no opportunity for consumers to apply data flow conditions requiring them to receive feedback on secondary uses of their data. Magnusson's Stage 3, as described in the Literature Review Chapter, is apparent with the inclusion of the Government entities as both data 'senders' and 'receivers' and 'approving authority' for consumer data that maybe anonymised or fully identifiable. 
Table 63: Privacy Framework Transmission Principles Engagement Level 0

\begin{tabular}{|c|c|c|c|c|c|c|c|c|}
\hline \multirow[b]{2}{*}{$\begin{array}{c}\text { Consumer } \\
\text { engagement }\end{array}$} & \multicolumn{4}{|c|}{ Data Flow Terms } & \multicolumn{4}{|c|}{ Data Flow Conditions } \\
\hline & $\begin{array}{c}\text { Data Re-use } \\
\text { Purpose }\end{array}$ & $\begin{array}{c}\text { Data } \\
\text { Subject }\end{array}$ & $\begin{array}{l}\text { Data } \\
\text { Sender }\end{array}$ & $\begin{array}{c}\text { Data } \\
\text { Receiver }\end{array}$ & Approving Authority & $\begin{array}{c}\text { Level of } \\
\text { anonymity }\end{array}$ & $\begin{array}{c}\text { Consumer consent } \\
\text { type (annual/study), } \\
\text { renewal frequency, } \\
\text { withdraw }\end{array}$ & $\begin{array}{l}\text { Feedback to Consumer on } \\
\text { Outcomes of Secondary Use }\end{array}$ \\
\hline \multirow{5}{*}{ Level 0} & $\begin{array}{l}\text { Commercial reuse } \\
\text { of data acquired } \\
\text { through health } \\
\text { service provision }\end{array}$ & $\begin{array}{l}\text { Consumers/patients } \\
\text { of health service }\end{array}$ & $\begin{array}{l}\text { Healthcare } \\
\text { providers, insurance } \\
\text { organisations, } \\
\text { pharmacy etc. }\end{array}$ & $\begin{array}{c}\text { Commercial } \\
\text { organisation eg. } \\
\text { pharmaceutical or } \\
\text { insurance sector } \\
\text { organisations or } \\
\text { marketers }\end{array}$ & $\begin{array}{c}\text { Healthcare provider, } \\
\text { insurer who acquired } \\
\text { the data through } \\
\text { service delivery, } \\
\text { pharmacy }\end{array}$ & $\begin{array}{l}\text { Fully identifiable } \\
\text { or anonymised }\end{array}$ & Not required & Not required \\
\hline & $\begin{array}{l}\text { Transfer/sale to } \\
\text { Data Broker } \\
\text { organisation }\end{array}$ & $\begin{array}{l}\text { Consumers/patients } \\
\text { of health service }\end{array}$ & $\begin{array}{c}\text { Healthcare } \\
\text { providers, insurance } \\
\text { organisations, } \\
\text { pharmacy etc. }\end{array}$ & $\begin{array}{l}\text { Data Broker } \\
\text { organisations eg. } \\
\text { AusGrid, Brogan } \\
\text { Inc and IMS }\end{array}$ & $\begin{array}{c}\text { Healthcare provider, } \\
\text { insurer who acquired } \\
\text { the data through } \\
\text { service delivery, } \\
\text { pharmacy }\end{array}$ & $\begin{array}{l}\text { Should be } \\
\text { anonymised }\end{array}$ & Not required & Not required \\
\hline & $\begin{array}{l}\text { Non-commercial } \\
\text { medical research }\end{array}$ & $\begin{array}{c}\text { Patients/Consumers } \\
\text { in target group e.g. } \\
\text { asthma, diabetes, } \\
\text { cancer etc. }\end{array}$ & $\begin{array}{l}\text { Healthcare } \\
\text { providers }\end{array}$ & $\begin{array}{l}\text { Non-commercial } \\
\text { medical } \\
\text { researchers }\end{array}$ & HREC & $\begin{array}{l}\text { May be identified } \\
\text { or de-identified } \\
\text { depending on } \\
\text { nature of } \\
\text { research }\end{array}$ & HREC may stipulate & Not required \\
\hline & $\begin{array}{l}\text { Commercial medical } \\
\text { research }\end{array}$ & $\begin{array}{c}\text { Patients/Consumers } \\
\text { in target group eg. } \\
\text { asthma, diabetes, } \\
\text { cancer, } \\
\text { schizophrenia etc. }\end{array}$ & $\begin{array}{l}\text { Healthcare } \\
\text { providers }\end{array}$ & $\begin{array}{l}\text { Commercial } \\
\text { medical } \\
\text { researchers }\end{array}$ & HREC & $\begin{array}{l}\text { May be identified } \\
\text { or de-identified } \\
\text { depending on } \\
\text { nature of } \\
\text { research }\end{array}$ & HREC may stipulate & Not required \\
\hline & $\begin{array}{l}\text { Government } \\
\text { purposes }\end{array}$ & $\begin{array}{c}\text { Entire } \\
\text { consumer/patient } \\
\text { population }\end{array}$ & $\begin{array}{l}\text { Healthcare } \\
\text { providers }\end{array}$ & $\begin{array}{l}\text { Government } \\
\text { entities }\end{array}$ & Government & Fully Identifiable & Not required & Not required \\
\hline
\end{tabular}

Level 1 engagement includes the same data re-use purposes and data flow conditions with consumers appearing as approving authority and empowered to make decisions regarding level of anonymity. At Level 1 consumers can provide a resounding "NO" to the use of their medical data for secondary purposes and given the hierarchical structure of the subsequent levels there is no further input required by the consumer. In this Privacy Framework a "NO" at Level 1 ends all secondary use of a consumer's medical data for all of the 
proposed data re-use purposes. A "YES" at this Level offers an opportunity to engage on issues of anonymity and broad secondary use categories including Non-commercial medical research and transfer/sale to Data Broker organisation.

Table 64: Privacy Framework Transmission Principles Engagement Level 1

\begin{tabular}{|c|c|c|c|c|c|c|c|c|}
\hline \multirow[b]{2}{*}{$\begin{array}{l}\text { Consumer } \\
\text { engagement }\end{array}$} & \multicolumn{4}{|c|}{ Data Flow Terms } & \multicolumn{4}{|c|}{ Data Flow Conditions } \\
\hline & $\begin{array}{l}\text { Data Re-use } \\
\text { Purpose }\end{array}$ & $\begin{array}{l}\text { Data } \\
\text { Subject }\end{array}$ & $\begin{array}{l}\text { Data } \\
\text { Sender }\end{array}$ & $\begin{array}{c}\text { Data } \\
\text { Receiver }\end{array}$ & Approving Authority & $\begin{array}{c}\text { Level of } \\
\text { anonymity }\end{array}$ & $\begin{array}{c}\text { Consumer consent } \\
\text { type (annual/study), } \\
\text { renewal frequency, } \\
\text { withdraw }\end{array}$ & $\begin{array}{l}\text { Feedback to Consumer on } \\
\text { Outcomes of Secondary Use }\end{array}$ \\
\hline \multirow{5}{*}{ Level 1} & $\begin{array}{c}\text { Reuse of } \\
\text { commercial } \\
\text { data acquired } \\
\text { through health } \\
\text { service } \\
\text { provision }\end{array}$ & $\begin{array}{c}\text { Consumers/patients of } \\
\text { health service }\end{array}$ & $\begin{array}{l}\text { Healthcare } \\
\text { providers, } \\
\text { insurance } \\
\text { organisations, } \\
\text { pharmacy etc. }\end{array}$ & $\begin{array}{l}\text { Commercial organisation } \\
\text { e.g. pharmaceutical or } \\
\text { insurance sector } \\
\text { organisations or } \\
\text { marketers }\end{array}$ & Individual Consumer & $\begin{array}{l}\text { Consumer } \\
\text { discretion }\end{array}$ & Not required & Not required \\
\hline & $\begin{array}{l}\text { Transfer/sale } \\
\text { to Data Broker } \\
\text { organisation }\end{array}$ & $\begin{array}{c}\text { Consumers/patients of } \\
\text { health service }\end{array}$ & $\begin{array}{l}\text { Healthcare } \\
\text { providers, } \\
\text { insurance } \\
\text { organisations, } \\
\text { pharmacy etc. }\end{array}$ & $\begin{array}{c}\text { Data Broker } \\
\text { organisations e.g. } \\
\text { Brogan Inc and IMS }\end{array}$ & Individual Consumer & $\begin{array}{l}\text { Should be } \\
\text { anonymised }\end{array}$ & Not required & Not required \\
\hline & $\begin{array}{l}\text { Non- } \\
\text { commercial } \\
\text { medical } \\
\text { research }\end{array}$ & Consumer & $\begin{array}{l}\text { Healthcare } \\
\text { Providers }\end{array}$ & Medical researchers & Individual Consumer & $\begin{array}{l}\text { Consumer } \\
\text { discretion }\end{array}$ & Not required & Not required \\
\hline & $\begin{array}{l}\text { Commercial } \\
\text { medical } \\
\text { research }\end{array}$ & Consumer & $\begin{array}{l}\text { Healthcare } \\
\text { Provider }\end{array}$ & $\begin{array}{l}\text { Commercial medical } \\
\text { researchers }\end{array}$ & Individual consumer & $\begin{array}{l}\text { Consumer } \\
\text { discretion }\end{array}$ & Not required & Not required \\
\hline & $\begin{array}{c}\text { Government } \\
\text { purposes }\end{array}$ & $\begin{array}{c}\text { Entire } \\
\text { consumer/patient } \\
\text { population }\end{array}$ & $\begin{array}{c}\text { Healthcare } \\
\text { providers }\end{array}$ & Government entities & Individual consumer & $\begin{array}{l}\text { Consumer } \\
\text { discretion }\end{array}$ & Not required & Not required \\
\hline
\end{tabular}

Level 1 engagement also sees consumers appear in the data flow conditions as the approving authority for Government re-use purposes. The inclusion of consumers as the approving authority for conditional data flows for Government purposes would be an important advancement of privacy for consumers and would minimise the opportunity for Government surveillance through medical records. 
Level 2 engagement sees the introduction of consent types and consent frequency and consent withdrawal issues regarding secondary uses of consumer data. Research protocols imposed by HREC at Level 0 may have introduced these consent issues to the commercial and non-commercial medical research purposes. At Level 2 consumers further engage in privacy matters by indicating if they prefer to provide consent for each proposed secondary use study or if they prefer an alternate solution, such as annual or once only consent. A specific question in the consumer survey related to the frequency of consent and there was mixed response with some consumers content with once-only consent. Others strongly opposed and expecting to provide specific consent for each study (an attitude particularly strong among women) and others were satisfied with broader consent. There was support for the option of withdrawing consent at any time; hence at this level of engagement the conditions of data flow have been expanded to capture the consent matters

Table 65: Privacy Framework Transmission Principles Engagement Level 2

\begin{tabular}{|c|c|c|c|c|c|c|c|c|}
\hline \multirow[b]{2}{*}{$\begin{array}{l}\text { Consumer } \\
\text { engagement }\end{array}$} & \multicolumn{4}{|c|}{ Data Flow Terms } & \multicolumn{4}{|c|}{ Data Flow Conditions } \\
\hline & $\begin{array}{l}\text { Data Re-use } \\
\text { Purpose }\end{array}$ & $\begin{array}{l}\text { Data } \\
\text { Subject }\end{array}$ & $\begin{array}{l}\text { Data } \\
\text { Sender }\end{array}$ & $\begin{array}{c}\text { Data } \\
\text { Receiver }\end{array}$ & $\begin{array}{l}\text { Approving } \\
\text { Authority }\end{array}$ & $\begin{array}{c}\text { Level of } \\
\text { anonymity }\end{array}$ & $\begin{array}{c}\text { Consumer } \\
\text { consent type } \\
\text { (annual/study), } \\
\text { renewal } \\
\text { frequency, } \\
\text { withdraw }\end{array}$ & $\begin{array}{l}\text { Feedback to Consumer on } \\
\text { Outcomes of Secondary Use }\end{array}$ \\
\hline \multirow{5}{*}{ Level 2} & $\begin{array}{c}\text { Reuse of } \\
\text { commercial data } \\
\text { acquired through } \\
\text { health service } \\
\text { provision }\end{array}$ & $\begin{array}{l}\text { Consumers/patients of health } \\
\text { service }\end{array}$ & $\begin{array}{l}\text { Healthcare } \\
\text { providers, } \\
\text { insurance } \\
\text { organisations, } \\
\text { pharmacy etc. }\end{array}$ & $\begin{array}{l}\text { Commercial organisation e.g. } \\
\text { pharmaceutical or insurance } \\
\text { sector organisations or } \\
\text { marketers }\end{array}$ & Individual Consumer & $\begin{array}{l}\text { Consumer } \\
\text { discretion }\end{array}$ & $\begin{array}{l}\text { Consumer } \\
\text { discretion }\end{array}$ & Not required \\
\hline & $\begin{array}{l}\text { Transfer/sale to } \\
\text { Data Broker } \\
\text { organisation }\end{array}$ & $\begin{array}{l}\text { Consumers/patients of health } \\
\text { service }\end{array}$ & $\begin{array}{l}\text { Healthcare } \\
\text { providers, } \\
\text { insurance } \\
\text { organisations, } \\
\text { pharmacy etc. }\end{array}$ & $\begin{array}{l}\text { Data Broker organisations } \\
\text { e.g. Brogan Inc and IMS }\end{array}$ & Individual Consumer & $\begin{array}{l}\text { Should be } \\
\text { anonymised }\end{array}$ & $\begin{array}{l}\text { Consumer } \\
\text { discretion }\end{array}$ & Not required \\
\hline & $\begin{array}{l}\text { Non-commercial } \\
\text { medical research }\end{array}$ & Consumer & $\begin{array}{l}\text { Healthcare } \\
\text { Providers }\end{array}$ & Medical researchers & Individual Consumer & $\begin{array}{l}\text { Consumer } \\
\text { discretion }\end{array}$ & $\begin{array}{l}\text { Consumer } \\
\text { discretion }\end{array}$ & Not required \\
\hline & $\begin{array}{c}\text { Commercial medical } \\
\text { research }\end{array}$ & Consumer & $\begin{array}{l}\text { Healthcare } \\
\text { Provider }\end{array}$ & $\begin{array}{c}\text { Commercial medical } \\
\text { researchers }\end{array}$ & Individual consumer & $\begin{array}{l}\text { Consumer } \\
\text { discretion }\end{array}$ & $\begin{array}{l}\text { Consumer } \\
\text { discretion }\end{array}$ & Not required \\
\hline & $\begin{array}{l}\text { Government } \\
\text { purposes }\end{array}$ & $\begin{array}{l}\text { Entire consumer/patient } \\
\text { population }\end{array}$ & $\begin{array}{l}\text { Healthcare } \\
\text { providers }\end{array}$ & Government entities & Individual consumer & $\begin{array}{l}\text { Consumer } \\
\text { discretion }\end{array}$ & $\begin{array}{l}\text { Consumer } \\
\text { discretion }\end{array}$ & Not required \\
\hline
\end{tabular}


Level 3 engagement terms and conditions of data flow include conditions related to the feedback that a consumer expects prior to allowing the data flow. Through the qualitative comments gathered via the consumer surveys, many consumers expressed a desire to receive feedback on use of their data. If the consumer wishes to incorporate the provision of such feedback as a requirement of data access they can specify this at Level 3. Not represented in this matrix is the additional feature of Level 3 which is the enabling of consumers to self-nominate as interested in being contacted directly on secondary use matters related to their health data. 
Table 66: Privacy Framework Transmission Principles Engagement Level 3

\begin{tabular}{|c|c|c|c|c|c|c|c|c|}
\hline \multirow[b]{2}{*}{$\begin{array}{l}\text { Consumer } \\
\text { engagement }\end{array}$} & \multicolumn{4}{|c|}{ Data Flow Terms } & \multicolumn{4}{|c|}{ Data Flow Conditions } \\
\hline & $\begin{array}{l}\text { Data Re-use } \\
\text { Purpose }\end{array}$ & $\begin{array}{c}\text { Data } \\
\text { Subject }\end{array}$ & $\begin{array}{l}\text { Data } \\
\text { Sender }\end{array}$ & $\begin{array}{l}\text { Data } \\
\text { Receiver }\end{array}$ & Approving Authority & $\begin{array}{c}\text { Level of } \\
\text { anonymity }\end{array}$ & $\begin{array}{c}\text { Consumer consent } \\
\text { type (annual/study), } \\
\text { renewal frequency, } \\
\text { withdraw }\end{array}$ & $\begin{array}{l}\text { Feedback to Consumer on } \\
\text { Outcomes of Secondary Use }\end{array}$ \\
\hline \multirow{5}{*}{ Level 3} & $\begin{array}{l}\text { Reuse of } \\
\text { commercial data } \\
\text { acquired through } \\
\text { health service } \\
\text { provision }\end{array}$ & $\begin{array}{l}\text { Consumers/patients of } \\
\text { health service }\end{array}$ & $\begin{array}{l}\text { Healthcare } \\
\text { providers, } \\
\text { insurance } \\
\text { organisations, } \\
\text { pharmacy etc. }\end{array}$ & $\begin{array}{c}\text { Commercial } \\
\text { organisation e.g. } \\
\text { pharmaceutical or } \\
\text { insurance sector } \\
\text { organisations or } \\
\text { marketers }\end{array}$ & Individual Consumer & $\begin{array}{l}\text { Consumer } \\
\text { discretion }\end{array}$ & Consumer discretion & Consumer discretion \\
\hline & $\begin{array}{l}\text { Transfer/sale to } \\
\text { Data Broker } \\
\text { organisation }\end{array}$ & $\begin{array}{l}\text { Consumers/patients of } \\
\text { health service }\end{array}$ & $\begin{array}{l}\text { Healthcare } \\
\text { providers, } \\
\text { insurance } \\
\text { organisations, } \\
\text { pharmacy etc. }\end{array}$ & $\begin{array}{l}\text { Data Broker } \\
\text { organisations e.g. } \\
\text { Brogan Inc and IMS }\end{array}$ & Individual Consumer & $\begin{array}{l}\text { Should be } \\
\text { anonymised }\end{array}$ & Consumer discretion & Consumer discretion \\
\hline & $\begin{array}{l}\text { Non-commercial } \\
\text { medical research }\end{array}$ & Consumer & $\begin{array}{l}\text { Healthcare } \\
\text { Providers }\end{array}$ & Medical researchers & Individual Consumer & $\begin{array}{l}\text { Consumer } \\
\text { discretion }\end{array}$ & Consumer discretion & Consumer discretion \\
\hline & $\begin{array}{c}\text { Commercial } \\
\text { medical research }\end{array}$ & Consumer & $\begin{array}{l}\text { Healthcare } \\
\text { Provider }\end{array}$ & $\begin{array}{l}\text { Commercial medical } \\
\text { researchers }\end{array}$ & Individual consumer & $\begin{array}{l}\text { Consumer } \\
\text { discretion }\end{array}$ & Consumer discretion & Consumer discretion \\
\hline & $\begin{array}{l}\text { Government } \\
\text { purposes }\end{array}$ & $\begin{array}{l}\text { Entire consumer/patient } \\
\text { population }\end{array}$ & $\begin{array}{l}\text { Healthcare } \\
\text { providers }\end{array}$ & Government entities & Individual consumer & $\begin{array}{l}\text { Consumer } \\
\text { discretion }\end{array}$ & Consumer discretion & Consumer discretion \\
\hline
\end{tabular}

The next section considers the final component of the Privacy Framework, Component G, as suggested by Tavani and Moor (2001). External controls in the form of privacy policy and legislation are required. 


\subsection{External Controls}

In Australia at the time of completing this thesis the Australian Law Reform Commission (ALRC) recommendations surrounding privacy remained unaddressed. The need for universal privacy principles specifically for the healthcare sector also remains unaddressed, despite the finalisation of the 2010 Healthcare Identifiers Act which allocated a unique individual healthcare identifier to every Australian.

The Privacy Framework proposed here calls for a far more sophisticated interpretation of privacy than that generally adopted in the healthcare sector. Locking information away, de-identifying it and then claiming privacy has thus been delivered to consumers is woefully inadequate.

External controls and privacy guidelines have seen a plethora of glossy brochures with legal language appear in health service provider waiting rooms. Enabling the proposed Privacy Framework privacy engagement levels 1-3 is a far more substantial and genuine treatment of privacy than printing out shiny brochures that provide privacy statements that tell healthcare consumers that their data is 'safe'. In addition, requesting that consumers agree to data management policies at the point-oftreatment is also a shallow attempt at privacy management. The power balance is heavily against consumers at such vulnerable times. The most ideal time to engage with consumers on privacy issues is when they are reasonably well and capable and interested in engagement on secondary use matters.

The proposed Privacy Framework could be used to capture consumers secondary use instructions and could be attached to the Individual Healthcare Identifier. There would be then no doubt about the consumers' secondary use and privacy directives and wherever the Individual Healthcare Identifier is used the individual privacy directives on secondary use would also be available. 


\subsection{Limitations of the proposed Privacy Framework}

The lifecycle of data can see personal information travel many pathways and this can provide a challenge for the proposed Privacy Framework. Support could be provided through an organisation taking on a data governance role overseeing data that Australians would make available for secondary purposes. Currently there is no such data governance authority and successful operation of the Privacy Framework would rely on oversight and responsibility resting within the portfolio of an independent data governance body. Another Government agency would not be appropriate because, as illustrated above, the Australian Government, and associated agencies, likes to be the data sender, data receiver and authoriser of all matters pertaining to health information and this is a government surveillance issue that goes to the heart of the concept of privacy in $21^{\text {st }}$ Century Australian society. 


\subsection{Chapter Summary}

This Chapter began by constructing the skeleton of the Privacy Framework from existing privacy theory - predominantly the work of Nissenbaum (2010), Tavani and Moor (2001). The inclusion of Moor and Tavani's RALC theory was supplemented by hearing the Australian consumer voice that was heard through the surveys described in Chapters 4 and 5.

A new conceptualisation of privacy for secondary use of medical data was introduced through the Levels 0-3 of consumer engagement. These Levels of engagement assisted in describing the data attributes and sensitivity levels and the terms and conditions for data flow that was first introduced by Nissenbaum. Intangible RALC principles underpin the Privacy Framework as evidenced through the scenarios used to illustrate the framework.

The inadequacy of external privacy controls (legislation and policy) in the Australian context was highlighted and limitations of the Privacy Framework were considered.

The Introduction chapter considered the role consumers play as stakeholders in the development of electronic health records (EHR) and reflected on the marginalisation of consumers in early phases of the system development life cycle guiding the development of the Australian EHR. The Privacy Framework proposed here is the product of a deep engagement with consumers to determine their requirement regarding secondary use of their medical data and could inform physical implementation of health systems and supporting business processes.

The next Chapter offers a summary of the conclusions that can be drawn from this study, links to earlier research, limitations of the study and future research directions. 


\section{CONCLUSION}

\subsection{Introduction}

This study investigated the application of privacy theory from Tavani and Moor (2001) and Nissenbaum (2010) to secondary use of medical data. In addition, the opinion of citizens in Australia and Canada were investigated, through selfadministered postal surveys, regarding the secondary use of their medical data particularly considering privacy matters. A privacy framework for secondary use of medical data was proposed. The foundation of the privacy framework was existing privacy theory with refinements based on consumer survey findings. The privacy framework addressed concerns and diverse expectations of stakeholders involved in the secondary use of medical data. The privacy framework also encouraged engagement with consumers on secondary use matters. Upon deployment, the privacy framework could facilitate a paradigm shift away from the 'limited access' approach to consumer privacy to a more sophisticated engagement with interested, capable consumers. This study is the first to have:

- $\quad$ combined the privacy theory of Tavani and Moor (2001) and Nissenbaum (2010),

- $\quad$ applied these theories to the secondary use of medical data context,

- $\quad$ investigated Australian consumers views regarding secondary use of their medical data,

- $\quad$ compared Australian and Canadian consumers views on these matters, and

- $\quad$ proposed a privacy framework as a mechanism to assist in engagement with consumers regarding secondary use of their medical data.

This chapter presents the principal conclusions of the present study, links to earlier research, limitations of the study and future research directions. 


\subsection{Principal Conclusions}

The principal conclusions of this study make a contribution to the problem definition and improved understanding of foundation privacy matters pertaining to secondary use of medical data. The conclusions from this study inform the early analysis stage of the system development life cycle associated with development of health information systems. This study purposefully engaged with the traditionally under represented consumers (Townend 2010; Buckley, Murphy et al. 2011) to aid in the inclusion of their 'voices' in the important preliminary SDLC analysis. The principal conclusions of this study address the two overarching research questions which are:

\section{Research Question 1}

What are consumer's expectations and concerns regarding secondary uses of their medical data, particularly with respect to privacy matters?

\section{Research Question 2}

Does the RALC theory (Tavani and Moor 2001) and the framework for contextual integrity (Nissenbaum 2010) offer privacy concepts that can: (1) be applied in the secondary use of medical data context and (2) gain support from interested consumers?

With respect to Research Question 1 the principal conclusions are:

For Australia:

- There are statistically significant differences of opinion across consumers' age, highest education level, and status as self-reported healthcare workers. Rather than generalising Australian consumers as a homogenous group, when referring to secondary use privacy matters, the consumer group can be stratified as discussed in thesis section 5.2.1.

- The healthcare sector have long been proponents of the concept of privacy being equivalent to 'limited access' but many consumers are not 
aware of this being a priority within the healthcare sector as discussed in thesis section 5.2.1.2.

- Consumers express attitudes of concern regarding the secondary use of their medical data and associated privacy issues particularly when the insurance and pharmaceutical sectors are the secondary users as presented in thesis section 5.2.1.4.

- Responses to the concept of a 'right' to privacy differ with statistical significance across consumer gender and age, with women responding more positively to this concept than men, as discussed in thesis section 5.2.1.5.

- There are statistically significant differences across consumer education level and age regarding the concept of needing to re-use medical data to aid in 'getting-the-balance-right' to deliver benefit to society through secondary use of data, as discussed in 5.2.1.5.

In comparison to Canada:

- In terms of the privacy concept there are statistically significant differences between Australians and Canadians on anxiety about medical receptionists and IT professionals having access to an individuals' medical data, withholding data from secondary use due to potential misuse, and anxiety over insurance sector misuse of data.

- In terms of privacy justification there are statistically significant differences between Canadians and Australians regarding citizens 'rights'. Qualitative analysis concluded Australians engage more with the altruistic donation of data to benefit society.

- In terms of privacy management statistically significant differences exist between Canadian and Australian consumers regarding the facility for a consumer to view and correct medical information. 
The discussion regarding these comparative conclusions is found in thesis sections 6.1.5 and 6.1.6. Canada is further progressed in the deployment of electronic health records than Australia and citizens may therefore have more experience and awareness of the issues surrounding secondary use of the collected data. This may account for some of the variation between the survey results. The response rate to the Canadian survey included in this study is low hence caution is required when considering the results.

The principal conclusions concerning Research Question 2 are:

- The outcomes from the investigation into the tripartite components of privacy concept, privacy justification and privacy management indicate that the hybrid Restricted Access Limited Control (RALC) could be applied to the secondary use of medical data context.

The pilot and final surveys deployed in Australia and Canada as part of this study included thirty attitudinal statements that investigated the concept, justification or management of privacy. The 1,573 consumers who responded to the survey were able to engage with the attitudinal statements and analysis of quantitative results, classified according to privacy concept or justification or management, provided reliable results as discussed in thesis section 3.5.2. There was no expectation that survey respondents would conceptualise the tripartite components of the privacy theory. Each of the carefully selected attitudinal statements, many first trialled in the pilot surveys, sought to engage consumers on one particular tripartite component. The classification was transparent to the respondents and relied upon the researcher to compile constructs appropriately as discussed in thesis sections 3.5.3.2 (pilot survey) and 3.5.5 (final survey).

- The essential components of the Contextual Integrity privacy theory (Nissenbaum 2010) - actors, attributes and transmission principles - can be applied to the secondary use of medical data context. 
Without specifically defining these theoretical constructs for consumers, it was possible to identify these Contextual Integrity components within Australian and Canadian consumer survey respondent's open-ended comments. The survey comments identified different actors, attributes and transmission principles. The Canadian and Australian consumer open-ended comments, particularly those regarding components of Contextual Integrity, enabled refinement of the Privacy Framework and definition of the Levels 0-3 of consumer engagement as discussed in thesis section 7.3.1.

- The response to the consumer survey instrument used in this study indicates that combining and applying RALC and contextual integrity privacy theory to the secondary use of medical data would gain support from interested consumers with many seeking further engagement on secondary use matters.

The survey response rate and the clarity and volume of qualitative and quantitative survey data indicate support for applying RALC and Contextual Integrity theories. The level of support and engagement amongst consumers is diverse and the proposed Privacy Framework, incorporating Levels 0-3 consumer engagement, supports this diversity.

\subsection{Links to Earlier Research}

This study is linked to earlier research from across a variety of domains including legal, philosophical, health and health informatics, and information systems. Links are particularly strong to the privacy theories proposed by Tavani and Moor (Moor 2000; Tavani and Moor 2001; Tavani 2007b) and Nissenbaum (2004; 2010) with their theories forming the 'initial skeleton' of the secondary use of medical data Privacy Framework proposed here. The consumer survey instrument deployed in both Australia and Canada drew heavily on the tripartite approach to privacy proposed by Tavani and Moor (Tavani and Moor 2001). 
Earlier Canadian joint investigations (2003; Willison, Keshavjee et al. 2003; Willison, Schwartz et al. 2007; Willison, Emerson et al. 2008; Willison, Steeves et al. 2009) into consumers' attitudes towards secondary data use provided very useful initial insights. Willison's published criticisms of the Lowerance Nuffield trust report Privacy, confidentiality and related notions provided a link to the study described in this dissertation by providing an insightful, alternate point of view which encouraged pursuit of the consumer opinion. Statements 8, 9 and 27 echo questions used in Willison's earlier consumer research.

Magnusson's (2004) conceptualisation of the loss of individual privacy includes Concept 3:Trans-Organisational Health Data Flows which, when published in 2004, warned of 'function creep' with personal data moving to become part of public health infrastructure and with value in a national surveillance architecture. Magnusson (Magnusson 1995b) also published on the loss of consumer rights apparent through the Australian Breen V Williams legal action. Statements 24 and 30 in the consumer survey directly relate to the earlier research of Magnusson and consumer responses gathered through this study build on his earlier publications by collecting primary data from consumers. The attitude consumers recorded in the survey re-enforce the validity of the issue previously raised by Magnusson.

This research links with recent calls for more meaningful engagement with consumers on secondary use of their medical data (Buckley 2008; Ruyter, Louk et al. 2010; Shelton 2011; Showell 2011) and calls for more research into the opinions of the under-represented healthcare consumers (Townend 2010; Buckley, Murphy et al. 2011).

The Privacy Framework proposed in Chapter 7 links with earlier reports concerning the need for a mechanism to assist Human Research Ethics Committees (HREC) in managing the approvals for research involving medical information (Croll and Croll 2006; Croll 2007). The Privacy Framework can also assist in overcoming inconsistencies in operation of Research Ethics Boards (REB) (Willison, Emerson et al. 2008; Elger, Lavindrasana et al. 2010) through reference to consumer specified privacy directions. 


\subsection{Major Implications}

Implications for medical researchers:

This study has investigated a paradigm shift away from 'limited access' privacy theory towards a more contemporary approach to consumer privacy in terms of enhanced engagement with consumers regarding secondary use of their data. This work coincides with very recent calls from within the medical research community for enhanced levels of understanding and engagement with the general public concerning medical research.

The Australian and Canadian consumers who participated in this study have provided important insight into their attitudes, concerns and expectations regarding secondary use of their medical data and associated privacy matters and the information thus gained provides valuable input for decision makers involved in developing national health information systems. Human research ethics committee members and researchers involved in medical, health service and population health research may also gain valuable insight into what consumer think regarding privacy and secondary use of medical data through the results of this study.

Implications for Consumers

The Privacy Framework proposed in Chapter 7 meets the dual purpose of aiding medical researchers in their engagement with consumers while simultaneously offering consumers an opportunity to provide secondary use directions. The Privacy Framework assists consumer by clearly stating whether they allow medical researcher access but deny access to their data for other stakeholder purposes, such as commercial organisations. Another implication for consumers is that this study has documented their diverse views and demonstrated their capacity and interest in discussing secondary uses of their medical data. Hopefully this will encourage meaningful engagement and opportunities for decision making in collaboration with other stakeholders. 
Implications for Government and policy makers

In democratic nations Government entities and policy makers are called upon to make decisions in the best interest of citizens. The discussion of privacy issues from multiple perspectives in the literature review of this dissertation provides policy makers and government with a concise insight to diverse interests.

The qualitative and quantitative data from the consumer survey is also available and valuable for future planning, legislation and decision making, particularly in the Australian context.

Implications for Privacy Researchers and Privacy Advocates

This study demonstrates, for the first time, the combination of Tavani and Moors (Tavani and Moor 2001) (RALC) with Nissenbaum's contextual integrity privacy theories. These theories are then applied to the secondary use of medical data context, also for the first time, thus applying the theories in the 'real-world'.

This study provides qualitative and quantitative data about Australian and Canadian citizens' views regarding secondary use of their medical data and their associated privacy concerns and expectations. This is valuable attitudinal information of use to privacy advocates in their various projects and campaigns to raise societal awareness of the importance of privacy issues in the sensitive area of healthcare.

Implications for Information Systems Professionals

This dissertation gives voice to consumers and the implications for system analysts are substantial as they can no longer simply listen to the healthcare stakeholders who have, to date, dominated health information systems design.

System analysts and designers are presented with real world problems seeking technological solutions. Frequently the technological solutions must be accompanied by organisational or business enhancements or substantial change. The problem in the secondary use context relates to privacy and there are many IT solutions wrestling with the delivery of solutions that implement 'restricted access' functionality and detailed consent mechanisms as if they were the 'silver-bullet' for 
addressing privacy issues. This study has taken a step back from the technological solutions and has reframed the privacy challenge. Organisational and business changes, particularly in terms of moving the healthcare sector beyond 'restricted access' = 'privacy', need to be tackled by systems and business analysts. The answer does not lie in micro management of consumer consent attached to small components of the consumers EHR. The answer lies in treating consumers as equal partners and building meaningful long term partnerships as called for by Ruyter et al. (2010). This poses a challenge for information systems professionals who need to partner with forward looking clinicians to bring about privacy changes.

\subsection{Limitations of the Research}

The consumers who responded to the survey could be described as interested in secondary use of medical data and privacy issues given their dedication of time and effort to complete the survey. The lack of engagement with young consumers, aged eighteen to twenty-five years is a particular limitation to the study. This is a similar limitation to that found by the recent Irish consumer survey (Buckley, Murphy et al. 2011). Hence the survey results do not necessarily represent the views of all Australians. This is acknowledged and the proposed Privacy Framework has been designed to be as flexible as possible to allow those consumers with no interest in engagement to be protected, by default, by existing secondary use protections.

The low response rate to the consumer survey in Canada has been a limitation to this research. With only 203 Canadians responding, and with most of them located in Ontario, it is not possible to claim they are representative of Canadians. Therefore care was taken when comparing the results to Australian survey results. The MannWhitney $U$ test used to gauge statistical significance between two sample populations is tolerant of the different sample sizes hence the statistically significant results found are valid. The Mann-Whitney $U$ test however does not attempt to identify what the differences are between the two populations. Hence the drawing of conclusions on the Canadian and Australian Comparison is very conservative. 
Changes in levels of consumer engagement over time have not been incorporated into the Privacy Framework. Future research regarding the Privacy Framework could address the important temporal aspects associated with changing consumer opinion.

\subsection{Future Research}

Future research arising from this study can be grouped according to the tripartite approach to privacy and extended to trials of the proposed Privacy Framework.

\section{Privacy Concept}

The Privacy Concept construct of the Australian consumer survey resulted in 11 statistically significant results across age, highest education level and self-reported healthcare worker status. The Chi-Square test results are summarised in Table 46. Anxiety levels about privacy varied substantially for citizens with those of higher education levels less anxious and older Australians more anxious about privacy. Further research could investigate the reasons behind these differences as they may have impact on future privacy policy and guidelines.

Future Research Questions on Age: Why does anxiety over privacy vary across age groups? What are the specific concerns for each group? What is the impact of familiarity with social networking and living on-line on the level of anxiety over privacy?

Future Research Questions on Education Level: Why are postgraduate educated Australians less anxious about the privacy of their medical information? Given that most healthcare professionals making decisions about secondary use, are postgraduate educated are they 'out-of-step' with the broader community?

Future Research Questions for non-Healthcare Workers: Why is it that non healthcare workers do not understand the 'restricted access' approach to privacy adopted by the health sector? Why are healthcare workers in Australia more worried about the insurance sector access to secondary use of medical data? Is it their knowledge of the potential abuse that makes them register stronger views than those registered by the non-healthcare workers? 


\section{Privacy Justification}

The Privacy Justification construct of the Australian consumer survey resulted in 6 statistically significant results across gender, age and highest education level with Chi-Square test results summarised in Table 46.

Future Research Questions across Gender: Why do women express stronger views on a 'right to privacy' and a 'right to share information' than do men?

Future Research Questions across Age: Why are older citizens less concerned with 'rights'? Why are citizens who are older than 66 years more inclined towards altruism rather than individual 'rights'?

Future Research Questions across Education: Why are tertiary (Bachelor and Postgraduate) educated Australians less altruistic in terms of using their medical data to help others (Statement 12) than are less educated Australians?

\section{Privacy Management}

Future Research Questions by Gender: Why is it that women have stronger views on shared data stewardship than men? Why do women seek more control over their medical data than men? What are the implications for future secondary use? Combined with the questions about postgraduate educated decision makers, what are the implications of there being fewer women at the senior decision making level in the health sector? Why women are more accepting than men about allowing a person withhold their medical record from secondary use?

Future Research Questions by Age: Why are citizens younger than 25 years and older than 66 years happier to let their doctors have stewardship over their data? As the younger Australians suffer more medical problems will their attitudes change? What are the implications on secondary use in the future? Will there be less opposition from younger Australians to secondary access without consumer engagement? 
Future Research Questions by Education Level: Why do the higher educated Australians seek more engagement on consent than just a single, on-going consent to data use? What is the implication for future secondary use?

Future Research Questions for Healthcare Workers: What motivates the strongly expressed desire to have control over the third parties with access to their own medical data for secondary purposes? Have they witnessed the misuse of data? How would they respond to a consumer/patient wanting to release their data to a third party that the healthcare worker was not prepared to support?

\section{Instantiation of the Privacy Framework}

Future research starting in 2012 includes the application of the Privacy Framework in two scenarios; the first in Australia and the second in Canada. The first opportunity builds on the results of the consumer survey indicating that women are more interested in engaging in secondary use matters and involves a General Practice based trial of the Privacy Framework with female consumers. Discussions are underway regarding a trial at a large New South Wales south coast General Practice. Using the knowledge gained through the consumer survey the trial proposes to invite women aged over 26 years to participate by using the Privacy Framework to record their secondary use directions. The General Practice context acts as a hub to collecting patient data that spans an extended periods of time. The data to be collected includes data from specialist consultations, lifestyle and family history information. This dataset, combined with secondary use direction gathered in a manner trialling the Privacy Framework, will provide an important medical research resource.

The second opportunity relates specifically to the secondary use of physiological readings captured by life support devices. While patients in critical care are attached to various monitors and life support devices visually displaying second by second physiological readings, historically critical care documentation of this information has been limited to paper charting of hourly at best spot readings. In addition to the move from paper to electronic charting of this information, recent research is highlighting the need to progress from the 3600 (60 seconds * 60 Minutes) to one 
spot reading order of magnitude of data loss to the storage of the second by second readings. The research is proposing new approaches to the real-time analysis of that high frequency physiological data for greatly improved clinical decision support. This second trial proposes to explore the application of the Privacy Framework proposed in this thesis to support the capture, storage, transmission and analysis of this data to the secondary use context for population based retrospective analysis.

The Chapter 2 Literature Review raised a future research area regarding consideration of the importance of privacy in various cultures, and the underlying moral philosophy (Croll 2008; Cullen 2008; Maurushat 2008). Pursuit of this area of research would be valuable as results would inform the debate about globalisation of data management. Cross-border cultural differences concerning adequate privacy of stored data were also raised by consumers through the surveys.

\subsection{Conclusion}

The research study presented in this dissertation is the first to combine Nissenbaum's (2010) framework for contextual integrity and Moor and Tavani's (2001) restricted access/limited control (RALC) privacy theory to propose a Privacy Framework. The consumer pilot and final surveys regarding secondary use of medical data developed and deployed in this research study, attracted 1,573 respondents. This is the first study to gather primary data from consumers within the tripartite approach to privacy (Tavani and Moor 2001). The consumer survey results and proposed Privacy Framework for secondary use of medical data make a valuable contribution to a clear problem definition, requirements analysis, and logical model as required in early phases of the system development life cycle. The findings of this research are well suited to inform the future physical implementations of health information systems. 


\section{REFERENCES}

Al-Shahi, R \& Warlow, C 2000, 'Using patient-identifiable data for observational research and audit', British Medical Journal, vol.321, no.7268, pp.1031-1032.

Allen, A 1988, Uneasy Access : privacy for women in a free society, Rowman \& Littlefield, Totowa, New Jersey.

Appelbaum, P S 2000, 'Protecting Privacy While Facilitating Research', American Journal of Psychiatry, vol.157, no.11, pp.1725-1726.

Arora, N K \& McHorney, C A 2000, 'Patient Preferences for Medical Decision Making: Who Really Wants to Participate?', Medical Care, vol.38, no.3, pp.335-341.

Austin, S 2008, 'The Labour Force Involvement of Women: Lessons from a Comparison of Canada and Australia', Public Policy, vol.3, no.2, pp.125-140.

Australian Government 1988, accessed 8 Oct 2012, http://www.austlii.edu.au/au/legis/cth/consol act/pa1988108/.

Australian Health Ministers Advisory Council 2009, Healthcare Identifiers and privacy: Discussion paper on proposals for legislative support, Canberra.

Australian Institute of Health and Welfare, accessed 8 Oct 2012, http://www.aihw.gov.au/rural-health-remoteness-classifications/.

Australian Law Reform Commission 2008, For Your Information: Australian Privacy Law and Practice (ALRC Report 108), Sydney, Australia.

Australian Privacy Foundation 1998, accessed 15 Jun 2011, http://www.privacy.org.au/.

Australian Schizophrenia Research Institute, accessed 17 Feb 2010, http://www.schizophreniaresearch.org.au/bank/index.php? $\mathrm{r}=5 \& \mathrm{menu}=\mathrm{Access}$ + Process\& $\mathrm{p}=4$

Baird, A, North, F \& Raghu, T S 2011, 'Personal Health Records (PHR) and the future of the physician-patient relationship', Proceedings of ACM International Conference Proceeding Series, Seattle, Washington, 8-11 February 2011, pp. 281-288.

Baird, W, Jackson, R, Ford, H, et al. 2009, 'Holding personal information in a disease specific register: the perspectives of people with multiple sclerosis and professionals on consent and access', Journal of Medical Ethics, vol.35, pp.92-96.

Bansal, G, Zahedi, F \& Gefen, D 2008a, 'The Moderating Influence of Privacy Concern on the Efficacy of Privacy Assurance Mechanisms for Building Trust: A Multiple-Context Investigation', Proceedings of International Conference on Information Systems (ICIS), Paris, France, 14-17 Dec 2008, pp.

Bansal, G, Zahedi, F \& Gefen, D 2008b, 'Efficacy of Privacy Assurance Mechanisms in the Context of Disclosing Health Information Online', Proceedings of Americas Conference on Information Systems, Toronto, Canada, 14-17 Aug 2008, pp.

Barbone, F, McMahon, A D, Davey, P G, et al. 1998, 'Association of road-traffic accidents with benzodiazepine use', The Lancet, vol.352, pp.1331-1336. 
Barrett, G, Cassell, J A, Peacock, J L \& Coleman, P 2006, 'National survey of British public's views on use of identifiable medical data by the national cancer registry', British Medical Journal, vol.332, pp.1068-1072.

Beckerman, Z, Potts, J, Leifer, J \& Rosenbaum, S 2008, Health Information Privacy, Patient Safety, and Health Care Quality: Issues and Challenges in the Context of Treatment for Mental Health and Substance Use, Arlington, Virginia.

Bergkvist, L \& Rossiter, J R 2007, 'The Predictive Validity of Multiple-Item Versus Single-Item Measures of the Same Constructs', Journal of Marketing Research, vol.XLIV, pp.174-184.

Beskow, L M \& Dean, E 2008, 'Informed Consent for Biorepositories: Assessing Prospective Participants Understanding and Opinions', Cancer Epidemiol Biomarkers Prev, vol.17, pp.1440-1451.

Bishop, L S, Holmes, B J \& Kelley, C M 2005, National Consumer Health Privacy Survey 2005, California HealthCare Foundation \& Forrester Research, Inc., California.

Blendon, R J, Schoen, C, DesRoches, C M, et al. 2002, 'Inequalities in Health Care: A Five-Country Survey', Health Affairs, vol.21, no.3, pp.182-191.

Bourque, L B \& Fielder, E P 2003, How to Conduct Self-Administered and Mail Surveys, Sage Publications, Thousand Oaks.

Braithwaite, J \& Mannion, R 2011, 'Government plans for public reporting of performance data in health care: the case against', Medical Journal of Australia, vol.195, no.1.

Brin, D 1998, The Transparent Society, Perseus Books, Jackson, TN.

BroganInc 2011, Brogan Inc, accessed 22 Jun 2011, www.broganinc.com.

Bryman, A 2006, 'Integrating quantitative and qualitative research: how is it done?', Qualitative Research, vol.6, pp.97-112.

Bryman, A 2007, 'Barriers to Integrating Quantitative and Qualitative Research', Journal of Mixed Methods Research, vol.1, pp.8-22.

Buckley, B 2008, 'The need for wider public understanding of health care research', Primary Health Care Research \& Development 2008, vol.9, pp.3-6.

Buckley, B S, Murphy, A W \& MacFarlane, A E 2011, 'Public attitudes to the use in research of personal health information from general practitioners' records: A survey of the Irish general public', Journal of Medical Ethics, vol.37, no.1, pp.50-55.

Byrne, D 2002, Interpreting Quantitative Data, SAGE Publications, London.

Camp, L J, Nissenbaum, H \& McGrath, C 2002, 'Trust: A Collision of Paradigms', Proceedings of Financial Cryptography 2001, Grand Cayman, West Indies, 19-22 Feb 2002, pp. 91-105.

Campbell, D T \& Fiske, D W 1959, 'Convergent and discriminant validation by the multitrait-multimethod matrix', Psychol Bull, vol.56, pp.81-105.

Campbell Research And Consulting 2004, The Impact of Privacy Legislation on NHMRC Stakeholders, National Health and Medical Research Council, Canberra, Australia.

Clarke, R 1988, 'Just another piece of plastic for your wallet: The 'Australia Card' system', Computer and Society, vol.18, no.1.

Clarke, R 2010, 'What is Uberveillance? (And What Should Be Done About it?)', IEEE Technology and Society Magazine, vol.Summer 2010, pp.17-25.

Clarke, R 2011a, 'Google+', accessed 20 Feb 2012, http://www.privacy.org.au/Papers/Google-110630.pdf. 
Clarke, R 2011b, 'Point-To-Point Cameras', accessed 22 Feb 2012, http://www.privacy.org.au/Papers/ACT-Pt-to-Pt-110717.pdf.

Clarke, R 2011c, 'Submission to the Independent Media Inquiry An Appropriate Public Regulatory Body', accessed 22 Feb 2012, http://www.privacy.org.au/Papers/MediaInq-Sub-111118.pdf.

Cohen, J 2000, 'Examined Lives: Informational Privacy and the Subject as Object', Stanford Law Review, vol.52, pp.1373-1437.

Creswell, J W 2008, Planning a Mixed Methods Study, accessed 22 Feb 2012, http://sitemaker.umich.edu/creswell.../files/creswell power point slides.ppt.

Creswell, J W 2009, Research Design: Qualitative, Quantitative, and Mixed Methods Approaches, Sage Publications, Thousand Oaks, California.

Creswell, J W, Fetters, M D \& Ivankova, N V 2004, 'Designing A Mixed Methods Study In Primary Care', Annals of Family Medicine, vol.2, no.1, pp.7-12.

Creswell, J W \& Plano Clark, V 2011, Designing and Conducting Mixed Methods Research, Sage Publications, Thousand Oaks.

Creswell, J W, Plano Clark, V L, Gutman, M L \& Hanson, W E 2003, 'Advanced Mixed Methods Research Designs', in Handbook of Mixed Methods in Social and Behavioural Research, (eds.) A. Tashakkori \& C. Teddlie, Sage, Thousand Oaks, California, pp.

Creswell, J W, Shope, R, Plano Clark, V \& Green, D O 2006, 'How Interpretive Qualitative Research Extends Mixed Methods Research', Research in the Schools, vol.13, no.1, pp.1-11.

Creswell, J W \& Tashakkori, A 2007, 'Differing Perspectives on Mixed Methods Research', Journal of Mixed Methods Research, vol.1, no.4, pp.303-308.

Croll, P 2007, Submission on Privacy in Health Information to the Australian Law Reform Commission, Health Informatics Society of Australia, Brunswick East, Australia.

Croll, P 2008, Confidentiality and Privacy with Health ICT, accessed 22 Feb 2012, http://healthprivacy.com.au/doc/Confidentiality and Privacy_with_Health_I CT V2.pdf.

Croll, P \& Croll, J 2006, 'Privacy Compliance - Managing the Risks when Integrating Health Data', Proceedings of HIC 2006 Sydney, Australia, 20-22 Aug 2006, pp. 133-138.

Croll, P R 2008, 'Privacy Impact Assessments-The Organisation versus the Individual's Viewpoints', paper presented to HIC08, Melbourne, Australia, 31 Aug - 2 Sep 2008.

Croll, P R 2011, 'Determining the privacy policy deficiencies of health ICT applications through semi-formal modelling', International Journal of Medical Informatics, vol.80, no.2, pp.e32-e38.

Croll, P R \& Croll, J 2007, 'Investigating risk exposure in e-health systems', International Journal of Medical Informatics, vol.76, no.5-6, pp.460-465.

Croll, P R \& Morarji, H 2006, 'Perceived risk: human factors affecting ICT of critical infrastructure', Proceedings of Research Network for a Secure Australia (RNSA) Conference on The Social Implications of Information Security Measures on Citizens and Business, Wollongong, Australia, 29 May 2006, pp. 213-221.

Cullen, R 2008, 'Citizens' concerns about the privacy of personal information held by government: a comparative study, Japan and New Zealand.', paper presented to 41st Hawaii International Conference on System Sciences, Big Island, Hawaii, 7-10 Jan 2008. 
Culver, C, Moor, J, Duerfeldt, W, et al. 1994, 'Privacy', Professional Ethics vol.3 \& 4, pp.3-25.

Damschroder, L J, Pritts, J L, Neblo, M A, et al. 2007, 'Patients, privacy and trust: Patients' willingness to allow researchers to access their medical records', Social Science and Medicine, vol.64, no.1, pp.223-235.

Dash, E 2007, 'Data breach could affect millions of TJX shoppers', The New York Times, 19 Jan 2007, accessed 18 Jun 2011, www.nytimes.com/2007/01/19/business/19data.html.

Dearne, K 2010, 'Medicare snoops escape sack', The Australian, 21 July, accessed 23 Feb 2012, http://www.theaustralian.com.au/australianit/government/medicare-snoops-escape-sack/story-fn4htb9o-1225895209553.

Deem, R 2002, 'Talking to manager-academics: Methodological dilemmas and feminist research strategies', Sociology, vol.36, pp.835-855.

Dinev, T, Bellotto, M, Hart, P, et al. 2006, 'Privacy calculus model in e-commerce - a study of Italy and the United States', European Journal of Information Systems, vol.15, pp.389-402.

Doll, R \& Peto, R 2001, 'Rights involve responsibilities for patients', British Medical Journal, vol.322, no.7288, pp.730.

Dyer, C 2009, 'Researchers have failed to ease access to patients' data for research', British Medical Journal vol.338, no.b1961.

EKOS Research Associates 2007, Electronic Health Information and Privacy - What Canadians Think - 2007, Canada Health Infoway, Health Canada, Office of the Privacy Commissioner of Canada, Ottawa, Ontario.

Electronic Privacy Information Centre, accessed 18 Jul 2011, http://epic.org.

Elger, B, S, Lavindrasana, J, Lo Iacono, L, et al. 2010, 'Strategies for health data exchange for secondary, cross-institutional clinical research', Computer Methods and Programs in Biomedicine, vol.99, pp.230-251.

Falcao-Reis, F, Cost-Pereira, A \& Correia, M E 2008, 'Access and Privacy Rights Using Web Security Standards to Increase Patient Empowerment', in Medical and Care Compunetics 5, (eds.) L. Bos, IOS Press, pp. 275-285.

Fernando, J 2004, 'Factors that have Contributed to a Lack of Integration of Health Information System Security', The Journal on Information Technology in Healthcare, vol.2, no.5, pp.313-328.

Fernando, J 2009, 'Australian Privacy Foundation Policy Position eHealth Data and Health Identifiers', accessed 18 Jul 2011, http://www.privacy.org.au/Papers/eHealth-Policy-090828.pdf.

Fernando, J 2011, 'APF Submission to Inquiry into the provisions of the Personally Controlled Electronic Health Records Bill 2011 and a related Bill', accessed 2 Feb 2011, http://www.privacy.org.au/Papers/Sen-PCEHR-Bill-111221.pdf.

Fernando, J 2011, eHealth Consumer Consultation and Project Governance, accessed 18 Jul 2011, http://www.privacy.org.au/Papers/Roxon-PCEHR-Ltr110417.pdf.

Fink, A 2005, How to Manage, Analyze, and Interpret Survey Data, Sage Publications, Inc., Thousand Oaks, California.

Floridi, L 2005, 'The Ontological Interpretation of Informational Privacy', Ethics and Information Technology, vol.7, no.4, pp.185-200.

Floridi, L 2006, 'Four challenges for a theory of informational privacy', Ethics and Information Technology, vol.8, pp.109-119.

Fraser, A 2003, 'Privacy and the secondary use of data in health research in Scotland', Journal of Health Serv Res Policy, vol.8, no.S1, pp.12-16. 
Fried, C 1968, 'Privacy: A Moral Analysis', Yale Law Journal, vol.77, no.1, pp.475493.

Froomkin, A M 2000, 'The Death of Privacy', Stanford Law Review, vol.52, pp.14611543.

Gavison, R 1980, 'Privacy and the Limits of the Law', Yale Law Journal, vol.89, pp.421-471.

Gerstein, R 1984, 'Intimacy and Privacy', in Philosophical Dimensions of Privacy:An Anthology, (eds.) F. Shoeman, Cambridge University Press, Cambridge, pp. 265-271.

Gordis, L, Gold, E \& Seltser, R 1977, 'Privacy Protection in Epidemiological and medical research: A challenge and a responsibility', American Journal of Epidemiology, vol.105, no.3, pp.163-168.

Grodzinsky, F S \& Tavani, H 2010a, 'Privacy in "the cloud": Applying Nissenbaum's Theory of Contextual Integrity', SIGCAS Computers and Society, vol.40, no.4, pp.38-47.

Grodzinsky, F S \& Tavani, H 2010b, 'Can the 'Contextual Integrity' Model of Privacy Be Applied to Blogs and the Blogosphere?', International Journal of Internet Research Ethics, vol.3, no.1, pp.38-47.

Gulcher, J R \& Stefansson, K 2000, 'The Icelandic Healthcare database and Informed Consent', The New England Journal of Medicine, vol.342, no.24, pp.18271830.

Gunter, T D \& Terry, N P 2005, 'The Emergence of National Electronic Health Record Architectures in the United States and Australia: Models, Costs and Questions', J Med Internet Res, vol.7, no.1, pp.e3-e13.

Hair, J H J, Anderson, R E, Tatham, R L \& Black, W C 1995, Multivariate Data Analysis, Prentice Hall, Upper Saddle River, NJ.

Hall, M 2009, Property, Privacy, and the pursuit of Integrated Electronic Medical Records, $\quad 11$ accessed 2011 , http://papers.ssrn.com/sol3/papers.cfm?abstract id=1334963.

Hansen, D, Gurney, P, Morgan, G \& Barraclough, B 2011, 'The Australian e-Health Research centre: enabling the health care information and communication technology revolution', Medical Journal of Australia, vol.194, no.4, pp.S5S7.

Hanson, W E, Creswell, J W, Plano Clark, V, et al. 2005, 'Mixed Methods Research Designs in Counseling Pstchology', Journal of Counseling Psychology, vol.52, no.2, pp.224-235.

Harchaoui, T, Jean, J \& Tarkhani, F 2005, 'Comparisons of Economic Performance, Canada versus Australia, 1983-2000', Monthly Labor Review,no.April 2005, pp.36-47.

Hayrinen, K, Saranto, K \& Nykanen, P 2008, 'Definition, structure, content, use and impacts of electronic health records: A review of the research literature', International Journal of Medical Informatics, vol.77, pp.291-304.

Helliwell, T 2001, 'Cancer registries fear collapse (letter to editor)', British Journal of General Practice, vol.322, pp.730.

Iacono, L L 2007, 'Multi-centric Universal Pseudonymisation for Secondary Use of the EHR', in From Genes to Personalized Healthcare: Grid Solutions for the Life Sciences, (eds.) N. Jacq, IOS Press, pp. 239-247.

IMS-Health 2008, 'IMS Health 2008 Annual Report', accessed 27 Feb 2012, http://www.imshealth.com/imshealth/Global/Content/Document/Annual\%20 Reports/AR_2008.pdf. 
Jick, S S, Dean, A D \& Jick, H 1995, 'Antidepressants and suicide', British Medical Journal, vol.310, pp.215-218.

Jick, T D 1979, 'Mixing Qualitative and Quantitative Methods: Triangulation in Action', Administrative Science Quarterly, vol.24, no.4, pp.602-611.

Johnson, B 2001, 'Empowerment and disempowerment: Models of staff/patient interaction', Journal of Research in Nursing, vol.6, no.6, pp.936-948.

Jorm, C \& Frommer, M 2011, 'Government plans for public reporting of performance data in health care: the case for', Medical Journal of Australia, vol.195, no.1, pp.40.

Kalra, D 2006, 'Electronic Health Record Standards', IMIA Yearbook of Medical Informatics 2006,pp.136-144.

Kang, J 1998, 'Information Privacy in Cyberspace Transactions', Stanford Law Review, vol.50, no.4, pp.1193-1294.

Kidd, M P \& Shannon, M 1996, 'The Gender Wage Gap: A Comparison of Australia and Canada', Industrial and Labor Relations Review, vol.49, no.4, pp.729746.

Kohler Riessman, C 2002, 'Narrative Analysis', in The Qualitative Researchers Companion, (eds.) A. M. Huberman \& M. B. Miles, Sage Publiocations, Thousand Oaks, California, pp. 217-270.

Litwin, M S 2003, How to Assess and Interpret Survey Psychometrics, Sage Publications, Thousand Oaks.

Lo, B \& Alpers, A 2000, 'Uses and abuses of prescription drug information in pharmacy benefits management programs.', Journal of the American Medical Association, vol.283, pp.801-806.

Lowrance, W W 1997, Privacy and Health Research, U.S Secretary of Health and Human Services, Washington D.C.

Lowrance, W W 2002, Learning from Experience: Privacy and the Secondary Use of Data in Health Research,

Lowrance, W W 2003, 'Learning from experience: privacy and the secondary use of data in health research', Journal of Health Serv Res Policy, vol.8, no.S1, pp.27.

Ludwick, D, Manca, D \& Doucette, J 2010, 'Primary care physicians' experiences with electronic medical records', Canadian Family Physician, vol.56, no.January 2010, pp.40-47.

Magnusson, R S 2002, 'Data Linkage, Health Research and Privacy: Regulating Data Flows in Australia's Health Information System', Sydney Law Review, vol.24, pp.5-55.

Magnusson, R S 2004, 'The changing legal and conceptual shape of health care privacy', Journal of Law, Medicine and Ethics, vol.32, no.4, pp.680-691.

Magnusson, R S \& Opie, H 1998, 'Patient Access to Medical Records: Fiduciary Duties and Other Issues - A Classroom Interactive', Sydney Law Review, vol.17, no.2, pp.99-133.

Marwick, C 1996, 'Increasing Use of Computerized recordkeeping Leads to Legilsative Proposals for Medical Privacy', Journal of the American Medical Association, vol.276, no.4, pp.270-271.

Maurushat, A 2008, 'The benevolent health worm: comparing Western human rightsbased ethics and Confucian duty-based moral philosophy', Ethics and Information Technology, vol.10, pp.11-25. 
McCarthy, D B, Shatin, D, Drinkard, C R, et al. 1999, 'Medical Records and Privacy: Empirical Effects of Legislation', Health Services Research, vol.34, no.1, pp.417-425.

McCurdy, B M C, Duggan, L, Howlett, S \& Clark, B G 2009, 'A comparison of medical physics training and education programs - Canada and Australia', Australasian Physical \& Engineering Sciences in Medicine, vol.32, no.4, pp.251-258.

McKinley, R, Manku-Scott, T, Hastings, A, et al. 1997, 'Reliability and validity of a new measure of patient satisfaction with out of hours primary medical care in the United Kingdom: development of a patient questionnaire', British Medical Journal, vol.314, no.193.

Mechanic, D 1978, 'Sex, illness, illness behaviour and use of health services', Soc Sci Med, vol.1978, no.12B, pp.207-214.

Mechanic, D 1998, 'The functions and limitation of trust in the provision of medical care', Journal of Health Politics, Policy and Law, vol.23, no.4, pp.661-686.

Melton, L J 1997, 'The Threat to medical-Records Research', The New England Journal of Medicine, vol.November 13, 1997, pp.1466-1470.

Metcalfe, C, Martin, R, M, Noble, S, et al. 2008, 'Low risk research using routinely collected identifiable health information without informed consent: encounters with the Patient Information Advisory Group', Journal of Medical Ethics, vol.34, pp.37-40.

Miles, M B \& Huberman, A M 1994, Qualitative Data Analysis: An Expanded Sourcebook, SAGE Publications, London.

Miller, M 1998, 'An Australian Nanavut? A Comparison of Inuit and Aboriginal Rights Movements in Canada and Australia', Emory International Law Review, vol.12, pp.1175-1214.

Mitchell, J, Clarke, A \& Nuttall, J 2007, 'Cooperating Teachers' Perspectives Under Scrutiny: A comparative Analysis of Australia and Canada', Asia-Pacific Journal of Teacher Education, vol.35, no.1, pp.5-25.

Mitka, M 1998, 'Do-It-Yourself Report on Patient Privacy', Journal of the American Medical Association, vol.280, no.22, pp.1897.

Moor, J 2000, 'Towards a Theory of Privacy for the Information Age', in Cyberethics:Moral, Social, and Legal Issues in the Computer Age, (eds.) R. M. Baird, R. Ramsower \& S. Rosenbaum, Prometheus Books, Amherst, New York, pp. 200-212.

Moor, J 2005, 'Why we need better ethics for emerging technologies', Ethics and Information Technology, vol.7, no.111-119.

Moor, J H 1997, 'Towards a theory of privacy in the information age', SIGCAS Comput. Soc., vol.27, no.3, pp.27-32.

Morton, A, P., Smith, S E, Croll, D P \& Whitby, R M 2009, 'Health information privacy and patient safety ', Medical Journal of Australia, vol.190, no.7, pp.398.

Mulligan, E C 2001, 'Confidentiality in health records: evidence of current performance from a population survey in South Australia', Medical Journal of Australia, vol.174, pp.637-640.

Myers, M D 2011, Qualitative Research in Information Systems, accessed 24 Aug 2011, http://www.qual.auckland.ac.nz/.

Myers, M D \& Klein, H K 2011, 'A Set of Principles for Conducting Critical Research in Information Systems', MIS Quarterly, vol.35, no.1, pp.17-36.

Nathanson, C 1977, 'Sex, illness and medical care', Soc Sci Med, vol.11, pp.13-25. 
Nehf, J 2003, 'Recognizing the Societal Value in Information Privacy', Washington Law Review, vol.78, pp.1-91.

$\mathrm{Ng}$, B M 2000, 'Universal Health Identifier: Invasion of Privacy or Medical Advancement', Rutgers Computer and Technology Law Journal, vol.26, no.2, pp.331-356.

NHMRC 2007, 'National Statement on Ethical Conduct in Research Involving Humans(2007)',accessed http://www.nhmrc.gov.au/guidelines/publications/e72.

Nissenbaum, H 2004, 'Privacy as Contextual Integrity', Washington Law Review, vol.79, no.1, pp.119-157.

Nissenbaum, H 2010, Privacy in Context, Stanford University Press, Stanford, California.

North, M 2002, The Hippocratic Oath, accessed 29 Jan 2012, http://www.nlm.nih.gov/hmd/greek/greek oath.html.

Nunnally 1978, Psychometric Theory, McGraw-Hill, New York.

Nunnally, J C \& Berstein, I H 1994, Psychometric Theory, McGraw-Hill, New York.

O'Keefe, C M 2008, 'Privacy and the Use of Health Data - Reducing Disclosure Risk', electronic Journal of Health Informatics, vol.3, no.1: e5.

O'Keefe, C M \& Connolly, C J 2010, 'Privacy and the use of health data for research', Medical Journal of Australia, vol.193, no.9, pp.537-541.

Orlikowski, W J \& Baroudi, J J 1991, 'Studying Information Technology in Organizations: Research Approaches and Assumptions', Information Systems Research, vol.2, pp.1-28.

Orphanoudaki, E, Voss, H, Kouroubali, A, et al. 2007, 'eHealth Consumer Attitudes in Greece and Denmark', paper presented to MEDINFO 2007, Brisbane, Australia, 20 - 24 Aug 2007.

Parkin, L \& Paul, C 2011, 'Public good, personal privacy: A citizens' deliberation about using medical information for pharmacoepidemiological research', Journal of Epidemiology and Community Health, vol.65, no.2, pp.150-156.

Parliament of Australia 2012, Public hearing: Personally Controlled Electronic Health Records Bill 2011 [Provisions] and Personally Controlled Health Records (Consequential Amendments) Bill 2011 [Provisions], accessed 6 February 2012, http://www.aph.gov.au/senate/committee/red.htm.

Perera, G, Holbrook, A, Thabane, L, et al. 2011, 'Views on health information sharing and privacy from primary care practices using electronic medical records', International Journal of Medical Informatics, vol.80, no.2, pp.94101.

Pettigrew, L, Roman, M \& Drazen, E 2010, 'CSC Healthcare Research Report : A Rising Tide of Expectations', accessed 22 Feb 2012, http://www.csc.com/au/insights/51406csc health report a rising tide of expectations.

Philippon, D J \& Braithwaite, J 2008, 'Health System Organisation and Governance in Canada and Australia: A Comparison of Historical Developments, Recent Policy Changes and Future Implications', Healthcare Policy, vol.4, no.1, pp.168-187.

Plano Clark, V 2010, 'The Adoption and Practice of Mixed Methods: U.S. Trends in Federally Funded Health-Related Research', Qualitative Inquiry, vol.16, pp.428-440.

Plano Clark, V \& Creswell, J W 2008, The Mixed Methods Reader, Sage, Thousand Oaks, California. 
Plano Clark, V, Garrett, A \& Leslie-Pelecky, D L 2010, 'Applying Three Strategies for Integrating Quantitative and Qualitative Databases in a Mixed Methods Study of a Nontraditional Graduate Education Program', Field Methods, vol.22, no. 154 .

Powers, D \& Xie, Y 2000, Statistical methods for categorical data analysis, Academic Press, London.

PricewaterhouseCoopers 2009, Transforming healthcare through secondary use of medical data, Pricewaterhouse Coopers,

Privacy International, accessed 19 Jun 2011, www.privacyinternational.org/.

Privacy Rights Clearing House, accessed 10 Feb 2011, https://www.privacyrights.org/.

Rachels, J 1975, 'Why Privacy is Important', Philosophy and Public Affairs, vol.4, no.4, pp.323-333.

Regan, P 1995, Legislating Privacy, University of North Carolina Press, Chapel Hill.

Rindfleish, T C 1997, 'Privacy, Information Technology and Healthcare', Communications of the ACM, vol.40, no.8, pp.93-100.

Robling, M R, Hood, K, Houston, H, et al. 2004, 'Public attitudes towards the use of primary care patient record data in medical research without consent: a qualitative study', Journal of Medical Ethics, vol.30, pp.104-109.

Rodwin, M 2009, 'The Case for Public Ownership of Patient Data', Journal of the American Medical Association, vol.302, no.1, pp.86-88.

Rosenbaum, S 2010, 'Data Governance and Stewardship: Designing Data Stewardship Entities and Advancing Data Access', Health Services Research, vol. 45 , no. 5 .

Rossiter, J R 2002, 'The C-OAR-SE procedures for scale development in marketing', International Journal of Research in Marketing, vol.19, no.4, pp.305-355.

Ruyter, K W, Louk, K, Jorqui, M, et al. 2010, 'From Research Exemption to Research Norm: Recognising an Alternative to Consent For Large Scale Biobank Research', Medical Law International, vol.10, pp.287-323.

Sadan, B 2000, 'Patient data confidentiality and patient rights', International Journal of Medical Informatics, vol.62, pp.41-49.

Safran, C, Bloomrosen, M, Hammond, W E, et al. 2006, Toward a National Framework for the Secondary Use of Health Data: An American Medical Informatics Association White Paper, Maryland, USA.

Satzinger, J, Jackson, R \& Burd, S 2009, Systems Analysis and Design in a Changing World, Course Technology, Boston.

Schattner, E 2011, Why the term 'patient' is so important in healthcare, accessed 5 Dec 2011, http://www.medicallessons.net/2011/01/why-the-term-patient-isso-important-in-health-care/.

Schneider, S, Kerwin, J, Robins, C \& Dean, D 2009, Consumer engagement in developing electronic health information systems. Final report., Rockville, MD.

Shelton, R H 2011, 'Electronic consent channels: Preserving patient privacy without handcuffing researchers', Science Translational Medicine, vol.3, no.69.

Shoemaker, D 2009, 'Self-exposure and exposure of the self: informational privacy and the presentation of identity', Ethics and Information Technology, vol.12, no.1, pp.3-15.

Showell, C 2011, 'Citizens, patients and policy: a challenge for Australia's national electronic health record', Health Information Management Journal, vol.40, no.2, pp.39-43. 
Silversides, A 2009, 'Privacy concerns raised over "secondary use" of health records', Canadian Medical Association Journal, vol.181, no.12, pp.E287.

Singleton, P \& Wadsworth, M 2006, 'Consent for the use of personal medical data in research', British Medical Journal, vol.333, pp.255-258.

Snider, D E 1997, 'Patient Consent for Publication and the Health of the Public', Journal of the American Medical Association, vol.278, no.8, pp.624.

Sobel, R 2002, 'The Demeaning of Identity and Personhood in National Identification Systems', Harvard Journal of Law and Technology.

Spencer, L, Ritchie, J \& O'Connor, W 2003, 'Analysis: Practices, Principles and Processes', in Qualitative Research Practice, (eds.) R. J. \& J. Lewis, SAGE Publications, Thousand Oaks, California, pp. 199-218.

Spiliotopoulou, G 2009, 'Reliability reconsidered: Cronbach's alpha and paediatric assessment in occupational therapy', Australian Occupational Therapy Journal, vol.56, no.3, pp.150-155.

Staff-Reporter 2008, "Serious breach': medical records found in park', accessed www.abc.net.au/news/stories/2008/06/27/2288377.htm?site=news.

Staff-Reporter 2010, 'Birth-to-8yo data tracking for SA children', accessed 10 Jun 2010, www.abc.net.au/news/stories/2010/06/10/2923397.htm?section=justin.

Staff-Reporter 2011, 'Online medical privacy breach to be probed', ABC News, 18 Jul 2011, accessed $18 \mathrm{Jul}$ 2011, http:/www.abc.net.au/news/2011-07-18/medvetprivacy-breach-online/2798650.

Steeves, V 2004, 'Will changes in data health privacy legislation kill research as we know it?', paper presented to 2004 Annual Labelle Lectureship-Centre for Health Economics and Policy Analysis, McMaster University, Hamilton, Ontario Canada, October 2004.

Stout, D \& Zeller, T 2006, 'Vast data cache about veterans is stolen', The New York Times, 23 May 2006, accessed 16Jun 2011, www.nytimes.com/2006/05/23/washington/23identity.html.

Straub, D, Quantitative, Positivist Research Methods in Information Systems, accessed 24 Aug 2011, http://dstraub.cis.gsu.edu:88/quant/2philo.asp.

Straub, D, Gefen, D \& Boudreau, M-C 2004, The ISWorld Quantitative, Positivist Research Methods Website, accessed 24 Aug 2011, http://dstraub.cis.gsu.edu:88/quant/.

Sutcliffe, A 2006, 'Trust: From cognition to conceptual models and design', Lecture Notes in Computer Science, vol.4001/2006, pp.3-17.

Svensson, E 2001, 'Guidelines to Statistical Evaluation of data from Rating Scales and Questionnaires', Journal of Rehab Med, vol.33, pp.47-48.

Tarini, B A, Goldenberg, A, Singer, D, et al. 2010, 'Not without my permission: Parents' willingness to permit use of newborn screening samples for research', Public Health Genomics, vol.13, pp.125-130.

Tashakkori, A \& Teddlie, C 1998, Mixed methodology: combining qualitative and quantitative approaches., Sage, Thousand Oaks, California.

Tavani, H 1996b, 'Cyberethics and the future of computing', SIGCAS Comput. Soc., vol.26, no.2, pp.22-29.

Tavani, H 1999a, 'Privacy online', SIGCAS Comput. Soc., vol.29, no.4, pp.11-19.

Tavani, H 1999b, 'KDD, data mining and the challenge for normative privacy', Ethics and Information Technology, vol.1, pp.265-273.

Tavani, H 2003, 'Ethics and Technology: Ethical Issues in an Age of Information and Communication Technology (John Wiley \& Sons, 2004)', SIGCAS Comput. Soc., vol.33, no.3, pp.1. 
Tavani, H 2007a, Ethics \& Technology Ethical Issues in an Age of Information and Communication Technology, John Wiley \& Sons Inc, Hoboken, NJ.

Tavani, H \& Moor, J 2001, 'Privacy protection, control of information, and privacyenhancing technologies', SIGCAS Comput. Soc., vol.31, no.1, pp.6-11.

Tavani, H, T. 2007b, 'Philosophical Theories of Privacy: Implications for an Adequate Online Privacy Policy', Metaphilosophy, vol.38, no.1.

Terry, N P 2009, 'What's Wrong with Health Privacy', Journal of Health and Biomedical Law vol.V, pp.1-32.

The Nuffield Trust 2011, The Nuffield Trust, accessed 20 Jun 2011, http://www.nuffieldtrust.org.uk/.

Torrey, T 2011, What do you want to be called?, accessed 5 Dec 2011, http://patients.about.com/b/2011/01/10/what-do-you-want-to-be-called.htm.

Townend, D 2010, 'Privacy, health insurance, and medical research: Tensions raised by European data protection law', New Genetics and Society, vol.29, no.4, pp.477-493.

Tracy, C S, Dantas, G C \& Upshur, R E 2004, 'Feasibility of a patient decision aid regarding disclosure of personal health information: qualitative evaluation of the Health Care Information Directive', BMC Medical Informatics and Decision Making, vol.4, no.13.

Trinidad, S B, Fullerton, S M, Ludman, E J, et al. 2011, 'Research practice and participant preferences: The growing gulf', Science, vol.331, no.6015, pp.287-288.

Trope, R L, Power, E M, Polley, V I \& Morley, B C 2007, 'A coherent strategy for data security through data governance', IEEE Security and Privacy, vol.5, no.3, pp.32-39.

Turban, E \& Aronson, J 2001, Decision Support Systems and Intelligent Systems, Prentice-Hall Inc, Upper Saddle River, New Jersey.

Tutton, R 2007, 'Constructing Participation in Genetic Databases: Citizenship, Governance, and Ambivalence', Science, Technology, \& Human Values, vol.32, no.2, pp.172-195.

Van den Hoven, J 2003, 'Privacy and the Varieties of Informational Wrong doing.', in Readings in CyberEthics, (eds.) R. A. Spinello \& H. Tavani, Jones and Bartlett Publishers, Sudbury, MA, pp. 488-500.

Walton, J, Doll, R, Asscher, W, et al. 1999, 'Consequences for research if use of anonymised patient data breaches confidentiality', British Medical Journal, vol.319, no.7221, pp.1366-.

Warren, S \& Brandeis, L 1890, 'The Right to privacy (The Implicit Made Explicit)', in Philosophical Dimensions of Privacy: An Anthology, (eds.) F. D. Schoeman, Harvard Law Review, Cambridge, MA, pp. 193-220.

Weill Cornell Medical College 2005, From antiquity to eternity: Revised Hippocratic Oath resonates with graduates, accessed 29 Jan 2012, http://www.news.cornell.edu/stories/june05/hippocratic oath.mh.html.

Westin, A 1967, Privacy and Freedom, Atheneum, New York.

Whiddett, D, Hunter, I, Engelbrecht, J \& Handy, J 2007, 'Privacy and Access to Electronic Health Records', in Encyclopedia of Information Ethics and Security, (eds.) M. Quigley, IGI Global, pp. 534-540.

whitepages, C 2011, White Pages website, accessed 17 Dec 2011, http://www.whitepages.ca/reverse_address. 
Willison, D 2003, 'Privacy and the secondary use of data for health research: experience in Canada and suggested directions forward', Journal of Health Serv Res Policy, vol.Supplement 1.

Willison, D J, Emerson, C, Szalaka-Meneok, K V, et al. 2008, 'Access to medical records for research purposes: varying perceptions across research ethics boards.', Journal of Medical Ethics, vol.34, pp.308-314.

Willison, D J, Keshavjee, K, Nair, K, et al. 2003, 'Patients' consent preferences for research uses of information in electronic medical records: interview and survey data', British Medical Journal, vol.326, pp.373-377.

Willison, D J, Schwartz, L, Abelson, J, et al. 2007, 'Alternatives to project-specific consent for access to personal information for health research: What is the opinion of the Canadian public?', Journal of American Medical Informatics Association, vol.14, pp.706-712.

Willison, D J, Steeves, V, Charles, C, et al. 2009, 'Consent for use of personal information for health research: Do people with potentially stigmatising health conditions and the general public differ in their opinions?', BMC Medical Ethics, vol.10, no.10.

Wood, G 2000, 'A Cross Cultural Comparison of the Contents of Codes of Ethics: USA, Canada and Australia', Journal of Business Ethics, vol.25, pp.287-298.

Woodward, B 1995, 'The Computer-based Patient Record and Confidentiality', The New England Journal of Medicine, vol.333, no.21, pp.1419-1422.

Woolf, S, Rothemich, S, F., Johnson, R E \& Marsland, D W 2000, 'Selection Bias From Requiring Patients to Give Consent to Examine Data for Health Services Research', Arch Fam Med, vol.9, no.Nov/Dec 2000, pp.1111-118.

Yates, D, Moore, D \& McCabe, G 1999, The Practice of Statistics, W.H. Freeman, New York.

Zeps, N, Iacopetta, B, Schofield, L, et al. 2007, 'Waiver of individual patient consent in research: when do potential benefits to the community outweigh private rights?', Medical Journal of Australia, vol.186, no.2, pp.88-90. 
APPENDIX A: ETHICS APPROVAL

INITIAL APPLICATION APPROVAL

In reply please quote: HE09/186

\section{October 2009}

Dr Katina Michael

School of Information Systems and Technology

University of Wollongong

Dear Dr Michael

Thank you for your response to the HREC initial review letter dated 9 June 2009. I am pleased to advise that the application has been approved.

For future reference, the request to revise the participant information sheet was in relation to describing the research, its potential benefits and risks/costs to the participants. As this is an anonymous survey supplied with the participant information sheet the current form is approved, but the researchers should not assume this will be the case for other projects.

Ethics Number: HE09/186

Project Title: $\quad$ Public opinion survey regarding secondary use of medical data

Researchers: $\quad$ Dr Katina Michael, Dr Russell Pearson, Ms Jennifer Heath

Approval Date: $\quad 10$ September 2009

Expiry Date: $\quad 9$ September 2010

The University of Wollongong/SESIAHS Humanities, Social Science and Behavioural HREC is constituted and functions in accordance with the NHMRC National Statement on Ethical Conduct in Human Research. The HREC has reviewed the research proposal for compliance with the National Statement and approval of this project is conditional upon your continuing compliance with this document. As evidence of continuing compliance, the Human Research Ethics Committee requires that researchers immediately report:

- proposed changes to the protocol including changes to investigators involved

- serious or unexpected adverse effects on participants

- unforseen events that might affect continued ethical acceptability of the project.

You are also required to complete monitoring reports annually and at the end of your project. These reports are sent out approximately 6 weeks prior to the date your ethics approval expires. The reports must be completed, signed by the appropriate Head of School, and returned to the Research Services Office prior to the expiry date.

Yours sincerely

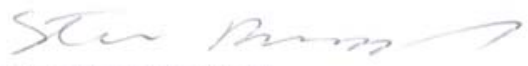

A/Professor Steven Roodenrys

Chair, Human Research Ethics Committee

Research Services Office University of Wollongong NSW 2522 Australis Telephone: +61 242213386 Facsimile: +6124221 4338 research_services@uow.edu.au www.uow.edu.au/research 


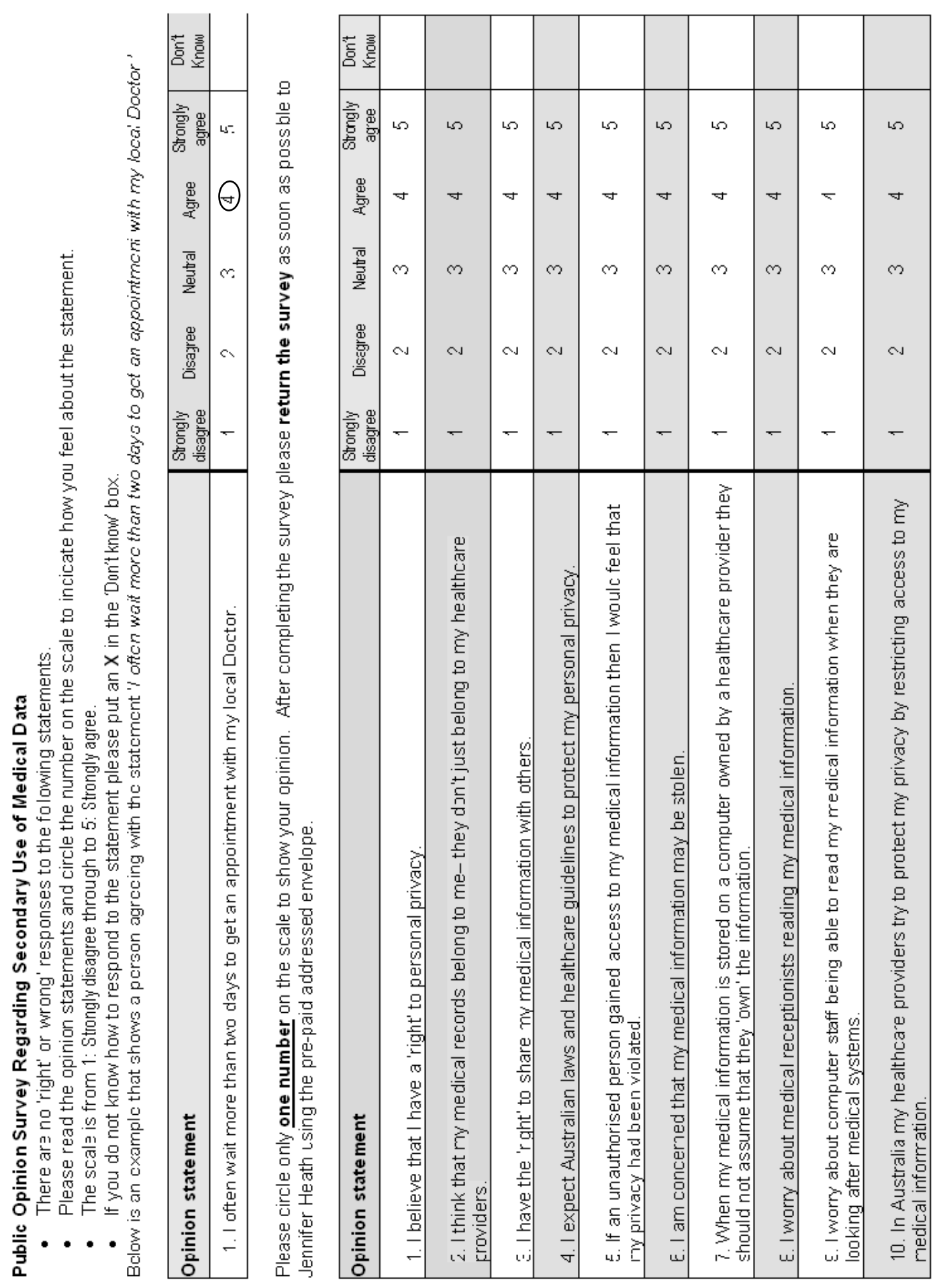




\begin{tabular}{|c|c|c|c|c|c|c|c|c|c|c|c|c|}
\hline 唁 & L & is & $L S$ & $\omega$ & Lo & 5 & 5 & Lo & SLL & $\omega$ & 10 & 10 \\
\hline 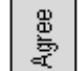 & $\nabla$ & 寸 & $\forall$ & $\nabla$ & $\leftarrow$ & $\nabla$ & $\nabla$ & $\nabla$ & $\nabla$ & 寸 & $\nabla$ & $\nabla$ \\
\hline $\begin{array}{l}\frac{\bar{m}}{\bar{n}} \\
\frac{3}{2}\end{array}$ & $m$ & $m$ & $m$ & $m$ & $m$ & $m$ & $m$ & 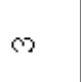 & $m$ & $m$ & 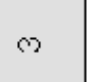 & $m$ \\
\hline 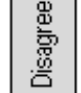 & $\sim$ & $\sim$ & $\sim$ & $\sim$ & $\propto$ & $\sim$ & $N$ & $\infty v$ & $\sim$ & $\sim$ & $c$ & $\sim$ \\
\hline 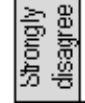 & - & - & - & - & - & - & - & - & - & - & - & - \\
\hline 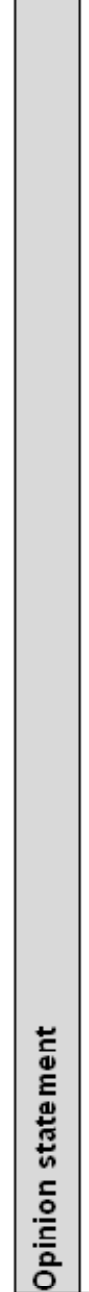 & 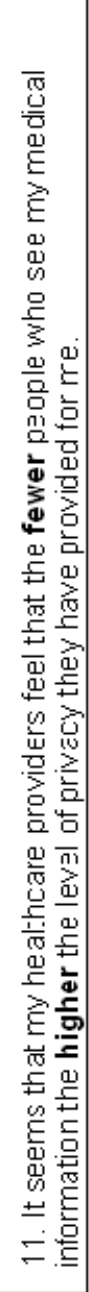 & 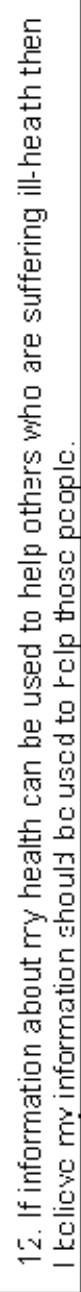 & 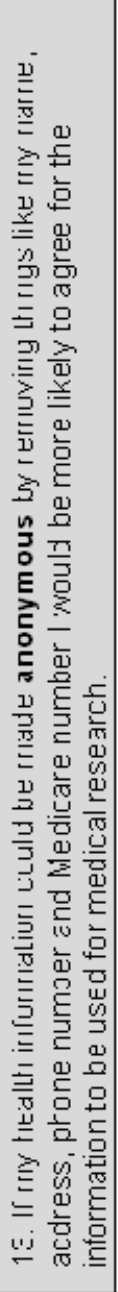 & 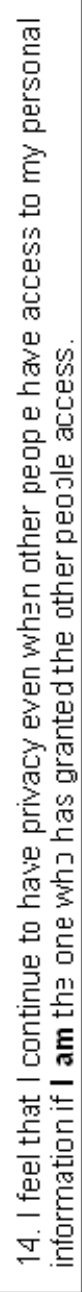 & 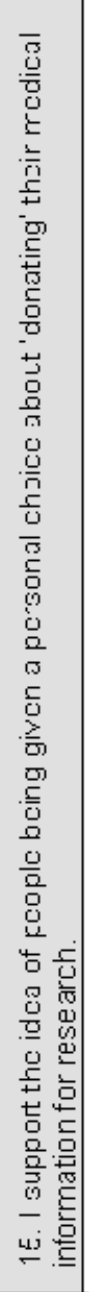 & 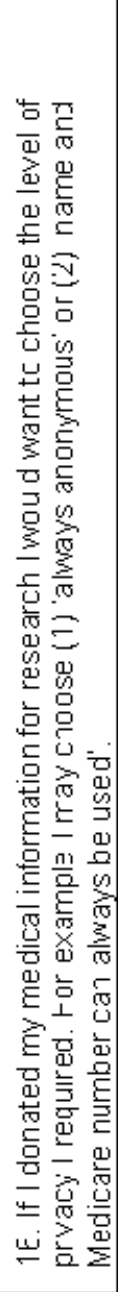 & 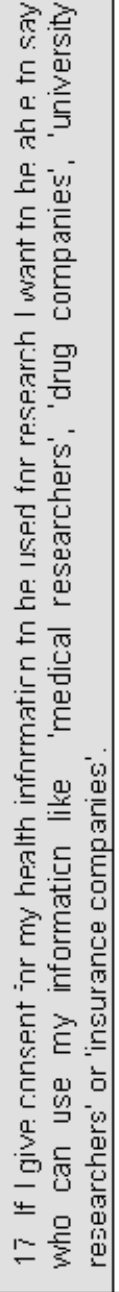 & 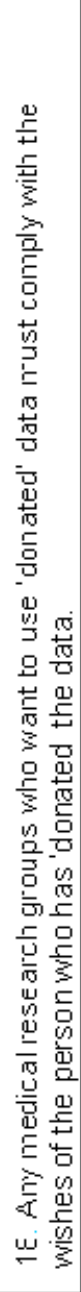 & 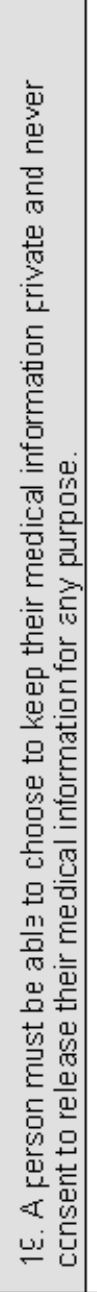 & 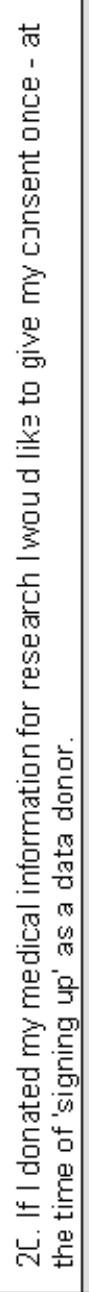 & 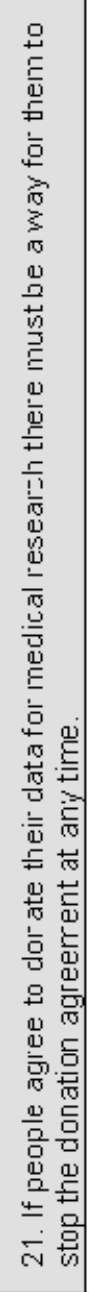 & 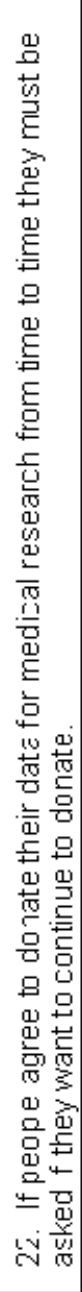 \\
\hline
\end{tabular}



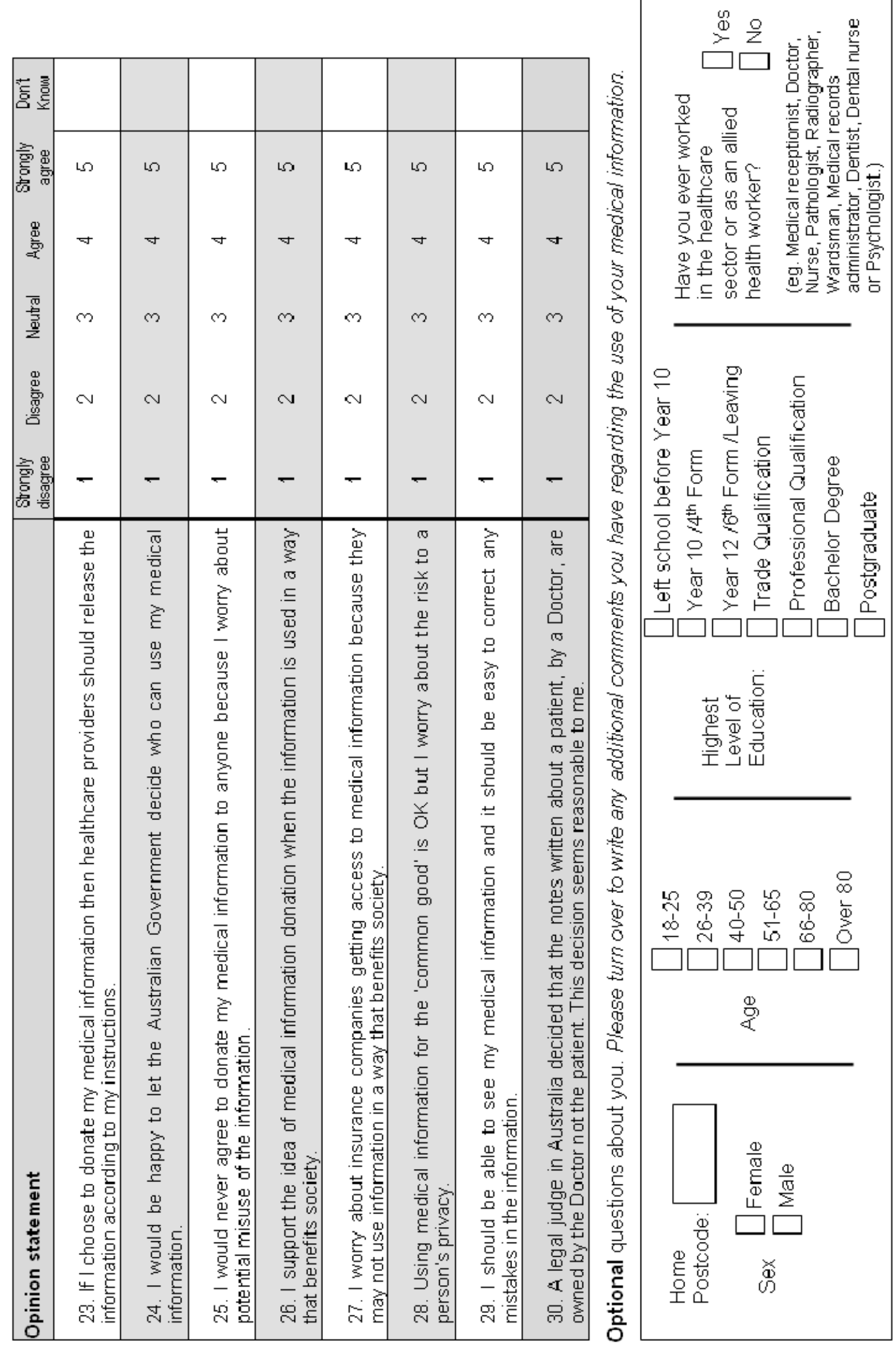

$\stackrel{\square}{\circ} \stackrel{\circ}{\circ}$

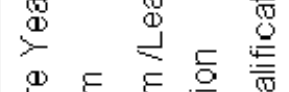

造

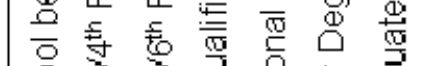

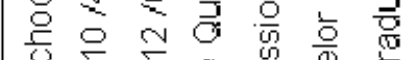

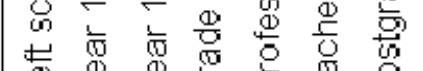

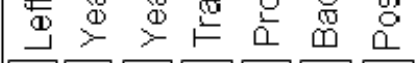

$\square \square \square \square \square \square \square$

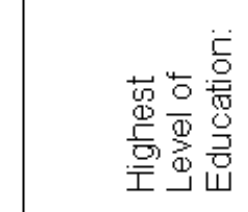

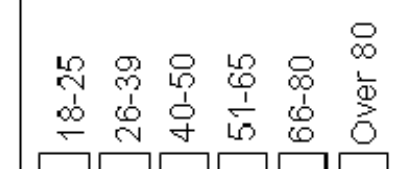

$\square \square \square \square \square \square$

o)

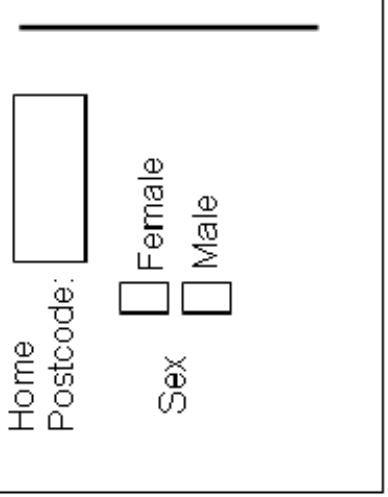




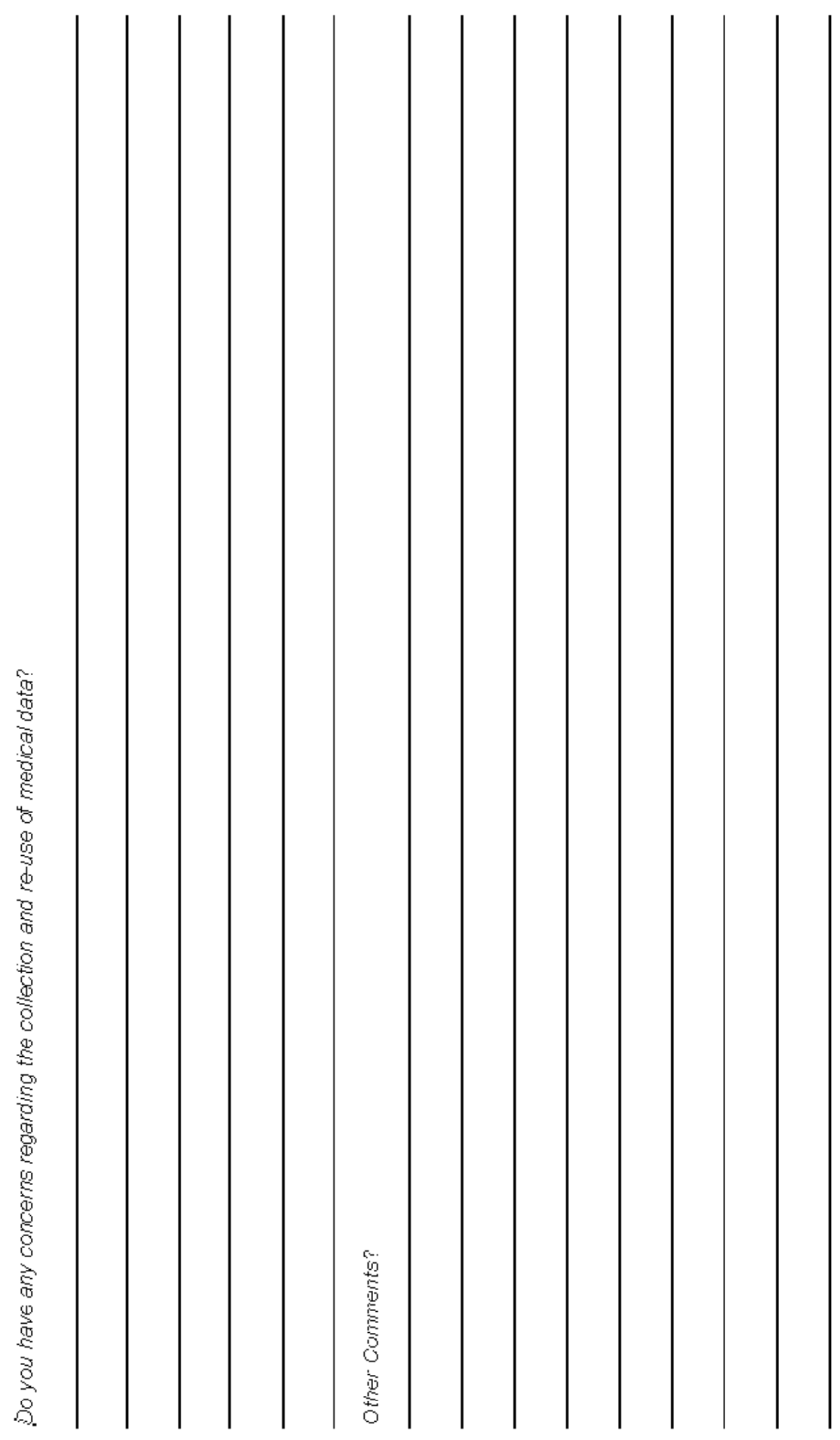

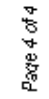

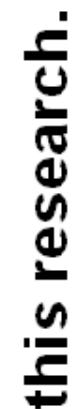

톨

를

를

는

$\bar{\partial}$

竧 


\section{APPENDIX C: AUSTRALIAN AND CANADIAN SURVEY COVERING LETTER}

University of Wollongong

November 2010

DearResident,

\section{Have you ever wanted to help with medical research?}

We need you to contribute your personal opinion.

Jennifer Heath, Dr Katina Michael and Dr Russell Pearson from the University of Wollongong are very interested in knowing your opinion about personal privacy and your medical data.

There are no 'right' or 'wrong' answers to the survey questions - it is your opinion that counts! Please fill out the attached survey and return it to us in the enclosed prepaid envelope. Anyone 18 years of age or older can complete this survey. It will take about ten minutes to complete the survey.

The Ethics Committee of the University of Wollongong has approved this research. If you have any concems or complaints regarding this research please contact the University of Wollongong Ethics Officer on (02) 42214457.

If you would like further infomation about our research please do not hesitate to contact Jennifer, Katina or Russell.

Thank you for helping us with this important research project.

\section{Jenrifer, Katina and Rassell}

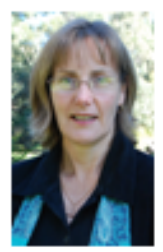

Jenrifer Heath $\mathrm{PhD}$ Candickate JHeathiousoweds.au (02) 42213026

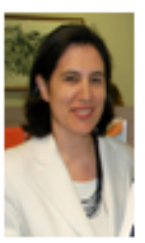

DrKatina Wichael Reserarch Stpervisor Katina(0um.eduau (02) 42213937

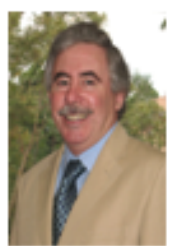

DrRussell Pearson Research Stpervisor Russell_Person@iow.edu.z. (02) 42215352

Uolvi, School of Information Systems and Techology and Grachate Schod of Wedicine Northields Anerue, INollongong, NSIOU, 2522 , Australie 


\section{OUOIT}

Dear Resident,

\section{Have you ever wanted to help with medical research?}

\section{We need you to contribute your personal opinion.}

Associate Professor Carolyn McGregor from the University of Ontario Institute of Technology (UOIT) and Jennifer Heath from the University of Wollongong (UOW) in Australia are very interested in knowing your opinion about personal privacy and your medical data.

There are no 'right' or 'wrong' answers to the survey questions - it is your opinion that counts! Please fill out the attached survey and return it to us in the enclosed prepaid envelope. Anyone 18 years of age or older can complete this survey. I will take about ten minutes to complete the survey.

The Ethics Committees of UOIT and UOW have approved this research. If you have any concerns or complaints regarding this research please contact the UOIT Compliance Officer via email at compliance@ouoit.ca or phone 905.721 .8668 ext 3693 .

If you would like further infomation about our research please do not hesitate to contact Jennifer or Carolyn.

Thank you for helping us with this important research project.

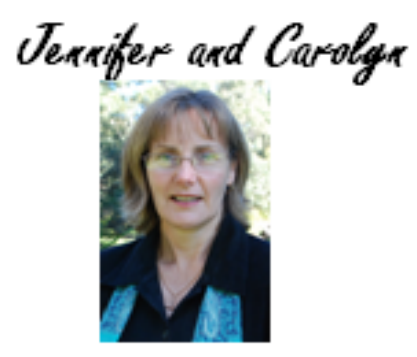

Jenrifer Heath

$\mathrm{PhD}$ Candictate,

University of Inlolongong

Anstralia

JHeath@uow.edu.aw

61242213025

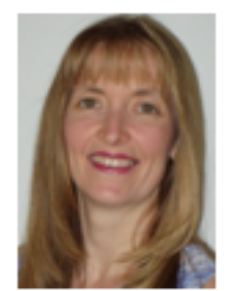

Associate Professor Carolyn WisGregor Caracta Researdn Clair Healh Informatics University of Onterio Institute of Technology Caracta

Cardyn. Wagregan(0ivoitca $905.721 .8568 \times 3597$ 
APPENDIX D: FINAL SURVEY QUALITATIVE DATA ENCODING SHEET

\begin{abstract}
Survey \# $\quad 48$ My overriding belief is that my medical record is mine but is distinct from doctors notes eg. Like a teacher's notes compiled before writing a student's report. I should have complete access to these and be the sole person who decides who has access to these. A doctor's notes are their own to use - but again, like a teacher contributing anecdotes to a textbook - should be anonymous. My medical records are constantly changing in response to my health journey. Do my consent needs continual updating ie. Whilst I am healthy I may not mind but once sick may change my mind.
\end{abstract}

Coding

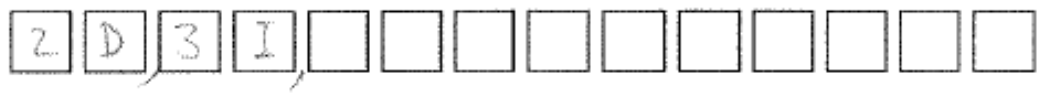

Encoder comment:
Survey \# $\quad 50$ I don't have a problem with use of my medical records so long as it is anonymous. If under exceptional circumstances a patients data needs to be identified, then permission should be sought from the patient.

Coding

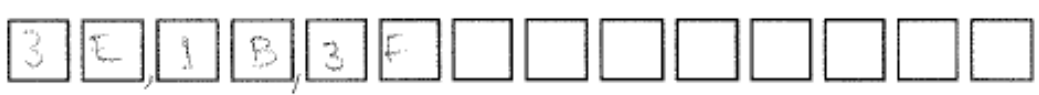

Encoder comment:

Survey\# $\quad 55$ Only that it should have the complete (signed) okay from the person giving the data.

Coding

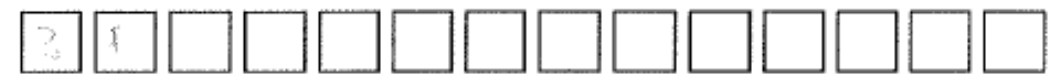

Encoder comment: Survey \# 56 Could be that we have no idea that our files are used however, without our knowledge not
consent. How did you get my address? Is there a privacy issue here???!!

Coding

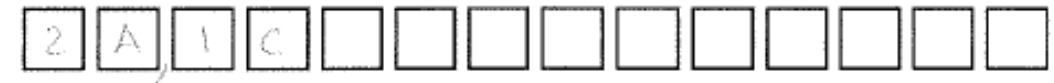

Encoder comment:

Survey \# $\quad 57$ So long as the patient has been fully informed regarding the details and implications of their own data in the first place. Some medical data is of a very private nature and should be restricted or only released anonymously whilst the other data has a 'stigma' attached to it, from the patients perspective. The patient should be able to stipulate one of three broad categories 1. no release 2 . anonymous release 3 , name attached.

Coding

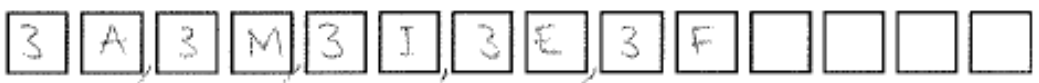

Encoder comment:

Survey \#

60 Only concern is that the data should only be available to health professionals and that it is totally secure. I should be entitled to have a copy of my medical information, if needed. Perhaps the latter could be a reasonably comprehensive summary with a file no. For health professional's perusal.

Coding
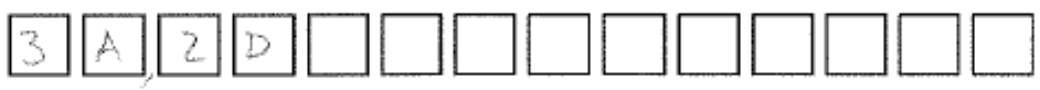

Encoder comment: 